\title{
Optimal Real-time Dispatch for Integrated Energy Systems
}

\author{
by \\ Ryan Michael Firestone \\ B.S. (Brown University) 1997 \\ M.S. (University of Texas, El Paso) 2001 \\ A dissertation submitted in partial satisfaction of the \\ requirements for the degree of \\ Doctor of Philosophy \\ in \\ Engineering- Mechanical Engineering \\ in the \\ Graduate Division \\ of the \\ University of California, Berkeley
}

Committee in charge:

Professor David Auslander, Chair

Professor Paul Wright

Professor Alex Farrell

Spring 2007 
The dissertation of Ryan Michael Firestone is approved:

Chair



Date

Date
Date

University of California

Spring 2007 
Optimal Real-time Dispatch for Integrated Energy Systems

(C) 2007

by Ryan Michael Firestone 


\author{
Abstract \\ Optimal Real-time Dispatch for Integrated Energy Systems \\ by \\ Ryan Michael Firestone \\ Doctor of Philosophy in Engineering- Mechanical Engineering \\ University of California, Berkeley \\ Professor David Auslander, Chair
}

This report describes the development and application of a dispatch optimization algorithm for integrated energy systems (IES) comprised of on-site cogeneration of heat and electricity, energy storage devices, and demand response opportunities. This work is intended to aid commercial and industrial sites in making use of modern computing power and optimization algorithms to make informed, nearoptimal decisions under significant uncertainty and complex objective functions. The optimization algorithm uses a finite set of randomly generated future scenarios to approximate the true, stochastic future; constraints are included that prevent solutions to this approximate problem from deviating from solutions to the actual problem. The algorithm is then expressed as a mixed integer linear program, to which a powerful commercial solver is applied.

A case study of United States Postal Service Processing and Distribution Centers $(P \& D C)$ in four cities and under three different electricity tariff structures is conducted to 1) determine the added value of optimal control to a cogeneration system over current, heuristic control strategies; 2) determine the value of limited 
electric load curtailment opportunities, with and without cogeneration; and 3) determine the trade-off between least-cost and least-carbon operations of a cogeneration system.

Key results for the P\&DC sites studied include 1) in locations where the average electricity and natural gas prices suggest a marginally profitable cogeneration system, optimal control can add up to $67 \%$ to the value of the cogeneration system; optimal control adds less value in locations where cogeneration is more clearly profitable; 2) optimal control under real-time pricing is a) more complicated than under typical time-of-use tariffs and b) at times necessary to make cogeneration economic at all; 3) limited electric load curtailment opportunities can be more valuable as a compliment to the cogeneration system than alone; and 4) most of the trade-off between least-cost and least-carbon IES is determined during the system design stage; for the IES system considered, there is little difference between leastcost control and least-carbon control. 


\section{Preface}

This report describes the development and application of a dispatch optimization algorithm for integrated energy systems comprised of on-site cogeneration of heat and electricity, energy storage devices, and demand response opportunities. This work is intended to aid commercial and industrial sites in making use of modern computing power and optimization algorithms to make informed, near-optimal decisions under significant uncertainty and complex objective functions.

This work makes headway in the more general and daunting field of multi-stage operational optimization, where multi-stage is in the hundreds of time-steps and optimization is over many mixed-integer decision variables. The context of the work, however, is an application to commercial and industrial energy consumption, a topic rising in popularity on the coat-tails of economic, political, and environmental concerns.

Part 1 of this report describes the integrated energy system (IES) and the dispatch optimization problem that arises from the system's uncertainty, operational constraints, and complex objective functions. Part 1 also describes prior research done on this and related topics. Part 2 describes the IES dispatch optimization algorithm. Part 3 illustrates the application of the algorithm. Part 4 provides conclusions and suggests directions for further research. 


\section{Acknowledgments}

My doctoral experience was made meaningful, enjoyable, and possible with the help and support of many, many people. It is with great pleasure that I have an opportunity to acknowledge some of them.

I would like to start by thanking my parents, Marc and Carole Firestone, who raised me to take education seriously, be curious, and pursue what interests me. I would further like to thank my father for keeping tabs on my research and offering his empathy during my times of frustration. Many other relatives have also provided encouragement throughout. Thanks to my grandparents Sam and Bertha Farber and Leon and Nancy Firestone - I wish I could have finished a little sooner so that you could enjoy this more. Thanks also to my sister Lisa, my cousins, and my aunts and uncles who have encouraged me and challenged me to explain my work in simple terms.

Many faculty members at U.C. Berkeley have given generously of their time and energy. I would like to thank the following professors for there assistance:

- Alice Agogino, Mechanical Engineering - qualifying exam committee member. Alice and her research group were very kind in critiquing a trial run of my exam presentation.

- Dave Auslander, Mechanical Engineering - dissertation committee chair.

- Van Carey, Mechanical Engineering - qualifying exam committee member. 
- Alex Farrell, Energy and Resources - dissertation committee member. Alex was particularly helpful in guiding the case study used in this research.

- Dan Kammen, Energy and Resources - qualifying exam committee member and minor field advisor.

- Dennis Lieu, Mechanical Engineering - qualifying exam committee chair and academic advisor. Dennis was the first professor to show me around when I visited campus the summer before my studies began and has been a friendly, enthusiastic face around campus throughout my time at Berkeley.

- Paul Wright, Mechanical Engineering - dissertation committee member.

I have spent most of my time as a graduate student doing research on distributed energy resources (DER) at the Lawrence Berkeley National Laboratory (LBNL). I would like to thank my supervisor, Chris Marnay, for his guidance over the years. My abilities and knowledge as a researcher have improved greatly during my time at LBNL, and I owe much of that improvement to Chris. Over the years, several coworkers at LBNL have influenced the research in this paper, including Owen Bailey, Karl Magnus Maribu, Afzal Siddiqui, and Michael Stadler. I would also like to thank the rest of our DER group: Emily “"99” Bartholomew, Charles Creighton, Bala Chandran, Jennifer Edwards, Kristina Hamachi-LaCommare, Judy Lai, Frank Ling, Juan Wang, and Nan Zhou. Furthermore, I would like to thank our larger Energy Markets and Policy group at LBNL for being a great, interesting, and helpful group of 
people. I have thoroughly enjoyed working amongst people who are enthused and passionate about their research.

This research builds on prior energy manager work coordinated by the Consortium for Electric Reliability Technology Solutions and funded by the California Energy Commission, Public Interest Energy Research Program, under Work for Others Contract No. BG 99-396 (00). The Assistant Secretary of Energy Efficiency and Renewable Energy, former Distributed Energy Program of the U.S. Department of Energy (under contract) and the California Public Utilities Commission, Division of Ratepayer Advocates have also provided support on related work.

Finding a building to participate in my research turned out to be quite challenging. I would like to thank Bill Golove (formerly of LBNL) for helping to get me set up with the United States Postal Service (USPS), Joe VandenBerg (USPS Pacific Area Energy Program) for his permission and help in accessing data for the San Diego Processing and Distribution Center (P\&DC), and Russel Seibert (USPS, San Diego P\&DC) for providing an extensive site tour of the San Diego P\&DC. I would also like to thank Steve Szychulda (USPS, San Bernardino P\&DC) for providing a tour of the San Bernardino P\&DC in 2002.

Many other people and institutions have been extremely helpful in identifying and characterizing this research topic by speaking with me and providing personal site tours. Thanks to Bob Schultze (BD Biosciences Pharmingen), Ray Miller (Clarus iv 
Energy), Wendy Gumb (Clarus Energy), Frank Pizzimenti (East Bay Municipal Utility District), Dana Levy (New York State Energy Research and Development Authority), Israel de Vera (California Public Utilities Commission), Andy Green (Contra Costa County), Vince Scoccia (John Muir Medical Center), Pat Giangrosso (United Technologies), Tim Lipman (Pacific Regional CHP Application Center), and Ron Hofman.

I would also like to thank my other employers and supervisors during my time in Berkeley; my experiences with them have complimented my work at LBNL in developing a broad understanding of the field.

- California Public Utilities Commissions, Division of Ratepayer Advocates Rob Wullenjohn

- Summit Blue Consulting - Floyd Keneipp and Jeff Erickson

- StrateGen Consulting - Janice Lin

My introduction to energy research was as a master's student at the University of Texas El Paso. I would like to thank my supervisors and coworkers there at the Wind Energy Research Laboratory; Professors Rick Zadoks and Andrew Swift, Dr. Jamie Chapman, and coworkers Javier Perea, Omar Cano, Mariano Olmos, and Joaquin Mendez. Thanks also to my employers and coworkers at Gold Coast GeoServices and Bay Computer Associates for their early introductions into engineering work. 
Finally, thank you to my friends for making the harder parts of the past six years bearable and for making the rest of the time so great. Thanks to Gidon Felsen for paving the way for me in Berkeley, Elif "Grandma Co-op" Ertekin, my housemates at Wolf House, The Convent, WnaffWac, and The Junkyard, and my neighbors The Hobbits. 
Table of Contents

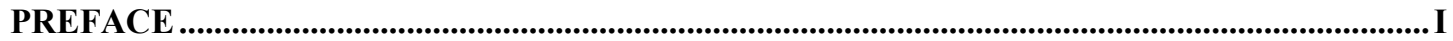

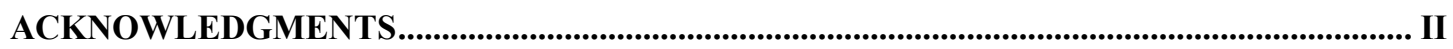

TABLE OF CONTENTS ..................................................................................................................

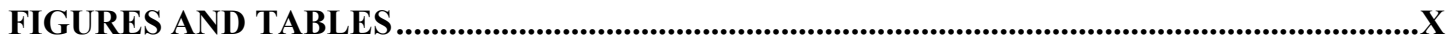

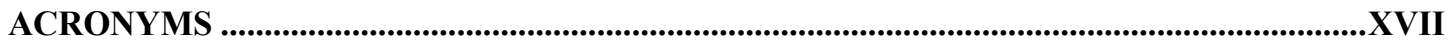

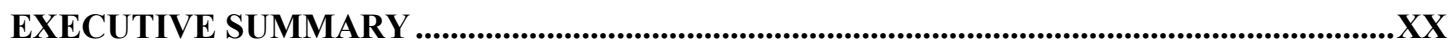

INTRODUCTION: INTEGRATED ENERGY SyStems (IES) AND THE NEED FOR GENERIC REAL-TIME

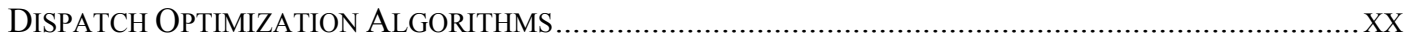

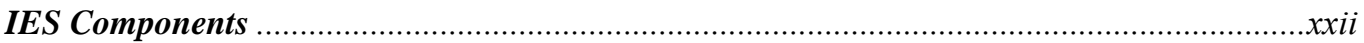

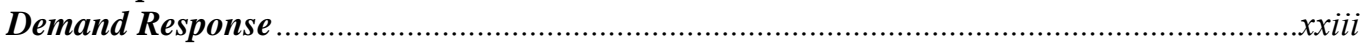

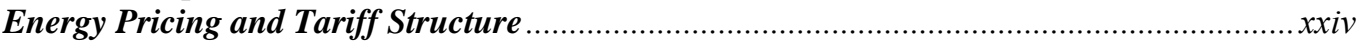

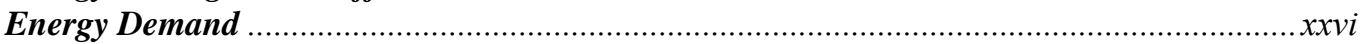

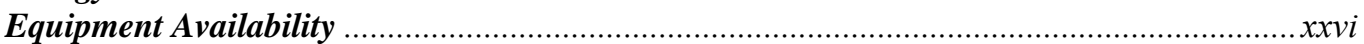

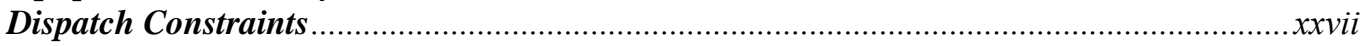

The Integrated Energy System ......................................................................................

HYPOTHESIS - HEURISTIC DISPATCH: FUNCTIONAL, NOT OPTIMAL ……................................... XXVIII

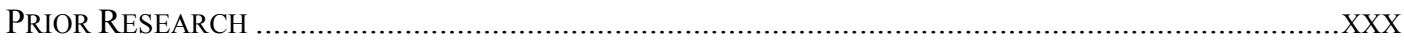

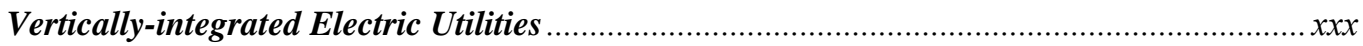

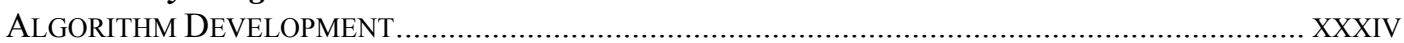

RT-OPTICOM Application: The United States Postal Service Processing and

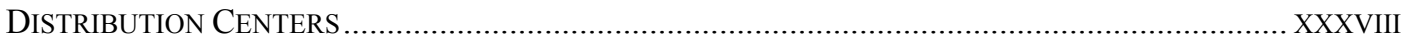

Site Description, Data Collection, and Modeling ………...........................................

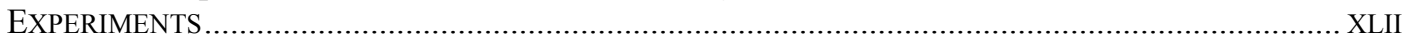

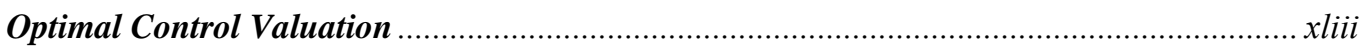

Demand Side Management Valuation ..........................................................................

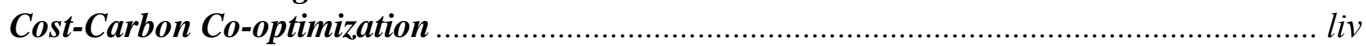

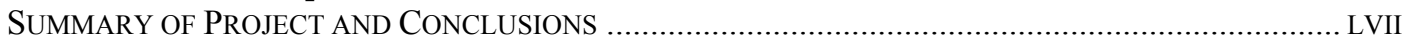

PART 1: INTRODUCTION TO INTEGRATED ENERGY SYSTEMS (IES) AND THE NEED FOR GENERIC REAL-TIME DISPATCH OPTIMIZATION ALGORITHMS ...........................1

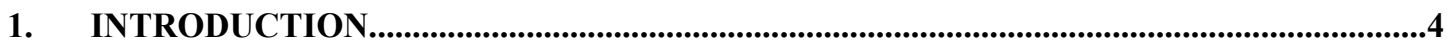

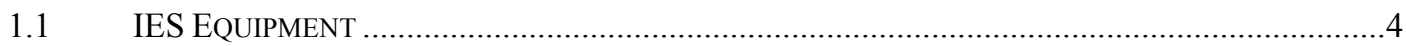

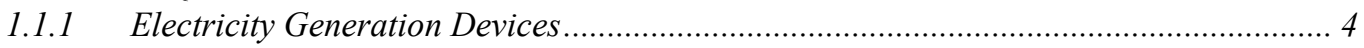

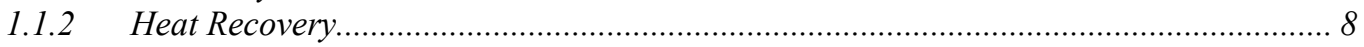

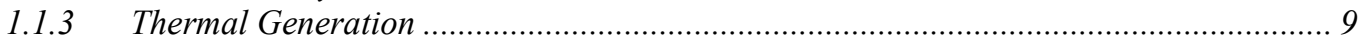

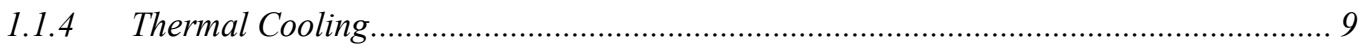

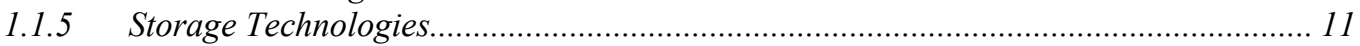

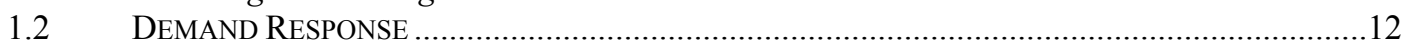

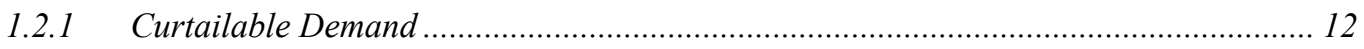

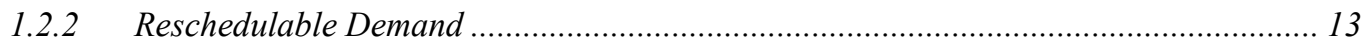

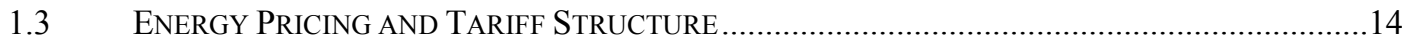

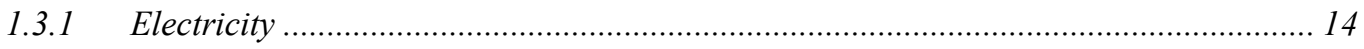

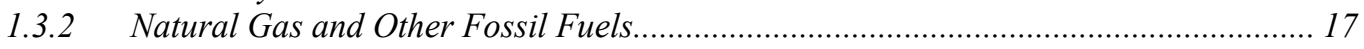

vii 


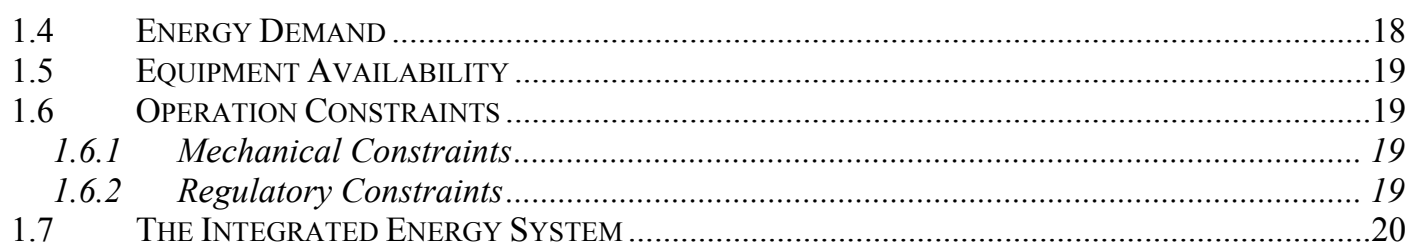

2. HYPOTHESIS - HEURISTIC DISPATCH: FUNCTIONAL, NOT OPTIMAL ..................22

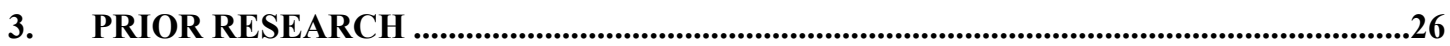

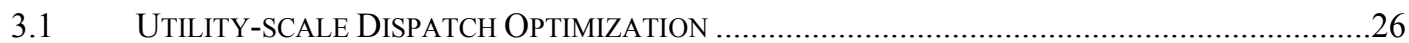

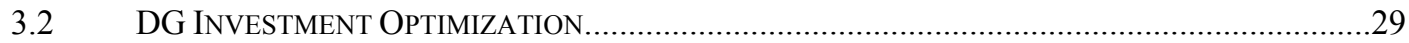

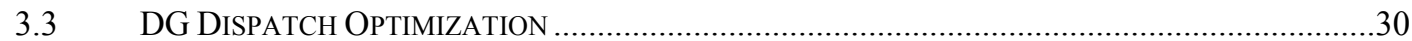

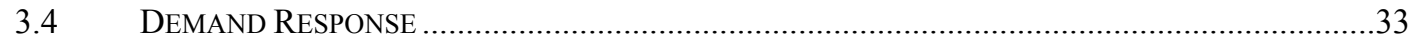

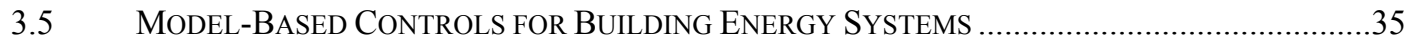

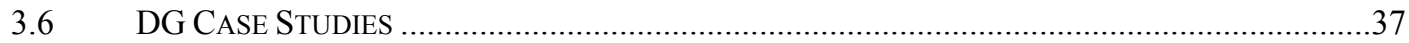

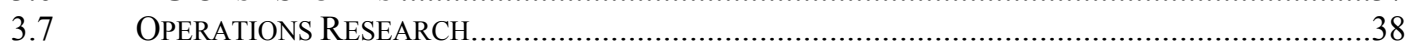

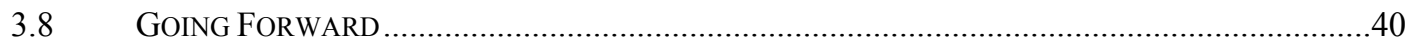

PART 2: THE RT-OPTICOM CONCEPT AND APPLICATION TO IES ......................................42

4. THE REAL-TIME OPTIMAL CONTROL MODEL (RT-OPTICOM) CONCEPT............45

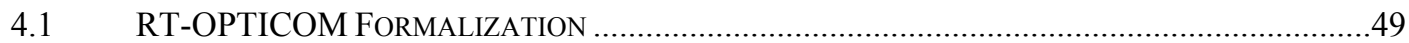

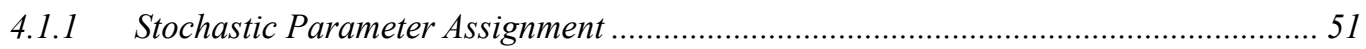

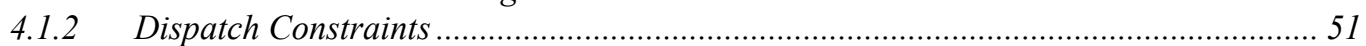

4.1.3 Deterministic Correction Constraints ................................................................. 52

5. APPLICATION OF RT-OPTICOM CONCEPT TO AN IES FOR COMMERCIAL/INDUSTRIAL BUILDINGS....................................................................................59

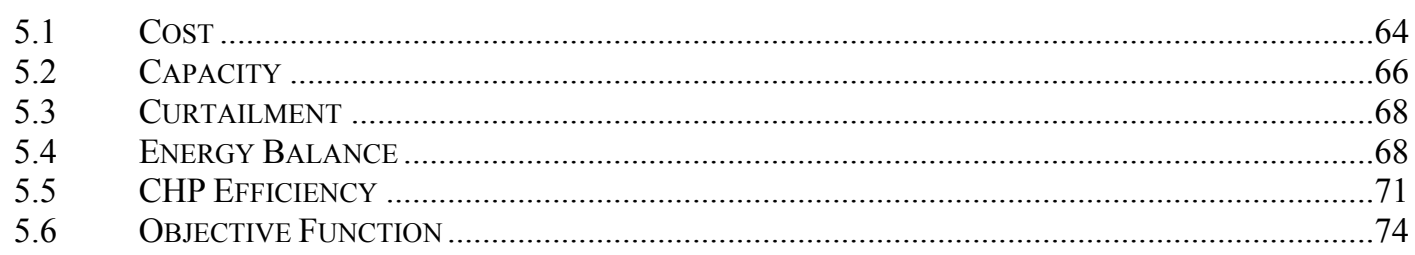

6. ADJUSTMENTS TO MODEL FOR MIXED INTEGER LINEAR PROGRAM .................75

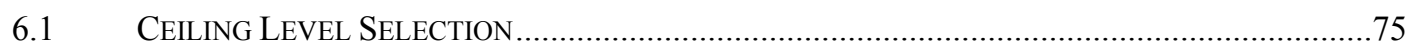

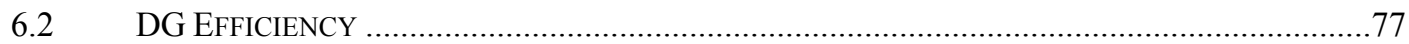

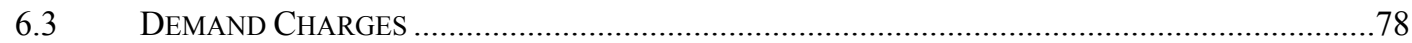

PART 3: RT-OPTICOM APPLICATION: THE UNITED STATES POSTAL SERVICE PROCESSING AND DISTRIBUTION CENTERS .......................................................................80

7. SITE DESCRIPTION, DATA COLLECTION, AND MODELING........................................82

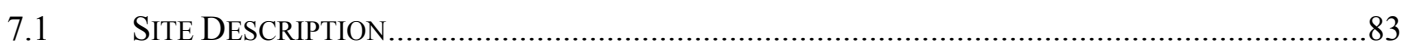

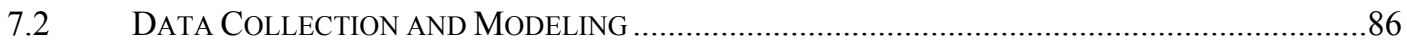

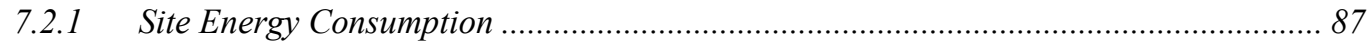

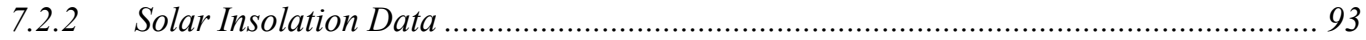

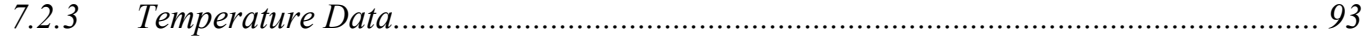

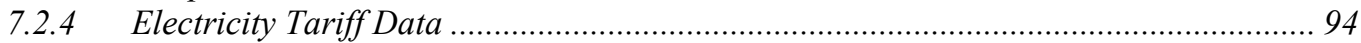

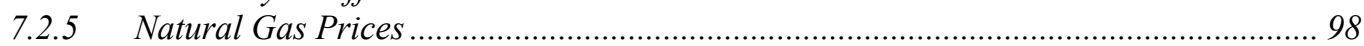

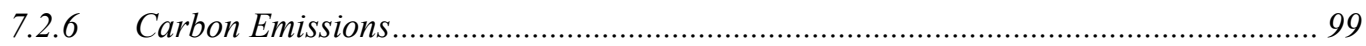

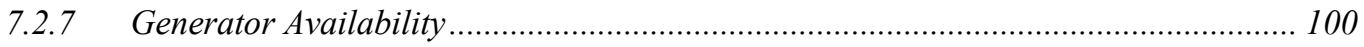

viii 
8. RT-OPTICOM EXPERIMENTS ................................................................................................104

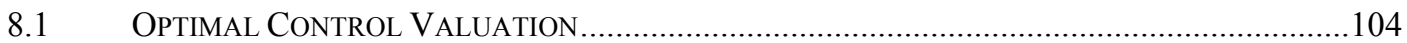

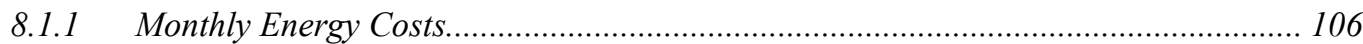

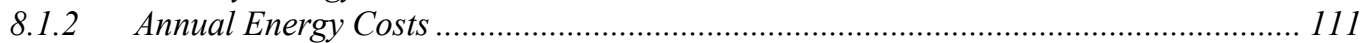

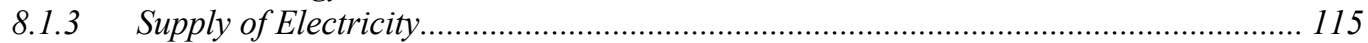

8.1.4 Optimal Control Valuation - Observations.......................................................... 128

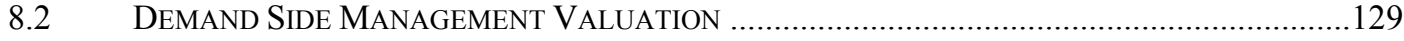

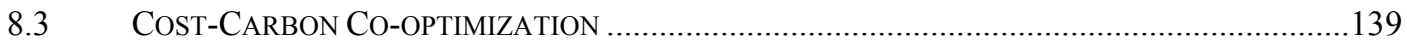

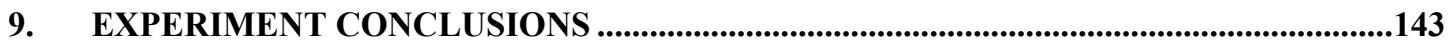

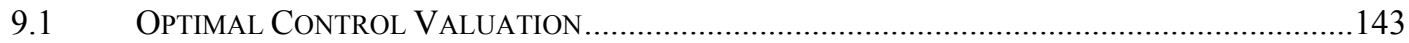

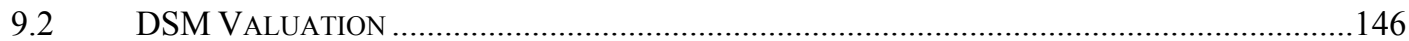

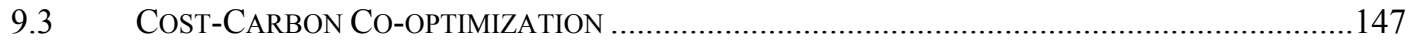

PART 4: CONCLUSIONS AND FUTURE WORK..................................................................149

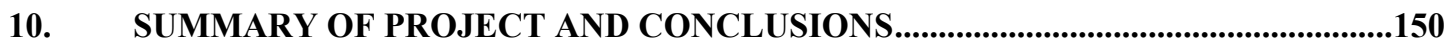

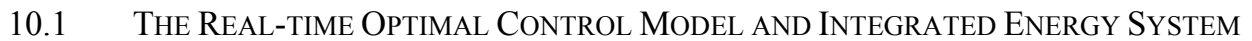

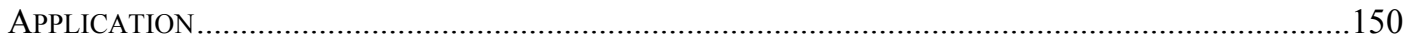

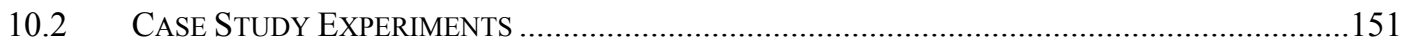

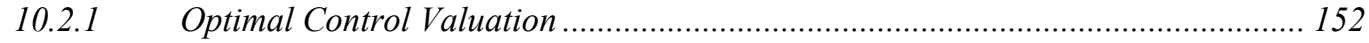

10.2.2 Demand Side Management Valuation................................................................ 153

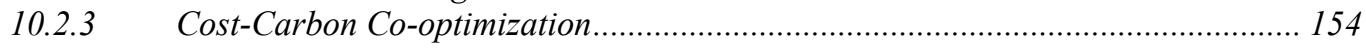

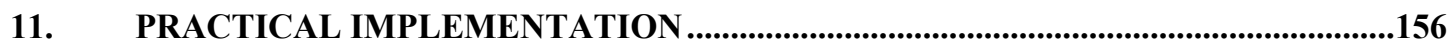

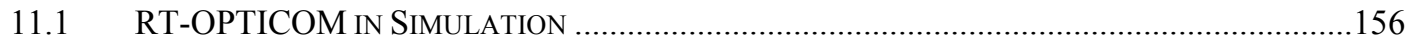

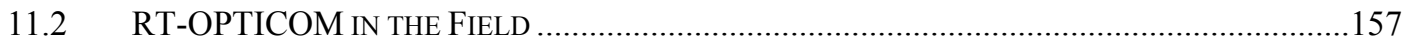

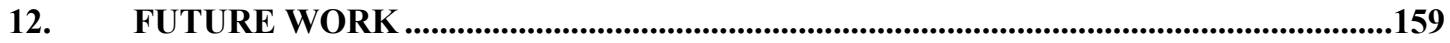

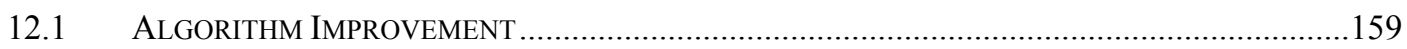

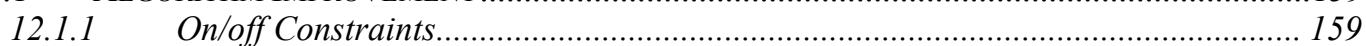

12.1.2 Storage and Intermittent Resources............................................................... 160

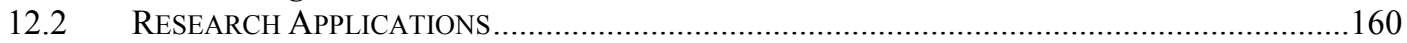

12.2.1 Near-optimal Heuristic Control.................................................................... 160

12.2.2 Scoping Studies of Building Types, Locations, and IES Designs .......................... 161

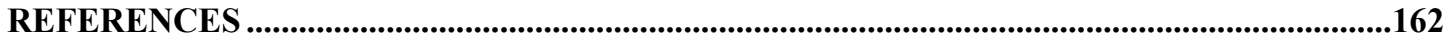




\section{Figures and Tables}

\section{Figures}

Figure ES 1. discrepancy between stochastic and deterministic scenarios ............xxxvi Figure ES 2. parameters and variables at time-step i of RT-OPTICOM................xxxvii Figure ES 3. electricity and natural gas prices for January 2004 to August 2006 and the ratio of electricity to natural gas price ...................................................... xlii

Figure ES 4. Boston - monthly energy costs under all tariffs and control strategies .xlv Figure ES 5. average annual value of DG .......................................................... xlvii

Figure ES 6. Baltimore - January 2004 - electricity purchase by hour, ordered from least to highest RTP.............................................................................. xlviii

Figure ES 7. Baltimore - July 2004 - electricity purchase by hour, ordered from least to highest RTP xlviii

Figure ES 8. Baltimore - November 2005 - electricity purchase by hour, ordered from least to highest RTP …………………………….................................

Figure ES 9. duration curves that demonstrate the peakier nature of DG customers' utility purchase

Figure ES 10. TOU - with-DG - annual value $(\mathrm{k} \$$ ) of varying DSM programs in 2006

Figure ES 11. Baltimore - cost-carbon Pareto front ....................................................1vi

Figure ES 12. Baltimore - cost-carbon Pareto front, as percentage of best-cost and

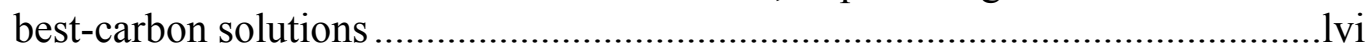

Figure ES 13. San Diego - cost-carbon Pareto front ...................................................vi

Figure ES 14. San Diego - cost-carbon Pareto front, as percentage of best-cost and best-carbon solutions ...................................................................................

Figure 1. average U.S. commercial natural gas price from 2000 to 2006 ....................18

Figure 2. discrepancy between stochastic and deterministic scenarios ........................48

Figure 3. typical part load efficiency.................................................................

Figure 4. typical part load fuel consumption............................................................ 78

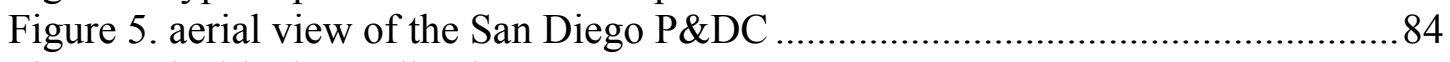

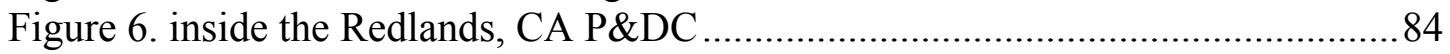

Figure 7. generator housing at the San Diego P\&DC .............................................. 84

Figure 8. General Electric Jenbacher 1.5 MW reciprocating engine installed at the San

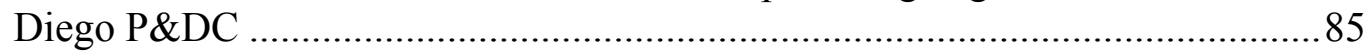

Figure 9. cooling tower for chillers at the San Diego P\&DC......................................8 85

Figure 10. one of two photovoltaic arrays $(\sim 6 \mathrm{~kW})$ at the San Diego P\&DC.............85

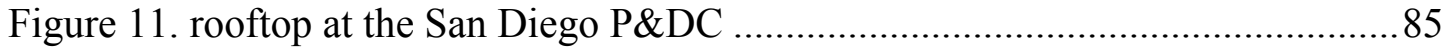

Figure 12. schematic of cooling and heating load model parameter determination....92

Figure 13. schematic of non-cooling electric load model parameters .........................92

Figure 14. electricity and natural gas prices for January 2004 to August 2006 and the ratio of electricity to natural gas price. 
Figure 15. two-state Markov model of generator availability

Figure 16. Baltimore - monthly energy costs under all tariffs and control strategies 107 Figure 17. Boston - monthly energy costs under all tariffs and control strategies.... 108 Figure 18. Houston - monthly energy costs under all tariffs and control strategies.. 109 Figure 19. San Diego - monthly energy costs under all tariffs and control strategies

Figure 20. Baltimore - average annual energy costs under all control strategies ..... 112 Figure 21. Baltimore- average annual savings over no-DG case under all other control strategies.

Figure 22. Boston - average annual energy costs under all control strategies

Figure 23. Boston- average annual savings over no-DG case under all other control strategies

Figure 24. Houston - average annual energy costs under all control strategies.

Figure 25. Houston- average annual savings over no-DG case under all other control strategies

Figure 26. San Diego - average annual energy costs under all control strategies ....113

Figure 27. San Diego- average annual savings over no-DG case under all other control strategies.

Figure 28. Baltimore - TOU - January 2004 - electricity supply for the first week of the month

Figure 29. Baltimore - CPP - January 2004 - electricity supply for the first week of the month

Figure 30. Baltimore - RTP - January 2004 - electricity supply for the first week of the month

Figure 31. Baltimore - January 2004 - electricity purchase by hour, ordered from least to highest RTP.

Figure 32. Baltimore - TOU - July 2004 - electricity supply for the first week of the month....

Figure 33. Baltimore - CPP - July 2004 - electricity supply for the first week of the month.

Figure 34. Baltimore - RTP - July 2004 - electricity supply for the first week of the month.

Figure 35. Baltimore - July 2004 - electricity purchase by hour, ordered from least to highest RTP

Figure 36. Baltimore - TOU - November 2005 - electricity supply for the first week of the month.

Figure 37. Baltimore - CPP - November 2005- electricity supply for the first week of the month

Figure 38. Baltimore - RTP - November 2005 - electricity supply for the first week of the month....

Figure 39. Baltimore - November 2005 - electricity purchase by hour, ordered from least to highest RTP.

Figure 40. Boston - TOU - January 2004 - electricity supply for the first week of the month 
Figure 41. Boston - CPP - January 2004 - electricity supply for the first week of the month

Figure 42. Boston - RTP - January 2004 - electricity supply for the first week of the month.

Figure 43. Boston - January 2004 - electricity purchase by hour, ordered from least to highest RTP

Figure 44. Boston - TOU - July 2004 - electricity supply for the first week of the month

Figure 45. Boston - CPP - July 2004 - electricity supply for the first week of the month

Figure 46. Boston - RTP - July 2004 - electricity supply for the first week of the month

Figure 47. Boston - July 2004 - electricity purchase by hour, ordered from least to highest RTP

Figure 48. Boston - TOU - November 2005 - electricity supply for the first week of the month

Figure 49. Boston - CPP - November 2005- electricity supply for the first week of the month

Figure 50. Boston - RTP - November 2005 - electricity supply for the first week of the month

Figure 51. Boston - November 2005 - electricity purchase by hour, ordered from least to highest RTP

Figure 52. Houston - TOU - January 2004 - electricity supply for the first week of the month

Figure 53. Houston - CPP - January 2004 - electricity supply for the first week of the month

Figure 54. Houston - RTP - January 2004 - electricity supply for the first week of the month

Figure 55. Houston - January 2004 - electricity purchase by hour, ordered from least to highest RTP

Figure 56. Houston - TOU - July 2004 - electricity supply for the first week of the month.

Figure 57. Houston - CPP - July 2004 - electricity supply for the first week of the month

Figure 58. Houston - RTP - July 2004 - electricity supply for the first week of the month

Figure 59. Houston - July 2004 - electricity purchase by hour, ordered from least to highest RTP

Figure 60. Houston - TOU - November 2005 - electricity supply for the first week of the month

Figure 61. Houston - CPP - November 2005- electricity supply for the first week of the month

Figure 62. Houston - RTP - November 2005 - electricity supply for the first week of the month 
Figure 63. Houston - November 2005 - electricity purchase by hour, ordered from

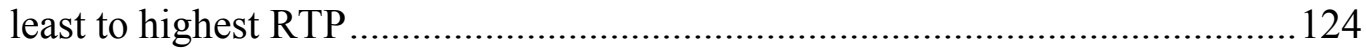

Figure 64. San Diego - TOU - January 2004 - electricity supply for the first week of

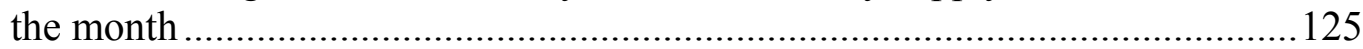

Figure 65. San Diego - CPP - January 2004 - electricity supply for the first week of

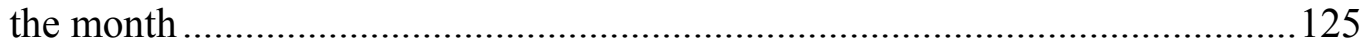

Figure 66. San Diego - RTP - January 2004 - electricity supply for the first week of

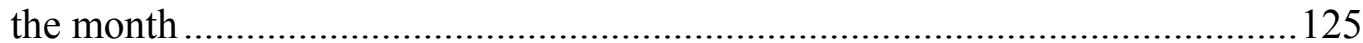

Figure 67. San Diego - January 2004 - electricity purchase by hour, ordered from least to highest RTP.................................................................................. 125

Figure 68. San Diego - TOU - July 2004 - electricity supply for the first week of the month 126

Figure 69. San Diego - CPP - July 2004 - electricity supply for the first week of the month..... 126

Figure 70. San Diego - RTP - July 2004 - electricity supply for the first week of the month

Figure 71. San Diego - July 2004 - electricity purchase by hour, ordered from least to highest RTP 126

Figure 72. San Diego - TOU - November 2005 - electricity supply for the first week of the month

Figure 73. San Diego - CPP - November 2005- electricity supply for the first week of the month.

Figure 74. San Diego - RTP - November 2005 - electricity supply for the first week of the month

Figure 75. San Diego - November 2005 - electricity purchase by hour, ordered from least to highest RTP

Figure 76. duration curves that demonstrate the peakier nature of DG customers' utility purchase

Figure 77. TOU - no-DG - annual energy cost $(\mathrm{M} \$)$ under varying DSM programs in 2006

Figure 78. TOU - no-DG - annual value (k\$) of varying DSM programs in 2006..132 Figure 79. TOU - with-DG - annual energy cost (M\$) under varying DSM programs in 2006

Figure 80. TOU - with-DG - annual value (k\$) of varying DSM programs in 2006

Figure 81. CPP - no-DG - annual energy cost $(\mathrm{M} \$)$ under varying DSM programs in 2006

Figure 82. CPP - no-DG - annual value $(\mathrm{k} \$$ ) of varying DSM programs in $2006 \ldots 134$

Figure 83. CPP - with-DG - annual energy cost $(\mathrm{M} \$$ ) under varying DSM programs in 2006

Figure 84. CPP - with-DG - annual value ( $\mathrm{k} \$$ ) of varying DSM programs in 2006135 Figure 85 . RTP - no-DG - annual energy cost $(\mathrm{M} \$)$ under varying DSM programs in 2006

Figure 86. RTP - no-DG - annual value (k\$) of varying DSM programs in $2006 \ldots 136$ 
Figure 87. RTP - with-DG - annual energy cost (M\$) under varying DSM programs in 2006

Figure 88. RTP - with-DG - annual value (k\$) of varying DSM programs in 2006137

Figure 89. Baltimore - cost-carbon Pareto front.

Figure 90. Baltimore - cost-carbon Pareto front, as percentage of best cost and best carbon solutions

Figure 91. Boston - cost-carbon Pareto front

Figure 92. Boston - cost-carbon Pareto front, as percentage of best cost and best carbon solutions

Figure 93. Houston - cost-carbon Pareto front

Figure 94. Houston - cost-carbon Pareto front, as percentage of best cost and best carbon solutions

Figure 95. San Diego - cost-carbon Pareto front

Figure 96. San Diego - cost-carbon Pareto front, as percentage of best cost and best carbon solutions

Figure 97. average annual value of DG

Figure 98. value of DG energy offsets in 2004 ..................................................... 146

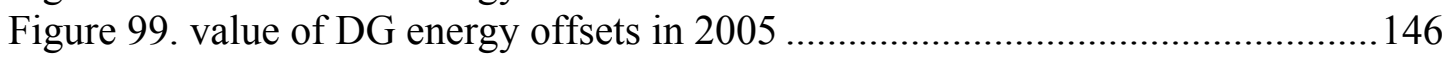

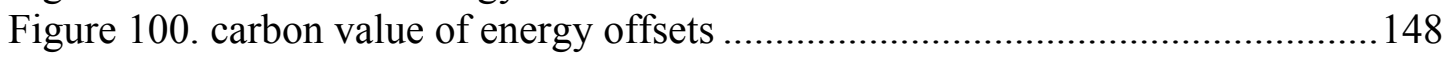

Figure 101. Baltimore - TOU - annual energy costs under all control strategies .... 182

Figure 102. Baltimore - TOU - annual savings over no-DG case under all other control strategies.

Figure 103. Baltimore - CPP - annual energy costs under all control strategies .....182

Figure 104. Baltimore - CPP - annual savings over no-DG case under all other control strategies.

Figure 105. Baltimore - RTP - annual energy costs under all control strategies ..... 183

Figure 106. Baltimore - RTP - annual savings over no-DG case under all other control strategies.

Figure 107. Boston - TOU - annual energy costs under all control strategies

Figure 108. Boston - TOU - annual savings over no-DG case under all other control strategies

Figure 109. Boston - CPP - annual energy costs under all control strategies ..........184

Figure 110. Boston - CPP - annual savings over no-DG case under all other control strategies

Figure 111. Boston - RTP - annual energy costs under all control strategies...........184

Figure 112. Boston - RTP - annual savings over no-DG case under all other control strategies

Figure 113. Houston - TOU - annual energy costs under all control strategies.......185

Figure 114. Houston - TOU - annual savings over no-DG case under all other control strategies

Figure 115. Houston - CPP - annual energy costs under all control strategies ........ 185

Figure 116. Houston - CPP - annual savings over no-DG case under all other control strategies

Figure 117. Houston - RTP - annual energy costs under all control strategies.........186 
Figure 118. Houston - RTP - annual savings over no-DG case under all other control strategies

Figure 119. San Diego - TOU - annual energy costs under all control strategies.... 186

Figure 120. San Diego - TOU - annual savings over no-DG case under all other control strategies.

Figure 121. San Diego - CPP - annual energy costs under all control strategies..... 187

Figure 122. San Diego - CPP - annual savings over no-DG case under all other control strategies.

Figure 123. San Diego - RTP - annual energy costs under all control strategies .... 187

Figure 124. San Diego - RTP - annual savings over no-DG case under all other control strategies.

\section{Tables}

Table ES 1. summary of average annual optimal control valuation xlvii

Table ES 2. DSM program value ( $\mathrm{k} \$$ /year) for a 10 hour/month, $100 \mathrm{~kW} /$ episode program and a 25 hour/month, $250 \mathrm{~kW} /$ episode program in 2006

Table 1. indices used in RT-OPTICOM problem formulation. 49

Table 2. parameters used in RT-OPTICOM problem formulation ...........................50

Table 3. variables used in RT-OPTICOM problem formulation ...............................50

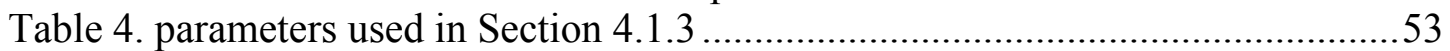

Table 5. cost of outage - stochastic and deterministic scenarios ...............................54

Table 6. indices used in the ceiling approach formulation .......................................55

Table 7. parameters used in the ceiling approach formulation................................56

Table 8. variables used in the ceiling approach formulation......................................56

Table 9. indices used in RT-OPTICOM IES formulation .......................................5

Table 10. parameters used in RT-OPTICOM IES formulation................................6 60

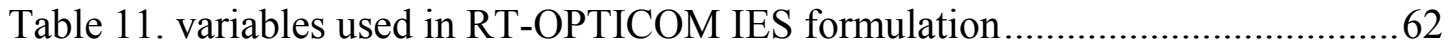

Table 12. electricity rates for Baltimore, 2004 ….................................................95

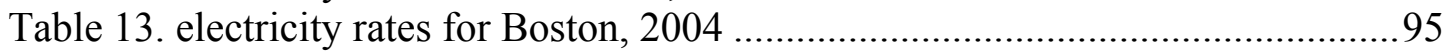

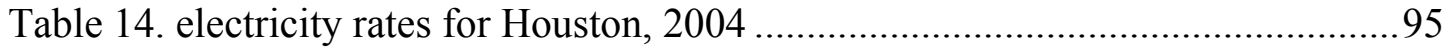

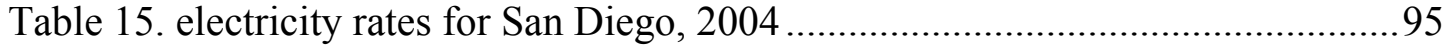

Table 16. ratio of CPP to TOU volumetric prices for SCE 2005 ...............................96

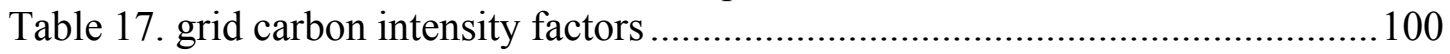

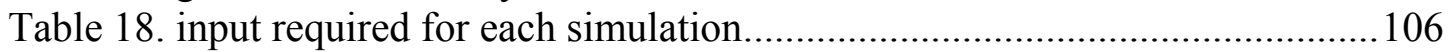

Table 19. the value of optimal control: average annual difference in energy costs

$(\mathrm{k} \$ / \mathrm{a})$ between optimally controlled and heat-following systems .................... 114

Table 20. DSM program value (k\$/year) for a 10 hour/month, $100 \mathrm{~kW} /$ episode program and a 25 hour/month, $250 \mathrm{~kW} /$ episode program in $2006 \ldots \ldots \ldots \ldots \ldots . . . . .139$

Table 21. summary of average annual optimal control valuation ............................ 144

Table 22. DSM program value ( $\mathrm{k} \$ /$ year) for a $10 \mathrm{hour} /$ month, $100 \mathrm{~kW} /$ episode program and a 25 hour/month, $250 \mathrm{~kW} /$ episode program in 2006 
Table 23. approximate number of feasible solution sets for month long optimization

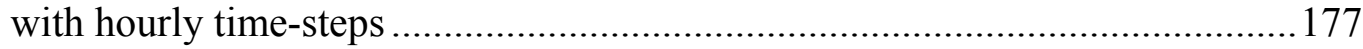




\section{Acronyms}

\begin{tabular}{|c|c|}
\hline $\mathrm{AC}$ & alternating current \\
\hline BEM & building energy model \\
\hline BGE & Baltimore Gas and Electric Company \\
\hline CAISO & California Independent System Operator \\
\hline CARB & California Air Resources Board \\
\hline $\mathrm{CHP}$ & combined heat and power \\
\hline CPLEX & a trademark of CPLEX Optimization, Inc \\
\hline $\mathrm{CPP}$ & critical peak pricing \\
\hline $\mathrm{DC}$ & direct current \\
\hline DER & distributed energy resources \\
\hline DER-CAM & Distributed Energy Resources Customer Adoption Model \\
\hline DG & distributed generation \\
\hline DR & demand response \\
\hline DSM & demand-side management \\
\hline $\mathrm{EE}$ & energy efficiency \\
\hline EIA & Energy Information Agency \\
\hline eQUEST & Quick Energy Simulation Tool \\
\hline ERCOT & Electric Reliability Council of Texas \\
\hline GA & genetic algorithm \\
\hline GAMS & General Algebraic Modeling System \\
\hline
\end{tabular}

xvii 


$\begin{array}{ll}\text { HOMER } & \text { Hybrid Optimization Model for Electric Renewables } \\ \text { HVAC } & \text { heating, ventilation, and air conditioning } \\ \text { IES } & \text { integrated energy system } \\ \text { ISO-NE } & \text { New England Independent System Operator } \\ \text { LBNL } & \text { Lawrence Berkeley National Laboratory } \\ \text { MILP } & \text { mixed integer linear program } \\ \text { NOx } & \text { nitrous oxides } \\ \text { NP } & \text { non-deterministic polynomial time } \\ \text { NRC } & \text { Natural Resources Canada } \\ \text { NREL } & \text { National Renewable Energy Laboratory } \\ \text { OLS } & \text { ordinary least squares } \\ \text { P\&DC } & \text { processing and distribution center } \\ \text { PJM } & \text { Pennsylvania, Jersey, Maryland Power Pool } \\ \text { PUCT } & \text { Public Utilities Commission of Texas } \\ \text { PURPA } & \text { Public Utility Regulatory Policy Act of 1978 } \\ \text { PV } & \text { photovoltaics } \\ \text { RETScreen } & \text { Renewable Energy Technologies Screening Tools } \\ \text { RReDC } & \text { Renewable Resources Data Center } \\ \text { RT-OPTICOM } & \text { Real-Time Optimal Control Model } \\ \text { RTP } & \text { real-time pricing } \\ \text { SCE } & \text { Southern California Edison } \\ \text { SDG\&E } & \text { San Diego Gas and Electric } \\ \text { SOx } & \text { sulfur oxides } \\ \text { N } & \end{array}$


TOU time of use

USPS United States Postal Service

WADE The World Alliance For Decentralized Energy

xix 


\section{Executive Summary}

\section{Introduction: Integrated Energy Systems (IES) and the Need for Generic Real- Time Dispatch Optimization Algorithms}

Market deregulation has shaped the United States energy sector for the past three decades. The Public Utility Regulatory Policy Act (PURPA) of 1978 first invited relatively small-scale generators into the electricity market, and wholesale competition has become widespread during the last decade, especially in some jurisdictions, notably California, New York, New England, and the PennsylvaniaNew Jersey-Maryland interconnection. On the customer side of the meter, the change has been less dramatic, but nonetheless, expectations of the electricity supply system have evolved following experiments with customer choice, greater exposure of consumers to the variability of electricity prices, and an emerging generation roller coaster investment cycle. And, of course, the 2000-2001 California energy crisis, the terrorist threat, and the August 2003 Northeast blackout have radically reshaped expectations of supply security.

Simultaneously, improvements to small-scale and renewable technology have spurred an industry that has, in recent years, made even smaller (business scale) electricity generation an economically viable option for some consumers. On-site energy

production, known as distributed generation (DG) offers consumers many benefits, such as energy cost reductions and predictability, improved system efficiency, improved reliability, control over power quality, and in many cases, greener 
electricity. Additionally, DG systems can benefit electric utilities by reducing congestion on the grid, reducing the need for new generation and transmission capacity, and offering ancillary services such as voltage support and demand response. Additional on-site energy storage and conversion devices offer further benefit, and include heat exchangers for waste heat recovery, thermally activated cooling, electrical storage, and thermal storage. These technologies are collectively referred to as distributed energy resources (DER).

The economic analysis of energy efficiency (EE) measures has become commonplace. Businesses and institutions have become less hostile to demand response (DR) measures - i.e. curtailment and rescheduling - due to government mandates, conservation campaigns (such as "Flex Your Power" in California), new tariffs that put a premium on electricity during times of system scarcity, and lucrative interruptible service contracts from utilities.

This suite of customer-side energy options - EE, DER, and DR - gives customers complex investment and operation decisions. The value of these investments is dependent on how the system is operated; therefore dispatch optimization is a necessary part of the investment optimization problem. However, the enumeratively large set of candidate EE/DER/DR systems in the investment problem necessitates a simplification of the dispatch problem. Typically, this simplification is achieved by limiting the number of days considered, assuming determistic loads, prices, and equipment availability, and approximating the electricity tariff structure. 
While the investment problem has been given considerable attention in recent years, the operation problem has not been adequately addressed. The approximate approaches used in investment optimizations may be adequate for rough system identification and sizing; however, they may not be accurate enough for a more detailed study of a particular system or as controllers for actual systems. It is the intent of this project to develop a general solution to the real-time optimal dispatch problem for integrated systems of DER and demand response, herein referred to as integrated energy systems (IES).

\section{IES Components}

IES for a site may consist of a large range of energy conversion and storage devices, as well as demand response options, giving the site control of both its supply of and demand for electrical and thermal energy. The economically optimal dispatch of any IES must be in response to current and forecasted energy prices, energy demand, and DER equipment availability. Dispatch must be within mechanical and regulatory constraints on the IES.

Typical electricity generation equipment found on-site includes natural gas-, propaneor biogas-fueled gas turbines, reciprocating engines, microturbines, and fuel cells. Heat recovery from these devices can be used for site steam or heating needs or for thermally-activated cooling. Often this use for the waste-heat from electricity 
generation is what tips the scales in favor of on-site generation. Renewable electricity sources (photovoltaics and small-scale wind turbines) and thermal sources (solar thermal collectors and ground-source heat pumps) are also present.

Thermally-activated cooling is achieved through absorption or adsorption chillers, which utilize a modified compression-chiller cycle to replace much of the electric energy input requirement with a thermal energy requirement. Desiccant dehumidifiers use heat to remove moisture from air before cooling it, which reduces the energy required to cool the air.

Electrical and thermal storage technologies can add value to an energy source by shifting its utilization from times of low value to times of high value. For example, the waste-heat from a continuously running generator can be stored throughout the day and used during times of high thermal load. Similarly, low-priced electricity such as off-peak power or excess wind-power can be stored for use during highpriced on-peak hours using a battery or other electrical storage device.

\section{Demand Response}

The high price of peak electricity has encouraged price responsiveness among some customers. Some customers may respond to price or control signals from their utility to reduce or reschedule electric loads, a practice known as demand response. Demand response opportunities can be characterized as 1) curtailable, such as non-essential 
lighting (e.g. hallways, parking garages), 2) reschedulable, such as energy-intensive industrial processes, or 3) part-curtailable/part-reschedulable, such as cooling loads. In pilot programs where the hourly and daily volatility of prices is passed directly to consumers, rather than monthly averaging, demand response behavior increases. This holds promise for bringing demand elasticity to the electricity market, a valuable step towards reducing peak capacity costs and mitigating the threat of market power abuse. Voluntary programs that hyper-incent demand response (and in some cases automatically shed customer load) have proved a cost-effective substitute for some amount ultra-peak capacity, i.e. peaker plants that are only used a handful of hours per year.

\section{Energy Pricing and Tariff Structure}

\section{Electricity}

Utilities incur both variable and fixed expenses; tariffs are typically designed to cover three kinds of costs:

- Fixed charges are invariant, $\$ /$ month. These are infrastructure costs of supply and delivery required by the customer regardless of their energy consumption for that month.

- Volumetric charges are proportional to the amount of energy consumed. They are expressed in $\$ / \mathrm{kWh}$ and may vary by time of day within a month. Volumetric rates are intended to cover the variable costs of producing 
electricity, such as fuel and some maintenance, in addition to the fixed costs that generators recover in their volumetric sales of electricity.

- Demand charges are expressed in $\$ / \mathrm{kW}$ and levied on the maximum power consumption during a specified time range (such as the on-peak hours of the month), regardless of the duration or frequency of that level of power consumption. Demand charges are intended to collect the fixed costs of infrastructure shared with other customers by raising revenue in proportion to the amount of power required by the individual.

Demand charges play an integral role in the problem of dispatch optimization because of their magnitude and mathematic non-linearity. The demand charges can be a third to a half of a customer's electricity bill. Because they are a function of the maximum power consumption during the month, they are non-linear and they act over the entire month, making decision making at one time-step dependent on plans for future timesteps.

In this research, three types of tariff structures are considered:

- time of use (TOU) - the volumetric price of electricity varies by on-peak, mid-peak, and off-peak periods of consumption each month

- critical peak pricing (CPP) - similar to TOU, but with much higher volumetric rates during periods of high system load 
- real-time pricing (RTP) - the volumetric price of electricity varies from hour to hour, reflecting to the true marginal cost of electricity to the utility.

Natural Gas and Other Fossil Fuels

Tariffs for natural gas and other fuels typically consist of fixed and volumetric components.

\section{Energy Demand}

Site energy demand can be divided into end-use types. A convenient division is noncooling electricity, cooling (which may be further divided into space-cooling, refrigeration, etc.), space-heating, and natural-gas-only (such as cooking and distributed space-heating). The reason for separating cooling from other electricity loads is that cooling loads can also be met or offset by thermally-activated cooling. Energy demand is stochastic in nature. The statistical makeup of these loads will depend on the site, but key influences on load are weather and business/operation state.

\section{Equipment Availability}

DER equipment is subject to failure, which results in unscheduled outages. The occurrence and duration of these outages are stochastic. For grid-connected DER, unplanned outages can create surges in utility electricity purchase, resulting in large 
demand charges. The intermittency of solar- and wind-powered electricity can have similar effect.

\section{Dispatch Constraints}

DER dispatch is limited by 1) physical constraints of the system, such as maximum ramping rates and rated capacities and 2) regulatory constraints such as limits on specific or total hours equipment can run or minimum system efficiency requirements.

\section{The Integrated Energy System}

In order to best meet a site's energy objectives, all of the equipment, loads, prices, forecasts, demand response options, and operational constraints should be viewed as a single, integrated energy system, or IES. IES contain several key features that make their optimal dispatch difficult. One of these features is uncertainty, which arises in energy loads, energy prices and IES equipment availability. Another is the intertemporal coupling of solutions caused by 1) demand charges, which act across an entire month, and 2) limits on the number of curtailment episodes and total hours of DER operation; these factors require scheduling as part of an optimal solution. Scheduling is further required to ensure minimum efficiency requirements, or to address limited fuel constraints. 
Demand charges make economic minimization particularly difficult in situations where the marginal cost of on-site generation is greater than that of utility electricity purchase, yet demand charges still make some amount of on-site generation economic. Here, the correct level of demand charge mitigation must be determined in light of stochastic loads and equipment availability.

Cost minimization may not be the sole objective of a site's IES dispatch optimization. Public sites may be more motivated by a reduction in primary fuel consumption and/or greenhouse gas emissions, as might environmental champions or imageconscious entities.

\section{Hypothesis - Heuristic Dispatch: Functional, Not Optimal}

The economically or environmentally optimal dispatch of a building's IES is a problem rarely addressed in building operations. Typically, building managers are in charge of dispatch decisions, yet their primary concern is ensuring that systems meet the needs of users, not that needs are met in an optimally efficient manner. Optimal dispatch would require continuous decision-making based on historic data, current conditions, equipment availability, demand response opportunities, and stochastic forecasts of the future (prices, loads, and availability of equipment and of intermittent renewable resources). 
Building managers typically employ heuristic controls to their IES, such as a schedule for running their DER, or a target electricity demand level that they try to avoid exceeding for each month. A detailed, quantitative analysis is not performed to ensure that, if a schedule is to be used, this particular schedule is the right one, or that the correct target demand level has been selected. To the author's knowledge, no such methodology exists in the public domain.

For cost minimization, demand charges, which can be a third to a half of a customer's utility electricity bill, turn a problem that would otherwise be a straight forward comparison of marginal costs into a problem requiring planning under significant uncertainty. Further planning is required when heat can be stored for later use and when curtailment can be used in limited frequency. For primary fuel or carbon emissions minimizations, planning is required to match fuel savings opportunities with energy requirements, again under uncertainty.

Given that IES have multiple degrees of freedom, and that IES operators consider only a limited set of dispatch options, it is most likely that optimal IES operation is not being achieved. This observation introduces the hypothesis of this research:

\section{Heuristic dispatch typically used by building managers is not optimal.} Optimization algorithms can be developed to make near-optimal decisions, resulting in improved realization of objectives such as the minimization of cost, primary fuel consumption, and/or carbon emissions. 
Two questions come directly from this hypothesis:

- How can optimal dispatch be determined?

- How much better could site objectives be met under optimal dispatch of IES? These questions were the initial motivation for this research.

\section{Prior Research}

This work builds on much prior work, including research on dispatch optimization from vertically-integrated electric utilities, distributed generation investment optimization, demand response.

\section{Vertically-integrated Electric Utilities}

The most direct comparison to the IES dispatch problem is the vertically-integrated utility dispatch optimization problem. This problem, in its entirety, is enormous, requiring decision making on the order of minutes over a timespan of a year or more (to include maintenance scheduling and the rationing of scarce resources), with uncertainty in demand and in generator/transmission/distribution availability at every time-step. To make the problem manageable, it is typically divided into three separate problems:

- a planning problem for the day-to-day problem (over the course of months);

- a unit commitment problem for the hour-to-hour problem (over the course of several days); and 
- a power flow problem for the minute-to-minute decisions (over the course of tens of minutes) and to ensure that transmission lines are not overloaded and to account for both real and reactive power demand.

The unit commitment problem is the one most closely related to IES dispatch. After more than a century, this problem is still an open field of research. The large number of discrete decisions (i.e. on/off decisions) required for this problem make it particularly challenging. Prior to the advent of modern computing power, heuristic approaches to the problem were developed in which priority lists of available units were generated, and generators were called on- or off-line based on their placement on the priority list. Over the years, the dominant approach to improved solutions to the unit commitment problem (both in research and in practice) has been to improve upon the methods for developing priority lists.

Optimization techniques developed in the field of operations research have proved useful for the unit commitment problem. Analytic techniques (e.g. Lagrangian relaxation), as well as stochastic techniques that mimic natural selection in heterozygous reproduction (e.g. genetic algorithms) have both had success.

\section{Distributed Generation Investment Optimization}

With the recent advent of small (100s of kW to several MW) DG that is cost competitive with utility power purchase, much research has been done on the DG 
investment optimization problem. Dispatch must be considered in the investment optimization problem because the value of a given DG system will depend on how it is operated. Several software tools have been developed to determine optimal investment, including Lawrence Berkeley National Laboratory's Distributed Energy Resources Customer Adoption Model (DER-CAM), National Renewable Energy Laboratory's Hybrid Optimization Model for Electric Renewables (HOMER), Natural Resource Canada's Renewable Energy Technologies Screening tools (RETScreen), and InterEnergy Software's D-Gen Pro. Determining the value of a specific DER system requires knowledge of how the system will be operated; the investment optimization problem necessarily includes the dispatch optimization problem. The investment tools listed necessarily make many simplifying assumptions about operation in order to consider a large set of investment options.

The true dispatch optimization problem, however, contains many details that are not covered by investment optimization programs, yet affect the bottom line of actual systems. These details include the stochastic natural of equipment availability, energy loads, and energy prices, regulatory constraints on DG operation, the complexity of electricity tariff structures, and integrated decision making for complex systems. Several research efforts have made in-roads on the DG dispatch optimization problem. This research furthers the detail covered in prior research and additionally considers the entire IES. 
Studies of utility and building experience with demand response include those by Goldman, Kintner-Meyer, and Heffner (2002), Goldman et al. (2004), Motegi, Piette, and Kinney (2003b), Piette et al. (2004), and Watson et al. (2004). Key results of these studies include

- Approximately $85 \%$ of DR is load curtailment, rather than rescheduling;

- Lighting and air conditioning are the most common DR loads, but elevators, process loads, and plug-loads are also common; and

- Most customers handle DR manually; additional savings would be possible with automated DR.

- In typical commercial and industrial buildings, automated DR reductions of at least $5-15 \%$ are feasible.

DSM, though, has been proven to be valuable to informed customers, even in the absence of strong signals from special demand response programs (Stadler et al. 2006 and Firestone, Stadler, and Marnay 2006b). This dissertation makes a new contribution by examining the interaction of DG with DSM, and, more generally examining the value of integrating decision making of disparate energy options in a building.

DG Case Studies

xxxiii 
During the process of developing DER-CAM, case studies were performed by the LBNL DER team (Bailey et al. 2003 and Firestone et al. 2003). The intent of the case-studies was to validate DER-CAM by comparing investment solutions posed by DER-CAM with those chosen by sites. One significant realization from these casestudies and later ones by the LBNL DER team was frustration that building managers expressed over the discrepancy in performance of their system and cost results with those expected prior to installation. Much of this was because of demand charges: initial maintenance schedules were often made to include maintenance on DG equipment during business hours (when the maintenance crew was most available), which resulted in no decrease in demand charges. Furthermore, frequent unplanned outages - however brief - also resulted in no demand charge savings. Some managers

mentioned that they did not consider how changes in natural gas prices from month to month would affect system economics; often they realized several months too late that they should have changed their operation schedule in response to changes in energy prices. Given the inevitable spikes in demand during unscheduled outages, some building managers wondered how worthwhile it would be to curtail or reschedule some of their loads. The experiences and ponderings of these building managers were the inspiration for this dissertation research.

\section{Algorithm Development}

This research develops an algorithm for determining near-optimal solutions to multistage optimization problems with several stochastic parameters. The resulting Real- 
Time Optimal Control Model (RT-OPTICOM) is then applied to the IES problem of a DG system with limited curtailment opportunities subject to uncertainty in energy loads, energy prices, and DG equipment availability. The RT-OPTICOM IES model is developed as a mixed integer linear program (MILP), for which various robust commercial solvers are available.

In order to be expressed as a MILP, randomly generated scenarios are used to represent stochastic parameters. Each scenario contains randomly generated values of energy loads (non-cooling electric, electric, and heating), electricity prices, DG availability, and solar insolation.

The optimization problem is discretized into time-steps in the range of minutes to an hour. It is solved sequentially at each time-step, although dispatch decisions made at each time-step must be made for the current time-step as well as for all future timesteps. All future dispatch decisions are conditional on the future i.e., there is a separate decision for each scenario at each future time-step. Future optimization, or a strategy, is necessary because 1) electricity demand charges are non-additive, but rather are determined by the maximum over all time-steps in the month and 2) there are inter-temporal (annual) constraints such as regulatory limits on system efficiency and emissions.

The true stochastic optimization problem contains branching sets of scenarios, whereas the finite-scenario optimization problem contains only single-strands of $\mathrm{XXXV}$ 
scenarios. Figure ES 1 illustrates this. Because of this discrepancy, certain additional constraints must be added to the finite-scenario problem. These constraints must ensure that solutions that would be unrealistic for the real, nondeterministic system are not attempted. The most obvious example of this is when a significant but unlikely event happens at the end of a timespan in a scenario. If this event is deterministically known, the optimal behavior of the system in time-steps prior to the event is different than if it is only known that there is some probability of this occurrence.

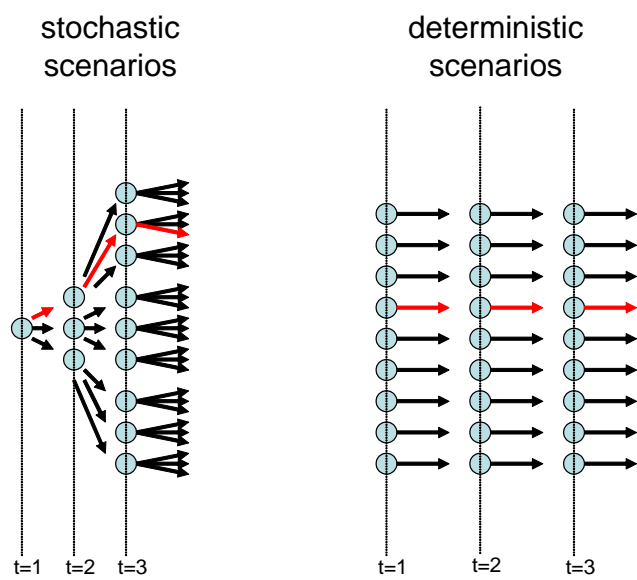

Figure ES 1. discrepancy between stochastic and deterministic scenarios

RT-OPTICOM can be used for two purposes: real-time dispatch optimization and system simulation. For real-time dispatch optimization, past and current information is the actual information about the energy system (loads, equipment availability, prices), whereas for system simulation, the "actual values" are an additional randomly 
generated scenario or set of historic actual values. For either purpose, "actual values" for a particular time-step are not revealed to RT-OPTICOM until that time-step.

Figure ES 2 illustrates the parameters and variables at time-step $i$ of timespan length T. Rows are different parameter variables types. Columns are time-steps and the current time-step is $i$. Each box in the figure represents a set of data or variables for a particular time-step, $t$. The actual parameter values for all past and the current timestep, $(0 \leq t \leq i)$, are known and sent to RT-OPTICOM. For future time-steps $(t>i)$, sets of stochastic possible parameter values are also sent to RT-OPTICOM. Finally, all previous dispatch decisions are sent to RT-OPTICOM. The program then determines the actual dispatch for the current time-step, $i$, and a set of dispatch plans, contingent on future parameter values, for all scenarios $1, \ldots, n$ at all future times $i+1, \ldots, T$.

\begin{tabular}{|c|c|c|c|c|c|}
\hline & & \multicolumn{4}{|l|}{$\mid$ timestep, $t$} \\
\hline \multirow{5}{*}{$\begin{array}{l}\text { actual parameters } \\
\text { stochastic } \\
\text { parameters }\end{array}$} & $\overline{A P_{t}}$ & \multicolumn{3}{|c|}{ parameters sent to RT-OPTICOM } & \multirow{2}{*}{\begin{tabular}{|l|} 
unknown \\
parameters
\end{tabular}} \\
\hline & $\mathbf{S P}_{1, \mathrm{t}}$ & \multirow{2}{*}{\multicolumn{2}{|c|}{ unnecessary }} & & \\
\hline & $\underline{\mathbf{S P}_{2, \mathrm{t}}}$ & & & & sent to \\
\hline & $\dot{\vdots}$ & & & & RT-OPTICOM \\
\hline & $\dot{\mathrm{SP}_{\mathrm{n}, \mathrm{t}}}$ & & & & \\
\hline actual dispatch & $A D_{t}$ & \multicolumn{3}{|c|}{ parameters sent to RT-OPTICOM } & unknown \\
\hline \multirow[t]{4}{*}{ dispatch strategy } & $\mathrm{DS}_{1, \mathrm{t}}$ & \multicolumn{2}{|l|}{ unnecessary } & & variables \\
\hline & $\underline{D S_{2, t}}$ & & & & determined \\
\hline & $\vdots$ & & & & in RT-OPTICOM \\
\hline & $\overline{D S_{n, t}}$ & & & & \\
\hline
\end{tabular}

Figure ES 2. parameters and variables at time-step i of RT-OPTICOM

Figure ES 2 is explained mathematically in equation (ES 1). 


$$
A D_{t}=\arg \min \left(E\left(\cos t\left(\begin{array}{l}
A P_{1}, \ldots, A P_{t}, \\
S P_{1, t+1}, \ldots S P_{n, t+1}, \ldots, S P_{1, T}, \ldots, S P_{n, T}, \\
A D_{1}, \ldots, A D_{t-1}, A D_{t}, \\
D S_{1, t+1}, \ldots D S_{n, t+1}, \ldots, D S_{1, T}, \ldots, D S_{n, T},
\end{array}\right)\right)\right)
$$

where

- $\mathbf{i}$ is the current time-step

- $\mathbf{T}$ is the last time-step of the timespan

- $\mathbf{E}(\operatorname{cost}())$ is the expected energy costs for the timespan 1 to $T$

- $\mathbf{A D}_{\mathbf{t}}$ is the actual dispatch at time-step $t$ (a parameter for $t<i$, a variable for $t$ = Ii)

- $\mathbf{A P}_{\mathbf{t}}$ is the actual scenario parameter values (known for $t \leq i$ )

- $\mathbf{S P}_{\mathbf{j}, \mathbf{t}}$ is the randomly generated parameter values for stochastic scenario $j$ at time-step $t$ (known for all $t$, but replaced by $A P_{t}$ for all $t \leq i$ )

- $\mathbf{D S}_{\mathbf{j}, \mathrm{t}}$ is the planned dispatch for stochastic scenario $j$ at time $t$ (a variable for all $j$ and for all $t>i$ )

\section{RT-OPTICOM Application: The United States Postal Service Processing and Distribution Centers}

The validation of the RT-OPTICOM IES tool was in the process of answering several previously unanswered questions: 
- To what extent are the heuristic controls strategies employed for CHP systems sub-optimal, i.e. to what extent could more intelligent controls improve site objectives?

- What is the value of an integrated approach to site energy dispatch decisions?

- For dispatch decisions, what is the tradeoff between cost minimization and carbon emissions minimization?

The United States Postal Service Processing and Distribution Centers (P\&DCs) were selected as a case study for this research. These light-industrial sites collect and route both incoming and outgoing mail for their regions using energy intensive machinery. P\&DCs are fairly similar across regions; their energy-situations vary by climatedriven thermal loads, local energy prices, and emissions from electricity production, but not by schedule or machinery load.

RT-OPTICOM is used to study P\&DCs from several regions, and several tariff structures in each region, illustrating the usefulness of such a general model while answering the questions posed here.

\section{Site Description, Data Collection, and Modeling}

The United States Postal Service (USPS) operates nearly 300 Processing and Distribution Centers (P\&DCs) across the United States. The machinery used to align, scan, sort, and route mail is energy-intensive, with sites typically having peak electric xxxix 
loads of approximately 1-3 MW. The tremendous amount of heat given off by the machinery makes for large cooling loads, even on days of mild temperature. The relatively flat energy profile and significant space conditioning loads make P\&DCs good candidates for DER.

P\&DCs offer a rare opportunity for industrial building energy research because they are federal, rather than private, buildings. Most private buildings contacted by the author for this project would not release detailed energy consumption data, and in general considered most information about their buildings proprietary. This lack of access to actual energy consumption data limits the scope of much building energy research. P\&DCs, on the other hand, are not limited by competition concerns, but only by security concerns. As well, the USPS has regional offices actively pursuing energy and energy-cost savings, which encourage research that might benefit their sites.

For this research, the USPS Margaret L. Sellers P\&DC in San Diego, California was studied in detail. A DER system was recently installed there, consisting of a 1.5 MW natural-gas-fired reciprocating engine coupled to a $1 \mathrm{MW}$ (300 ton) absorption chiller. The chiller offsets the site's electric compression chiller load by $250 \mathrm{~kW}$ at rated capacity. Additionally, $12 \mathrm{~kW}$ of PV are installed at the site.

The CHP system uses a load-following control i.e., the generator is run as high as possible at all times. One objective of this research is to examine economic 
efficiency of this load-following control strategy by comparing energy costs from a load-following strategy to those from an optimal dispatch control strategy.

An additional objective is to examine the results and character of optimal control under varying tariff structures. Time-of-use (TOU) tariffs are the default from the utility, and critical peak pricing (CPP) tariffs are already an option. Debate over realtime pricing (RTP) tariffs continues and could possibly be offered or imposed in the near future.

P\&DC sites across the United States have similar machines, building design, and operating schedules. The most significant differences in energy consumption at similarly sized P\&DC sites across the United States are due to climactic differences. The San Diego site was studied in detail to understand the non-cooling electric loads - which would not vary by location - and to correlated space conditioning loads to weather and electric loads. This information was then used to develop building energy simulation models of P\&DCs in four United States cities: San Diego, CA, Baltimore, MD, Boston, MA, and Houston, TX.

A great deal of data were required for the site modeling and simulations. Energy consumption data were collected from the San Diego P\&DC. Historic electricity and natural gas prices were collected from the local utilities. Real-time clearing prices were collected from the regional independent system operator (ISO) or its equivalent. Historic temperature and solar insolation data were collected from the Weather xli 
Underground and the National Renewable Energy Laboratory, respectively.

Stochastic models of loads and clearing prices were correlated to temperature data. A stochastic model of generator availability was also developed.

Figure ES 3 shows the average monthly price for electricity and natural gas for industrial customers in California. The thin solid (red) line is the ratio of the two, or spark spread, with values plotted on the right vertical axis. The spark spread has ranged from 1.96 to 4.31 in less than three years. Given that DG converts natural gas to electricity, optimal dispatch must be responsive to the relative fluctuations in these two commodities' prices.

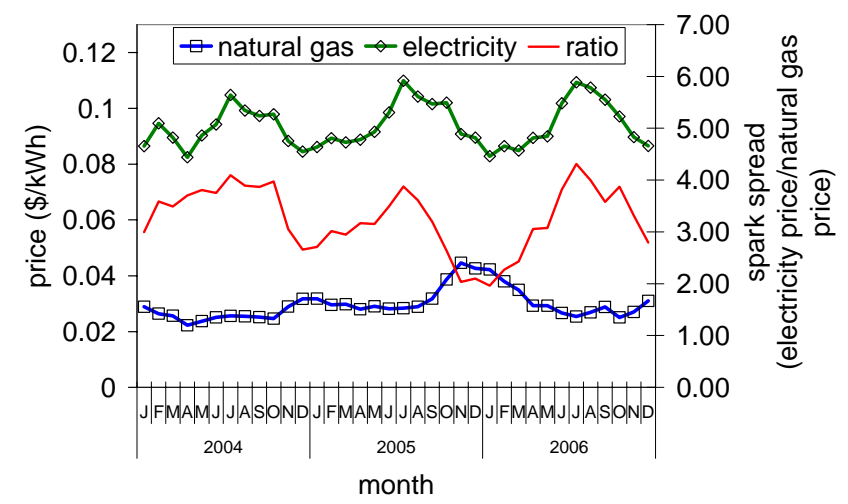

source: EIA

Figure ES 3. electricity and natural gas prices for January 2004 to August 2006 and the ratio of electricity to natural gas price

\section{Experiments}

Three experiments were conducted using RT-OPTICOM and the P\&DC data sets. These experiments were intended to demonstrate the capabilities of RT-OPTICOM 
and begin to explore some pertinent open questions concerning DG and demand response. The three experiments were

1. a valuation of optimal DG control under various tariff structures

2. a valuation of demand side management options with and without DG

3. a co-optimization of cost and carbon emissions using DG

All experiments were conducted on all four cities and under all three tariff structures to provide insight into the effects of energy-situation on results.

\section{Optimal Control Valuation}

One of the early questions that motivated this research project was of what value a sophisticated dispatch optimization - relative to standard heuristic controls - would be for a DG system. To explore this question, simulation of the P\&DC sites for each month from January 2004 to December 2006 was conducted under four control strategies:

- no-DG - The generator and absorption chiller are not run, showing site behavior prior to DG installation.

- load-following - The generator is run as much as possible, mimicking the site's current strategy.

- heat-following - The generator is dispatched to run at a level for which all recovered heat will be useful to the absorption chiller and space-heating.

- optimal dispatch - The full optimization program is used to make dispatch decisions. 
The simulations were repeated for each of the three tariff structures (TOU, CPP, and RTP). All input data were consistent across tariff structure and control strategy.

Thus, for a given month of simulation, the actual values and stochastic forecast values of non-cooling loads and DG availability were the same for each location, tariff, and control strategy. Cooling and heating loads for each location were determined by the non-cooling loads and the local weather. Actual clearing prices for each location were used for the actual years, and the location and weather dependent stochastic model of clearing prices was used to generate the clearing price stochastic scenarios. These clearing prices were then used to determine the CPP episode days - the six highest priced weekdays in each of the summer months. Actual solar insolation data for each of the stochastic scenario years were used, and historic average data were used for the actual years ${ }^{1}$.

Figure ES 4 plots the resulting monthly energy prices for Boston. The optimal solution for the TOU and CPP tariffs is approximately a selection between one of the three heuristic strategies. During most of 2004 and 2005, the optimal control strategy was approximately no-DG, whereas in 2006 , the optimal control strategy was

\footnotetext{
${ }^{1}$ Data for the actual years considered (2004 to 2006) could not be found - average daily profiles from the 1961 to 1970 data were used instead. For a site with more sizeable solar energy harvesting, this averaging would not be appropriate. However, for this particular site, the $12 \mathrm{~kW}$ photovoltaic system provides, at most, about $0.5 \%$ of the site's electric load. Including the stochastic solar insolation in the model is mostly a placeholder for studies targeted at renewables, for which the only modification to this work would be to update the solar data for the actual years considered.
} 
approximately to heat- or load-follow. Where there was a significant difference between heat- and load-following, heat-following was almost always a lower-cost strategy than load-following. Under RTP tariff, optimal control provides lower cost in many months than any of the heuristic strategies.
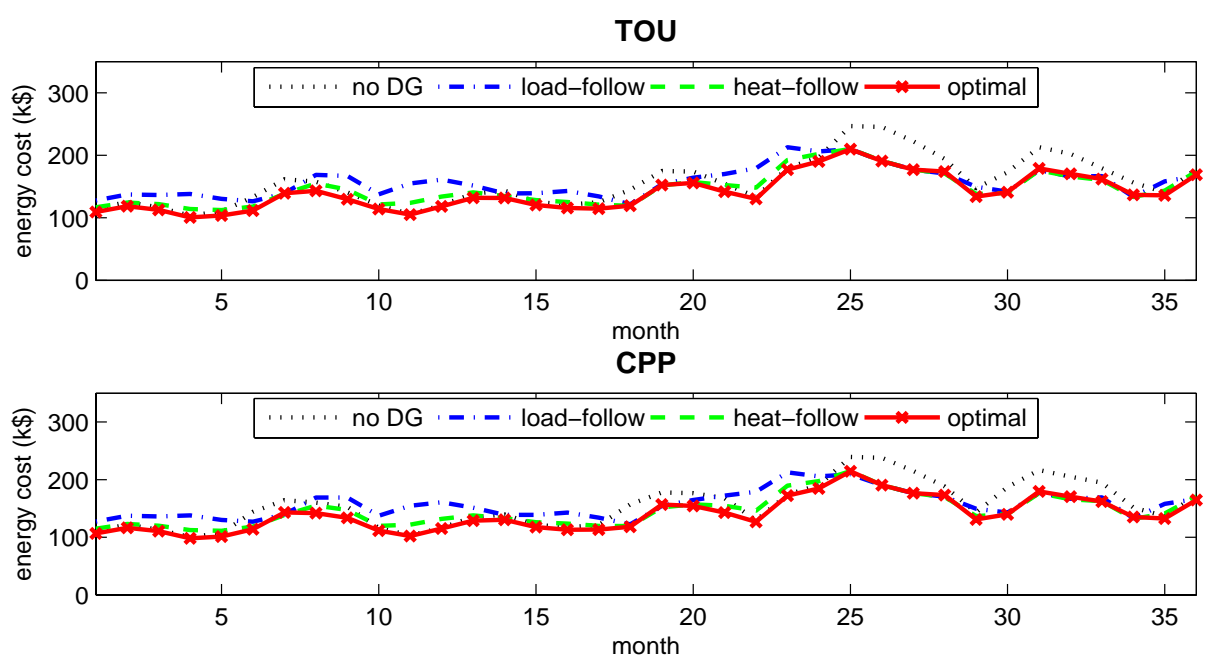

RTP

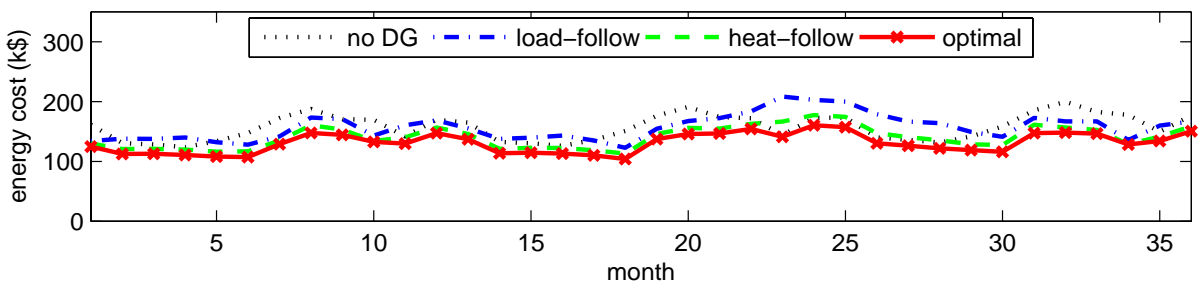

Figure ES 4. Boston - monthly energy costs under all tariffs and control strategies

Similar results were obtained for all four cities. The results for the four cities demonstrate that, quite often, optimal control can be reasonably approximated by a monthly selection between one of the three heuristic control strategies. This is particularly noticeable in the results under TOU and CPP tariffs. Under RTP tariffs, 
optimal control becomes more valuable, as scheduling alone is an inadequate approach to stochastic, volatile energy prices.

Table ES 1 summarizes these cost results. The maximum value of $D G$ is defined as the difference between average annual energy costs under no-DG and under optimal control strategies. The optimal control value is defined as the difference between average annual energy costs under heat-following (consistently the most valuable heuristic control strategy) and under optimal control. This value as a percentage of the maximum value is also reported. Figure ES 5 shows this information graphically, where it becomes clear that optimal control 1) has the most value in the two cities where DG has the least value (Baltimore and Boston), 2) has marginal value in the city where DG has intermediate value (Houston), and 3) has almost no value in the city where DG is most valuable (San Diego). In other words, the value of optimal control is generally inversely proportional to the overall value (with or without optimal control) of DG. Here, relative levels of DG value are estimated by the magnitude of difference between electricity prices and natural gas prices. The reason for this inverse relationship is that in areas like San Diego or Houston, where dispatching DG is economic in most months, there is little need for a sophisticated controller. However, in areas like Baltimore or Boston, where dispatching DG is only economic in certain months, an intelligent controller provides value by identifying uneconomic DG dispatch. 
For reference, the turnkey capitol cost of a a 1.5 MW engine and $1 \mathrm{MW}$ (300 ton) absorption chiller like those installed at the San Diego P\&DC is approximately $\$ 3,000,000$ to $\$ 4,000,000$ (using data from US-EPA 2007 and Firestone 2004) ${ }^{2}$. Assuming a 5\% discount rate and 20 year lifetime, this is an annualized cost of $\$ 230,000$ to $\$ 310,000 /$ year. Annual savings greater than this suggest profitable circumstances for the site, a third party that installs and owns the CHP, or some combination of the two. Where subsidies for CHP systems are available, DG may even be profitable when annual energy savings are lower than $\$ 230,000$ to $\$ 310,000$. At these estimated annualized costs and without subsidy, only the San Diego site would be an economically attractive site for CHP.

Table ES 1. summary of average annual optimal control valuation

\begin{tabular}{|c|c|c|c|c|c|}
\hline & & Baltimore & Boston & Houston & San Diego \\
\hline \multirow[t]{3}{*}{ TOU } & $\begin{array}{r}\text { maximum value of DG } \\
(\mathrm{k} \$ / \text { year) }\end{array}$ & 200 & 184 & 265 & 415 \\
\hline & $\begin{array}{r}\text { optimal control value } \\
(\mathrm{k} \$ / \text { year) }\end{array}$ & 77 & 71 & 19 & 3 \\
\hline & $\begin{array}{r}\text { optimal control value } \\
\text { (\% of maximum value) }\end{array}$ & $38 \%$ & $38 \%$ & $7 \%$ & $1 \%$ \\
\hline \multirow[t]{3}{*}{ CPP } & $\begin{array}{r}\text { maximum value of DG } \\
(\mathrm{k} \$ / \text { year })\end{array}$ & 217 & 194 & 281 & 419 \\
\hline & $\begin{array}{r}\begin{array}{r}\text { optimal control value } \\
(\mathrm{k} \$ \text { /year) }\end{array} \\
\end{array}$ & 87 & 75 & 28 & 6 \\
\hline & $\begin{array}{r}\text { optimal control value } \\
\text { (\% of maximum value) }\end{array}$ & $40 \%$ & $39 \%$ & $10 \%$ & $1 \%$ \\
\hline \multirow[t]{3}{*}{ RTP } & $\begin{array}{r}\text { maximum value of DG } \\
(\mathrm{k} \$ / \text { year) }\end{array}$ & 335 & 317 & 358 & 453 \\
\hline & $\begin{array}{r}\text { optimal control value } \\
\text { (k\$/year) }\end{array}$ & 134 & 118 & 57 & 9 \\
\hline & $\begin{array}{r}\text { optimal control value } \\
\text { (\% of maximum value) }\end{array}$ & $40 \%$ & $37 \%$ & $16 \%$ & $2 \%$ \\
\hline
\end{tabular}

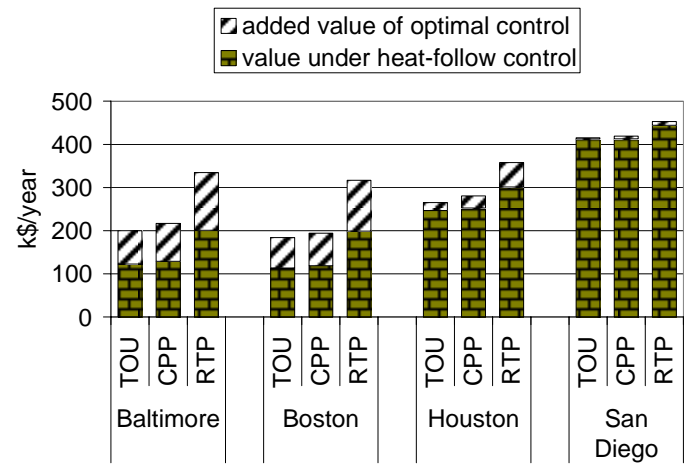

Figure ES 5. average annual value of DG

Figure ES 6 through Figure ES 8 plot the offset of utility electricity purchase (from DG and cooling offsets from absorption cooling) using optimal control under each of the three tariffs for January 2004, July 2004, and November 2005. The hours are ordered from hour of lowest RTP to highest RTP - note that the RTP prices are only

${ }^{2}$ No financial details of the actual San Diego installation were revealed to the author. These cost estimates are based on publicly available reviews of CHP cost and performance. 
seen by the optimization under the RTP tariff (directly) and the CPP tariff (indirectly through critical episodes). In these figures the real-time price is plotted on the right vertical axis and the electricity offset under the three tariffs is plotted on the left vertical axis. A 20-hour rolling average is used to smooth the RTP-ordered consumption plots. Under RTP, the site is responding to the fluctuations in price, producing significant demand elasticity. Note the in November 2005, during a natural gas price spike, almost all DG dispatch was uneconomic. Regardless, there were some hours of high real-time electricity price in which dispatch was economic.

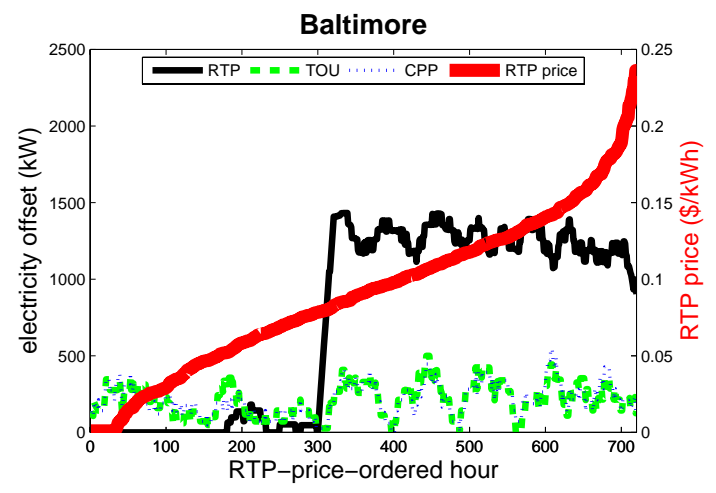

Figure ES 6. Baltimore - January 2004 electricity purchase by hour, ordered from least to highest RTP

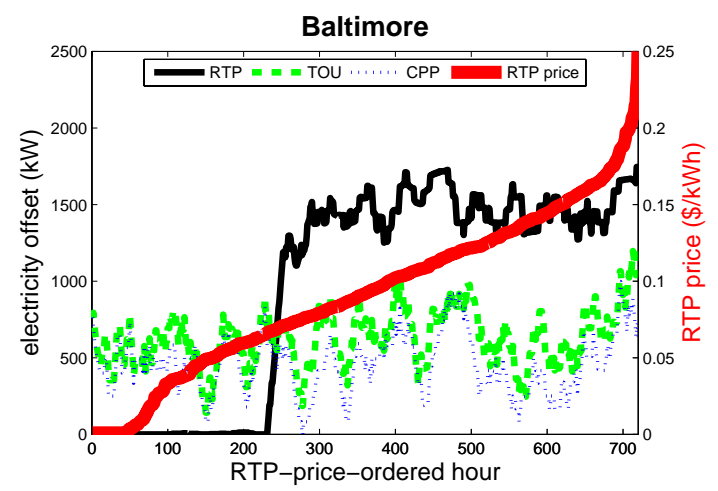

Figure ES 7. Baltimore - July 2004 electricity purchase by hour, ordered from least to highest RTP 


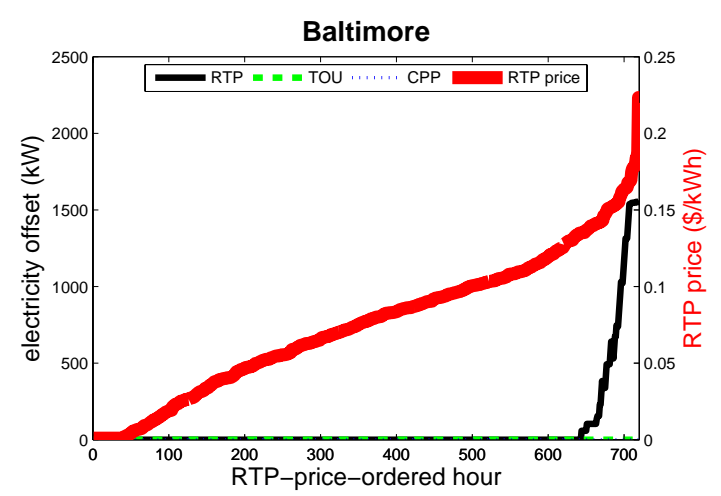

Figure ES 8. Baltimore - November 2005 - electricity purchase by hour, ordered from least to highest RTP

The results of this experiment demonstrate the potential price-responsiveness of DG under RTP tariffs. This behavior can improve price stability and grid stability to the extent that prices reflect supply margins. However, as seen in the third experiment, RTP tariffs can incent less DG dispatch than TOU or CPP tariffs, reducing the energy and environmental benefits of CHP.

\section{Demand Side Management Valuation}

The second experiment conducted was a valuation of demand side management (DSM) programs. Unplanned DG outages often cause DG site utility consumption to be much peakier than that of their non-DG counterparts. It was hypothesized by the author that DSM programs could be more valuable to DG sites than non-DG sites by mitigating demand charges. This synergy between DG and DSM was demonstrated by Firestone, Stadler, and Marnay (2006b). 
Figure ES 9 illustrates this phenomenon. The graph on the left is a load duration curve of on-peak hours for a site with no-DG. The red dashed line indicates $80 \%$ of peak demand; the intersection of the $80 \%$ line with the duration curve is used to identify the number of hours of DSM required to successfully reduce monthly demand by $20 \%$. In this example, approximately 90 hours of curtailment would be required. The middle graph plots utility electricity consumption for the same site, in the same order of hours as the left graph, although this time with DG and subject to random DG outages. Peaks in the middle graph indicate hours of DG outage. The graph on the right shows the load duration curve for the site with DG, i.e. the utility purchase from the middle graph is now reordered from hour of greatest purchase to hour of least purchase. In this example, DG successfully mitigates almost the full $20 \%$ of demand cost. Nearly $25 \%$ more demand could be mitigated if DSM could be used for the few hours of the month when the DG is unavailable. This figure shows how much fewer hours of DSM may be required to achieve equivalent (or greater) demand charge mitigation if DG is present. 


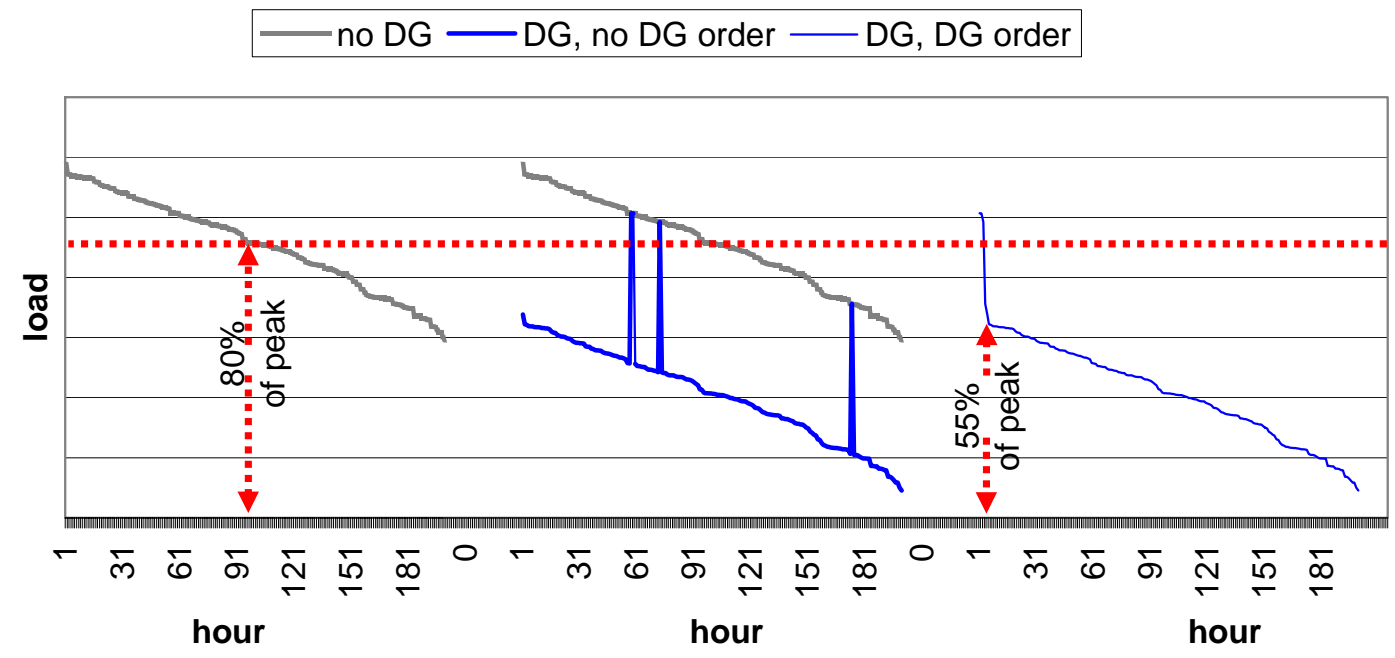

Figure ES 9. duration curves that demonstrate the peakier nature of DG customers' utility purchase

For this experiment, a DSM program of 1-hour curtailments was considered, with two program parameters: 1) number of allowable curtailments per month, and 2) the magnitude of curtailment. For each of the four sites, under each of the three tariff structures, for the 2006 data, site simulation using RT-OPTICOM for dispatch optimization was conducted for the following cases:

- no DG or DSM dispatch: the site purchases electricity to meet all electric demand and natural gas to meet all thermal demand

- DG dispatch only: the site meets electric and thermal demands through a combination of DG operation, electricity purchase, and natural gas consumption in boilers/furnaces.

- DSM dispatch only: the site purchases electricity to meet all electric demand and natural gas to meet all thermal demand, but also does a limited amount of curtailment to offset electric loads. 
- DG and DSM dispatch: the site meets electric and thermal demands through a combination of DG operation, electricity purchase, natural gas consumption in boilers/furnaces, and limited curtailment of electric loads.

For all cases with DSM dispatch, RT-OPTICOM runs with all combinations of curtailable hours $\{5,10,15,20,25\}$ and curtailable magnitude $(\mathrm{kW})\{50,100,150$, $200,250\}$ were considered. The results from these cases were then used to determine the value of DSM programs with and without DG systems. For the TOU tariff and with DG, Figure ES 10 shows contour plots of the annual value of the DSM program, i.e. the difference between the annual energy cost without DSM and with DSM, ceteris paribus.
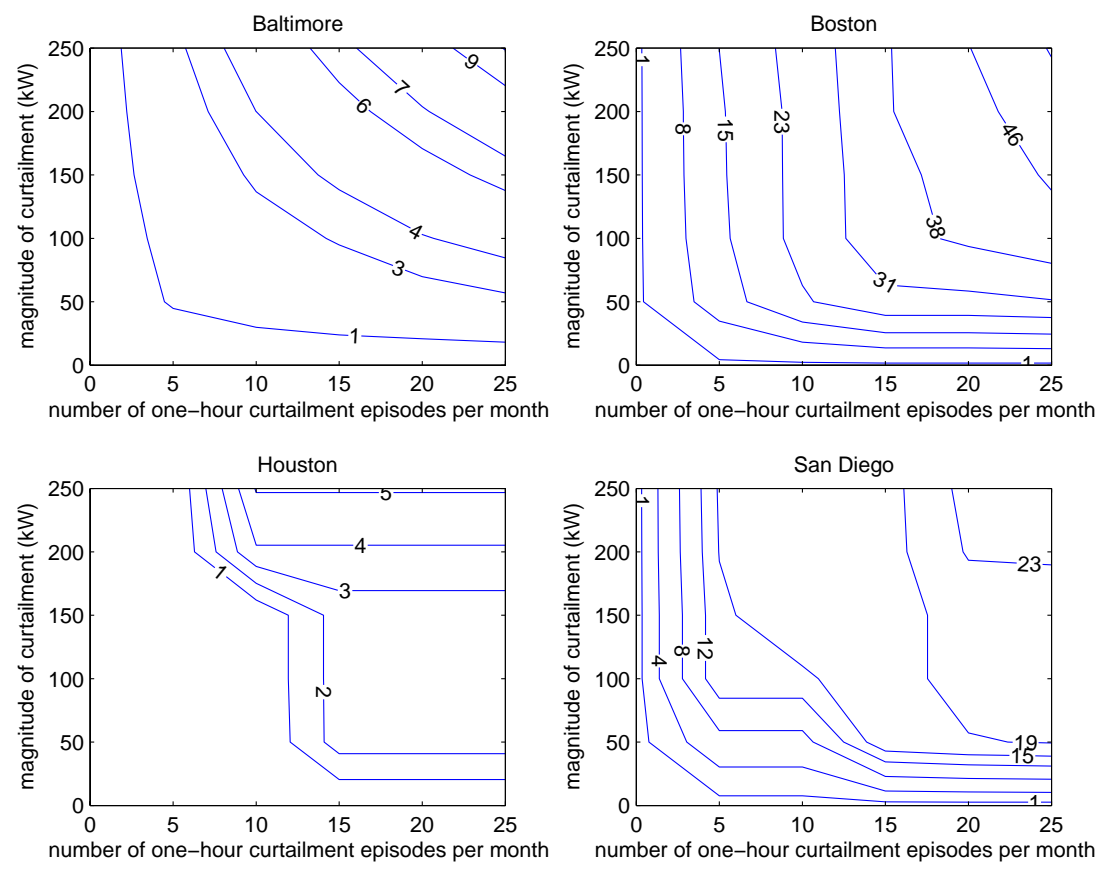

Figure ES 10. TOU - with-DG - annual value $(\mathrm{k} \$$ ) of varying DSM programs in 2006 
Table ES 2 summarizes the DSM value for each combination of tariff, city, and presence/absence of DG dispatch at two levels: 1) 10 hours/month of $100 \mathrm{~kW}$ curtailment and 2) 25 hours/month of $250 \mathrm{~kW}$ curtailment. Peak loads at the sites are approximately $2 \mathrm{MW}$. Without DG, DSM is most valuable under CPP tariffs, where curtailment episodes coincide with critical episodes. When DG is included in the dispatch, DSM generally becomes more valuable for a small curtailment program (10 hours per month at $100 \mathrm{~kW}$ ), i.e. the hypothesized synergy between DG and DSM as illustrated in Figure ES 9 is observed. However, the results are not conclusive for a larger curtailment program (25 hours per month at $250 \mathrm{~kW}$ ); DSM becomes less valuable in two of the four cities (Baltimore and San Diego), more valuable in the other two (Boston and Houston). These results illustrate the complexity of determining DSM value, which is dependent on the particular DSM program, the size and structure of demand charges and the energy purchase duration curve. The duration curve is in turn dependent on generator availability and climate-driven thermal loads. 
Table ES 2. DSM program value (k\$/year) for a 10 hour/month, $100 \mathrm{~kW} /$ episode program and a 25 hour/month, $250 \mathrm{~kW} /$ episode program in 2006

\begin{tabular}{|c|c|c|c|c|c|}
\hline & \multicolumn{2}{|c|}{$\begin{array}{l}10 \text { one-hour curtailments per } \\
\text { month }\end{array}$} & \multicolumn{2}{|c|}{$\begin{array}{l}25 \text { one-hour curtailments per } \\
\text { month }\end{array}$} \\
\hline & & \multicolumn{2}{|c|}{$100 \mathrm{~kW}$ maximum curtailment } & \multicolumn{2}{|c|}{$250 \mathrm{~kW}$ maximum curtailment } \\
\hline & & without DG & with DG & without DG & with DG \\
\hline \multirow[t]{3}{*}{ Baltimore } & TOU & 2 & 2 & 10 & 10 \\
\hline & CPP & 3 & 4 & 18 & 14 \\
\hline & RTP & 2 & 2 & 14 & 8 \\
\hline \multirow[t]{3}{*}{ Boston } & TOU & 13 & 23 & 37 & 53 \\
\hline & CPP & 15 & 18 & 42 & 48 \\
\hline & RTP & 16 & 28 & 40 & 50 \\
\hline \multirow[t]{3}{*}{ Houston } & TOU & 1 & 1 & 5 & 5 \\
\hline & CPP & 2 & 2 & 10 & 13 \\
\hline & RTP & 2 & 1 & 10 & 7 \\
\hline \multirow[t]{3}{*}{ San Diego } & TOU & 4 & 14 & 14 & 25 \\
\hline & CPP & 5 & 5 & 21 & 15 \\
\hline & RTP & 5 & 7 & 16 & 11 \\
\hline
\end{tabular}

\section{Cost-Carbon Co-optimization}

The final experiment was to examine the trade-off between site-attributable carbon emissions and energy costs under optimal control and the three different tariffs. Siteattributable carbon emissions are the sum of emission from grid electricity and on-site natural gas consumption. One constraint in RT-OPTICOM is a ceiling on the amount of site-attributable carbon emissions in each month. For this experiment, for the months of January 2004 to December 2006, the simulation under optimal control and each of the three tariffs was rerun for a series of carbon constraint levels. For utility electricity, regional average marginal emissions factors from The Climate Trust (2005) were used. 
The set of costs and carbon emissions levels from these runs were then analyzed to obtain an estimate of the cost/carbon trade-off under each tariff structure. Results for Baltimore are plotted in Figure ES 11 and Figure ES 12, with carbon emissions on the horizontal axis and the corresponding minimum possible annual energy cost on the vertical axis. For each city, these values are plotted in average annual dollars and tons of carbon (graphs on the left) and as percentages of the lowest possible level of cost and carbon (graphs on the right). All points on these figures are determined by running the RT-OPTICOM model for each city/month/tariff combination at many different levels of carbon constraint and then solving a separate optimization problem which finds the least-cost combination of monthly results for a given total level of carbon emissions. These least cost values could not be obtained in practice because they assume perfect foresight in natural gas prices for the three years and general trends in electricity prices; however they do provide an estimate of the cost/carbon trade-off.

The approximately right angles in Figure ES 11 under all tariffs illustrate that there is very little room in dispatch decision-making for trade-off between cost and carbon. Figure ES 12 shows these dual optimization, or Pareto, fronts in more detail, and in terms of percentage of best-cost and best-carbon values. For TOU and CPP tariffs, least-cost solutions result in about $10 \%$ more carbon than least-carbon dispatch (bottom right corner of the graph), whereas least-carbon dispatch costs the site about $10 \%$ more than least cost dispatch. Under RTP tariffs, this angle is more rounded, showing more room for trade-off. 


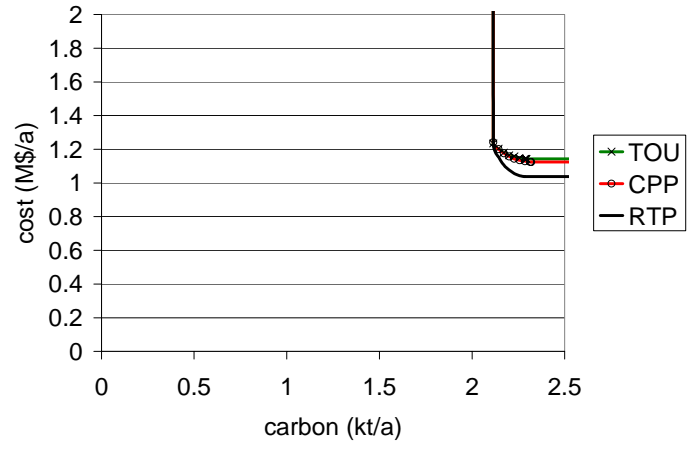

Figure ES 11. Baltimore - cost-carbon Pareto front

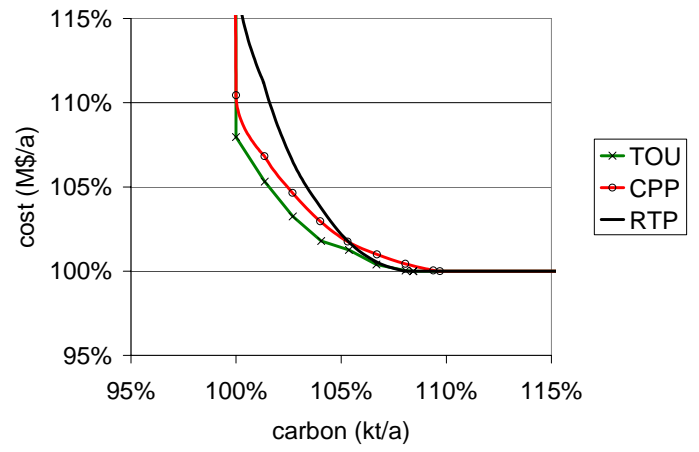

Figure ES 12. Baltimore - cost-carbon Pareto front, as percentage of best-cost and best-carbon solutions

Figure ES 13 and Figure ES 14 show these results for San Diego. Here, the Pareto fronts are right angles: least-cost dispatch is least-carbon dispatch.

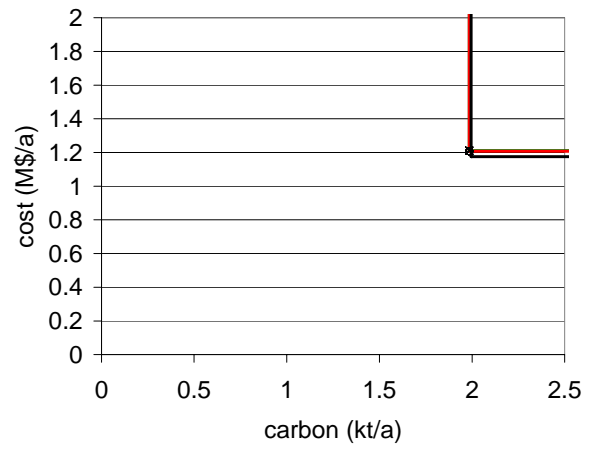

Figure ES 13. San Diego - cost-carbon Pareto front

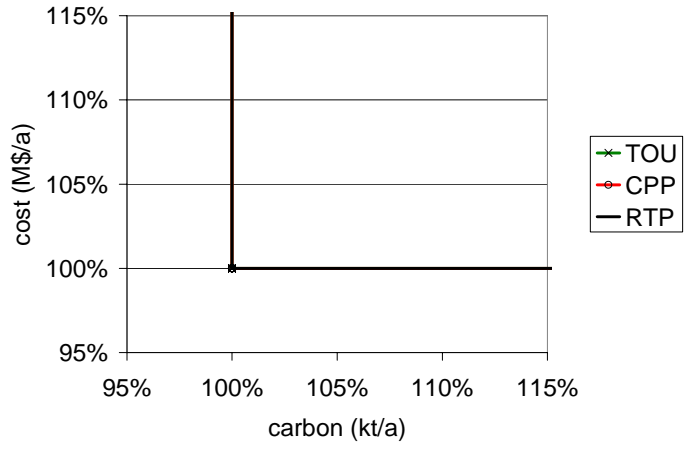

Figure ES 14. San Diego - cost-carbon Pareto front, as percentage of best-cost and best-carbon solutions

The results of this experiment show that, for the P\&DC sites considered, there is little or no difference between least-cost and least-carbon dispatch of the installed system. If greenhouse gas reductions are of interest to these sites, the crucial stage of the decision making is the design of the IES. 


\section{Summary of Project and Conclusions}

This project sought to quantify the economic savings possible from improved controls of integrated energy systems (IES). To accomplish this, a technique for obtaining near-optimal solutions to stochastic problems that are too complicated to solve analytically or using conventional operations research methods was required. This technique was developed and applied to the specific IES problem. Finally, case studies using the resulting program were conducted to answer several pertinent questions about DG dispatch and the integrated combination of DG and DSM. Key findings for the P\&DC sites include:

- Optimal control is most valuable in areas where DG is marginally costeffective, as predicted by the relative costs of electricity and natural gas. In these areas, up to $40 \%$ of the value of a DG system can be attributed to optimal control. Restated, optimal control can increase the value of a DG system by $67 \%$.

- For simple systems such as the single generator system considered here, simple heuristic strategies could achieve much of the benefit of optimalcontrol if they contained rules for switching between heuristic strategies as conditions change.

- Heuristics may not be adequate for more complicated situations such as that arising from real-time electricity pricing. 
- Demand charges in typical tariffs can make curtailment worthwhile at a site, even in the absence of a demand response incentive program.

- In situations where stochastic generator outages make for a particularly peaky utility electricity purchase profile, limited curtailment programs can be more beneficial as part of a DG/DSM IES than on their own.

- Cost-minimizing control is roughly carbon-minimizing control for all four sites. 


\section{PART 1: INTRODUCTION TO INTEGRATED ENERGY SYSTEMS (IES) AND THE NEED FOR GENERIC REAL-TIME DISPATCH OPTIMIZATION ALGORITHMS}

Market deregulation has shaped the United States energy sector for the past three decades. The Public Utility Regulatory Policy Act (PURPA) of 1978 first invited relatively small-scale generators into the electricity market, and wholesale competition has become widespread during the last decade, especially in some jurisdictions, notably California, New York, New England, and the PennsylvaniaNew Jersey-Maryland interconnection. On the customer side of the meter, the change has been less dramatic, but nonetheless, expectations of the electricity supply system have evolved following experiments with customer choice, greater exposure of consumers to the variability of electricity prices, and an emerging generation roller coaster investment cycle. And, of course, the 2000-2001 California energy crisis, the terrorist threat, and the August 2003 Northeast blackout have radically reshaped expectations of supply security.

Simultaneously, improvements to small-scale and renewable technology have spurred an industry that has, in recent years, made even smaller (business scale) electricity generation an economically viable option for some consumers. On-site energy production, known as distributed generation (DG), offers consumers many benefits, such as bill savings and predictability, improved system efficiency, improved 
reliability, control over power quality, and in many cases, greener electricity.

Additionally, DG systems can benefit electric utilities by reducing congestion on the grid, reducing the need for new generation and transmission capacity, and offering ancillary services such as voltage support and demand response. Additional on-site energy storage and conversion devices offer further benefit, and include heat exchangers for waste heat recovery, thermally activated cooling, electrical storage, and thermal storage. These technologies are collectively referred to as distributed energy resources (DER).

The economic analysis of energy efficiency (EE) measures has become commonplace. Businesses and institutions have become less hostile to demand response (DR) measures - i.e. curtailment and rescheduling - due to government mandates, conservation campaigns (such as "Flex Your Power" in California), new tariffs that put a premium on electricity during times of system scarcity, and lucrative interruptible service contracts from utilities.

This suite of customer-side energy options - EE, DER, and DR - gives customers complex investment and operation decisions. While the investment problem has been given considerable attention in recent years, the operation problem has not been adequately addressed. It is the intent of this project to develop a general solution to the real-time optimal dispatch problem for integrated systems of DER and demand response, herein referred to as integrated energy systems (IES). 
Part 1 introduces the IES and discusses the optimal dispatch problem. Chapter 1 describes the components of the IES, along with the tariff structures, and regulatory and operational constraints that make optimal dispatch a challenge. Chapter 2 presents the hypothesis of this research: that near-optimal dispatch of IES is a tractable problem. This chapter also discusses the merits of a generic solution to the IES dispatch problem, rather than a site specific approach. Chapter 3 discusses prior research on related optimization problems, DR potential, and operations research. 


\section{INTRODUCTION}

IES for a site may consist of a large range of energy conversion and storage devices, as well as demand response options, giving the site control of both its supply of and demand for electrical and thermal energy. The economically optimal dispatch of any IES must be in response to current and forecasted energy prices, energy demand, and DER equipment availability. Dispatch must be within mechanical and regulatory constraints on the IES. This chapter describes these factors.

\subsection{IES Equipment}

IES for a site may consist of electricity generation devices, energy conversion devices for the utilization of waste heat and/or solar insolation, energy storage devices, thermal cooling devices, and/or demand response. This section describes these devices. Several texts and reports provide more detailed overviews of generation devices, including Willis and Scott (2000), Goldstein et al. (2003) and WADE (2003).

\subsubsection{Electricity Generation Devices}

\subsubsection{Gas Turbines}

Prime-power on-site generation above $\sim 5 \mathrm{MW}$ is most commonly provided by gas turbines. Air is compressed, combined with gaseous fuel, combusted, and expanded through a turbine in a continuous process. Gas turbines typically have electrical 
efficiencies in the range of $25-40 \%$. The portion of fuel energy not converted to electricity exits the turbine in the form of hot exhaust $\left(250-750^{\circ} \mathrm{C}\right)$. Gas turbines are available in the range of $1 \mathrm{MW}$ to $100 \mathrm{~s}$ MW. Start-up times range from a few minutes for smaller units to a half hour for utility scale turbines.

\subsubsection{Reciprocating Engines}

Reciprocating engines are the most popular ${ }^{3}$ and oldest type of distributed generator worldwide. Reciprocating engines contain multiple cylinders with moving pistons, in which a four-stroke Otto or Diesel cycle is employed: fuel/air intake, compression, ignition, and exhaust. Engines are available in sizes ranging from $1 \mathrm{~kW}$ to $10 \mathrm{~s}$ of MW. Back-up power for sites with critical loads, such as hospitals and data servers, is often provided by reciprocating engines. Reciprocating engines are also used for continuous power DG, typically being cost-effective and dominant to other DG technologies for sites with electrical demands ranging from 100s of $\mathrm{kW}$ to $5 \mathrm{MW}$ (LaCommare et al. 2006). Reciprocating engines can be diesel-fueled (Diesel engine) or fueled by gasoline, natural gas, propane or bio-gas methane (Otto engines). Diesel engines typically have an electrical efficiency in the range of $28-40 \%$ and sparkignition engines typically have an electrical efficiency in the range of $20-43 \%$. The portion of fuel energy not converted to electricity is roughly evenly split between exhaust gas $\left(400-600^{\circ} \mathrm{C}\right)$ and engine cooling loop $\left(\sim 85^{\circ} \mathrm{C}\right)$.

\footnotetext{
${ }^{3}$ According to Willis and Scott (2000), 93\% of distributed generation equipment worldwide is reciprocating engines.
} 
Reciprocating engines have low capital costs (relative to other DG technologies), high reliability, and very fast ( $<60$ seconds) start-up times.

\subsubsection{Microturbines}

In recent years, smaller versions of gas turbines have become commercially available. These microturbines are available in the range of $30 \mathrm{~kW}$ to $100 \mathrm{~s} \mathrm{~kW}$. They have electrical efficiencies in the range of $25-30 \%$ and exhaust gas $\left(200-300^{\circ} \mathrm{C}\right)$ accounts for the remainder of fuel energy. Relative to reciprocating engines, microturbines (and gas turbines) offer significantly lower rates of NOx emissions ${ }^{4}$. Microturbines have been designed with all moving parts on a single shaft and with air bearings to eliminate the need for lubrication oils. Such a design offers the potential for low maintenance/high reliability machines, although this has yet to be conclusively demonstrated in the field. Microturbines have a start-up time of approximately two minutes.

\subsubsection{Fuel Cells}

Unlike combustion driven electricity generation equipment, fuel cells harness chemical oxidation to convert the chemical energy of gaseous fuels (reformed into hydrogen) to electricity. Unlike combustion-driven counterparts, fuel cells emit

\footnotetext{
${ }^{4}$ In California, the California Air Resources Board (CARB) must certify DG equipment before it can be installed. In 2003, CARB specified emissions levels for DG, and more stringent regulations were enacted in January 2007. To date, only fuel cells and one microturbine, the Ingersoll Rand $250 \mathrm{~kW}$ model, have been certified. No reciprocating engines have been (CARB 2007).
} 
virtually no NOx, SOx, or particulate matter (PM). Electrical efficiencies are in the range of $30-50 \%$ and the remainder of fuel energy is rejected through the stack cooling loop at temperatures $80-600^{\circ} \mathrm{C}$, depending on the type and design. Fuel cells are available in sizes ranging from several $\mathrm{kW}$ to several MW, although they are still a developing technology and not yet commercially viable. Public subsidies have spurred fuel cell adoption at 100s of sites across the U.S. Fuel cells have the poorest start-up times (minutes to hours) and ramping rates of fossil fuel driven DG and are not good candidates for responsive DG applications.

\subsubsection{Photovoltaics}

Photovoltaics (PV) are semiconductor devices that convert solar radiation to direct current (DC) electricity. Power electronic inverters are then used to convert this to low voltage AC electricity. PV, while more expensive than fuel driven electricity generation, can still have a positive net present value to investors, particularly with

public subsidies available in some areas. PV offers pollution and greenhouse-gas-free operation, no moving parts, and requires minimal maintenance. Public subsidies such as California's Self-Generation Incentive Program and Emerging Renewables Program and a positive public image have made PV commonplace. PV arrays are modular and available in sizes from 10 s of $\mathrm{W}$ to several MW. 


\subsubsection{Small-scale Wind Turbines}

Wind turbines convert the mechanical energy of wind into electricity. Small-scale wind turbines originated in Denmark in the 1890s and became popular on farms in the U.S. in the 1930s, before power lines had reached these areas. While large-scale wind farms have proven to be cost-competitive with fossil-fuel and nuclear power plants, small-scale wind generation for direct customer consumption is less economic, unless its purpose is to avoid the cost of extending the utility distribution system to a site. Wind power suffers from intermittency and significant siting restrictions due to view obstruction, the physical danger of heavy moving parts in an open environment, and danger to birds and bats.

\subsubsection{Heat Recovery}

Fuel-driven electricity generation devices can use "waste" heat toward site steam, process heat, space-heat, domestic hot water, and cooling (see Section 1.1.4) needs. Heat exchangers are designed to transfer heat from exhaust and cooling loops to useful medium. Using generators in this way is known as combined heat and power (CHP). CHP often tips the economic scales in favor of on-site generation. Although fuel-driven on-site electricity generation is often less electrically efficient than central generation and distribution, CHP systems can lead to reduced primary fuel consumption relative to utility electricity purchase. 


\subsubsection{Thermal Generation}

\subsubsection{Solar Thermal}

Solar radiation can be converted to useful heat by solar collectors. NRC (2006) provides a introduction to the numerous solar collector technologies and their attributes. Low temperature collectors are used to heat water to temperatures up to about $80^{\circ} \mathrm{C}$ for domestic hot water and low-grade process heat loads. High temperature collectors can heat high-pressure fluids to $400^{\circ} \mathrm{C}$, although at an order of magnitude higher cost than low temperature collectors. Firestone, Marnay, and Wang (2005b) provide a brief study of solar collector economic fitness and carbon mitigation potential as part of a DER system.

\subsubsection{Heat Pumps}

Heat pumps use high quality energy such as electricity or fuel to draw heat up a thermal gradient, typically from the ground to a building. They are most effective when the thermal gradient is not too large.

\subsubsection{Thermal Cooling}

In many regions, peak electric grid demand occurs during the summer months because of air conditioning and other cooling loads. The cost of energy consumption at peak times is higher than at off-peak times because of increased demand and because the "peaker" plants that provide this energy must recover their fixed 
infrastructure costs over a relatively small number of hours. For this reason, electric cooling load offsets are particularly valuable energy savings- cooling load offsets can be achieved by thermally activate cooling, which uses heat to replace part of the electric-cooling load.

\subsubsection{Absorption and Adsorption Cooling}

Thermal energy (i.e. heat) can be used to provide cooling through the use of an absorption or adsorption cycle. In absorption systems, the electric compression cooling cycle is modified so that the operating fluid is pumped (i.e. it remains a liquid), rather than compressed (i.e. as a gas). After being pumped, which requires much less electric energy than compression, heat is used to separate the operating fluid into a non-boiling liquid (i.e. absorbent), such as lithium bromide, and a boiling liquid (i.e. refrigerant), such as water. Adsorption systems work similarly, although a solid adsorber is used, rather than a liquid absorber. Double-effect chillers can be driven by higher quality heat and use two stages (with different operating fluids). Triple-effect chillers are also possible. Heat recovery from CHP systems can be used for thermally activated cooling.

\subsubsection{Desiccant Dehumidification}

Space-cooling loads can be reduced by reducing the humidity of air prior to cooling. Liquid or solid desiccants can be used to absorb moisture from air prior to cooling. 
Heat is then used to dry out the desiccant. This is achieved in a continuous cycle in a desiccant wheel.

\subsubsection{Storage Technologies}

\subsubsection{Electrical Storage Technologies}

Electricity can be stored in batteries (chemical energy), capacitors (electrical potential), flywheels (mechanical kinetic energy), and through pumping schemes (hydraulic head or pressure). While prohibitively expensive for most potential applications, each has found its niche: smoothing out intermittency, riding through short outages and start-up/ramping times on on-site equipment, and storing energy with limited present-time value for later use.

\subsubsection{Thermal Storage Technologies}

Thermal storage is a cost-effective way of eliminating the coincidence of heat or cooling production and demand. Water or solid medium in tanks can be used to store heat or cooling, as can the frame of a building. Cold storage for large sites may be in the form of ice, which can be economic when cooling loads are significant during expensive on-peak hours and off-peak electricity prices are considerably lower, or when an on-site generator's capacity is not otherwise needed during evening or nighttime hours. 


\subsection{Demand Response}

The high price of peak electricity has encouraged price responsiveness among some customers. Certain electricity loads may be curtailable or reschedulable. In pilot programs where the hourly and daily volatility of prices is passed directly to consumers, rather than monthly averaging, demand response behavior increases. This holds promise for bringing demand elasticity to the electricity market, a valuable step towards reducing peak capacity costs and mitigating the threat of market power abuse. Voluntary programs that hyper-incent demand response (and in some cases automatically shed customer load) have proved a cost-effective substitute for some amount ultra-peak capacity, i.e. peaker plants that are only used a handful of hours per year. There are two different types of demand response: curtailable demand and reschedulable demand.

\subsubsection{Curtailable Demand}

Curtailable demands have a preferred level, but the demand level can be lowered if a certain cost is associated with the load reduction. For example, air conditioning operates at a temperature setpoint requiring a certain chiller load. If the setpoint is

raised, a warmer indoor building temperature ensues and lowers occupant amenity. During times of particularly high electricity prices, the cost of this incremental discomfort may be outweighed by the incremental cost of electricity purchase. Other curtailable load is non-workplace lighting (e.g. parking garages and hallways), 
elevators, plug-loads, and process loads at industrial sites. Curtailable demand is not made up for later; it represents a reduction in total energy demand.

Curtailable loads can be quantified by the following parameters:

- full load demand,

- percentage of load that can be curtailed,

- cost of curtailment,

- lead time needed before curtailment can begin,

- ramp rate at which load can go down,

- length of time for which load can be curtailed, and

- maximum frequency of curtailments.

\subsubsection{Reschedulable Demand}

Certain demands may be flexible in their scheduling. Rescheduling might mean staggering the start of several electric motors so that the large current associated with start-up is broken into several moderate power spikes rather than one large one. This is useful for avoiding 1) demand charges or 2) overloading an isolated DG system. Rescheduling could also involve shifting the execution of some energy intensive activities to later in the day, or further into the future. With proper planning, loads can be rescheduled backwards in time. An example of this would be pre-cooling a building during the less energy intensive (and less expensive) hours of the morning rather than waiting to start cooling until there is a cooling demand. Reschedulable 
demand rearranges the temporal parttern of enegy demand to lower cost or achieve other goals but does not reduce energy consumption.

Reschedulable loads could be specified by the following parameters:

- load demand,

- maximum time until rescheduled time, or acceptable time to reschedule,

- cost of rescheduling,

- lead time needed before rescheduling can take effect, and

- ramp-rate at which load goes down once it is rescheduled.

\subsection{Energy Pricing and Tariff Structure}

\subsubsection{Electricity}

Utilities incur both variable and fixed costs for providing electricity to customers. Variable costs come from producing electricity, among them buying fuel and operating power plants. They may be incurred directly if the plants are self-owned, indirectly through electricity purchase prices contracted with suppliers, or at market clearing prices. Infrastructure costs, including delivery, are largely fixed and depend on the size of system, but not actual electricity consumption. Some infrastructure costs are localized to individual customers (power lines and substations directly feeding a site); others, like power plants or administration, serve the entire customer 
base; while many lie between these two extremes, for example, shared distribution lines and substations.

Based on these variable and fixed expenses, utilities and their regulators typically design tariffs to cover three kinds of costs:

- Fixed charges are invariant, $\$$ month. These are infrastructure costs of supply and delivery required by the customer regardless of their energy consumption for that month.

- Volumetric charges are proportional to the amount of energy consumed. They are expressed in $\$ / \mathrm{kWh}$ and may vary by time of day within a month. Volumetric rates are intended to cover the variable costs of producing electricity, such as fuel and some maintenance, as well as the fixed costs that generators recover in their volumetric sales of electricity.

- Demand charges are expressed in $\$ / \mathrm{kW}$ and levied on the maximum power consumption during a specified time range (such as the on-peak hours of the month), regardless of the duration or frequency of that level of power consumption. Demand charges are intended to collect the fixed costs of infrastructure shared with other customers by raising revenue in proportion to the amount of peak power required by the individual.

Demand charges play an integral role in the problem of dispatch optimization because of their magnitude and mathematic non-linearity. The demand charges can be a third to a half of a customer's electricity bill. Because they are a function of the maximum 
power consumption during the month, they are non-linear and they act over the entire month, making decision making at one time-step dependent on plans for future timesteps. Even with DG, demand charges can be difficult to avoid because of stochastic DG outages; many customers complain that this is a large barrier to DG and CHP system adoption.

Volumetric and demand charges may have a block structure, in which there are different prices for different quantities of consumption. An example would be a customer that incurs a volumetric charge of $\$ 0.10 / \mathrm{kWh}$ for their first $1000 \mathrm{kWh}$ of power each month, $\$ 0.08$ cents for their next $2000 \mathrm{kWh}$, and $\$ 0.07 / \mathrm{kWh}$ for all consumption in excess of $3000 \mathrm{kWh}$.

Volumetric charges are typically have one of the four following structures

- flat - the volumetric price of electricity is constant throughout the day and throughout the month

- time of use (TOU) - the volumetric price of electricity varies by on-peak, mid-peak, and off-peak periods of consumption each month

- critical peak pricing (CPP) - similar to TOU, but with much higher volumetric rates during periods of high system load

- real-time pricing (RTP) - the volumetric price of electricity varies from hour to hour, reflecting to the true marginal cost of electricity to the utility. 
The two major components of customer electricity bills are variable electricity, or supply, costs and infrastructure and service, or delivery, costs. Historically, although fixed in nature, some delivery costs have been collected through volumetric pricing ( $\$ / \mathrm{kWh}$ ) by adding them to the charges for supply. When a class of customers has similar, regular consumption patterns, volumetric delivery prices can equitably recover cost and generate some profit. However, if there are significant differences in customer usage patterns, volumetric delivery pricing may no longer be fair. This is the case with many customers who produce some electricity on-site and purchase some from the grid. This issue is discussed in greater detail by Firestone, Marnay, and Maribu (2006) and Firestone and Marnay (2005b).

\subsubsection{Natural Gas and Other Fossil Fuels}

Tariffs for natural gas and other fuels typically consist of fixed and volumetric components. The volumetric prices can be volatile, as seen in Figure 1, which shows natural gas prices to U.S. commercial customers from 2000 to 2006. 


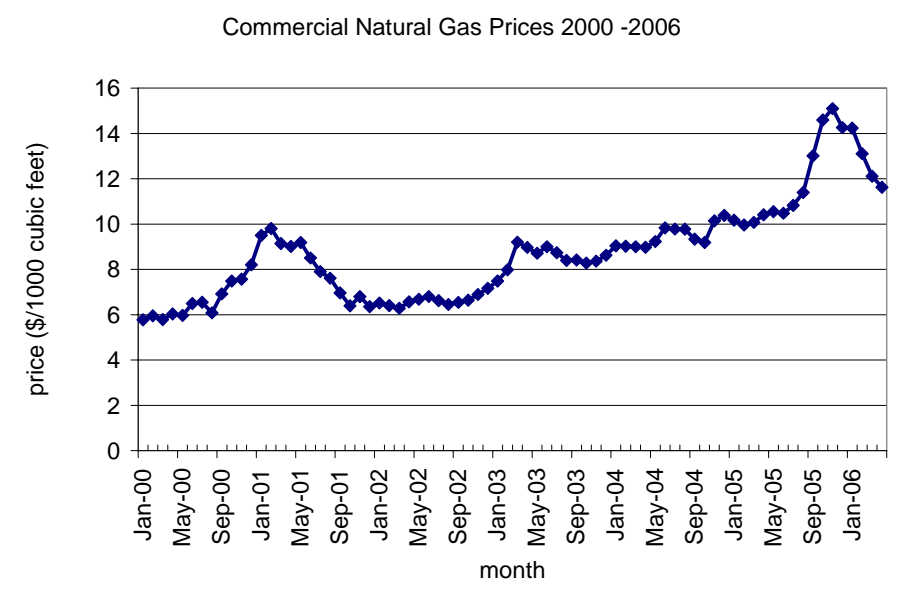

source: Energy Information Agency

Figure 1. average U.S. commercial natural gas price from 2000 to 2006

\subsection{Energy Demand}

Site energy demand can be divided into end-use types. A convenient division is noncooling electricity, cooling (which may be further divided into space-cooling, refrigeration, etc.), space-heating, natural gas only (such as cooking and distributed space-heating). The reason for separating cooling from other electricity loads is that cooling loads can also be met or offset by thermal cooling.

Energy demand is stochastic in natural. The statistical makeup of these loads will depend on the site, but key influences on load are weather and business/operation state. 


\subsection{Equipment Availability}

DER equipment is subject to failure, which results in unscheduled outages. The occurrence and duration of these outages are stochastic. For grid-connected DER, unplanned outages can create surges in utility electricity purchase, resulting in large demand charges. The intermittency of solar and wind powered electricity can have a similar effect. The modeling and quantification of equipment availability, particularly as a function of maintenancing/servicing arrangement, is a poorly studied problem.

\subsection{Operation Constraints}

\subsubsection{Mechanical Constraints}

Mechanical constraints will limit the set of achievable setpoints of on-site energy equipment. Examples of such constraints are minimum-start times, ramping rates, frequency limits on switching between on and off, and time required for scheduled maintenance.

\subsubsection{Regulatory Constraints}

Equipment operation may be further constrained by regulatory constraints such as

- emissions limits which may restrict the total number or specific hours that equipment may run; 
- noise constraints which may limit the specific hours that equipment may run; and/or

- minimum CHP system efficiency, which may have to be maintained in order to receive favorable electricity or natural gas rates.

\subsection{The Integrated Energy System}

In order to best meet a site's energy objectives, all of the equipment, loads, prices, forecasts, demand response options, and operational constraints should be viewed as a single, integrated energy system, or IES. IES contain several key features which make their optimal dispatch difficult. One of these features is uncertainty, which arises in energy loads, energy prices and IES equipment availability. Another is the multi-stage, intertemporal nature of the problem: limits on the number of curtailment episodes and total hours of DER operation require scheduling, as dispatch at one time-step will affect the set of feasible dispatch at future time-steps. Scheduling is further required to ensure minimum efficiency requirements, or to address limited fuel constraints.

Demand charges make economic minimization particularly difficult in situations where there marginal cost of on-site generation is greater than that of utility electricity purchase, yet demand charges still make some amount of on-site generation economic. Here, the correct level of demand charge mitigation must be determined in light of stochastic loads and equipment availability. 
Cost minimization may not be the sole objective of a site's IES dispatch optimization.

Public sites may be more motivated by a reduction in primary fuel consumption and/or greenhouse gas emissions, as might environmental champions or imageconscious entities. 


\section{HYPOTHESIS - HEURISTIC DISPATCH: FUNCTIONAL, NOT OPTIMAL}

The economically or environmentally optimal dispatch of a building's IES is a problem rarely addressed in building operations. Typically, building managers are in charge of dispatch decisions, yet their primary concern is ensuring that systems meet the needs of users, not that needs are met in an optimally efficient manner. Optimal dispatch would require continuous decision-making based on historic data, current conditions, equipment availability, demand response opportunities, and stochastic forecasts of the future (prices, loads, and availability of equipment and of intermittent renewable resources).

Building managers typically employ heuristic controls to their IES, such as a schedule for running their DER, or a target electricity demand level that they try to avoid exceeding for each month. A detailed, quantitative analysis is not performed to ensure that, if a schedule is to be used, this particular schedule is the right one, or that the correct target demand level has been selected. To the author's knowledge, no such methodology exists in the public domain. However, the vast diversity of combinations of load characteristics, tariff structures, energy prices, and IES characteristics make it improbable that a few simple heuristic strategies are adequate for near-optimal utilization of IES. 
For cost minimization, demand charges, which can be a third to a half of a customer's utility electricity bill, turn a problem that would otherwise be a straight forward comparison of marginal costs into a problem requiring planning under significant uncertainty. Further planning is required when heat can be stored for later use and when curtailment can be used in limited frequency. For primary fuel or carbon emissions minimizations, planning is required to match fuel savings opportunities with energy requirements, again under uncertainty.

Given that IES have multiple degrees of freedom, and that IES operators consider only a limited set of dispatch options, it is most likely that optimal IES operation is not being achieved. This observation introduces the hypothesis of this research:

\section{Heuristic dispatch typically used by building managers is not optimal.} Optimization algorithms can be developed to make near-optimal decisions, resulting in improved realization of objectives such as the minimization of cost, primary fuel consumption, and/or carbon emissions.

Two questions come directly from this hypothesis:

- How can optimal dispatch be determined?

- How much better could site objectives be met under optimal dispatch of IES? These questions were the initial motivation for this research. 
This work focuses on the actual dispatch decisions that must be made once a particular system has been designed and installed. It can also be used in simulation to refine the initial savings or performance estimate that a simultaneous investment and operation optimization would provide. This research does not consider the parallel question of DER investment optimization. As will be discussed in Section 3.2, the investment optimization necessarily must simultaneously solve the dispatch optimization problem. Prior research has approached this problem. However, the complexity that integer investment decisions add have not allowed for the dispatch optimization problem to be modeled in as much detail as in the work described here.

While it may be cost-effective for large industrial sites to contract for a custom IES control systems, this would most likely not hold true for smaller industrial and commercial sites. A generic solution for these sites that achieves near-optimal dispatch is desirable. The range of sites, however, is enormous, as sites can be characterized on multiple dimensions, including:

- IES system components,

- magnitude of site loads,

- variation of site loads over hours, days, and months,

- volumetric electricity and natural gas prices,

- demand charges,

- electricity tariff structure, 
- curtailment opportunities and cost,

- rescheduling opportunities and cost,

- site energy objectives (e.g. minimization of cost, fuel consumption and/or emissions), and

- regulatory constraints on operation.

Part 2 of this report introduces a technique for approximately solving the optimal IES dispatch problem and describes the development of a model capable of solving this problem for a wide range of sites. Part 3 quantifies the benefits of improved dispatch for a case-study site. 


\section{PRIOR RESEARCH}

This dissertation has been inspired and guided by much prior research. This chapter discusses prior research on utility-scale electricity system dispatch optimization, DG research on investment and dispatch optimization, demand response studies, and developments in operations research.

\subsection{Utility-scale Dispatch Optimization}

Dispatch optimization for vertically integrated utilities is a good comparison to the IES dispatch optimization problem. The utility dispatch problem, in its entirety, is enormous. Optimal or near-optimal control of the system requires decision making on the order of minutes, over a timespan of a year or more (to include maintenance scheduling and the rationing of scarce resources), with uncertainty in demand and in generator/transmission/distribution availability at every time-step. To make the problem manageable, it is typically divided into three separate problems:

- a planning problem for the day-to-day problem (over the course of months);

- a unit commitment problem for the hour-to-hour problem (over the course of several days); and

- a power flow problem for the minute-to-minute decisions (over the course of tens of minutes) and to ensure that transmission lines are not overloaded and to account for both real and reactive power demand.

Using this multi-tiered dispatch strategy, the availability of units is determined through planning; the prioritization of dispatch of available units is determined 
through unit commitment; and fine-tuning of the system is done through power flow optimization.

After more than a century of electric utility presence, the unit commitment problem, subject to the practical constraints described in Appendix A, is still an open field of research. Prior to the advent of modern computing power, heuristic approaches to the problem were developed in which priority lists of available units were generated, and generators were called on/off-line based on their placement on the priority list. Over the years, the dominant approach to improved solutions to the unit commitment problem (both in research and in practice) has been to improve upon the methods for developing priority lists. Momoh (2001) includes a chapter on the unit commitment problem, in which several ranking criteria for priority lists are described.

Lagrangian techniques are the dominant approach to constrained optimization problems (Hillier and Lieberman 1995). In this approach, constraints are converted into terms in the objective function and scaled by an unknown variable, i.e. the Lagrangian multiplier. A dual problem is also developed, which is easier to solve and aids in the search for solutions to the primal problem. Lagrangian techniques are, in general, a powerful approach to problems with a large number of variables. Momoh's (2001) chapter on the unit commitment problem describes, in detail, a Lagrangian relaxation (i.e. integer constraints are relaxed at some points during the search) method for finding an optimal solution. 
For discontinuous solution sets, additional methods are required to search amongst the candidate sub-sets. The branch-and-bound techniques described in Hillier and Lieberman (1995) are a common approach, in which the optimization problem is divided into sub-problems by dividing and sub-dividing the set of feasible solutions and noting the optimal solution from the sub-set.

Genetic algorithms (GAs) are a less analytic approach to optimal solution search in discontinuous space, which have also had success in combinatorially immense problems. GAs mimic the natural mixing and occasional mutation of genes in heterozygous reproduction. Through many rounds of reproduction, in which more favorable solutions are the dominant reproducers, natural selection is mimicked, and optimal solutions are approached.

Valenzuela and Smith (2003) propose a hybrid optimization approach to the unit commitment problem. First a (GA) is applied, with individual solutions guided and coaxed by additional rules. Second, a Lagrangian relaxation method is used to search of for improved solutions from GA candidate solutions. This research includes consideration of start-up and shut-down costs and time constraints, and examines the hourly dispatch problem over a 24-hour timespan. This paper includes a brief review of the past three decades of approaches to the same class of unit commitment problems. 
Appendix A includes a discussion of similarities and differences between the utility electric system and IES dispatch optimization problems.

\subsection{DG Investment Optimization}

With the recent advent of small (100s of $\mathrm{kW}$ to several MW) DG that is cost competitive with utility power purchase, much research has been done on the DG investment optimization problem. Dispatch must be considered in the investment optimization problem, because the value of a given DG system will depend on how it is operated.

The Distributed Energy Resources Customer Adoption Model (DER-CAM) is a DG investment optimization program developed at the Lawrence Berkeley National Laboratory (LBNL) (Bailey et al. 2003). DER-CAM considers a site's end-use energy loads (electricity, cooling, space-heating, water-heating, and natural-gas-only), electricity and natural gas tariff structure and prices; and DG investment opportunities (i.e. equipment type, cost, and performance characteristics). This work assumes deterministic energy loads, and represents each month of the year-long optimization as three characteristic day-types: typical weekday, peak weekday, and weekend. Optimization includes dispatch at each hour of these characteristic days. Demand charges are included in the tariff representation, although $100 \%$ reliability is assumed of DG equipment. DER-CAM is written as a mixed-integer linear program (MILP). 
Other DG investment optimization tools, such as the National Renewable Energy Laboratory's (NREL) Hybrid Optimization Model for Electric Renewables (HOMER) (Lilienthal, Flowers, and Rossmann 1995), Natural Resources Canada's (NRC) Renewable Energy Technologies Screening Tool (RETScreen International) (NRC 2007), and D-Gen Pro (InterEnergy Software 2002), have developed investment optimization tools that do enumerative searches through a user specified set of possible investment options. Because these programs consider a smaller set of possible investment options, there is potential to consider the dispatch optimization in more detail ${ }^{5}$ than DER-CAM does.

\subsection{DG Dispatch Optimization}

The value of a DG investment is dependent on how the DG system is operated; therefore dispatch optimization is a necessary part of the investment optimization problem. However, the enumeratively large set of candidate DG systems in the investment problem necessitates a simplification of the dispatch problem. In the work of Bailey et al. (2003) this simplification is achieved by only considering 36 characteristic days in a year and by assuming deterministic loads and 100\% DG equipment reliability. Other investment optimization research has considered only a handful of candidate systems. This is the typical approach of DG developers. By exhaustively considering each system, a more detailed dispatch optimization is possible.

${ }^{5}$ For example, simulations can use 365 days/year instead of 36 or consider multiple years instead of a single year. 
Chalermkraivuth and Ilic (2001) detail the cost function of distributed generation to developers and consumers under several different financial agreement scenarios. This work is intended for developers to assess the value of a particular system. This work is one of the few to acknowledge the imperfect reliability of distributed generation, and therefore considers expected values, corrected for the risk aversion of investors, of an energy system under a given scenario. Outages are assumed to be path independent, with equal probability of occurrence at all time-steps. While operation schemes and stochastic generator outage are considered in determining the present value of a system, demand charges are not accounted for. This simplifies the dispatch problem considerably: each time-step can be examined independently, and total annual or lifetime costs are just the sum of costs at each time-step. However, accuracy is sacrificed by misrepresenting the tariff.

Regan, Sinnock, and Davis (2003) describe the initial stage of work done in developing a distributed generation dispatch controller suitable for a neighborhood. The controller would be capable of dispatching generation and the charging/discharging of a battery in an electricity market which allowed the DG system to supply power to the neighborhood and/or sell power to the grid. Neural networks are trained to predict site demand with respect to weather and time of day/year. Conveniently, residential customers are not subject to demand charges, yet in some cases can get time-of-use rates. 
Curtiss and Kreider (2003) discuss a few control strategies for the dispatch of distributed generation. In threshold control a threshold demand level is selected at the beginning of each month, and on-site generation is dispatched whenever site demand exceeds the threshold. This has the effect of mitigating demand charges by keeping demand below the threshold. This paper does not suggest a method for selecting an optimal threshold level, although it does illustrate the variation in savings over a range of thresholds for a particular year. Other simple control strategies described are

- buyback control in which on-site generation is dispatched to run at all times, and excess electricity is either 1) sold at the real-time wholesale price to the utility or 2) fed to the utility grid in exchange for credits that offset site utility consumption at other times ${ }^{6}$ (this is know as "net metering").

- cooling/heating priority control in which DG is dispatched such that recovered heat exactly meets heating and/or cooling (via absorption cooling) demand. This method ensures optimal system efficiency, as all recoverable heat is utilized.

Finally, the paper describes optimal control in which an entire month of time-steps is considered, and a plan developed for the dispatch of the DG system at each time-step, taking into account time-of-use volumetric electricity $(\$ / \mathrm{kWh})$ rates, demand charges, and volumetric natural gas prices. This optimization does not consider the part-load

\footnotetext{
${ }^{6}$ Each utility has its own rules regarding acceptance of DG electricity into the utility grid. Typically, for small DG owners, resale and net metering are not an option, with exceptions made for PV and sometimes for methane fueled generation in agricultural and landfill sites.
} 
efficiency of equipment, imperfect reliability, or stochastic variation in loads. This is similar in detail to what DER-CAM considers, where deterministic loads and equipment availability enable a relatively straightforward (yet unrealistic) planning optimization.

Coffey and Kutrowski (2006) propose a threshold control strategy for CHP dispatch optimization in the presence of demand charges. The paper assumes deterministic loads and $100 \%$ reliable CHP. Prior to the start of each month, monthly CHP system operation (and resulting costs) are simulated under varying threshold levels. The threshold level with least cost results is selected. For several Ontario, Canada buildings examined, the authors illustrate that using threshold control, rather than control based solely on volumetric price $(\$ / \mathrm{kWh})$ comparison, can lower the payback period of CHP system investment by two to three years. This is one of the few papers to identify the dependency of DG system value on control strategy, particularly under the influence of demand charges. This paper discusses excessive start-stop cycles as a practical concern of analytic dispatch optimization strategies.

\subsection{Demand Response}

Initially, demand response (DR) programs developed by vertically integrated utilities focused mostly on the largest, industrial customers. Here DR was part of integrated resource planning, i.e. if some load could be avoided, some capacity and infrastructure could be avoided. In deregulated markets, when electricity suppliers 
are scarce, DR can help maintain stability 1) physically on the grid and 2)

economically in the spot-market when electricity supplies are scarce. Tariff

structures and incentive programs are being developed to encourage smaller industrial and commercial customers to curtail or reschedule load during critical grid events.

Several of the tariffs and incentive programs have been implemented in places such as California and New York. The most popular tariff structures for DR are 1) realtime pricing (RTP), in which the day-ahead hourly electricity prices are passed directly to customers and 2) critical peak pricing (CPP), in which electricity prices are raised dramatically during a limited number of critical event periods in exchange for reduced prices at other times. Other programs offer payments to customers who agree to curtail a set percentage of their load when called upon, or agree to have certain loads automatically curtailed by the utility. Goldman, Kintner-Meyer, and Heffner (2002) and Goldman et al. (2004) assess the effectiveness of several of these programs. Key results of these studies include:

- Approximately $85 \%$ of DR is load curtailment, rather than rescheduling;

- Lighting and air conditioning are the most common DR loads, but elevators, process loads, and plug-loads are also common; and

- Most customers handle DR manually; additional savings would be possible with automated DR. 
Much research at LBNL has focused on the monitoring and automation of energy systems in buildings. Included in this research has been the assessment and design of automated DR systems capable of automatically curtailing previously specified loads in response to price signals (such as from a RTP or CPP tariff) (Motegi, Piette, and Kinney 2003, Piette et al. 2004, and Watson et al. 2004). This research has demonstrated feasible automated DR curtailment capabilities of at least 5-15\% in typical commercial and industrial buildings.

The format of curtailment in most of these studies is a few to 10 or 20 events per year, each event lasting three or four hours. While these structures and incentives are designed to directly or indirectly call upon DR when supplies are scarce, the standard demand charge that most commercial and industrial customers in the U.S. are subject to also incents some DR. One application of the research described in this dissertation has been a valuation of DR under standard demand charges (Firestone, Stadler, and Marnay 2006).

\subsection{Model-Based Controls for Building Energy Systems}

Coffey (2006) discusses the development of a dispatch optimization platform for building energy systems. This approach uses a building energy model (BEM) to simulate the building at each time-step under varying candidate dispatch decisions. This report focuses on the information architecture, i.e. setting up the BEM and having it communicate with an optimization module. The author writes uses a 
genetic algorithm (GA) to solve the problem, yet acknowledges that more sophisticated, hybrid approaches may produce optimal results more quickly (which is essential for real-time controllers). The current state of this author's research is to optimize dispatch to automatic window-blind controls, where the decision on how much to open window blinds is a tradeoff between reducing lighting loads and increasing cooling loads. Further research from the author will consider integrating window blind control with control of HVAC equipment and other building energy equipment. This research is similar to the IES dispatch optimization research in that modern computing power and optimization algorithms are exploited to make analytic dispatch optimization for integrated systems quickly enough to be considered a realtime approach. In both, dispatch optimization of the current steps requires a dispatch strategy for future time-steps.

From review of current research in DG investment optimization and in IES dispatch optimization, several possible improvements are apparent, all of which are important because of the significance of demand charges. The first improvement is to include an accurate representation of demand charges. The second is to consider stochastic variation of site loads and IES equipment availability because of their impact on demand charges. The third is to consider the integrated dispatch of various IES components. Firestone and Marnay (2005a) pose this optimization problem and discusses the data and information processing requirements of an energy manager entity capable of providing optimal dispatch control or advice. This dissertation research concerns the development of this energy manager algorithm. 


\subsection{DG Case Studies}

During the process of developing DER-CAM, case studies were performed by the LBNL DER team, including the author of this dissertation (Bailey et al. 2003 and Firestone et al. 2003). The intent of the case-studies was to validate DER-CAM by comparing investment solutions posed by DER-CAM with those chosen by sites. One significant realization from these case-studies and later ones by the LBNL DER team was building managers' frustration over the discrepancy in performance of their system and cost results with those expected prior to installation. Much of this was because of demand charges: initial maintenance schedules were often made to include maintenance on DG equipment during business hours (when the maintenance crew was most available), which eliminated demand charge savings potential.

Furthermore, frequent unplanned outages - however brief - had a similar effect. Some managers mentioned that they did not consider how changes in natural gas prices from month to month would affect system economics; often they realized several months too late that they should have changed their operation schedule in response to changes in energy prices. Given the inevitable spikes in demand during unscheduled outages, some building managers wondered how worthwhile it would be to curtail or reschedule some of their loads. The experiences and ponderings of these building managers were the inspiration for this dissertation research. 


\subsection{Operations Research}

In the past 60 years, the field of operations research has developed the theory and algorithms necessary to solve, or nearly solve optimization problems. The text by Hillier and Lieberman (1995) is a standard introductory reference to this field. Modern computing power and commercially available solvers now enable researchers with applied optimization problems to rely heavily on commercially available solvers, allowing these researchers to instead focus on model identification and representation of their model in a format compatible with these solvers.

The IES dispatch optimization is characterized as a multi-stage stochastic integer optimization problem. These types of problems are extremely difficult to solve exactly; recent advances in optimization are to solve two-stage stochastic integer optimizations where nondeterminism is represented during the first stage as a set of possible scenarios for the second stage, one of which is realized in the second stage (Gupta et al. 2005, Dhamdhere, Ravi, and Singh 2005, Ravi and Sinha 2004). While this representation of an uncertain future as a finite set of possible scenarios will be useful in this IES dispatch optimization work, it is clear that an analytic solution to our severely multi-stage problem is beyond the frontier of operations research.

A common approach to multi-stage optimization is dynamic programming ${ }^{7}$, in which contingent optimal solutions for consecutive stages - from last to first - are

\footnotetext{
${ }^{7}$ See Hillier and Lieberman (1995) for an overview of this approach.
} 
determined. A key requirement of this approach is that the objective function be additive at each stage, allowing the problem to be discretized into many separate, smaller problems. The optimal sum of sub-problem solutions is then the full-problem solution. Unfortunately, the presence of demand charges in IES dispatch optimization eliminates the possibility of using dynamic programming. However, even if a clever representation or approximation of demand charges was developed for use in a dynamic program, the IES dispatch problem contains too many stages, and too many dispatch variables at each stage, to conduct a fairly accurate search.

The dispatch optimization problem for integrated energy systems necessarily contains binary and integer variables. Fortunately, the problem can be decently approximated as a linear program, which is described in Chapter 6. Thus, the problem is a mixed integer linear program (MILP), for which CPLEX is the most popular and powerful commercial solver currently available. CPLEX uses a variety of techniques including Lagrangian relaxation and branch-and-bounch techniques - to search the set of feasible, discrete solutions and find optimal continuous variable solutions within candidate discrete solutions ${ }^{8}$. CPLEX is the solver used for this research, under the General Algebraic Modeling System (GAMS) platform.

\footnotetext{
${ }^{8}$ An example of this for an IES consisting of several heterogeneous generators with minimum load constraints would be determining which generators to turn on (from a set of discrete combinations) and then determining which level to run each generator at (over the continuous variable operating levels).
} 


\subsection{Going Forward}

The development of a solution to the IES dispatch optimization problem has benefited from the prior research described in this chapter. The electric utilities, particularly under the vertically integrated paradigm that was dominant until recently, deal with a similar optimization of constrained, least-cost energy provision to customers. The division of that problem into several different time-scales suggests a similar approach for IES dispatch optimization, especially given the similarity of the unit commitment and planning tiers of the utility problem with the IES problem. Modeling of generator costs and constraints in the unit commitment problem provides a starting point for modeling generators and other equipment in the IES problem.

Prior research into distributed generation investment and dispatch optimization are particularly useful for this research. The development DER-CAM has illustrated the feasibility of modeling DG dispatch problems as MILPs and the utility of CPLEX as a solver for such problems. DER-CAM also provides a technique for representing demand charges - a fundamentally non-linear term - in a linear program (see Section 6.3 for a description of this technique). Other studies have introduced unplanned DG outages in cost calculations. Case studies have highlighted the key factors that are often missed in estimating energy costs for sites with DG systems, such as financing, contractual agreements between sites and third-party owner/operators of DG systems, and utility interconnection requirements. 
The field of operations research has provided the analytic power useful for solving large optimization problems. Problems such as the IES dispatch can be posed and classified, which then suggests a solution approaches. For large problems for which exact solutions have not been developed, combinations of analytic solutions and search techniques have been developed and commercialized for common optimization program formats, such as MILPs. Techniques for expressing a variety of equality and inequality constraints as sets of linear constraints are particularly useful. Also useful in this research is the technique of representing nondeterminism as a finite set of deterministic, possible scenarios for multi-stage stochastic optimization problems.

Much less studied has been DSM. Many economists argue that short-run elastic demand is necessary for efficient free market for electricity (Borenstein and Bushnell 2000). Research on this topic has mostly focused on developing tariffs that encourage DSM and developing the information infrastructure necessary to send proper signals to electricity consumers. DSM, though, has been proven to be valuable to informed customers, even in the absence of strong signals such as critical peak pricing (CPP) (Stadler et al. 2006 and Firestone, Stadler, and Marnay 2006). This dissertation makes a new contribution by examining the interaction of DG with DSM, and, more generally examining the value of integrating the decision making of disparate energy options in a building. 


\section{PART 2: THE RT-OPTICOM CONCEPT AND APPLICATION TO IES}

The intent of this research is to develop a tool capable of aiding in the real-time optimal dispatch of IES. The tool should be versatile enough to benefit a wide range of smaller ${ }^{9}$ commercial and industrial sites, for which DER might be cost-effective, but custom-built optimization algorithms might not. This problem is computationally challenging because of

- the combinatorial nature of decisions: Many decision variables in the problem are discrete in nature, primarily demand response decisions (i.e. at a given time-step, either to curtail/reschedule or not) and on-site generator on/off decisions ${ }^{10}$.

- the large number of inter-related time-steps: Demand charges, which are a function of a maximum monthly demand, rather than cumulative consumption, require an entire month of planning for decisions made at the beginning of the month. Annual system minimum efficiency constraints likewise require long-term planning.

- the uncertainty involved in the problem: loads, generator availability, and energy prices (for real-time pricing of critical peak pricing schemes) are all uncertain, yet significant.

\footnotetext{
9 "Smaller" sites are defined as those with peak electric loads less than $2 \mathrm{MW}$

${ }^{10}$ Generators typically have a minimum load that they can operate at; at each timestep, one decision to make is whether the generator will run or not.
} 
Looking at a handful of independent, discrete dispatch decisions at each of hundreds to thousands of time-steps leads to an enormous number of discontinuous solution sets, far too many to search exhaustively. Even for a deterministic forecast of the future, dispatch planning for the entire month is required to determine the optimal dispatch for the current time-step. As is typical of MILPs, this problem is nondeterministic polynomial-time (NP) hard: the number of discrete feasible solutions increases exponentially with time. The practical implication of this is that solutions to the problem will require exponentially more computation time and memory as larger timespans are considered. Appendix A quantifies the large number of feasible discrete solutions to a typical IES dispatch optimization problem. To complicate the IES dispatch problem, there are several sources of uncertainty; therefore planning must consist of a strategy (i.e. a range of dispatch plans, contingent of stochastic parameter values), rather than a single monthly dispatch plan.

On top of the large number of discrete solutions, there are continuous variables within each discrete solution set to solve for. Continuous variables at each time-step include generator (if the generator is on) setpoint, absorption chiller setpoint (if electric chilling is also an option), and storage charging/discharging.

The challenge in developing an IES dispatch optimization tool, then, is to reduce the IES dispatch problem to a size tractable by contemporary optimization software, and yet accurate enough to provide benefit to a variety of users. The key reductions 
utilized in this research are 1) approximating uncertainty as a finite number of scenarios and 2) approximating the model as a mixed integer linear program (MILP).

Chapter 4 introduces the Real-time Optimal Control Model (RT-OPTICOM). RTOPTICOM approximates a multistage stochastic optimization problem as one with a finite number of deterministic scenarios capable of being solved by a current personal computer in a practical amount of time. Chapter 5 presents the IES model in the language of RT-OPTICOM. Chapter 6 describes how the model was approximated as a MILP, which commercial solvers can feasibly solve. 


\section{THE REAL-TIME OPTIMAL CONTROL MODEL (RT-OPTICOM) CONCEPT}

When confronted with operation and planning optimization problems, exhaustive considerations for possible futures are often infeasible because of the large number of

possible futures. A common approach to decision making under uncertainly is to consider a finite number of possible futures (i.e. scenarios) believed to span the range of possibility. Then, the results of a particular dispatch strategy can be evaluated for each of the deterministic scenarios considered and a meaningful performance metric assessed (e.g. mean and standard deviation of monthly energy cost).

Typical strategies considered for CHP are

- base loading: generators are run at $100 \%$ of rated capacity at all hours;

- peak shaving: generators are run at $100 \%$ of rated capacity during on-peak hours;

- load-following: generators follow the site load;

- heat load-following: generators are run such that the recovered heat from the generators is equal to the heat load of the site; and

- demand limiting (threshold control): utility purchase is restricted to a maximum demand level determined by the site; any time site loads approach this ceiling, the generators are dispatched to reduce site purchases. 
These heuristic approaches are easy to implement and within the means of attention that building managers can pay to the IES. However, as suggested in Chapter 1, they are most likely not optimal for a given site because:

- they ignore most of the set of feasible solutions;

- setpoints for switching between control strategies in response to energy prices are not identified (or even considered in most cases); and

- DSM opportunities are not considered and only the demand limiting strategy suggests when to deploy limited DSM opportunities.

The true dispatch optimization problem is a multi-stage, stochastic problem. A common approach to this type of problem is to consider a lattice or tree of possible scenarios for which dynamic programming techniques can provide solutions. Unfortunately, the dispatch problem is far too large for this type of approach: Where dynamic programming can handle problems with one stochastic variable, approximated by a few discrete possible values over a handful of time-steps, the dispatch optimization problem addresses several stochastic variables (energy loads, CHP availability, energy prices) over hundred of time-steps (there are 720 one-hour time-steps over the course of a 30 day month). Examining the branches of such a lattice would require examination of $S D^{T}$ discrete branches, where $S$ is the number of stochastic variables, $D$ is the number of discrete values used to approximate the possible values of the stochastic variables, and $T$ is the number of time-steps. For 
each branch, an optimal plan would be required. Clearly, this approach is not feasible for an IES dispatch optimization problem.

What the dynamic programming approach misses for the IES dispatch problem is the redundancy of many branches. Because of the large number of time-steps, many of these branches will be similar in their stochastic parameter statistics (e.g. magnitude and frequency of peak loads, chance of DG outage). The approach proposed in this research is to use a set of $S$ randomly generated scenarios to represent the stochastic forecast. S need not be large to approximate the needed stochastic forecast because of the redundancies among the entire set of possible scenarios. Using the scenarios (rather than a statistical description) in the optimization is a general approach; any forecasting model can be used to generate the scenarios. Scenarios can even consist of prior site data, which may be the most accurate forecast of future scenarios.

The true stochastic optimization problem contains branching sets of scenarios, whereas the finite-scenario optimization problem contains only single-strands of scenarios. Figure 2 illustrates this. Because of this discrepancy, certain additional constraints must be added to the finite-scenario problem. These constraints must ensure that solutions that would be unrealistic for the real, nondeterministic system are not attempted. The most obvious example of this is when a significant but unlikely event happens at the end of a timespan in a scenario. If this event is deterministically known, the optimal behavior of the system in time-steps prior to the 
event is different than if it is only known that there is some probability of this occurrence.
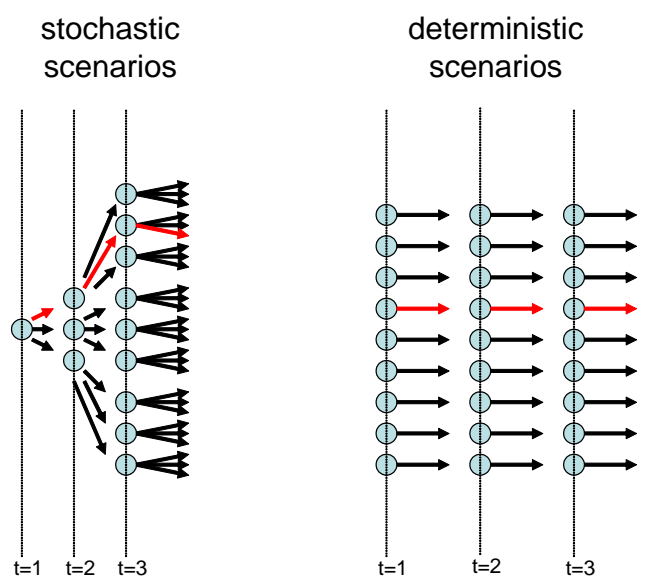

Figure 2. discrepancy between stochastic and deterministic scenarios

For economic optimization, this issue arises with demand charges. In a particular scenario, it may be deterministically known that a CHP outage will occur on the last day of the month, thus making demand charge mitigation via on-site electricity generation futile. In this case, the optimal dispatch may be to not run the CHP system at all during the month. However, this is not realistic because for the true, nondeterministic system, there is only a probability of such an event, and hedging behavior is necessary.

This, then, provides the qualitative description of the approach to real-time optimal dispatch. The following section (Section 4.1) formally describes this approach, the Real-time Optimal Control Model (RT-OPTICOM). 


\subsection{RT-OPTICOM Formalization}

The first step of the dispatch optimization process is forecast generation, which is done external to the optimization, to allow for various forecast models to be used interchangeably. Chapter 7 describes the forecast models used in this research. The product of these forecasts is sets of stochastic parameter values for each of the $S$ scenarios considered at each time-step, $t$, of the timespan, $T$, considered. Parameters for an IES application would include energy loads, energy prices, and equipment availability. These forecasts can be updated during the course of the timespan as more information becomes available. For each parameter value, the optimization must consider either the actual value if known, or the forecasted value.

Table 1 through Table 3 define the indices, parameters, and variables used in this formulation.

Table 1. indices used in RT-OPTICOM problem formulation

\begin{tabular}{|l|l|l|}
\hline Index & Description & Membership \\
\hline \hline dd & dispatch decision & $\left\{\begin{array}{l}\text { curtailment, generator-dispatch } \\
\text {, genearator- } \\
\left.\text { dispatch }_{2}, \ldots, \text { generator } \text { dispatch }_{\mathrm{G}}, \text { etc. }\right\}\end{array}\right.$ \\
\hline gen & generator & $\{1,2, \ldots, \mathrm{G}\}$ \\
\hline scen & scenario & $\{1,2, \ldots, \mathrm{S}\}$ \\
\hline sp & stochastic parameter & $\{$ electric-load, cooling-load, heat-load, \\
& & generator-availability, generator- \\
\hline
\end{tabular}




\begin{tabular}{|l|l|l|}
\hline & & $\begin{array}{l}\text { availability } 2, \ldots, \text { generator-availability } \\
\text { G }, \\
\text { electricity-price, solar insolation, etc. }\}\end{array}$ \\
\hline $\mathrm{t}$ & time-step & $\{1,2, \ldots, \mathrm{T}\}$ \\
\hline
\end{tabular}

Table 2. parameters used in RT-OPTICOM problem formulation

\begin{tabular}{|l|l|l|}
\hline Parameter & Full Name & Description \\
\hline AS(sp,t) & Actual Scenario & $\begin{array}{l}\text { parameter values for the actual scenario, } \\
\text { i.e. what has actually happened in the past }\end{array}$ \\
\hline CurrentTime & Current Time & the current time-step \\
\hline G & Generators & Number of generators \\
\hline HistD(dd,t) & Historic Dispatch & dispatch decisions for all past time-steps \\
\hline S & Scenarios & number of scenarios \\
\hline SPV(scen,sp,t) & Stochastic & stochastic parameter values for each \\
& Parameter Values & scenario used in optimization problem \\
\hline FV(scen,sp,t) & Forecast Values & the set of stochastic parameter values \\
& & generated from the forecast model for all \\
scenarios \\
\hline T
\end{tabular}

Table 3. variables used in RT-OPTICOM problem formulation

\begin{tabular}{|l|l|l|}
\hline Variable & Full Name & Description \\
\hline D(scen,dd,t) & Dispatch & $\begin{array}{l}\text { dispatch decision for each variable in each scenario } \\
\text { at each time-step }\end{array}$ \\
\hline
\end{tabular}




\subsubsection{Stochastic Parameter Assignment}

For all time-steps prior to and including the current time-step, stochastic parameter values are all known and are equal to the actual scenario parameter values.

$$
\operatorname{SPV}(\text { scen }, s p, t)=A S(\operatorname{sp}, t) \quad \forall \text { scen,sp, } \forall t \leq \text { CurrentTi me }
$$

For all future time-steps, the stochastic parameter values are the forecasted stochastic values generated for each scenario.

$$
S P V(\text { scen }, s p, t)=F V(\text { scen, sp,t }) \quad \forall \text { scen, sp, } \forall t>\text { CurrentTime }
$$

\subsubsection{Dispatch Constraints}

For all time-steps prior to the current time-step, dispatch is known and is the historical dispatch of the system.

$$
D(\text { scen }, d d, t)=H i s t D(d d, t) \quad \forall \text { scen, } d d, \forall t<\text { CurrentTime }
$$

For the current time-step, dispatch for each scenario must be equal, i.e. as there is only one actual scenario, there is only one actual dispatch.

$$
D(i, d d, t)=D(j, d d, t) \quad \forall i, j \in \text { scen }, \forall d d, t=\text { CurrentTime }
$$


For all time-steps beyond the current time-step, dispatch may vary by scenario. The set of dispatch decisions for all future time-steps for all scenarios represents a dispatch strategy.

\subsubsection{Deterministic Correction Constraints}

One major inaccuracy in considering a portfolio of deterministic scenarios must be addressed: Demand charges are based on the maximum electricity purchase over the timespan; there is only probabilistic knowledge of generator availability and maximum site demand over the course of the month, and this cannot be translated directly into a deterministic scenario.

This is best illustrated by example: consider a site with a constant load, $F$, and a generator that can meet the entire site load. For this example, the volumetric cost of producing electricity on-site is larger than the cost of purchasing it from the utility. However, high demand charges tip the scale in favor of on-site generation, provided the generator is $100 \%$ reliable. This, of course, is not the case, and if the generator has less than a certain probability of being available, $P A v l$, it will not be cost-effective to run the generator.

Assume that the site has two dispatch strategy options: 
1. Run the generators until an outage occurs (in an attempt to avoid the demand charge), and then do not run the generator for the rest of the timespan if an outage occurs (the demand charge has been incurred, and it is then cheaper to purchase utility electricity).

2. Do not run the generator.

The dispatch optimization problem is then to determine at what level of demand charge, $D C h$, relative to volumetric costs, UVol, of utility electricity and of on-site generation, GVol, should on-site generation be initiated.

Table 4 lists the parameters used in this example.

Table 4. parameters used in Section 4.1.3

\begin{tabular}{|l|l|}
\hline Parameter & Description \\
\hline \hline DCh & utility demand charge (\$/kW maximum demand) \\
\hline F & site demand \\
\hline GVol & generator volumetric cost $(\$ / \mathrm{kW}$ time-step) \\
\hline T & probability of generator being out a given time- \\
\hline UVol & number of time-steps \\
\hline
\end{tabular}


To determine this break-even value of $D C h$, the expected value of both dispatch strategies is derived. For strategy 1), Table 5 lists all of the possible DG outage scenarios, their probability of occurrence, the actual energy costs under this control strategy, and the cost computed using deterministic scenarios. The expected monthly energy cost is then the sum of the product of probability and cost for all scenarios.

Table 5. cost of outage - stochastic and deterministic scenarios

\begin{tabular}{|c|c|c|c|}
\hline scenario & $\begin{array}{c}\text { probability of } \\
\text { occurrence }\end{array}$ & $\begin{array}{c}\text { stochastic cost for this } \\
\text { scenario }\end{array}$ & $\begin{array}{l}\text { deterministic cost } \\
\text { for this scenario }\end{array}$ \\
\hline outage at $\mathrm{t}=1$ & 1-PAvl & F*U*VolT + F*DCh & $\begin{array}{l}\mathrm{F}^{*} \mathrm{UVol} * \mathrm{~T} \\
+\mathrm{F} * \mathrm{DCh} \\
\text { (DG is not } \\
\text { dispatched) }\end{array}$ \\
\hline outage at $t=2$ & PAvl(1-PAvl) & $\begin{array}{l}\mathrm{F}^{*} \mathrm{GVol}+\mathrm{F}^{*} \mathrm{UVol}(\mathrm{T}- \\
\text { 1) } \\
+\mathrm{F}^{*} \mathrm{DCh}= \\
\mathrm{F}^{*} \mathrm{Uvol}{ }^{*} \mathrm{~T}+\mathrm{F}^{*} \mathrm{DCh} \\
+\mathbf{F}^{*}(\mathbf{G V o l}-\mathbf{U v o l})\end{array}$ & $\begin{array}{l}\mathrm{F}^{*} \mathrm{UVol} * \mathrm{~T} \\
+\mathrm{F}^{*} \mathrm{DCh} \\
\text { (DG is not } \\
\text { dispatched) }\end{array}$ \\
\hline outage at $\mathrm{t}$ & $\mathrm{PAvl}^{\mathrm{t}-1}(1-\mathrm{PAvl})$ & $\begin{array}{l}\mathrm{F}^{*} \mathrm{GVol}(\mathrm{t}-1) \\
+\mathrm{F}^{*} \mathrm{UVol}(\mathrm{T}-\mathrm{t}+1) \\
+\mathrm{F}^{*} \mathrm{DCh}= \\
\mathrm{F}^{*} \mathrm{Uvol}^{*} \mathrm{~T}+\mathrm{F}^{*} \mathrm{DCh}\end{array}$ & $\begin{array}{l}\mathrm{F}^{*} \mathrm{UVol} * \mathrm{~T} \\
+\mathrm{F}^{*} \mathrm{DCh} \\
\text { (DG is not } \\
\text { dispatched) }\end{array}$ \\
\hline
\end{tabular}




\begin{tabular}{|l|l|l|l|}
\hline & & $+\mathbf{F}(\mathbf{t}-1)($ GVol-UVol) & \\
\hline no outages & PAvl $^{\mathrm{T}}$ & $\mathrm{F}^{*} \mathrm{GVol}^{*} \mathrm{~T}$ & $\mathrm{~F}^{*} \mathrm{GVol}^{* \mathrm{~T}}$ \\
& & & $(D G i s$ \\
& & & dispatched $)$ \\
\hline
\end{tabular}

From this table, we see that if we consider deterministic scenarios, we will not run the generator in any scenario where there is an outage at any time-step in the future. This is not realistic, as there is only a probabilistic knowledge of future outages.

Therefore, the deterministic approach leads to expected costs that are too low, because extra-realistic information is made available. Using the expected cost from the deterministic scenarios will lead to an expected value that is too small, suggesting a break-even demand charge lower than the true break-even demand charge.

The solution to this discrepancy is to add an additional constraint to the IES dispatch optimization problem that will cancel out the unjustified advantage of extra-realistic information. This constraint is to put a ceiling on utility demand purchase and to constrain solutions to stay below that ceiling in all scenarios whenever possible. In practice, this is similar to threshold control.

Tables Table 6, Table 7, and Table 8 describe the indices, parameters, and variables used to describe the mathematics of this ceiling approach. Table 6. indices used in the ceiling approach formulation 


\begin{tabular}{|l|l|l|}
\hline Index & Description & Membership \\
\hline scen & scenario & $\{1,2, \ldots, \mathrm{S}\}$ \\
\hline $\mathrm{t}$ & timestep & $\{1,2, \ldots, \mathrm{T}\}$ \\
\hline
\end{tabular}

Table 7. parameters used in the ceiling approach formulation

\begin{tabular}{|l|l|}
\hline Parameter & Description \\
\hline CurrentHour & current one-hour time-step \\
\hline ElectricLoad(scen,t) & total site electric load, inlcuding cooling \\
\hline MinimumElectricDemand(scen,t) & minimum possible electric demand to utility \\
\hline PossibleLoadReduction(scen,t) & sum of available on-site generation capacity, \\
& curtailment potential, and absorption chiller \\
& cooling offset \\
\hline
\end{tabular}

Table 8. variables used in the ceiling approach formulation

\begin{tabular}{|l|l|}
\hline Variable & Description \\
\hline Ceiling & $\begin{array}{l}\text { selected ceiling level }(\mathrm{kW}) \text { : utility purchase } \\
\text { should not go above this if possible }\end{array}$ \\
\hline CeilingFunction(scen,t) & $\begin{array}{l}\text { function describing the the maximum electricity } \\
\text { purchase }(\mathrm{kW}) \text { allowed under the ceiling } \\
\text { constraint }\end{array}$ \\
\hline UtilityElectricityPurchase(scen,t) & electricity purchased $(\mathrm{kW})$ from the utility \\
\hline
\end{tabular}


The first thing to determine is the minimum possible electric demand at each timestep and in each scenario, i.e. the minimum possible utility electricity purchase.

$$
\begin{aligned}
& \text { MinimumElectricDemand }(\text { scen }, t)= \\
& \text { ElectricLoad }(\text { scen, } t)-\text { PossibleLoadReduction }(\text { scen }, t) \quad \forall \text { scen }, t
\end{aligned}
$$

where ElectricLoad is the total site electric load (including cooling) and PossibleLoadReduction is the sum of available on-site generation capacity, curtailment potential, and absorption chiller cooling offset.

Next, the maximum utility purchase level must be selected, and that, if possible, the site can not purchase more that this ceiling amount. Importantly, this ceiling level must be the same for all scenarios. If the ceiling level cannot be avoided (e.g. during generator outage) than the minimum possible purchase is done and a new ceiling level is set at the current utility demand. Generating a ceiling function for each scenario for a given ceiling facilitates the expression:

$$
\begin{aligned}
& (\text { CeilingFunction }(\text { scen }, t))= \\
& \max \left(\begin{array}{l}
\text { Ceiling, } \\
\text { CeilingFunction }(\text { scen }, t-1), \\
\text { MinimumElectricDemand }(\text { scen }, t)
\end{array}\right) \quad \forall \text { scen }, \forall t>\text { CurrentHour }
\end{aligned}
$$

The utility electricity purchase is constrained to be at or below the ceiling function at all times. 
UtilityElectricityPurchase $($ scen, $t) \leq$

(CeilingFunction(scen,t))

The demand charge assessed in the optimization is then equal to the demand rate times the greater of the selected ceiling and the actual demand. Selecting a ceiling too low reduces the set of allowable dispatch and forces uneconomic dispatch; selecting a ceiling too high will incur unnecessarily high demand charges. Thus, there is proper incentive to select the correct ceiling level.

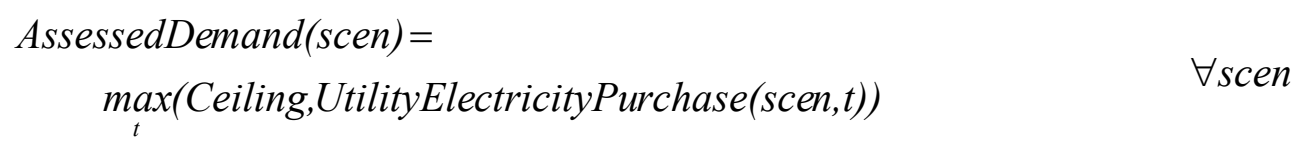




\section{APPLICATION OF RT-OPTICOM CONCEPT TO AN IES FOR COMMERCIAL/INDUSTRIAL BUILDINGS}

The IES dispatch optimization problem can now be formulated in the RT-OPTICOM format, as described in Chapter 4. Table 9 through Table 11 describe the indices, parameters, and variables used in the problem formulation throughout Chapters 5 and 6.

Table 9. indices used in RT-OPTICOM IES formulation

\begin{tabular}{|l|l|l|}
\hline symbol & \multicolumn{1}{|c|}{ description } & \\
\hline d & days & $\{1, \ldots, \mathrm{D}\}$ \\
\hline dd & dispatch decisions & $\{$ generation level, curtail $\}$ \\
\hline gen & generator & $\{1, \ldots, \mathrm{G}\}$ \\
\hline scen & stochastic scenarios & $\{1, \ldots, \mathrm{S}\}$ \\
\hline sp & stochastic parameter & $\{$ electric load, generation availability, solar \\
\hline t & time-steps & insolation $\}$ \\
\hline t-mid & subset of mid-peak time- & \\
& steps & $\{1, \ldots, \mathrm{T}\}$ \\
\hline t-off & subset of off-peak time- & \\
& steps & \\
\hline t-on & subs set of on peak hours & \\
\hline tou & time of use & $\{$ on-peak, mid-peak, off-peak $\}$ \\
\hline
\end{tabular}


Table 10. parameters used in RT-OPTICOM IES formulation

\begin{tabular}{|c|c|}
\hline parameter & description \\
\hline AbsCapacity & capacity $(\mathrm{kW})$ of the absorption chiller \\
\hline AbsCOP & $\begin{array}{l}\text { the coefficient of performance of the absorption } \\
\text { chiller }\end{array}$ \\
\hline CeilingFunction $_{\mathrm{i}}($ scen,t) & $\begin{array}{l}\text { the maximum permissible level of utility } \\
\text { electricity purchase }(\mathrm{kW}) \text { under ceiling level } \\
\text { Ceiling }_{i}\end{array}$ \\
\hline Ceiling $_{i}$ & $\begin{array}{l}\text { level of utility electricity purchase that system } \\
\text { must remain below if possible }\end{array}$ \\
\hline CurrentHour & $\begin{array}{l}\text { the current time-step; for this project, hourly } \\
\text { time-steps were used }\end{array}$ \\
\hline CurtDuration & permissible duration (time-steps) of curtailment \\
\hline CurtFreq & $\begin{array}{l}\text { permissible number of curtailment episodes per } \\
\text { month }\end{array}$ \\
\hline CurtMag & permissible magnitude $(\mathrm{kW})$ of curtailment \\
\hline $\mathbf{D}$ & number of days per month \\
\hline DemandRate(tou) & time-of-use specific demand rate $(\$ / \mathrm{kW})$ \\
\hline DemandRateFacility & $\begin{array}{l}\text { facility related demand rate }(\$ / \mathrm{kW}) \text {, active over } \\
\text { all hours }\end{array}$ \\
\hline DGCapacity(gen) & electric capacity $(\mathrm{kW})$ of DG unit \\
\hline DGFixed $_{\text {gen }}$ & fixed maintenance cost (\$/month) of DG \\
\hline
\end{tabular}




\begin{tabular}{|c|c|}
\hline DGMinCapacity(gen) & $\begin{array}{l}\text { minimum capacity }(\mathrm{kW}) \text { of a DG unit when it is } \\
\text { running }\end{array}$ \\
\hline DGVarCost $_{\text {gen }}$ & variable maintenance cost $(\$ / \mathrm{kWh})$ of DG \\
\hline Efficiency(gen,dispatch level) & $\begin{array}{l}\text { part-load electrical efficiency of generator at a } \\
\text { particular dispatch level }\end{array}$ \\
\hline EFixed & monthly fixed cost (\$) for electricity service \\
\hline ElectCOP & $\begin{array}{l}\text { the coefficient of performance of the electric } \\
\text { chiller }\end{array}$ \\
\hline ElectricityRate(tou) & volumetric rate $(\$ / \mathrm{kWh})$ \\
\hline $\mathbf{G}$ & number of generators \\
\hline HeatToElectRatio(gen) & $\begin{array}{l}\text { ratio of heat output }(\mathrm{kW}) \text { to electrical output } \\
(\mathrm{kW}) \text { from a generator }\end{array}$ \\
\hline MinCHPEffic & minimum allowable CHP efficiency \\
\hline MinEfficPenaltyPrice & $\begin{array}{l}\text { fictitious price of energy }(\$ / \mathrm{kWh}) \text { for the } \\
\text { variable MinEfficPenalty }\end{array}$ \\
\hline MinimumElectricDemand & $\begin{array}{l}\text { the lowest possible level of utility electricity } \\
\text { purchase }\end{array}$ \\
\hline NGFixed & monthly fixed cost (\$) for natural gas service \\
\hline NGRateForDG & natural gas rate $(\$ / \mathrm{kWh})$ for $\mathrm{DG}$ \\
\hline NGRateForHeat & natural gas rate $(\$ / \mathrm{kWh})$ for heating \\
\hline PVCapacity & rated capacity of photovoltaics \\
\hline $\mathbf{S}$ & number of scenarios \\
\hline
\end{tabular}




\begin{tabular}{|c|c|}
\hline SolarThermalCapacity & $\begin{array}{l}\text { thermal capacity }(\mathrm{kW}) \text { of the solar thermal } \\
\text { collector }\end{array}$ \\
\hline SPV(scen,sp,t) & $\begin{array}{l}\text { stochastic parameter values used for } \\
\text { optimization problem }\end{array}$ \\
\hline $\mathbf{T}$ & number of time-steps per month \\
\hline time-step & length (minutes) of time-steps considered \\
\hline UsefulToFuelHeatRatio & $\begin{array}{l}\text { conversion efficiency of combusting natural gas } \\
\text { for heat }\end{array}$ \\
\hline UsefulToRecoveredHeatRatio & $\begin{array}{l}\text { heat exchanger conversion efficiency of turning } \\
\text { generator waste heat into useful heat }\end{array}$ \\
\hline$\alpha$ & $\begin{array}{l}\text { linear coefficient in the equation for natural gas } \\
\text { consumption as a function of generation level }\end{array}$ \\
\hline $\boldsymbol{\beta}$ & $\begin{array}{l}\text { constant term in the equation for natural gas } \\
\text { consumption as a function of generation level }\end{array}$ \\
\hline
\end{tabular}

Table 11. variables used in RT-OPTICOM IES formulation

\begin{tabular}{|l|l|}
\hline \multicolumn{1}{|c|}{ variable } & \multicolumn{1}{c|}{ description } \\
\hline AbsOffset(scen,t) & $\begin{array}{l}\text { cooling load }(\mathrm{kWh}) \text { offset by the absorption } \\
\text { chiller }\end{array}$ \\
\hline AssessedDemand(scen) & $\begin{array}{l}\text { maximum monthly demand }(\mathrm{kW}) \text { used for cost } \\
\text { purposes }\end{array}$ \\
\hline CeilingFunction(scen,t) & the selected ceiling function from the set of \\
\hline
\end{tabular}




\begin{tabular}{|c|c|}
\hline & CeilingFunction $_{i}$ \\
\hline CHPEfficiency(scen) & \begin{tabular}{|l} 
monthly CHP efficiency \\
\end{tabular} \\
\hline Cost(scen) & $\begin{array}{l}\text { total monthly cost (\$) of electricity, natural gas, } \\
\text { and DG maintenance }\end{array}$ \\
\hline \begin{tabular}{|l} 
CurtailAmount(scen,t) \\
\end{tabular} & curtailed load $(\mathrm{kW})$ \\
\hline D(scen,dd,t) & dispatch decision \\
\hline DGCost(scen) & maintenance costs (\$) for regular DG servicing \\
\hline DGHeat(scen,t) & heat provided $(\mathrm{kWh})$ from $\mathrm{DG}$ \\
\hline ElectForCool(scen,t) & electricity (kWh) used for cooling \\
\hline ElectForElect(scen,t) & $\begin{array}{l}\text { electricity }(\mathrm{kWh}) \text { used for non-cooling electric } \\
\text { loads }\end{array}$ \\
\hline \begin{tabular}{|l} 
ElectricCost(scen) \\
\end{tabular} & monthly cost (\$) of electricity \\
\hline EPurch(scen,t) & electricity purchase $(\mathrm{kWh})$ at each time-step \\
\hline ExCost & $\begin{array}{l}\text { the expected monthly energy cost, including the } \\
\text { fictitious minimum efficiency costs }\end{array}$ \\
\hline flag $_{i}$ & $\begin{array}{l}\text { binary variable equal to unity for the argument of } \\
\text { the one ceiling level, Ceiling } \\
\text {, that is selected }\end{array}$ \\
\hline HeatForCool(scen,t) & heat ( $\mathrm{kWh}$ ) used by the absorption chiller \\
\hline HeatForHeat(scen,t) & heat $(\mathrm{kWh})$ used for heating loads \\
\hline MinEfficPenalty(scen) & $\begin{array}{l}\text { fictitious amount of useful energy }(\mathrm{kWh}) \text { the } \mathrm{CHP} \\
\text { system would need to meet the minimum } \\
\text { allowable efficiency constraint }\end{array}$ \\
\hline
\end{tabular}




\begin{tabular}{|l|l|}
\hline MinEfficPenaltyCost(scen) & fictitious cost (\$) of not meeting the minimum \\
CHP efficiency constraint
\end{tabular}

\subsection{Cost}

Electric costs are the sum of volumetric purchase, time of use demand charges, and fixed monthly service fees. 
ElectricCost $($ scen $)=$

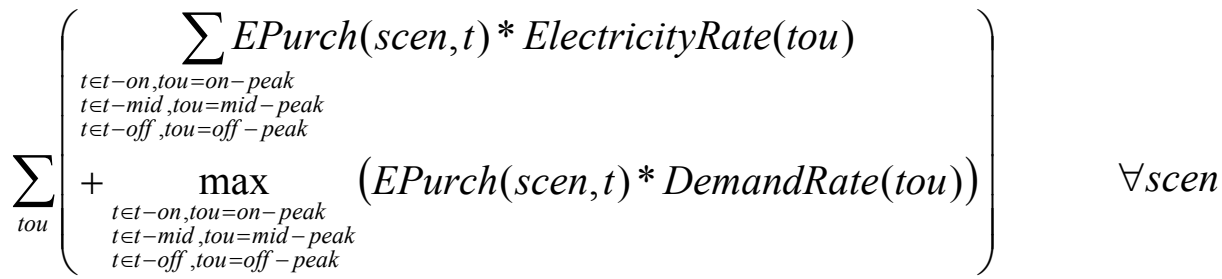

$$
\begin{aligned}
& +\max _{t}(\text { EPurch }(\text { scen }, t) * \text { DemandRateFacility }+ \text { EFixed })
\end{aligned}
$$

Natural gas costs are the sum of volumetric purchase (separate prices for general and DG service) and fixed monthly service fees.

$$
\begin{aligned}
& N G \operatorname{Cost}(\text { scen })= \\
& \sum_{t}\left(\begin{array}{l}
N G \text { forDG }(\text { scen }, t) * N G R \text { ateForDG } \\
+N G \text { forHeat }(\text { scen }, t) * N G R a t e F o r H e a t
\end{array}\right)+N G \text { Fixed } \quad \forall \text { scen }
\end{aligned}
$$

DG maintenance costs are the sum of variable $(\$ / \mathrm{kWh})$ and fixed $(\$ /$ month $)$ costs.

$$
\begin{aligned}
& D G C o s t(\text { scen })= \\
& \sum_{\text {gen }}\left(\begin{array}{l}
\sum_{t} D\left(\text { scen, }, \text { generation }- \text { level }_{\text {gen }} ", t\right) * D G \text { VarCost } \\
+ \text { DGFixed }_{\text {gen }}
\end{array}\right) \quad \forall \text { scen }
\end{aligned}
$$

Total cost for each scenario is then the sum of electricity, natural gas and DG maintenance costs.

$$
\begin{aligned}
& \operatorname{Cost}(\text { scen })= \\
& \quad \text { Electric Cost (scen })+N G \operatorname{Cost}(\text { scen })+D G \operatorname{Cost}(\text { scen }) \quad \forall \text { scen }
\end{aligned}
$$




\subsection{Capacity}

On-site generation is only allowed when the DG system is available, and must be less than or equal to the capacity of the system. Availability at each time-step and for each scenario (SPV(scen, "generation-availability",t)) is a binary variable equal to zero if the generator is unavailable and one if it is.

The decision to run each generator, gen, is a binary decision variable, $D$ (scen, “DGdispatch $\left.{ }_{g e n} ", t\right)$.

$$
\begin{aligned}
& D(\text { scen, "generation - levelgen" }, t) \leq \\
& \text { SPV(scen," generation - availabilitygen" }, t) \quad \forall \text { scen, gen, } t \\
& \text { *D(scen," DGdispatch }{ }_{\text {gen }} \text { ",t)*DGCapacity(gen) }
\end{aligned}
$$

If a generator is dispatched, generation must be above the minimum capacity of the generator.

$$
\begin{aligned}
& D(\text { scen," generation - levelgen" }, t) \geq \\
& \text { SPV(scen," generation - availabilitygen", } t) \quad \forall \text { scen, gen, } t \\
& \text { *D(scen," DGdispatch }{ }_{\text {gen }} \text {, }, \text { t) * DGMinCapacity(gen) }
\end{aligned}
$$

The absorption chiller is also constrained to operate at the rated capacity or below. 


$$
\begin{aligned}
& D(\text { scen, } " \text { AbsChiller - level" }, t) \leq \\
& \text { SPV }(\text { scen, } " \text { AbsChiller - availability" }, t) * \text { AbsCapacity } \quad \forall \text { scen }, t
\end{aligned}
$$

Minimum chiller levers are not considered, nor are multiple chillers. In future work, these details could be easily implemented in the fashion of the generator constraints.

The output from PV is constrained by the capacity of the PV system and the current solar insolation level. Note that the solar insolation parameter is expressed as the fraction of solar insolation used to rate solar electric and thermal equipment (1000 $\mathrm{W} / \mathrm{m}^{2}$ ). The inequality in Eq. (16) avoids an unallowable net exporting situation in case the PV output is greater than the site load.

$$
\begin{aligned}
& \text { PVOutput }(\text { scen }, t) \leq \\
& \quad \text { PVCapacity } * \operatorname{SPV}\left(\text { scen, }, \text { solar - insolation }{ }^{\prime}, t\right)
\end{aligned}
$$

Outages of the PV system are not considered, although could be implemented in the fashion of generator outages, or could be incorporated in the stochastic value of SPV(scen, "solar-insolation", $t)$ (i.e. set to zero to represent an outage).

The output from solar thermal collectors is constrained by the capacity of the solar thermal system and the current solar insolation level. The inequality in Eq.(17) avoids an unallowable net exporting situation in case the output is greater than the site load. 
SolarHeat $($ scen, $t) \leq$

$$
\text { SolarThermalCapacity * SPV(scen," solar-insolation" ,t) }
$$

\subsection{Curtailment}

The number of curtailment episodes per month is constrained.

$$
\sum_{t} D(\text { scen, } \text { curtail" }, t) \leq \text { CurtFreq } \quad \forall \text { scen }
$$

Each curtailment episode is constrained to a fixed duration and magnitude. Note that this equation also prevents overlapping curtailment amounts.

$$
\begin{aligned}
& \text { CurtailAmount }(\text { scen }, t+i)= \\
& \text { CurtMag* D(scen," curtail", } t) \quad \forall \text { scen, }, 0 \leq i \leq \text { CurtDuration }
\end{aligned}
$$

\subsection{Energy Balance}

Electricity loads must be met instantaneously by the sum of electricity purchase, onsite generation (including PV generation), and electric chiller load offset by heatdriven absorption chiller, and curtailment. Electric loads are separated into chiller and non-chiller loads. All curtailment is assigned to the non-chiller loads for the sake of convenience. 


$$
\begin{aligned}
& \text { SPV }(\text { scen," electric-load" }, t)= \\
& \text { EPurch }(\text { scen }, t)+\sum_{\text {gen }} D\left(\text { scen, }, \text { generation }- \text { level }_{\text {gen }}{ }^{\prime \prime}, t\right)+\text { PVOutput }(\text { scen }, t) \quad \forall \text { scen }, t \\
& + \text { AbsOffset }(\text { scen, } t)+\text { CurtailAmount }(\text { scen }, t)
\end{aligned}
$$

The electric (non-cooling) load must be met by non-cooling electricity consumption and curtailment.

$$
\begin{aligned}
& S P V\left(\text { scen, }, \text { ElectLoad }{ }^{\prime}, t\right) \leq \\
& \text { ElectForElect }(\text { scen, }, t)+\text { CurtailAmount(scen, } t) \quad \forall \text { scen }, t
\end{aligned}
$$

The electric cooling load must be met by cooling electricity and cooling-load offset provided by the absorption chiller.

$$
\begin{aligned}
& \text { SPV (scen," CoolingLoad" }, t) \leq \\
& \text { ElectForCool(scen, } t)+ \text { AbsOffset }(\text { scen }, t) \\
& \forall \text { scen, } t
\end{aligned}
$$

Electricity consumption must be balanced by electricity purchase, on-site generation, and PV output.

$$
\begin{aligned}
& \text { ElectForElect(scen,t) }+ \text { ElectForCool(scen, } t) \leq \\
& \text { EPurch (scen, }, \text { ) } \\
& +\sum_{\text {gen }} D\left(\text { scen," generation-level }{ }_{\text {gen }}{ }^{\prime}, t\right) \quad \forall \text { scen, } t \\
& + \text { PVOutput }(\text { scen }, t)
\end{aligned}
$$


Heating requirements are divided into heat needed for heating and heat needed for absorption chilling. Heating requirements must be met by DG recovered heat, natural gas combustion, and solar heat output.

$$
\begin{aligned}
& \text { HeatForCool }(\text { scen, } t)+\text { HeatForHeat }(\text { scen }, t)= \\
& \text { DGHeat }(\text { scen, } t)+N G H e a t(\text { scen }, t)+\text { SolarHeat }(\text { scen, } t)
\end{aligned} \quad \forall \text { scen,t }
$$

The absorption cooling offset is equal to the heat provided to the chiller, multiplied by the coefficient of performance (COP) of the absorption chiller, divided by the COP of the electric chiller. COP is defined as the ratio of useful heat removal to energy provided to the chiller.

$$
\operatorname{AbsOffset}(\text { scen }, t)=\frac{\operatorname{HeatForCool}(\text { scen }, t) * A b s C O P}{\operatorname{ElectCOP}} \quad \forall \text { scen, } t
$$

Heat provided by natural gas combustion is equal to the heat consumed for this purpose, scaled down by the ratio of useful to provided energy (i.e. the efficiency of fuel to useful heat conversion).

$$
\begin{aligned}
& \text { NGHeat(scen, } t)= \\
& \quad \text { NGforHeat(scen,t)*UsefulToFuelHeatRatio } \quad \forall \text { scen, } t
\end{aligned}
$$


Useful heat from DG is the product of DG electricity generation, the ratio of heat to electricity from the DG unit, and the ratio of useful to recovered heat (i.e. the heat exchanger conversion efficiency).

$$
\begin{aligned}
& \text { DGHeat }(\text { scen }, t)= \\
& \sum_{g e n}\left(\begin{array}{l}
D\left(\text { scen," generation }- \text { level }_{\text {gen }}, t\right) \\
* \text { HeatToElectRatio }(\text { gen }) \\
* \text { UsefulToRecoveredHeatRatio }
\end{array}\right) \quad \forall \text { scen, } t
\end{aligned}
$$

Heating loads must be met on a daily basis. It is assumed that tank storage is adequate to support daily asynchrony in thermal supply and demand.

$$
\left.\sum_{\mathrm{t} \in \mathrm{d}} \operatorname{SPV}(\text { scen,"heat }- \text { load", } \mathrm{t})=\sum_{\mathrm{t} \in \mathrm{d}} \text { HeatForHeat(scen, } \mathrm{t}\right) \quad \forall \mathrm{d}
$$

\subsection{CHP Efficiency}

Maintaining a minimum CHP system efficiency is common regulatory constraint for systems in order to obtain necessary operating permits or to receive government subsidies. System efficiency is typically defined as the ratio of electricity and useful heat provided by the system to fuel energy provided to the system. While this is typically an annual constraint, the current RT-OPTICOM model operates over only one month. While a year-long optimization using the formulation described here would be infeasibly large, a planning optimization - as described in Section 3.1 - that 
operates over an entire year to set system efficiency targets for each month would be useful.

Electricity generation is summed over the entire timespan. Consumption is converted from $\mathrm{kW}$ in each time-step, to $\mathrm{kWh}$ per time-step by multiplying by the ratio of minutes per time-step to minutes per hour.

$$
\begin{aligned}
& \text { TotalDGElect }(\text { scen })= \\
& \qquad \sum_{t} \sum_{\text {gen }} D(\text { scen, "electric }- \text { generategen } ", t) * \frac{\text { timestep }}{60} \quad \forall \text { scen }
\end{aligned}
$$

Useful heat is likewise summed.

$$
\text { TotalDGUsedHeat(scen } \left.)=\sum_{t} \sum_{\text {gen }} \text { DGHeat(scen, } t\right) \quad \forall \text { scen }
$$

Natural gas consumed per generator per time-step is equal to the dispatched generation level divided by the electrical conversion efficiency of the generator, multiplied by the fraction of an hour per time-step. The conversion efficiency is dependent on the level of operation of the generator. Note that this equation is nonlinear. Chapter 6 describes how this non-linearity is addressed in the linear model developed for this research. 


$$
\begin{aligned}
& \text { NGforDGPerGen }(\text { scen, gen }, t)= \\
& \frac{D(\text { scen, }, \text { generation - levelgen } ", t)}{\text { Efficiency }\left(\text { gen, } D\left(\text { scen, }, \text { generation }- \text { levelgen }^{\prime \prime}, t\right)\right)} \frac{\text { timestep }}{60} \quad \forall \text { scen, gen, } t
\end{aligned}
$$

Total natural gas consumption for DG is the sum of consumption over all time-steps and all generators.

$$
N G f o r D G(\text { scen })=\sum_{t} \sum_{\text {gen }} N G \text { forDGPerGen }(\text { scen,gen,t) } \quad \forall \text { scen }
$$

Efficiency is then defined as

$$
\begin{aligned}
& \text { CHPEfficiency }(\text { scen })= \\
& \frac{\text { TotalDGElect(scen })+ \text { TotalDGUsedHeat(scen })}{\text { NGforDG(scen })} \quad \forall \text { scen }
\end{aligned}
$$

and the CHP efficiency is constrained.

$$
\text { CHPEfficiency(scen) } \geq \text { MinCHPEffic } \quad \forall \text { scen }
$$

It is possible that none of the forecasted scenarios will preclude dispatch that will actually lead to a minimum efficiency violation. For example, none of the forecasted scenarios might predict an outage at the end of the month, during which the optimal strategy (based on the forecasted scenarios) was to run the CHP system in a highly efficient (i.e. much heat recovery) manner in order to boost the system efficiency up 
to the minimum level. To address this, at the end of the month, the site can purchase a phantom amount of useful energy for a stiff penalty price. Making the penalty price high ensures that the optimal strategy will not rely on such un-realities, yet provides a feasible solution in case the actual scenario varies significantly from forecasted scenarios. Eq. (35) describes this and is used in place of Eq. (33).

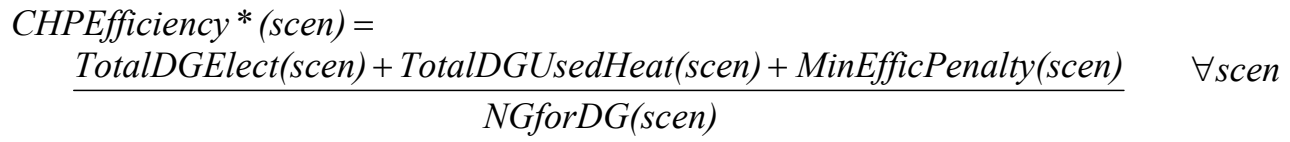

The penalty cost is then defined as

$$
\begin{aligned}
& \text { MinEfficPenaltyCost }(\text { scen })= \\
& \text { MinEfficPenalty(scen)*MinEfficPenaltyPrice } \quad \forall \text { scen }
\end{aligned}
$$

\subsection{Objective Function}

The total site expected energy cost is the average cost from each scenario, including the phantom cost for minimum CHP efficiency violation.

$$
E x \operatorname{Cost}=\frac{\left.\sum_{\text {scen }} \operatorname{Cost}(\text { scen })+\text { MinEfficPenaltyCost (scen }\right)}{S}
$$

The objective is then to minimize this expected cost. The optimal dispatch for the current time-step is contained in the solution to the minimized expected cost.

$$
D(\text { scen, } d d, t)=\operatorname{argmin}(\operatorname{ExCost}(D))
$$




\section{ADJUSTMENTS TO MODEL FOR MIXED INTEGER LINEAR PROGRAM}

Fast, powerful commercial solvers for MILPs are readily available. Provided the IES dispatch problem can be described as a reasonably sized MILP, optimal dispatch can be solved for in a reasonable amount of time ${ }^{11}$. Several of the equations in Chapter 5 must be modified to a linear form in order to pose the IES dispatch optimization problem as a MILP.

\subsection{Ceiling Level Selection}

Determining the ceiling function (i.e. the maximum permissible level of utility electricity purchase Eq. (6) ) requires the use of the maximum function, a non-linear function of the ceiling level, which is a decision variable. To avoid this, ceiling functions are generated for a set of possible ceiling levels prior to execution of optimization.

$\left(\right.$ CeilingFunction $\left._{i}(\text { scen }, t)_{)}\right)=$

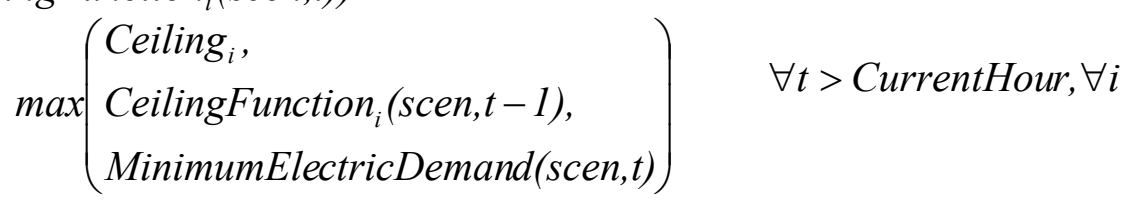

\footnotetext{
${ }^{11}$ In this case "reasonable" is less than the length of each time-step for implementation (10 to 60 minutes). However, for studies such as those included in this report, which rely on year-long simulations that make use of the optimization at each time-step, a much faster solution is required.
} 
A selection flag $\left(\right.$ flag $\left._{i}\right)$ is associated with each predetermined ceiling value (Ceiling $g_{i}$, and is considered as a binary decision variable. Only one ceiling value can be selected; the sum of flag values must be one.

$$
\sum_{i} \operatorname{flag}_{i}=1
$$

The actual, selected ceiling function is then the sum of flag values times ceiling values.

$($ CeilingFunction $($ scen,$t))=\sum_{i}\left(\right.$ flag $_{i} *$ CeilingFunction $_{i}($ scen,$\left.t)\right) \quad \forall$ scen,$t$

Finally, Eq. (7) is a valid linear expression with the only decision variables being UtilityElectricityPurchase(scen,t) on the left-hand side of the constraint and flag $_{i}$ on the right-hand side.

Eq. (39) through (41) describe the ceiling functions for the all-hours demand. There is actually a separate ceiling level selected for each billing time-of-use. For the sake of brevity, this detail is not included in the equations in this section. 


\subsection{DG Efficiency}

The expression for NG consumption by CHP equipment, Eq. (31) is non-linear. In order to be a linear expression, NG consumption, as a function of generation level, must be of the form of Eq. (42).

NGforDGPerGen $($ scen, gen,$t)=$
$\quad\left(\alpha D\left(\right.\right.$ scen,, generation - levelgen $\left.\left.{ }^{\prime \prime}, t\right)+\beta\right) \frac{\text { timestep }}{60} \quad \forall$ scen, gen, $t$

Figure 3 illustrates typical efficiency curves for reciprocating engines and microturbines. Figure 4 converts these graphs into plots of generation level versus total fuel consumption (normalized by the capacity of the generator). These plots are essentially linear, and the selection of $\alpha$ and $\beta$ does not compromise any accuracy in the model ${ }^{12}$. This analysis is done for each piece of equipment modeled to determine the unique $\alpha$ and $\beta$ values.

${ }^{12}$ Many fuel cells have concave, non-monotonic efficiency curves (i.e. the maximum efficiency is not at 100\% load). The method described here for expressing part-load efficiency would not be valid for fuel cells. 

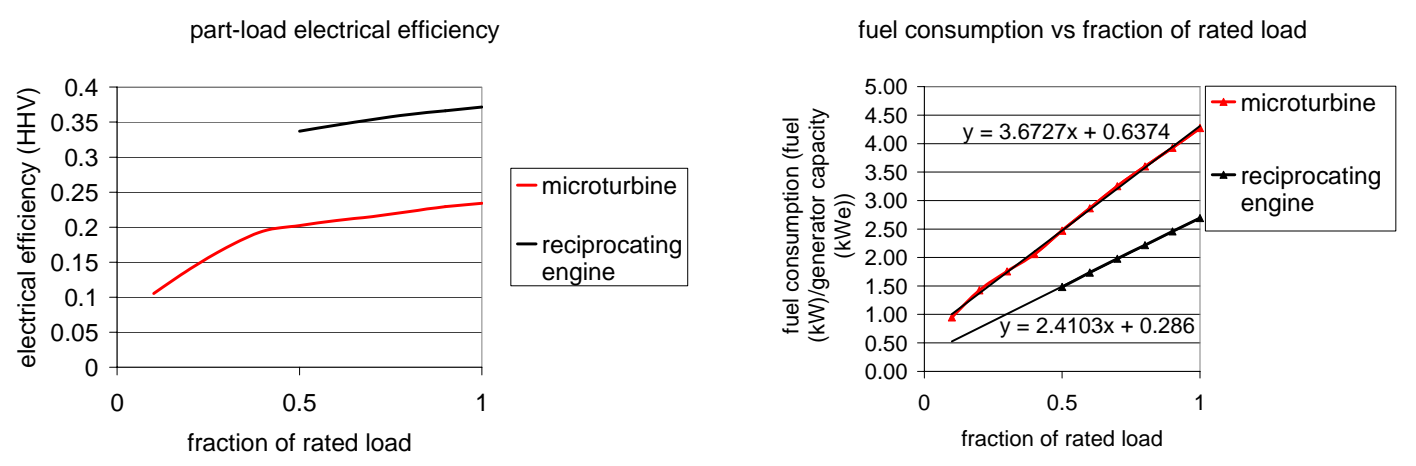

data source: Energy Nexus Group (2002)

and Caterpillar (2006)

Figure 3. typical part load efficiency

Figure 4. typical part load fuel consumption

\subsection{Demand Charges}

Demand charges, as expressed in Eq. (8) and (9), are a function of the maximum utility electricity purchase over the course of the month. This is not a linear function. Maximum functions can often be replaced by a series of greater-than constraints. In this case, Eq. (8) is replaced by

$$
\text { AssessedDemand(scen) } \geq \text { Ceiling }_{i} * \text { flag }_{i} \quad \forall \text { scen }
$$

and

$$
\text { AssessedDemand(scen }) \geq \text { EPurch(scen, } t)) \quad \forall \text { scen, } t
$$

AssessedDemand is associated with cost in the objective function; therefore there is incentive to set this variable as low as possible. However, Eq. (43) and (44) and prevent the assessed demand variable from being set any lower than is technically 
possible. The result is that the assessed demand is forced to be exactly what it actually is. 


\section{PART 3: RT-OPTICOM APPLICATION: THE UNITED STATES POSTAL SERVICE PROCESSING AND DISTRIBUTION CENTERS}

The validation of this tool will be in the process of answering several previously unanswered questions:

- To what extent are the heuristic control strategies employed for CHP systems sub-optimal, i.e. to what extent could more intelligent controls improve site objectives?

- What is the value of an integrated approach to site energy dispatch decisions?

- For dispatch decisions, what is the trade-off between cost minimization and carbon emissions minimization?

The United States Postal Service Processing and Distribution Centers (P\&DCs) were selected as a case study for this research. These light-industrial sites serve as regional interfaces between post offices and the postal transport network, sorting and routing millions of pieces of mail per day using energy intensive machinery. P\&DCs are fairly similar across regions; their energy-situations vary by climate-driven thermal loads, local energy prices, and emissions from electricity production, but not by schedule or machinery load.

RT-OPTICOM is used to study P\&DCs from several regions, and several tariff structures in each region, illustrating the usefulness of such a general model while 
answering the questions posed here. Chapter 7 describes the P\&DCs and the data collection and modeling used for this study. Chapter 8 describes the experiments conducted and presents their results. Chapter 9 draws conclusions from these results. 


\section{SITE DESCRIPTION, DATA COLLECTION, AND MODELING}

The United States Postal Service (USPS) operates nearly 300 Processing and Distribution Centers (P\&DCs) across the United States. P\&DCs serve as the interface between post offices and the postal transport network. These sites process millions of pieces of mail collected from the region each day, using a sophisticated array of machines to align pieces of mail, optically scan addresses, and sort mail by region. Similarly, incoming mail from other regions is automatically arranged by post office, and in most cases arranged in delivery-route-order of individual mail carriers. The machinery is energy-intensive, with sites typically having peak electric loads of approximately 1-3 MW. The tremendous amount of heat given off by the machinery makes for large cooling loads, even on days of mild temperature. The relatively flat energy profile and significant space conditioning loads make P\&DCs good candidates for DER.

P\&DCs offer a rare opportunity for industrial building energy research because they are federal, rather than private, buildings. Most private buildings contacted by the author for this project would not release detailed energy consumption data, and in general considered most information about their buildings proprietary. This lack of access to actual energy consumption data limits the scope of much building energy research. P\&DCs, on the other hand, are not limited by competition concerns, but only by security concerns. As well, the USPS has regional offices actively pursuing 
energy and energy-cost savings ${ }^{13}$, which encourage research that might benefit their sites.

\subsection{Site Description}

For this research, detailed energy consumption data from the USPS Margaret L.

Sellers P\&DC in San Diego, California was used to develop models of P\&DCs in four energy-distinct ${ }^{14}$ regions of the United States. The $50,000 \mathrm{~m}^{2}$ facility receives, sorts, and routes all outgoing mail in the San Diego region, as well as receiving and routing all incoming mail to the region. In all, it handles approximately 12 million pieces of mail daily. The site has a night-time peak electricity load of approximately 2 MW. The site's loads are dominated by the large, numerous mail-handling machines, which in turn necessitate a significant cooling load. The year-round moderate climate and consistent machine loads result in a year-round cooling demand. Figure 5 shows an aerial view of the site. Figure 6 shows machinery at the similar Redlands, CA P\&DC.

${ }^{13}$ Executive Order 13123, issued by President Clinton in June 1999, mandates federal buildings to reduce energy consumption per square foot by 30 percent by 2005 and by 35 percent by 2010, relative to a 1985 baseline. The Energy Policy Act of 2005 further mandates that a 2003 baseline be used and reductions of 2 percent per year be achieved in each year from 2006 to 2015.

${ }^{14}$ The term "energy-distinct" is used here to distinguish regions with different climates, energy prices, and emissions from grid electricity. 


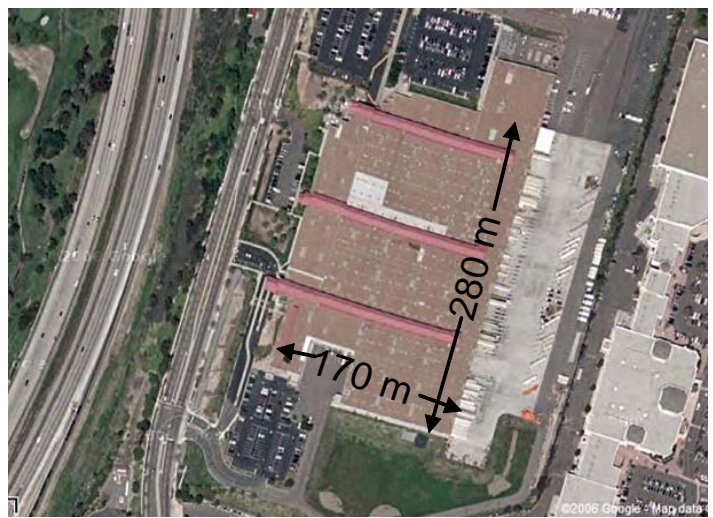

source: Google Maps

Figure 5. aerial view of the San Diego P\&DC

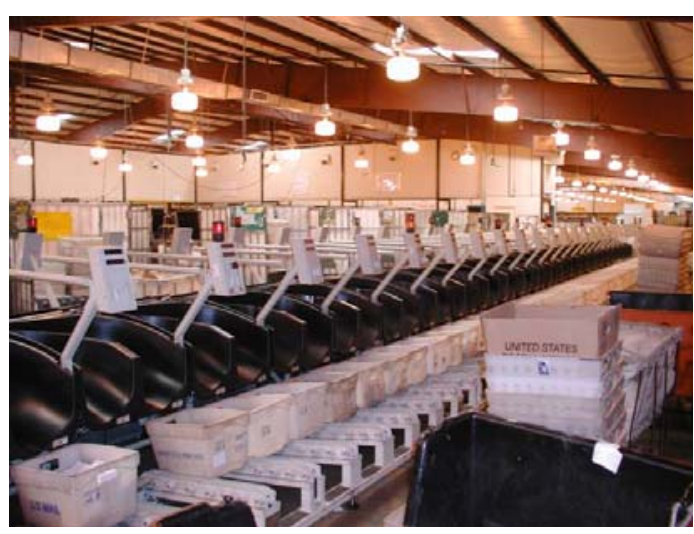

Figure 6. inside the Redlands, CA P\&DC

A DER system was recently installed at the site. The system consists of a 1.5 MW natural gas fired reciprocating engine coupled to a $1 \mathrm{MW}$ (300 ton) absorption chiller. The chiller offsets the sites electric compression chiller load by $250 \mathrm{~kW}$ at rated capacity. Additionally, $12 \mathrm{~kW}$ of PV are installed at the site. Photographs of DG equipment (Figure 7 through Figure 10) and the site rooftop (Figure 11) are shown below. Note the white roof and numerous sky-lights in Figure 11.

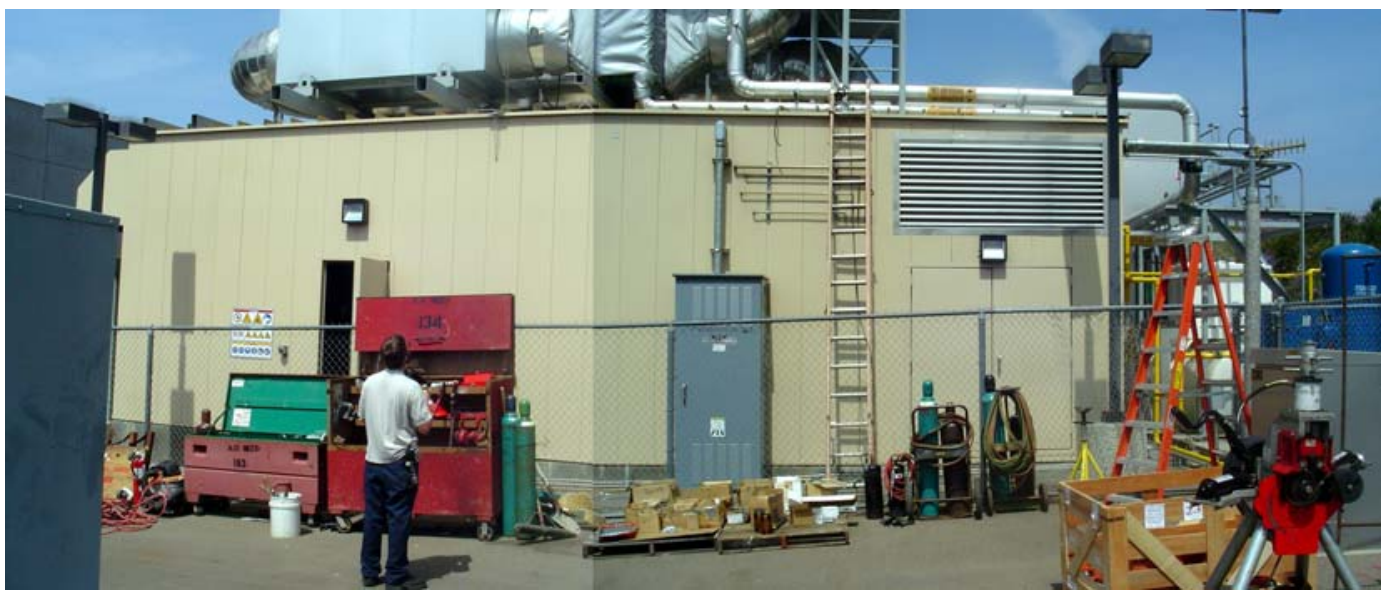

Figure 7. generator housing at the San Diego P\&DC 


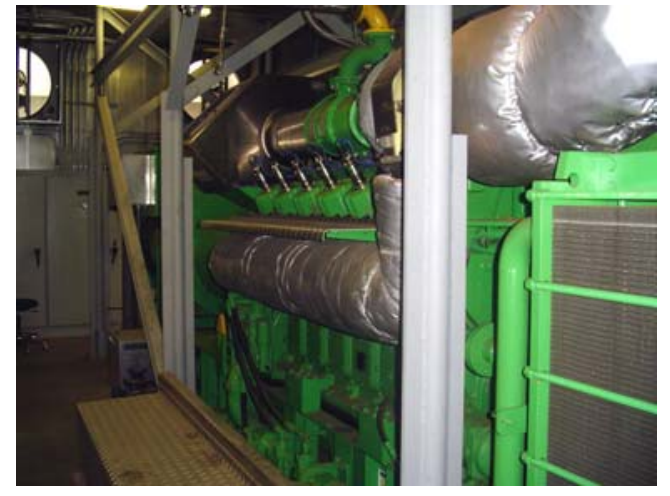

Figure 8. General Electric Jenbacher 1.5 MW reciprocating engine installed at the San Diego P\&DC

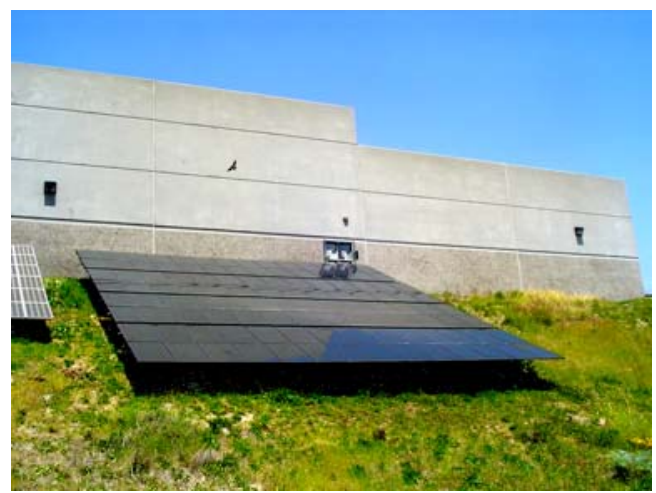

Figure 10. one of two photovoltaic arrays $(\sim 6 \mathrm{~kW})$ at the San Diego P\&DC

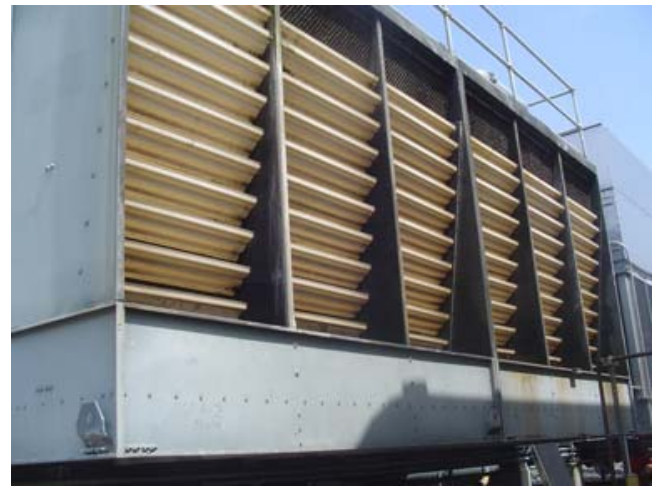

Figure 9. cooling tower for chillers at the San Diego P\&DC

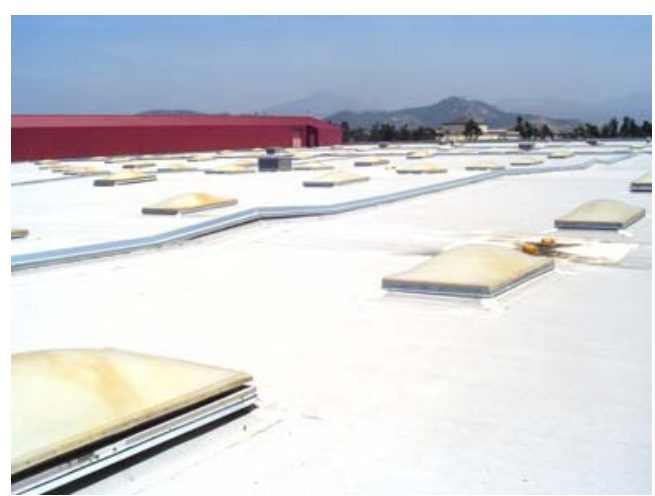

Figure 11. rooftop at the San Diego P\&DC

The CHP equipment is owned and operated by a third party. Electricity and heat from the CHP system are provided from the third party to the site at lower cost than San Diego Gas and Electric (SDG\&E), the local utility, provides. The CHP system uses a load-following control i.e., the generator is run as high as possible at all times. One objective of this research is to examine economic efficiency of this load- 
following control strategy by comparing energy costs from a load-following strategy to those from an optimal dispatch control strategy.

An additional objective is to examine the results and character of optimal control under other tariff structures. Critical peak pricing (CPP) tariffs are already an optional tariff from the utility. Debate over real-time pricing (RTP) tariffs continues and could possibly be offered or imposed in the near future.

P\&DC sites across the United States have similar machines, building design, and operating schedules. The most significant differences in energy consumption at similarly sized P\&DC sites across the United States are due to climactic differences. The San Diego site was studied in detail to understand the non-cooling electric loads - which would not vary by location - and to correlate space conditioning loads to weather and electric loads. This information was then used to develop building energy simulation models of P\&DCs in four United States cities: San Diego, CA, Baltimore, MD, Boston, MA, and Houston, TX.

\subsection{Data Collection and Modeling}

Experiments for this study examined the years 2004 to 2006, for which actual energy prices, temperature, and solar insolation were collected and used. Temperature and solar insolation data from 1961 to 1970 were also collected and used to develop the stochastic scenarios. 


\subsubsection{Site Energy Consumption}

Disaggregated electric loads (non-cooling and cooling) were desired, because noncooling loads are assumed to be independent of P\&DC location and climate, and cooling loads can be correlated to non-cooling loads and weather data. Disaggregated load data were not directly available; however, total electric load data from the San Diego site were obtained, and the building energy simulation software eQUEST (James J. Hirsch and Associates 2007) was used to develop a model of a California P\&DC, starting with the eQUEST default values for a climate-controlled storage facility, and adjusting occupancy, load (machine, lighting, office equipment), HVAC, and building shell data to best describe the P\&DC. The model was calibrated so that total electric load data (average daily profile and monthly total consumption) matched the total electric load data provided by the site ${ }^{15}$. This process is described below and is illustrated in Figure 12. This model was then adjusted to the three other cities (by increasing the insulation in Boston and Baltimore models) and used to determine energy loads for the hypothetical P\&DCs in these cities, including heating and cooling loads.

The following cooling load model was assumed:

${ }^{15}$ Days in which electricity purchase dipped below $1500 \mathrm{~kW}$ in any hour were not used in this analysis: it was assumed that the generator and absorption chiller were running during these hours, and no disaggregated data on generator output was available. 
CoolingLoad $(m, t)=$

$$
\beta_{C 0}+\beta_{C l} \operatorname{TotalLoad}(m, t)+\beta_{C 2} \operatorname{CoolingDegrees}(m, t)+\beta_{C 3} \operatorname{Daylight}(m, t)+\mu
$$

where

- $\boldsymbol{m}$ is the month $\{1,2, \ldots, 12\}$

- $\boldsymbol{t}$ is the hour of the month $\{1,2, \ldots[$ number of hours in the month $]\}$

- CoolingLoad is the amount of electricity required to provide the desired amount of air cooling

- TotalLoad is the total electric load reported by the eQUEST model

- CoolingDegrees is the number of degrees (Fahrenheit) above $65^{\circ} \mathrm{F}$ that the outdoor air temperature is, or zero if the temperature is below $65^{\circ} \mathrm{F}$

- Daylight is a binary variable set to one if $t$ is a daylight hour, zero if not $\{0,1\}$

An ordinary least squares (OLS) regression was performed to determine the $\beta_{\mathrm{C}}$ values. This model was then used to determine the cooling load from the actual site data, given the actual total electric consumption for the site and the outdoor temperatures. Finally, for the actual site total electric loads and corresponding temperature data, 1) the actual site cooling loads were determined from Equation (46) and 2) non-cooling loads were determined as the difference between total electric loads and cooling loads. This was done for every hourly data point.

The following non-cooling load model was assumed: 


$$
\begin{aligned}
& \text { NonCoolingLoad }(m, t)= \\
& \quad \text { AvgNonCoolingLoad }(m, h(t), d t(t)) * \text { DailyRand }(d(t))+\text { HourlyRand }(t)
\end{aligned}
$$

where

- $\boldsymbol{m}$ is the month $\{1,2, \ldots, 12\}$

- $\boldsymbol{t}$ is the hour of the month $\{1,2, \ldots$ [number of hours in the month] $\}$

- $\boldsymbol{h}(\boldsymbol{t})$ is the hour of the day of hour $t\{1,2, \ldots, 24\}$

- $\boldsymbol{d t}(\boldsymbol{t})$ is the day-type of the day that hour $t$ is in \{weekday, Sunday\}

- $\boldsymbol{d}(\boldsymbol{t})$ is the day of the month that hour $t$ is in $\{1,2, \ldots$, [number of days in the month]\}

- NonCoolingLoad is the non-cooling electric load determined by Equation (46)

- DailyRand is normally distributed random variable with an mean value of 1

- HourlyRand is a normally distributed random variable with a mean value of 0

This model assumes that energy consumption follows a fairly regular daily pattern (AvgNonCoolingLoad) because the site's operations and use of equipment do not vary significantly. DailyRand is used to scale consumption up or down for particular days to model the variability in volume of mail handled from day to day within a month; in reality, this variation is largely explained by typical commercial practices (e.g. what day of the week companies tend to send out particular types of mail) and proximity to holidays such as Christmas and Valentine's Day and other high mail-volume events. 
HourlyRand is used to introduce volatility to the smoothed (averaged) profile, to account for random variations in operations from hour to hour.

Using the assumption that the sum of HourlyRand values for each day was equal to zero, the value of DailyRand was determined for each day as the ratio of actual daily non-cooling consumption $(\mathrm{kWh})$ to average daily non-cooling consumption. Then, Equation (46) was used to determine the HourlyRand value for each hour. For each month, the mean, variance, minimum, and maximum values of DailyRand and HourlyRand were determined.

Non-cooling electric loads for the experiments in this project were randomly generated using the AvgNonCoolingLoad data previously determined and randomly generated values of DailyRand (a different value for each day) and HourlyRand (a different value for each hour). DailyRand and HourlyRand were normally distributed pseudo-random numbers generated in Matlab, using the mean and variance parameters determined above. Random values were truncated at the minimum and maximum values determined above.

For consistency, the same non-cooling electric load data were used for all four sites. Cooling loads for the four sites were determined from Equation (45) using the randomly generated non-cooling loads, and the city-specific temperature.

The following heating load model was assumed: 
$\operatorname{HeatingLoad}(m, t)=$

$$
\beta_{0}+\beta_{H 1} \text { TotalLoad }(m, t)+\beta_{H 2} \text { HeatingDegrees }(m, t)+\beta_{H 3} \operatorname{Daylight}(m, t)+\mu
$$

where

- $\boldsymbol{m}$ is the month $\{1,2, \ldots, 12\}$

- $t$ is the hour of the month $\{1,2, \ldots$ [number of hours in the month] $\}$

- TotalLoad is the total electric load reported by the eQUEST model

- HeatingDegrees is the number of degrees (Fahrenheit) below $65^{\circ} \mathrm{F}$ that the outdoor air temperature, or zero if the temperature is above $65^{\circ} \mathrm{F}$

- Daylight is a binary variable set to one if $t$ is a daylight hour, zero if not $\{0,1\}$

An OLS regression was performed on the eQUEST data for each of the four sites to determine the $\beta_{\mathrm{H}}$ values. The randomly generated non-cooling loads, coupled with the actual temperature data for each city were then used to generate the heating loads.

This procedure was used to randomly generate complete site load data for three actual years (2004 to 2006) and ten years of stochastic scenario data (using weather data from 1961 to 1970$)$.

Figure 12 illustrates the information flow, starting from P\&DC site detail and the eQUEST default model and leading to the cooling and heating load model parameters. The feedback loop on the top left of the figure was used to calibrate the 
eQUEST San Diego P\&DC model to the San Diego P\&DC actual electric load data.

This calibrated eQUEST model was then used at the base from which to model

hypothetical P\&DC sites in the other cities considered. Figure 13 illustrates the

information flow from San Diego P\&DC total electric load data and temperature data

to non-cooling model parameters. By removing temperature dependent electricity

loads (i.e. air conditioning), the remaining non-cooling load model was valid for all

four cities.

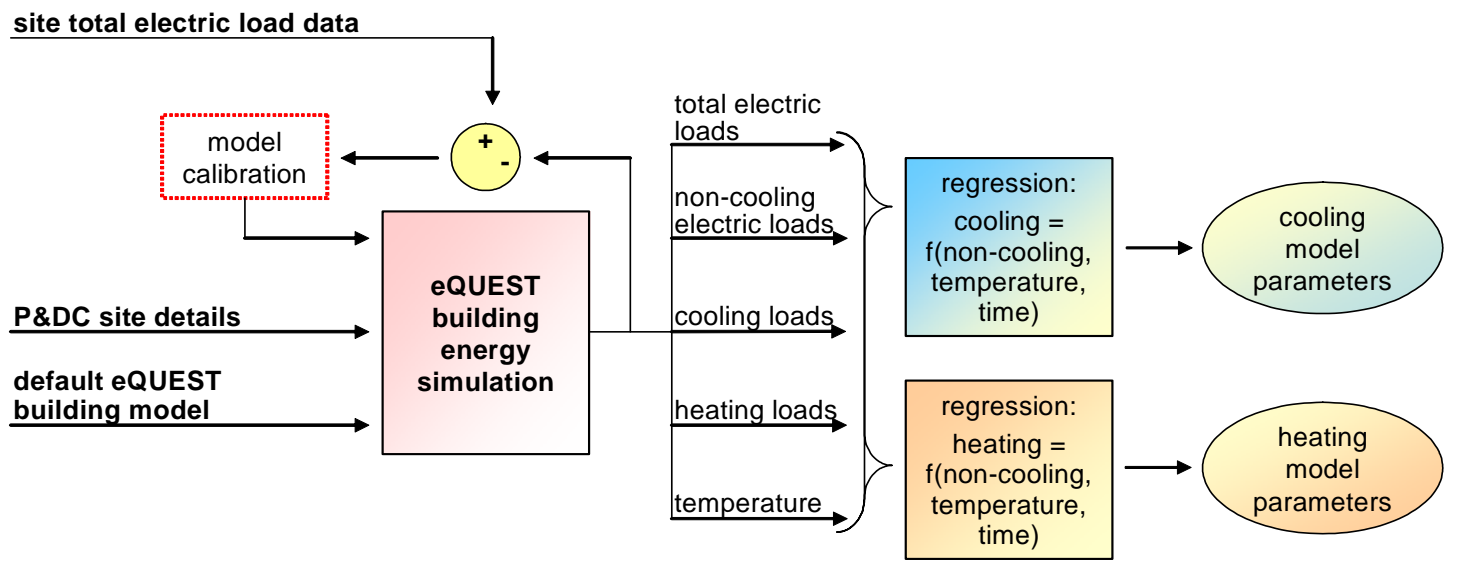

Figure 12. schematic of cooling and heating load model parameter determination

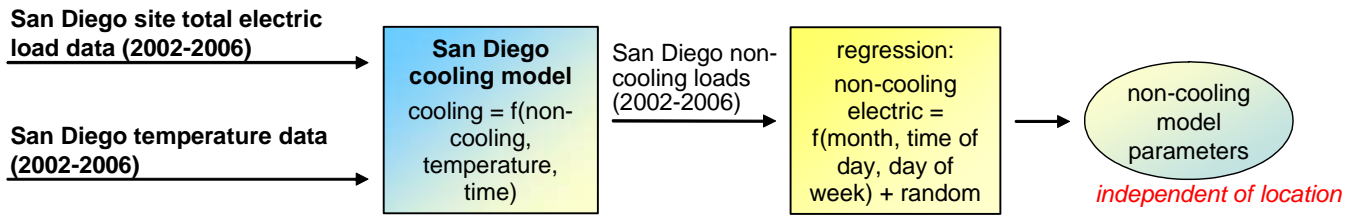

Figure 13. schematic of non-cooling electric load model parameters 


\subsubsection{Solar Insolation Data}

Hourly solar insolation data for the ten stochastic scenario model years (1961 to 1970) were obtained from the Renewable Resources Data Center at NREL (RReDC 2007). Data for the actual years considered (2004 to 2006) could not be found average daily profiles from the 1961 to 1970 data were used instead. For a site with more sizeable solar energy harvesting, this averaging would not be appropriate. However, for this particular site, the $12 \mathrm{~kW}$ photovoltaic system provides, at most, about $0.5 \%$ of the site's electric load. Including the stochastic solar insolation in the model is mostly a placeholder for future studies targeted at renewables, for which the only modification to this work would be to update the solar data for the actual years considered.

\subsubsection{Temperature Data}

Daily maximum and minimum temperature data for 1961 to 1970 and 2004 to 2006 were obtained from the Weather Underground online weather query service (Weather Underground, 2007). Hourly temperatures were estimated assuming a sinusoidal daily temperature pattern with maximum temperature at 4 p.m. and minimum temperature at 4 a.m. 


\subsubsection{Electricity Tariff Data}

\subsubsection{Time of Use}

Electricity tariff data were collected from the utilities serving the four cities studied. The general service primary voltage time-of-use tariff for customers with peak loads of $2.5 \mathrm{MW}$ was obtained for each city:

- Baltimore - Baltimore Gas and Electric Company, Schedule P: primary voltage, demand greater than $1500 \mathrm{~kW}$ (BGE 2007a)

- Boston - NSTAR Electric, Rate G-3: primary voltage (NSTAR 2007)

- Houston - Reliant Energy Retail Services, Large General Service, (PUCT 2007)

- San Diego - San Diego Gas and Electric Company, Schedule AL-TOU-DER, (SDG\&E 2007a)

Tariffs are generalized into the following information

- summer months

- winter months

- on-, mid-, and off- peak hours for summer and winter months

- fixed costs $(\$ /$ month $)$

- TOU volumetric costs $(\$ / \mathrm{kWh})$, variable by time of use and by month

- TOU demand charges $(\$ / \mathrm{kW})$, variable by time of use and by month

- non-coincident demand charges $(\$ / \mathrm{kW})$, variable by month 
The state-specific relative change in average electricity cost $(\$ / \mathrm{kWh})$ to industrial customers from year to year, as reported by the Energy Information Agency (EIA 2007a) was used to scale the volumetric and demand charge portions of data for years in which actual tariff data was not available ${ }^{16}$. TOU rates for 2004 for all four cities are shown in Table 12 through Table 15.

Table 12. electricity rates for Baltimore, 2004

2004 Electricity Rates - Baltimore

\begin{tabular}{|r|c|c|}
\hline & summer & winter \\
\hline Fixed (\$/month) fee & \multicolumn{2}{|c|}{750} \\
\hline Volumetric (\$/kWh) rates \\
\hline on-peak & 0.087 & 0.071 \\
\hline mid-peak & 0.069 & 0.062 \\
\hline off-peak & 0.060 & 0.051 \\
\hline Demand (\$/kW) rates \\
\hline all-hours & 1.85 & 1.85 \\
\hline on-peak & - & - \\
\hline mid-peak & - & - \\
\hline off-peak & - & - \\
\hline
\end{tabular}

Table 13. electricity rates for Boston, 2004

2004 Electricity Rates - Boston

\begin{tabular}{|r|c|c|}
\hline & summer & winter \\
\hline Fixed (\$/month) fee & 237 \\
\hline Volumetric (\$/kWh) rates \\
\hline on-peak & $0.078-0.086$ & $0.066-0.083$ \\
\hline mid-peak & $0.078-0.086$ & $0.066-0.083$ \\
\hline off-peak & $0.078-0.086$ & $0.066-0.083$ \\
\hline Demand (\$/kW) rates \\
\hline all-hours & - & - \\
\hline on-peak & 16.12 & 11.55 \\
\hline mid-peak & - & - \\
\hline off-peak & - & - \\
\hline
\end{tabular}

Table 14. electricity rates for Houston, 2004

2004 Electricity Rates - Houston

\begin{tabular}{|r|c|c|}
\hline & summer & winter \\
\hline Fixed (\$/month) fee & \multicolumn{2}{|c|}{480} \\
\hline Volumetric (\$/kWh) rates \\
\hline on-peak & 0.067 & 0.040 \\
\hline mid-peak & 0.067 & 0.040 \\
\hline off-peak & 0.067 & 0.040 \\
\hline Demand (\$/kW) rates \\
\hline all-hours & 11.06 & 5.03 \\
\hline on-peak & - & - \\
\hline mid-peak & - & - \\
\hline off-peak & - & - \\
\hline
\end{tabular}

Table 15. electricity rates for San Diego, 2004

2004 Electricity Rates - San Diego

\begin{tabular}{|r|c|c|}
\hline & summer & winter \\
\hline Fixed (\$/month) fee & \multicolumn{2}{|c|}{194} \\
\hline Volumetric (\$/kWh) rates \\
\hline on-peak & 0.104 & 0.104 \\
\hline mid-peak & 0.078 & 0.078 \\
\hline off-peak & 0.066 & 0.066 \\
\hline Demand (\$/kW) rates \\
\hline all-hours & 10.16 & 10.16 \\
\hline on-peak & 4.41 & 3.48 \\
\hline mid-peak & - & - \\
\hline off-peak & - & - \\
\hline
\end{tabular}

${ }^{16}$ For example, if on-peak demand charges were $\$ 10.00 / \mathrm{kW}$ in the 2006 tariffs and the EIA reported that the average electricity cost was 2\% less in 2005 than in 2006, then the 2005 on-peak demand charge would be $\$ 9.80$. 


\subsubsection{Critical Peak Pricing}

Southern California Edison (SCE), the neighboring utility to the north of SDG\&E, offers an optional general service CPP tariff (SCE 2007). Hypothetical CPP tariffs for all four cities were modeled as TOU tariffs, with the volumetric prices adjusted by a different multiple for winter hours, non-event summer on-, mid-, and off-peak hours, and event summer hours (12:00 PM to 3:00 PM as critical moderate peak and 3:00 PM to 6:00 PM as critical high peak). These multiples were determined by comparing the SCE TOU and CPP tariffs; the resulting multiples are reported in Table 16. Note that on- and mid-peak volumetric rates are discounted during noncritical times by a factor of 0.9 and on-peak volumetric rates are increased by a factor 2.3 during critical moderate peak periods and a factor of 5.9 during critical high peak periods.

Table 16. ratio of CPP to TOU volumetric prices for SCE 2005

2005 ratio of CPP to TOU volumetric prices

\begin{tabular}{|l|c|}
\cline { 2 - 2 } \multicolumn{1}{c|}{} & ratio \\
\hline noncritical on-peak hours & 0.9 \\
\hline noncritical mid-peak hours & 0.9 \\
\hline noncritical off-peak hours & 1 \\
\hline critical moderate peak ${ }^{\star \star *}$ & 2.3 \\
\hline critical high peak & 5.9 \\
\hline
\end{tabular}

*there are a maximum of six critical episodes per month

**there are a maximum of 12 critical episodes per year

***moderate peak is from 12:00 PM to 3:00 PM

**** high peak is from 3:00PM to 6:00 PM

\subsubsection{Real-time Prices}

City specific hourly averaged real-time clearing price for 2004 to 2006 were collected from the following sources. 
- Baltimore - PJM Interconnection clearing prices, compiled by Suez Energy Resources, NA (2007)

- Boston - ISO-NE (2007)

- Houston - ERCOT (2007)

- San Diego - CAISO (2007)

For each city, a mean-reverting Brownian motion model, as described in Deng (2000), was fit to this data. The mean prices at each hour of the year, required for this technique were the expected price for the given month, hour of the day, day-type (weekday or weekend), cooling degrees (degrees above $65^{\circ} \mathrm{F}$ ), and heating degrees (degrees below $65^{\circ} \mathrm{F}$ ). This process is described in 0 . For stochastic scenario years (1961 to 1970) these mean-reversion models were used to generate stochastic price scenarios for the actual years 1961-1970.

Hypothetical RTP tariffs were constructed by using spot-market clearing prices, TOU fixed and demand charges, and adding a cost-neutral distribution adder $(\$ / \mathrm{kWh})$ to the clearing price. This follows the model of the mandatory RTP tariff for large customers (peak demand $>2 \mathrm{MW}$ ) that the Niagara Mohawk utility in upstate New York imposes (National Grid 2007), in which distribution costs (volumetric and demand based) are added to the day-ahead forecast of zonal clearing prices. The principal of rate-neutrality, by which a utility's revenue for a typical customer is independent of the tariff structure (e.g. the utility would expect the same revenue 
from the same customer under either TOU or RTP tariff) was used to determine the appropriate volumetric distribution adders to the clearing prices for the four cities considered through the following process:

1. determine the electricity purchase for 2004 to 2006 with no-DG

2. determine site electricity costs for 2004 to 2006 with no-DG under the TOU tariff

3. determine the site electricity costs for 2004 to 2006 with no-DG under the RTP tariff and a $\$ 0.00 / \mathrm{kWh}$ distribution adder value

4. determine the average $\$ / \mathrm{kWh}$ price of electricity for the TOU and RTP cases

5. set the distribution adder value to the difference between the average price under TOU and RTP cases

\subsubsection{Natural Gas Prices}

Current natural gas prices (during 2006) were collected from the local utilities ${ }^{17}$ (BGE 2007b, Keyspan Energy 2007, SDG\&E 2007b). Data from the U.S. Energy Information Agency (EIA 2007b) for city gate natural gas prices in each state were added to current distribution costs to estimate historic natural gas prices. For each month long simulation/optimization, the price of natural gas was assumed to be constant and deterministic. Natural gas prices can be volatile; Figure 14 plots these prices for January 2004 through December 2006, along with the average California

${ }^{17}$ EIA end-use industrial prices were used for Houston, because local delivery costs could not be found. 
retail industrial electricity price, as reported by the EIA. The ratio of electricity to natural gas price is also plotted, to illustrate the volatility of this ratio, or spark spread, which has ranged from 1.96 to 4.31 in three years. Given that DG converts natural gas to electricity, optimal dispatch must be responsive to the relative fluctuations in these two commodities' prices.

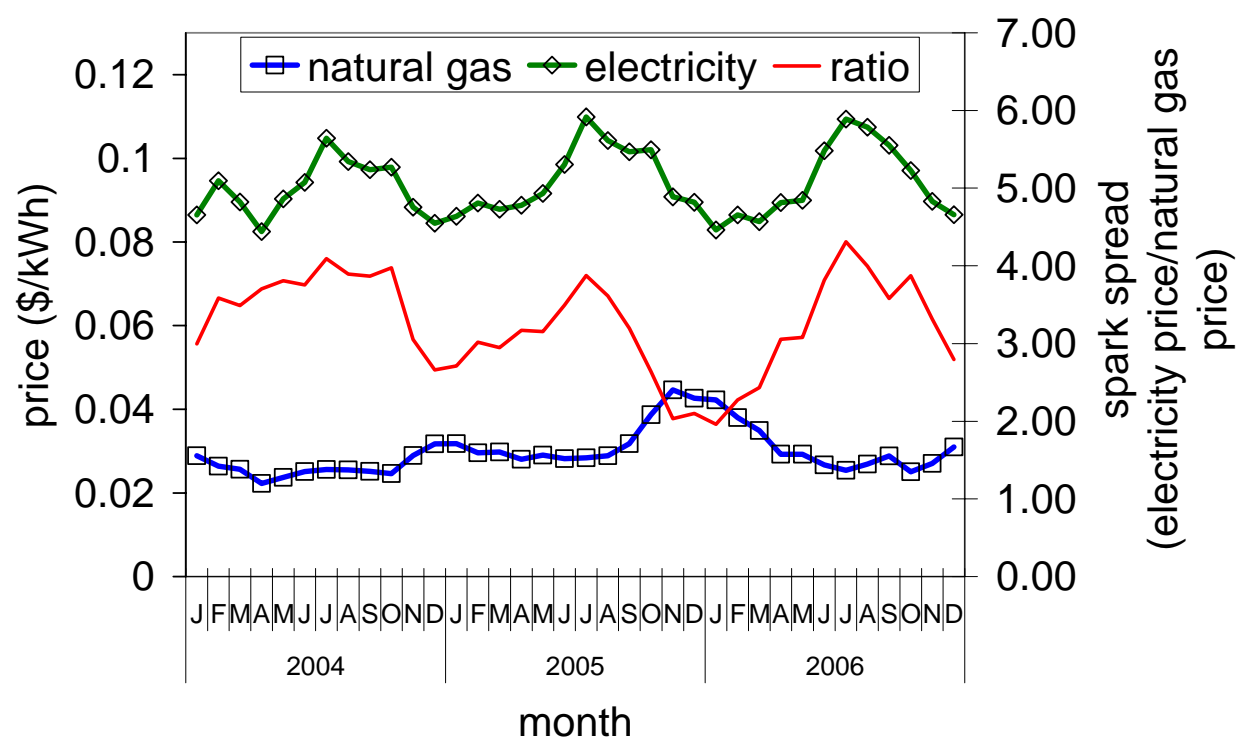

source: EIA

Figure 14. electricity and natural gas prices for January 2004 to August 2006 and the ratio of electricity to natural gas price

\subsubsection{Carbon Emissions}

Region-specific carbon emissions rates were obtained from The Climate Trust (2005).

Regions are the 27 U.S. sub-regions defined by the National Energy Reliability Council (NERC). Emissions rates are reported as a grid intensity factor: the evenly weighted average of the marginal grid carbon emissions and the marginal build 
(average emissions of newly built marginal plants). This is a proxy for the true marginal emissions factors, which are difficult to determine. Table 17 states these factors for the four regions of interest in this research.

Table 17. grid carbon intensity factors

\begin{tabular}{|l|c|c|c|}
\multicolumn{1}{c|}{} & \multicolumn{2}{c|}{ grid intensity factor } \\
city & $\begin{array}{c}\text { NERC sub- } \\
\text { region }\end{array}$ & $\begin{array}{c}\text { (metric tons } \\
\text { CO2/MWh) }\end{array}$ & (kg C / kWh) \\
\hline Baltimore & MACC & 0.617 & 0.168 \\
\hline Boston & NEWE & 0.545 & 0.149 \\
\hline Houston & ERCT & 0.548 & 0.149 \\
\hline San Diego & CALI & 0.493 & 0.134 \\
\hline
\end{tabular}

source: The Climate Trust (2005)

\subsubsection{Generator Availability}

A Markov process is used to model generator availability, as demonstrated by Borgonovo, Marseguerra, and Zio (2000). At each time-step that the equipment is available, there is a less than unity probability, $p_{o}$, that the equipment will be available at the next time-step. Likewise, if equipment is unavailable at the current time-step, there is a less than unity probability, $p_{x}$, that the equipment will remain unavailable at the next time-step. The subscripts $o$ and $x$ refer to the "available" and "unavailable" states, respectively. This describes a hybrid system in which, at each time-step, equipment is in one of two states - available or unavailable - with some probability of switching to the other state. The model will result in some brief outages (to represent grid line faults that that the system protectively turns off during) 
and some longer outages (to represent equipment failures that require manual servicing).

Figure 15 illustrates the Markov model. $p_{o}$ and $p_{x}$ can be derived from commonly cited parameters: expected availability (portion of hours generator is available), $A$, and expected outage length, $E_{x}$. These expressions are show in Equations (48) and (49).

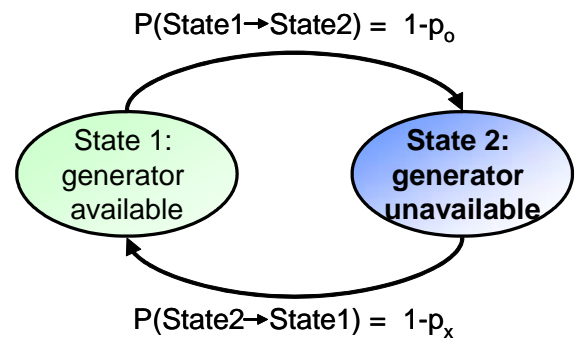

Figure 15. two-state Markov model of generator availability

$$
\begin{gathered}
p_{x}=\frac{E_{x}}{1+E_{x}} \\
p_{o}=\frac{A E x}{1-A+A E_{x}}
\end{gathered}
$$

This model predicts sustained generator outages of varying lengths, which reflects

field experience, where unexpected outages can vary in length (from a few minutes to a few weeks) depending on the type of outage and maintenance availability circumstances. 
More detailed Markov models could be developed in which there are separate "unavailable" states for different categories of failures. Such categories might include

- Grid fault: The generator trips off because of a fault on the grid (voltage or frequency variations); This is technically not a "failure" because the generator is designed to do this, and can typically be restarted soon after the fault. This type of outage typically last minutes to hours.

- Component failure, replacement on-hand: The generator fails because a part or group of parts fails. A service technician visits the site and replaces the component(s). This type of outage typically lasts hour to days, depending on the specifications of the service contract, and technician availability and proximity.

- Component failure, replacement must be ordered: The generator fails because of component failure and the service technician must order replacement parts. This type of outage typically last days to weeks.

Until more detailed information about generator availability is available for this specific site, a model more detailed than the two-state model is not warranted.

Stochastic availability histories for the actual years studied (2004 to 2006) and the stochastic scenario years $(1961-1970)$ were generate using the two-state Markov 
model by generating uniformly distributed pseudo-random numbers in Matlab at successive time-steps to determine when state switches occurred. 


\section{RT-OPTICOM EXPERIMENTS}

Three experiments were conducted using RT-OPTICOM and P\&DC data sets. These experiments were intended to demonstrate to capabilities of RT-OPTICOM and begin to explore some pertinent open questions concerning DG and demand response. The three experiments were

1. a valuation of optimal DG control under various tariff structures

2. a valuation of demand side management options with and without DG

3. a co-optimization of cost and carbon emissions using DG

All experiments were conducted on all four cities and under all three tariff structures to provide insight into the effects of energy-situation on results.

\subsection{Optimal Control Valuation}

One of the early questions that motivated this research project was of what value a sophisticated dispatch optimization - relative to standard heuristic controls - would be for a DG system. To explore this question, simulation of the P\&DC sites for each month from January 2004 to December 2006 was conducted under four control strategies

- no-DG - The generator and absorption chiller are not run, showing site behavior prior to DG installation.

- load-following - The generator is run as much as possible, mimicking the site's current strategy. 
- heat-following - The generator is dispatched to run at a level for which all recovered heat will be useful to the absorption chiller and space-heating.

- optimal dispatch - The full optimization program is used to make dispatch decisions.

For the optimal dispatch strategy, the stochastic scenarios, as described in Chapter 4, were based on actual data from 1961-1970.

The simulations were repeated for each of the three tariff structures (TOU, CPP, and RTP). All input data were consistent across tariff structure and control strategy. The availability data and non-cooling electric loads used for the actual years (2004 through 2006) and the stochastic scenarios (represented by years 1961 to 1970) were the same across location, tariff, and control strategy. Cooling and heating loads for each location were determined by the non-cooling loads and the local weather (Section 7.2.1). Actual clearing prices for each location were used for the actual years, and the location and weather dependent stochastic model of clearing prices was used to generate the clearing price stochastic scenarios (Section 7.2.4.3). These clearing prices were then used to determine the CPP episode days - the six highest priced weekdays in each of the summer months. Actual solar insolation data for each of the stochastic scenario years were used, and historic average data were used for the actual years (Section 7.2.2).

Table 18 summarizes the input required for each 36 month simulation. 
Table 18. input required for each simulation

\begin{tabular}{|l|c|c|c|}
\hline input data & \multicolumn{2}{|l|}{ specific to... } \\
location & $\begin{array}{c}\text { tariff } \\
\text { structure }\end{array}$ & $\begin{array}{c}\text { control } \\
\text { strategy }\end{array}$ \\
\hline \hline non-cooling loads & & & \\
\hline cooling loads & $\mathrm{x}$ & & \\
\hline heating loads & $\mathrm{x}$ & & \\
\hline grid carbon intensity & $\mathrm{x}$ & & \\
\hline $\begin{array}{l}\text { tariff seasons and time- } \\
\text { of-use hours }\end{array}$ & $\mathrm{x}$ & & \\
\hline electricity prices & $\mathrm{x}$ & $\mathrm{x}$ & \\
\hline natural gas prices & $\mathrm{x}$ & & \\
\hline control strategy & & & $\mathrm{x}$ \\
\hline
\end{tabular}

\subsubsection{Monthly Energy Costs}

Monthly energy costs (electricity and natural gas) for the site are plotted in Figure 16 through Figure 19. Each figure plots these prices under each control strategy for each of the three tariff structures.

\subsubsection{Baltimore}

Figure 16 plots the monthly energy prices for Baltimore. For 2004 through 2005 (months 1 through 24) under TOU and CPP tariffs, there is not a significant difference in monthly energy cost from any of the control strategies until the natural gas price spike of winter 2005. Here, the optimal strategy approximates the no-DG strategy. Later, in 2006, as natural gas prices subside and electricity prices increase, the optimal strategy approximates the load-following strategy. Note that the heat and load-following strategies have similar results because much of the waste-heat is useful - the two strategies converge when all of the waste-heat is useful. Under RTP 
tariff, however, the optimal control strategy is clearly lower cost than any of the other control strategies. This intuitive result shows that when pricing becomes more complex, heuristic control strategies become less effective.
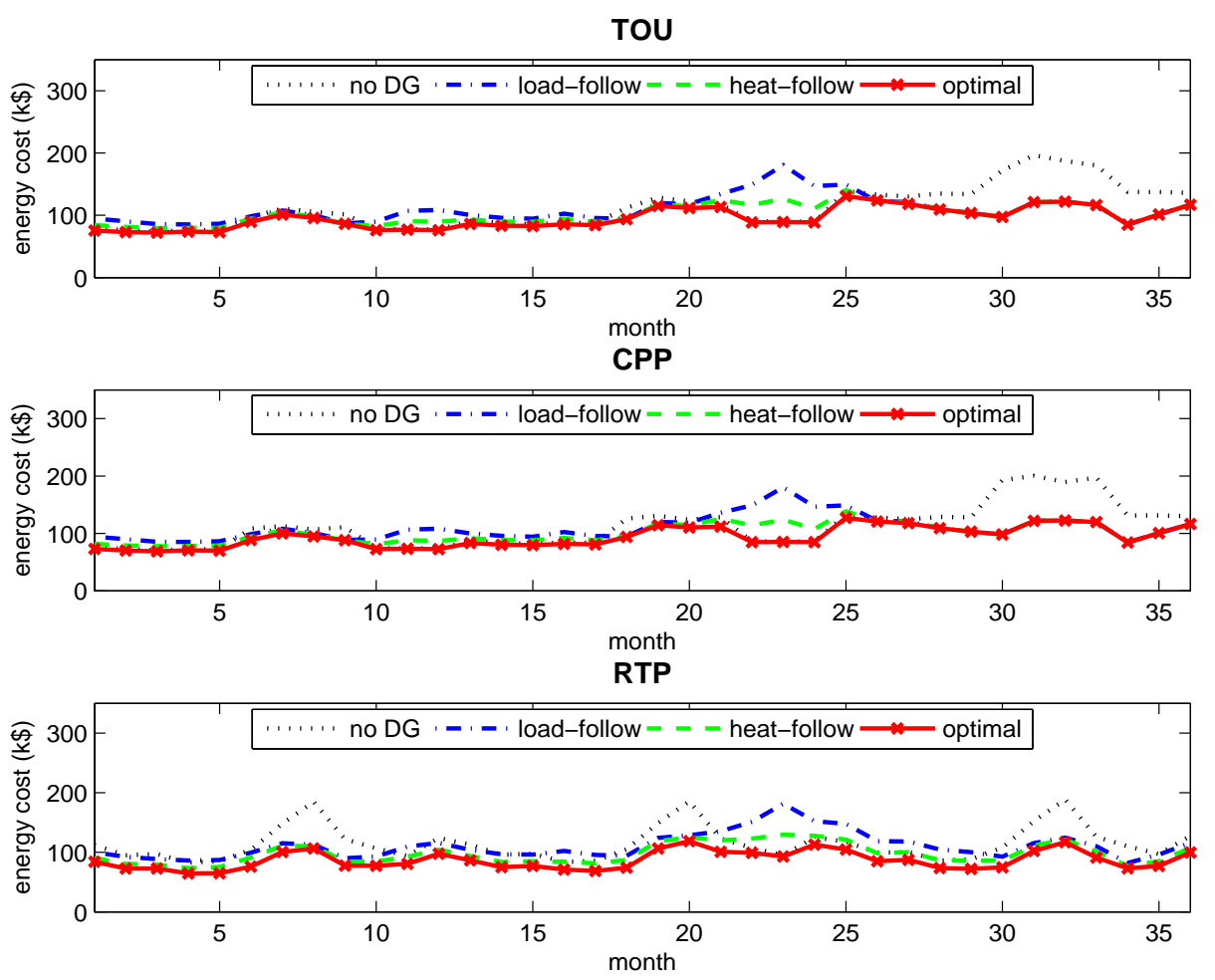

Figure 16. Baltimore - monthly energy costs under all tariffs and control strategies 


\subsubsection{Boston}

Figure 17 plots the monthly energy prices for Boston. Here again, the optimal solution for the TOU and CPP tariffs is approximately a selection between one of the three heuristic strategies. During most of 2004 and 2005, the optimal control strategy was approximately no-DG, whereas in 2006 , the optimal control strategy was approximately to heat- or load-follow. As in Baltimore, under RTP tariff, optimal control provides lower cost in many months than any of the heuristic strategies.
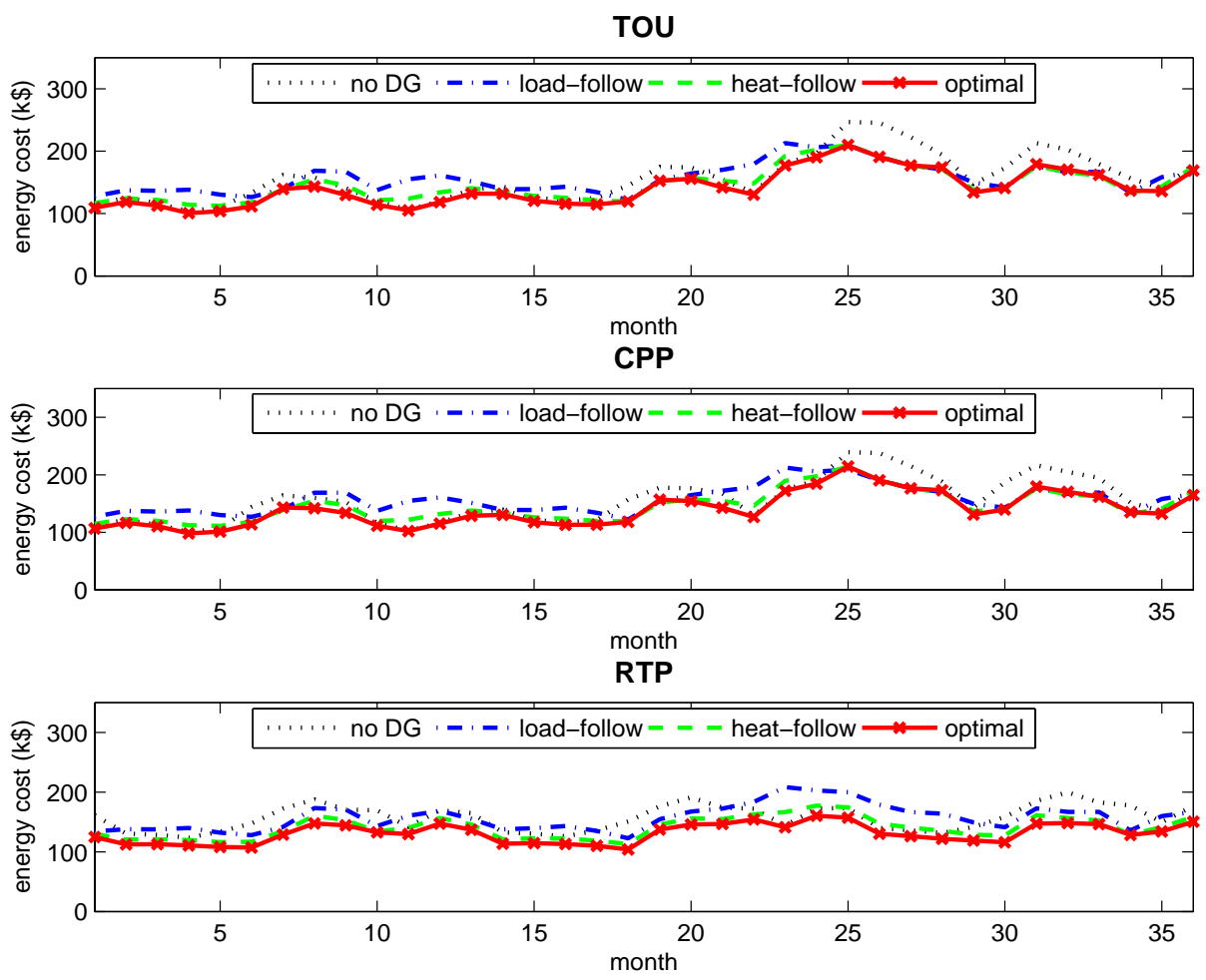

Figure 17. Boston - monthly energy costs under all tariffs and control strategies 


\subsubsection{Houston}

Figure 18 plots the monthly energy prices for Houston. As in Baltimore and Boston, optimal control under TOU and CPP tariffs is approximately a decision between noDG and load-following or heat-following. Here there is a clear seasonal pattern: during summer months using as much DG as possible is cost-effective, whereas during winter months, using DG is about as cost-effective as not using DG. The RTP results are similar to the TOU and CPP results.
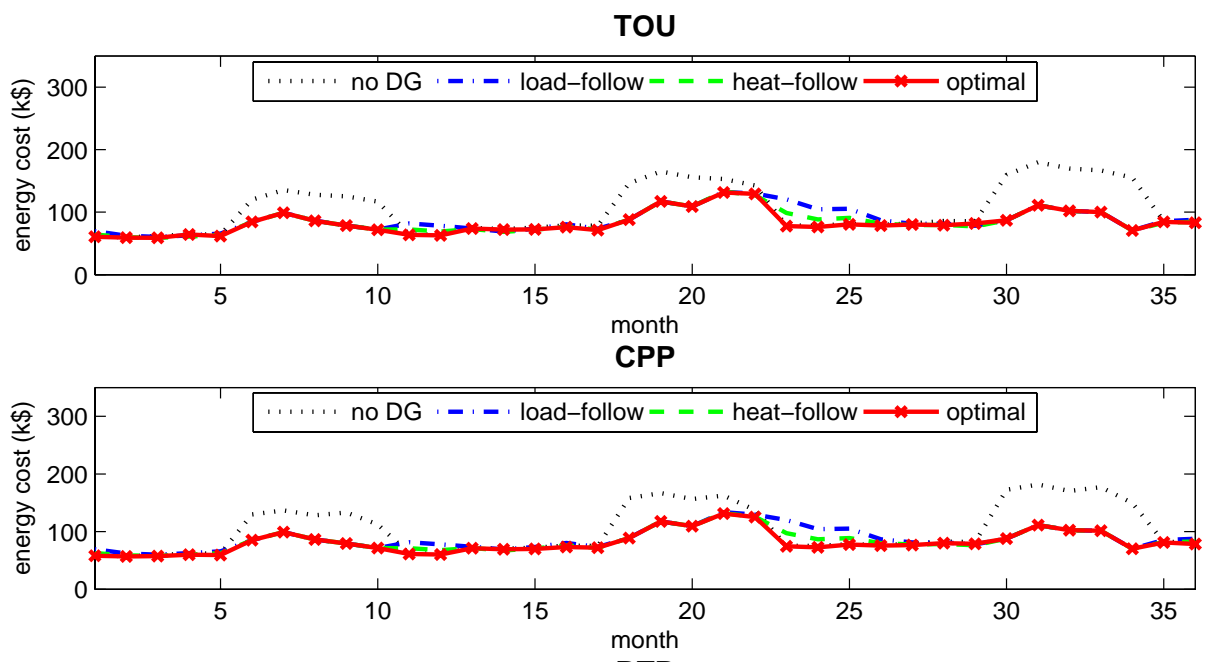

RTP

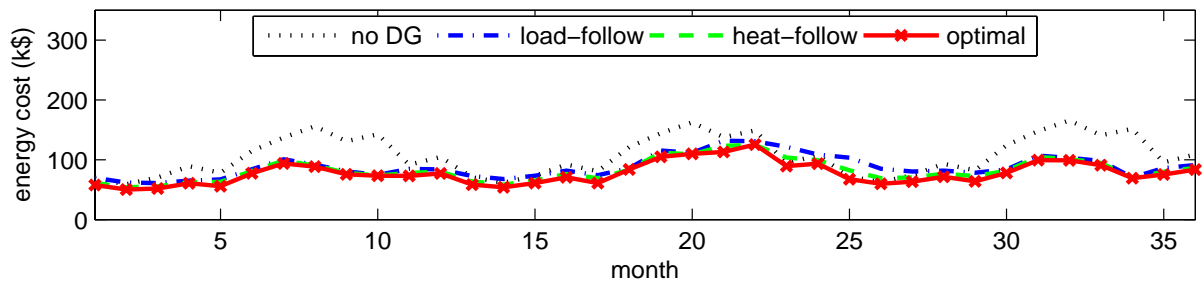

Figure 18. Houston - monthly energy costs under all tariffs and control strategies 


\subsubsection{San Diego}

Figure 19 plots the monthly energy prices for San Diego. In almost all months, under all tariffs, the optimal control strategy is approximately load-following. However, during the natural gas price spike of winter 2005, under TOU and CPP tariffs, turning off the DG was the optimal control strategy.
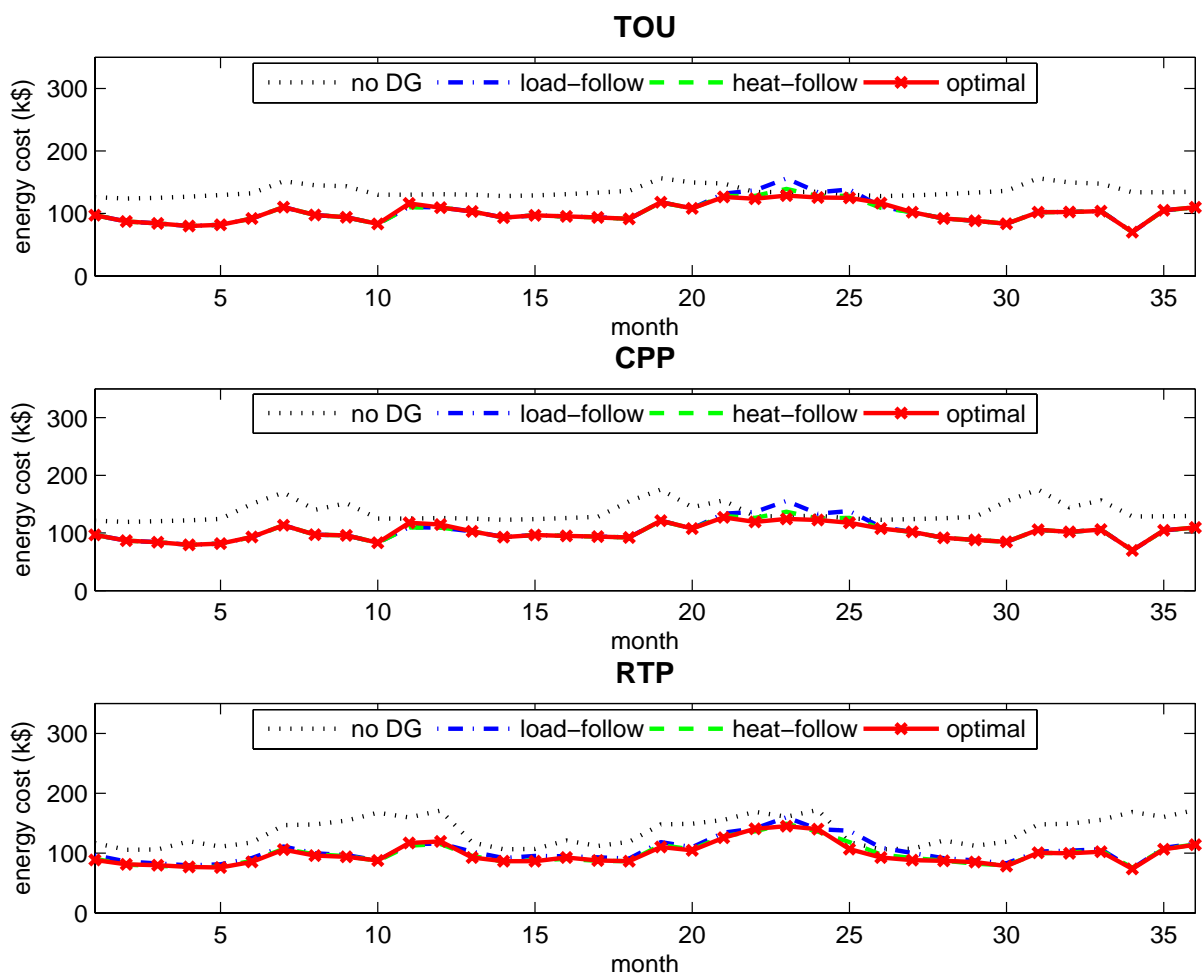

Figure 19. San Diego - monthly energy costs under all tariffs and control strategies 


\subsubsection{Annual Energy Costs}

Figure 20 through Figure 27 summarize the average annual energy costs and energy cost savings (over no-DG dispatch) over the three years considered under each of the three tariff structures. For a site considering DG, these values could be used to determine if the investment in DG is economic, given the cost of a proposed DG system. For a site with DG, these results could be used to determine if the investment in sophisticated cost-minimizing controls is economic. Note that in all cities, under all tariffs, heat-following is a more cost-effective control strategy than loadfollowing. Results for individual years (2004 through 2006) are provided in Appendix D.

For reference, the turnkey capitol cost of a 1.5 MW engine and $1 \mathrm{MW}$ (300 ton) absorption chiller like those installed at the San Diego P\&DC is approximately $\$ 3,000,000$ to $\$ 4,000,000$ (using data from US-EPA 2007 and Firestone 2004) ${ }^{18}$. Assuming a 5\% discount rate and 20 year lifetime, this is an annualized cost of $\$ 230,000$ to $\$ 310,000 /$ year. Annual savings greater than this suggest profitable circumstances. Where subsidies for CHP systems are available, DG may be profitable at lower levels of annual savings. At these estimated annualized costs, only the San Diego site would be an economically attractive site for CHP.

${ }^{18}$ No financial details of the actual San Diego installation were revealed to the author. These cost estimates are based on publicly available reviews of CHP cost and performance. 


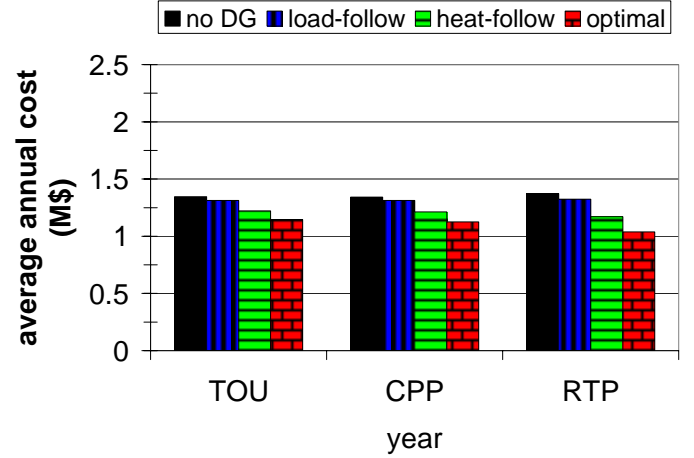

Figure 20. Baltimore - average annual energy costs under all control strategies

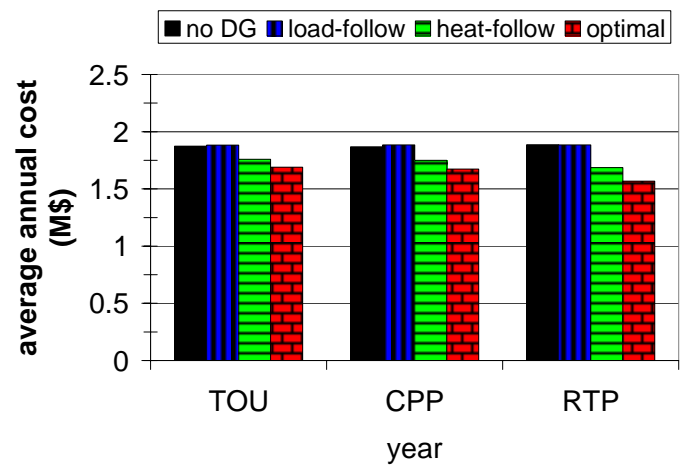

Figure 22. Boston - average annual energy costs under all control strategies

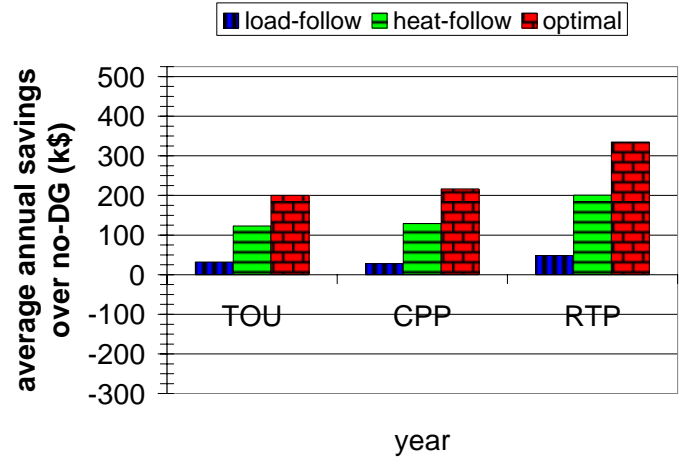

Figure 21. Baltimore- average annual savings over no-DG case under all other control strategies

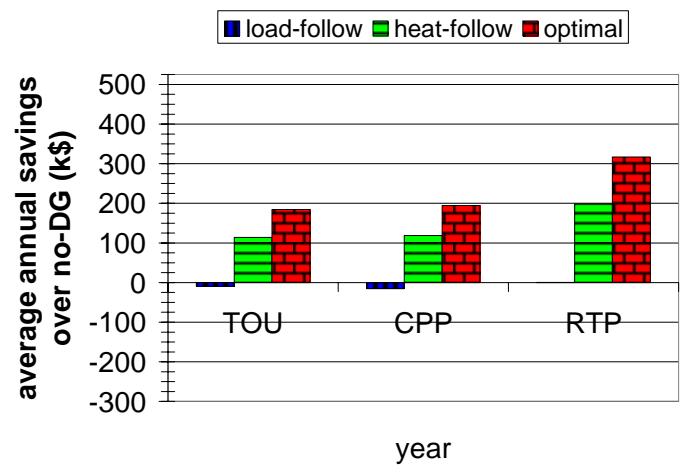

Figure 23. Boston- average annual savings over no-DG case under all other control strategies 


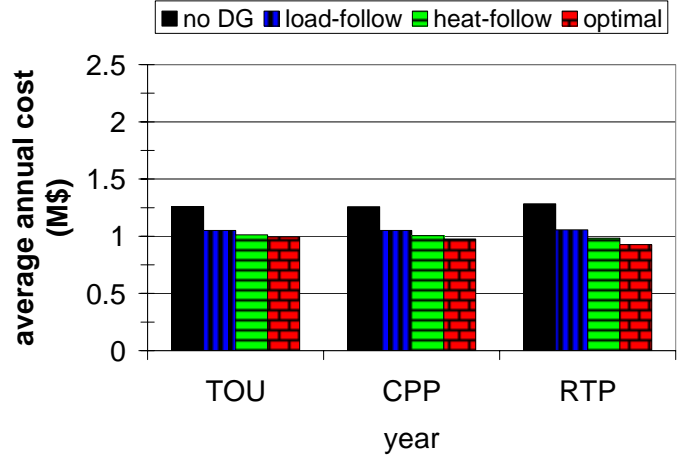

Figure 24. Houston - average annual energy costs under all control strategies

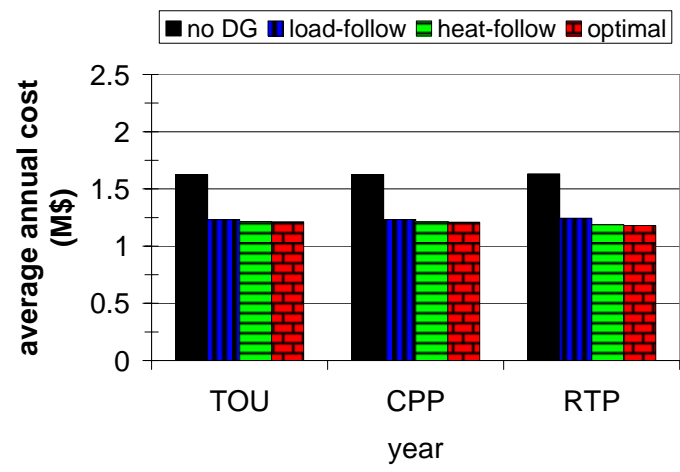

Figure 26. San Diego - average annual energy costs under all control strategies

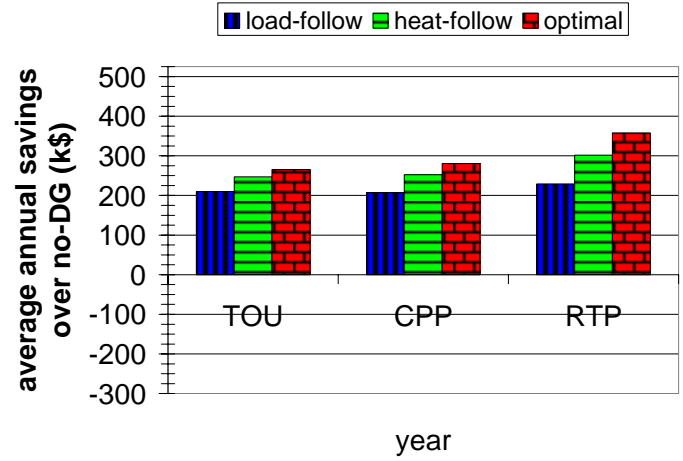

Figure 25. Houston- average annual savings over no-DG case under all other control strategies

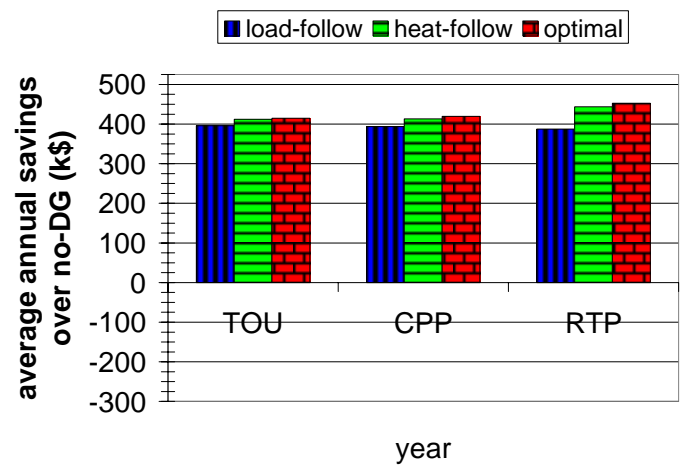

Figure 27. San Diego- average annual savings over no-DG case under all other control strategies

Table 19, a summary of Figure 20 through Figure 27, answers the first question of this chapter - what the value of intelligent controls is - by reporting the difference in annual energy costs between an optimally controlled system and a heat-following system. For Baltimore and Boston, under TOU and CPP tariffs, intelligent control is worth approximately $\$ 70,000$ to $\$ 90,000$ /year. As seen in Figure 16 and Figure 17 , much of this value could be captured by simply identifying which months to operate the system, and which not - strongly a function of electricity prices, natural gas 
prices, and the use for waste heat. Interestingly, in Baltimore and Boston, a DG system would have no value if it were strictly controlled by load-following (Figure 21 and Figure 23). For these cities, the value of intelligent control under RTP tariff increases to $\$ 134,000 /$ year and $\$ 118,000 /$ year respectively. Price responsiveness under RTP cannot be approximated by a time-based schedule, as it can under TOU and CPP tariffs. Given the value of intelligent control in Baltimore and Boston, it would almost certainly be cost-effective to install intelligent controls at these sites, although much of the value of such controls could be achieved through a control scheme much simpler than RT-OPTICOM.

The value of intelligent control in Houston is not as compelling - $\$ 19,000, \$ 28,000$ and $\$ 57,000$ per year under the TOU, CPP, and RTP tariffs, respectively. However, at these values, control intelligence is possibly still worthwhile. In San Diego, however, heat- and load-following strategies capture almost all of the benefit of DG, and intelligent control adds only a few thousand dollars per year in benefits.

Table 19. the value of optimal control: average annual difference in energy costs $(\mathrm{k} \$ / \mathrm{a})$ between optimally controlled and heat-following systems

\begin{tabular}{|l|c|c|c|}
\hline & TOU & CPP & RTP \\
\hline \hline Baltimore & 77 & 87 & 134 \\
\hline Boston & 71 & 75 & 118 \\
\hline Houston & 19 & 28 & 57 \\
\hline San Diego & 3 & 6 & 9 \\
\hline
\end{tabular}




\subsubsection{Supply of Electricity}

Figure 28 through Figure 75 show how electricity demand is met by utility purchase and site equipment for the months of January 2004, July 2004, and November 2005. January 2004 and July 2004 were selected as typical winter and summer months respectively. November 2005 was selected because natural gas prices were unusually high, making DG dispatch less (entirely in some cases) economic. In each set of four figures, the first three illustrate where electricity is supplied from in the first full week (Monday - Sunday) of the month.

The fourth figure plots the offset of utility electricity purchase (from DG and cooling offsets from absorption cooling) using optimal control under each of the three tariffs. The hours are ordered from hour of lowest RTP to highest RTP - note that the RTP prices are only seen by the optimization under the RTP tariff (directly) and the CPP tariff (indirectly through critical episodes). In these figures the real-time price is plotted on the right vertical axis and the electricity offset under the three tariffs is plotted on the left vertical axis. A 20-hour rolling average is used to smooth the RTPordered consumption plots. Under RTP, the site is responding to the fluctuations in price, producing significant demand elasticity

Commentary is provided underneath each set of four figures to mention the factors contributing to the optimal dispatch patterns, such as the relative prices of electricity and natural gas and the climate-driven use of waste heat for heating or cooling. 


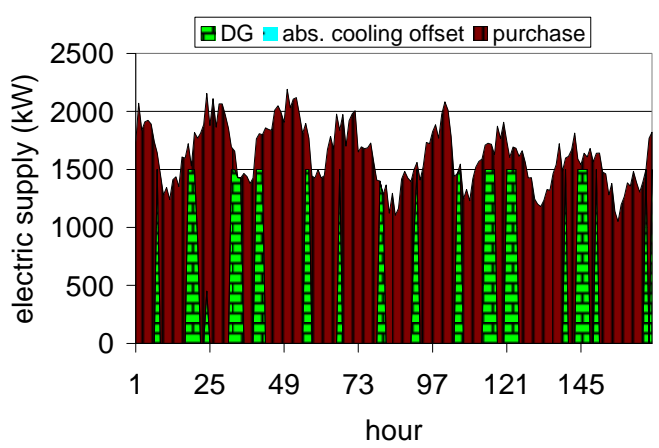

Figure 28. Baltimore - TOU - January 2004 - electricity supply for the first week of the month

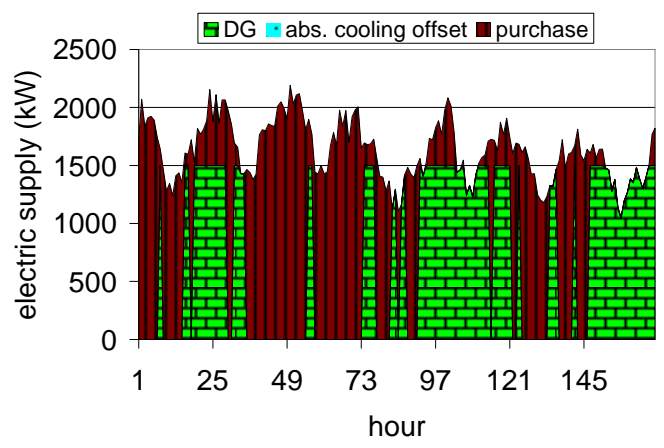

Figure 30. Baltimore - RTP - January 2004 - electricity supply for the first week of the month

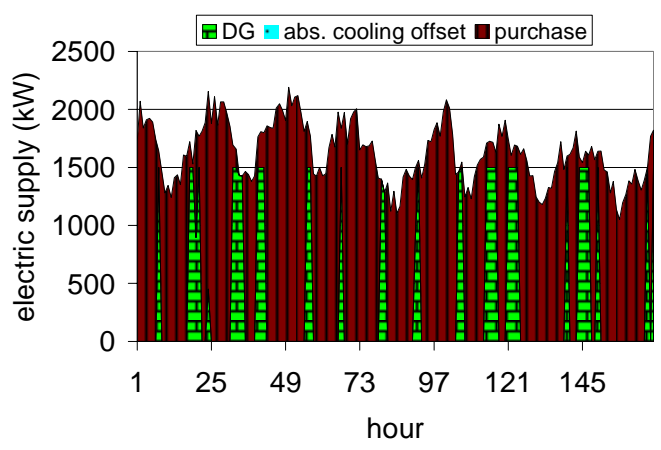

Figure 29. Baltimore - CPP - January 2004 - electricity supply for the first week of the month

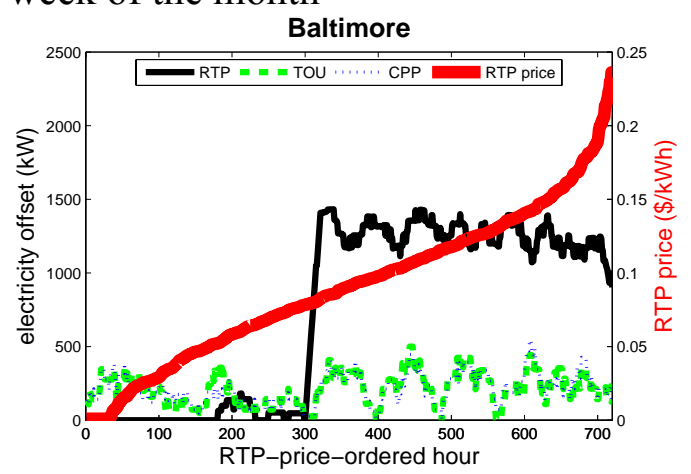

Figure 31. Baltimore - January 2004 electricity purchase by hour, ordered from least to highest RTP

In January 2004 in Baltimore, TOU and CPP electricity prices were low enough to make most DG dispatch uneconomic. However, the actual clearing prices were high enough in more than half of the hours (see Figure 31) to incent DG operation under RTP. 


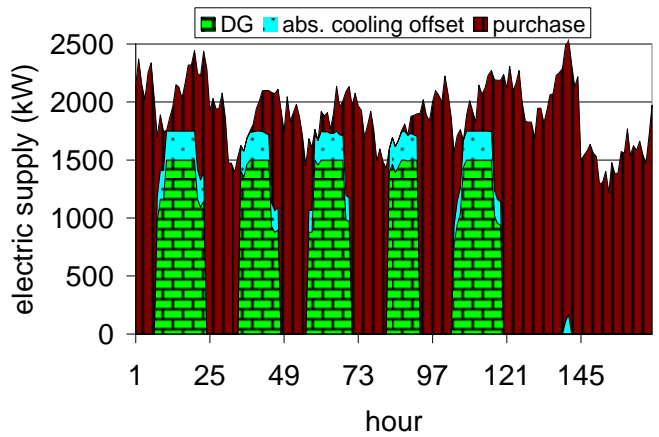

Figure 32. Baltimore - TOU - July 2004 - electricity supply for the first week of the month

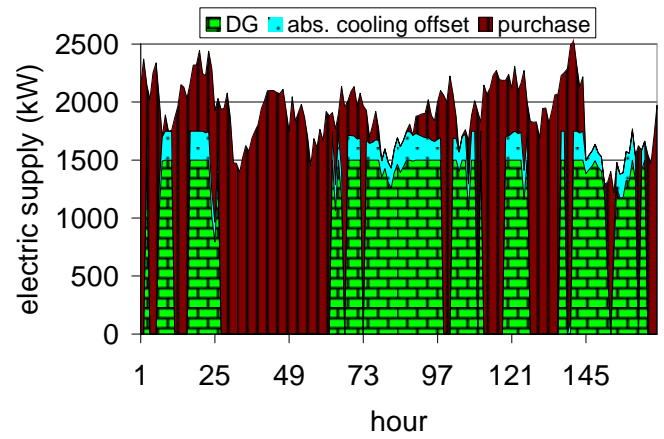

Figure 34. Baltimore - RTP - July 2004 - electricity supply for the first week of the month

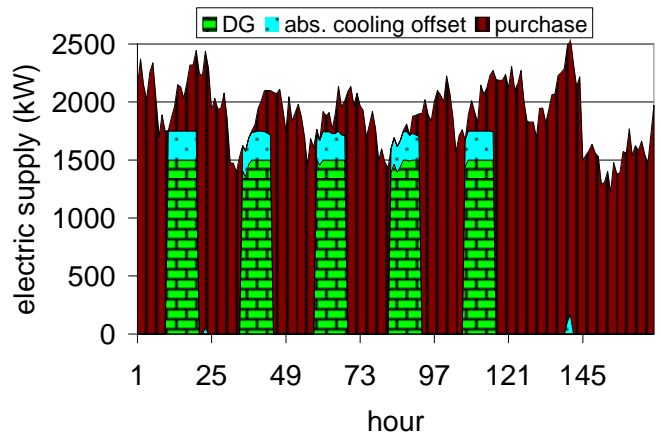

Figure 33. Baltimore - CPP - July 2004 - electricity supply for the first week of the month

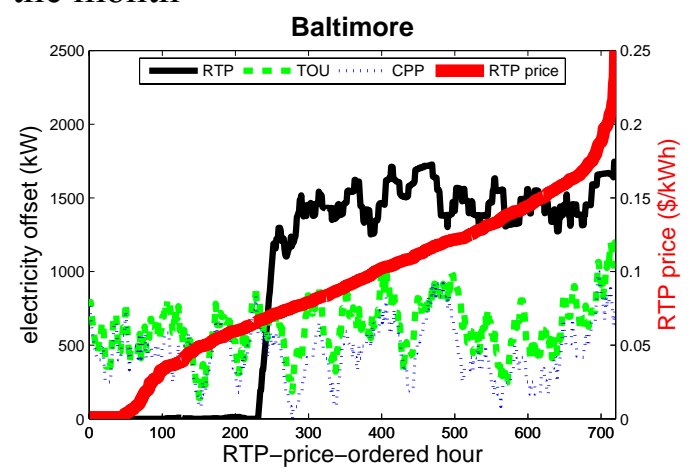

Figure 35. Baltimore - July 2004 electricity purchase by hour, ordered from least to highest RTP

In July 2004 in Baltimore, TOU and CPP electricity prices were only high enough to make DG dispatch economic during on-peak hours (weekday, late morning to evening). Economics are aided by the electricity load offset provided by absorption cooling. The actual clearing prices on Tuesday never got high enough to incent DG dispatch under RTP, while they did get high enough over the weekend (Figure 34). 


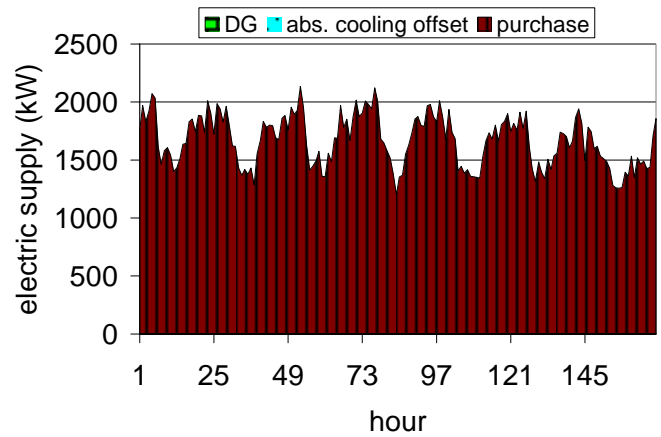

Figure 36. Baltimore - TOU - November 2005 - electricity supply for the first week of the month

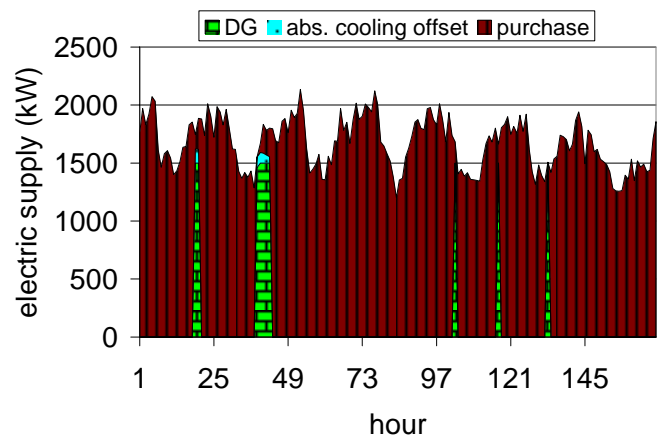

Figure 38. Baltimore - RTP - November 2005 - electricity supply for the first week of the month

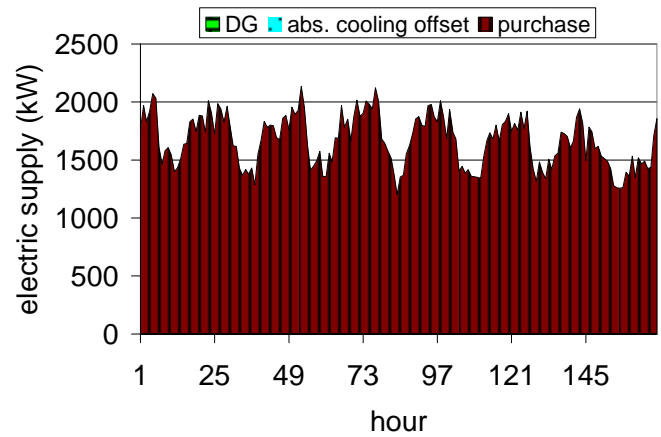

Figure 37. Baltimore - CPP -

November 2005- electricity supply for the first week of the month

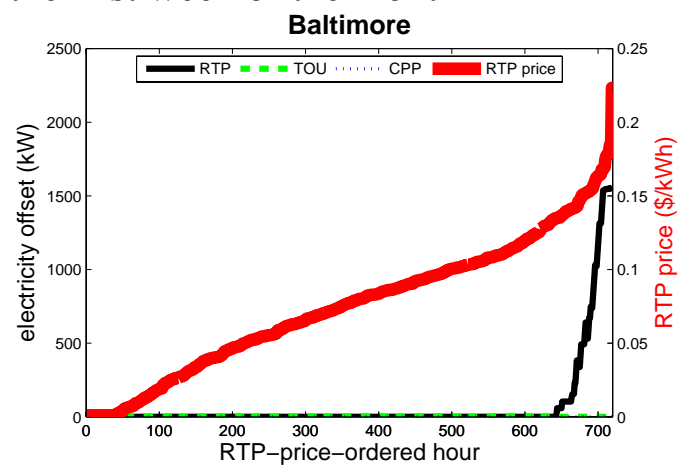

Figure 39. Baltimore - November 2005 - electricity purchase by hour, ordered from least to highest RTP

In November 2005 in Baltimore, high natural gas prices made DG dispatch uneconomic under all tariffs, except for a small number of high RTP hours under RTP (Figure 39). 


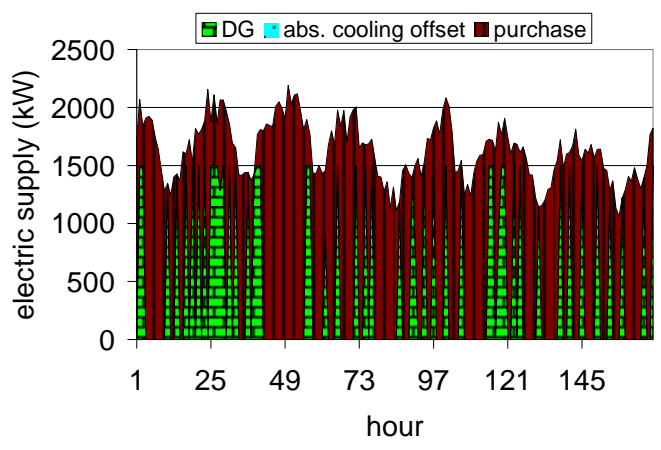

Figure 40. Boston - TOU - January 2004 - electricity supply for the first week of the month

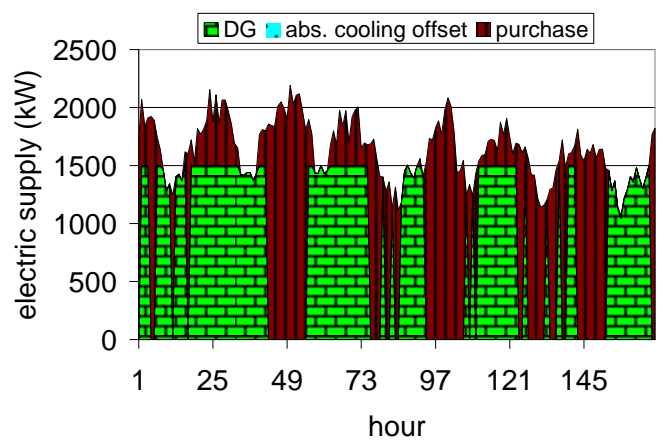

Figure 42. Boston - RTP - January 2004 - electricity supply for the first week of the month

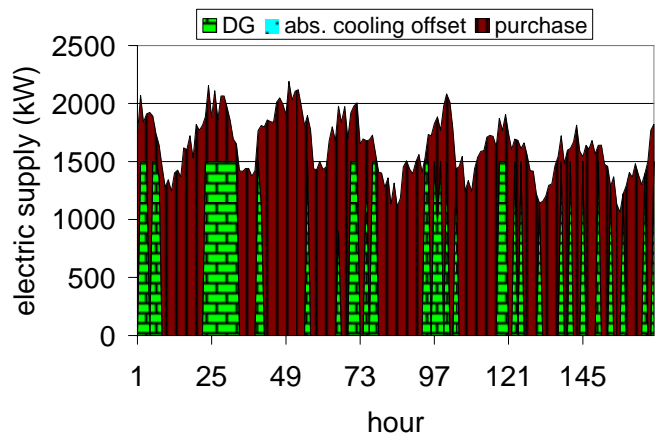

Figure 41. Boston - CPP - January 2004 - electricity supply for the first week of the month

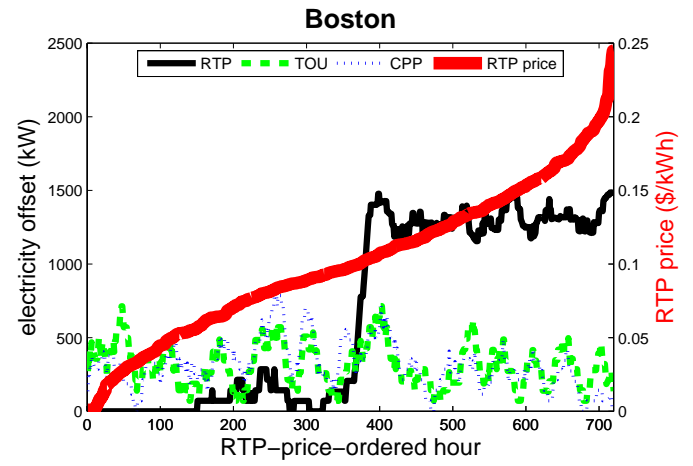

Figure 43. Boston - January $2004-$ electricity purchase by hour, ordered from least to highest RTP

In January 2004 in Boston, TOU and CPP electricity prices were low enough to make most DG dispatch uneconomic. However, the actual clearing prices were high enough in more than half of the hours (see Figure 40) to incent DG operation under RTP. 


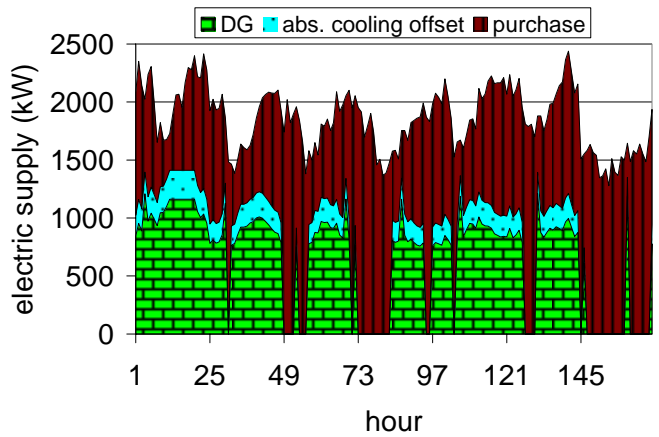

Figure 44. Boston - TOU - July $2004-$ electricity supply for the first week of the month

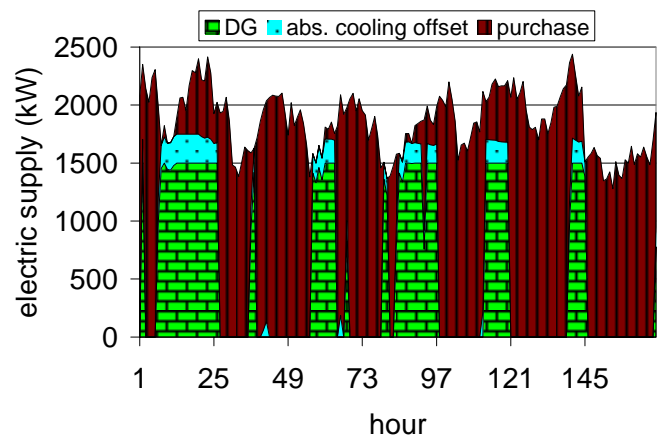

Figure 46. Boston - RTP - July 2004 electricity supply for the first week of the month

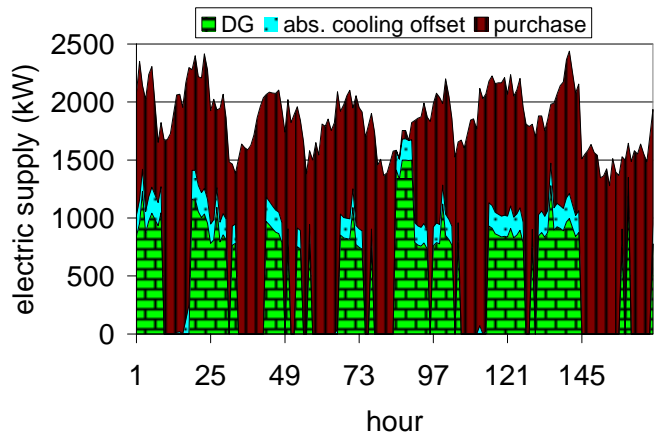

Figure 45. Boston - CPP - July 2004 electricity supply for the first week of the month

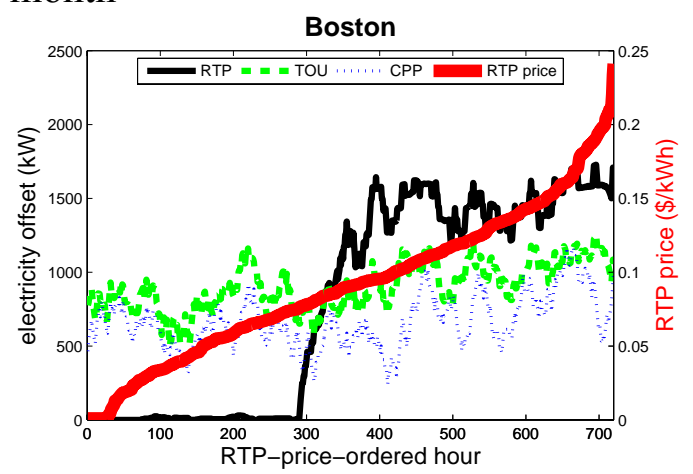

Figure 47. Boston - July 2004 electricity purchase by hour, ordered from least to highest RTP

In July 2004 in Boston, TOU and CPP electricity prices were high enough to make DG dispatch economic when loads were largest (Monday - Saturday) to the extent that waste heat could be utilized for absorption cooling - note that in Figure 44 and Figure 45 the generators are not operated at their maximum capacity $(1500 \mathrm{~kW})$. The actual clearing prices (Figure 46) incent less hours of DG dispatch, but at higher levels. 


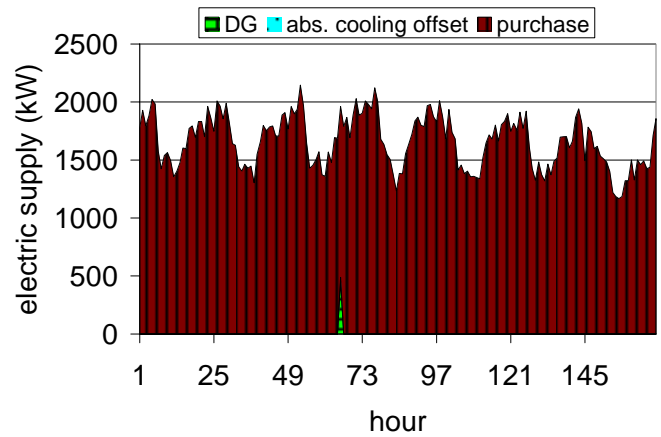

Figure 48. Boston - TOU - November 2005 - electricity supply for the first week of the month

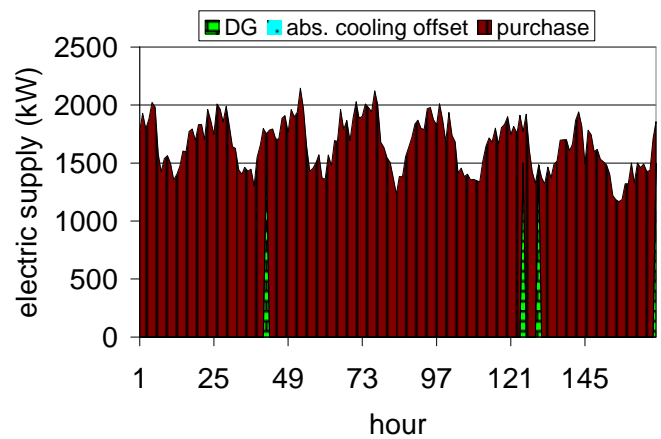

Figure 50. Boston - RTP - November 2005 - electricity supply for the first week of the month

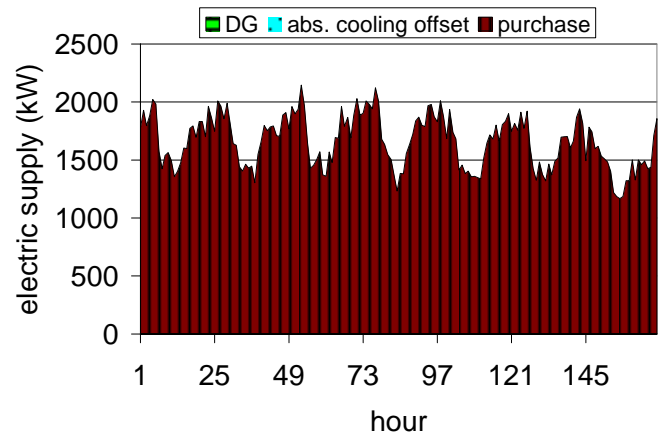

Figure 49. Boston - CPP - November 2005- electricity supply for the first week of the month

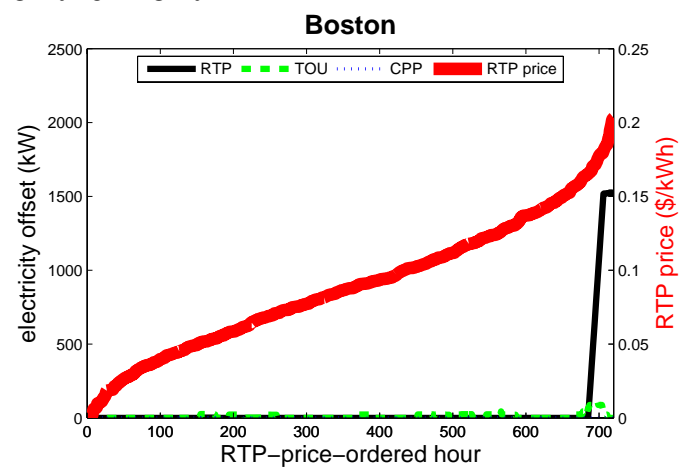

Figure 51. Boston - November 2005 electricity purchase by hour, ordered from least to highest RTP

In November 2005 in Boston, as in Baltimore, high natural gas prices make DG dispatch uneconomic under all tariffs, except for a small number of high RTP hours under RTP (Figure 51). 

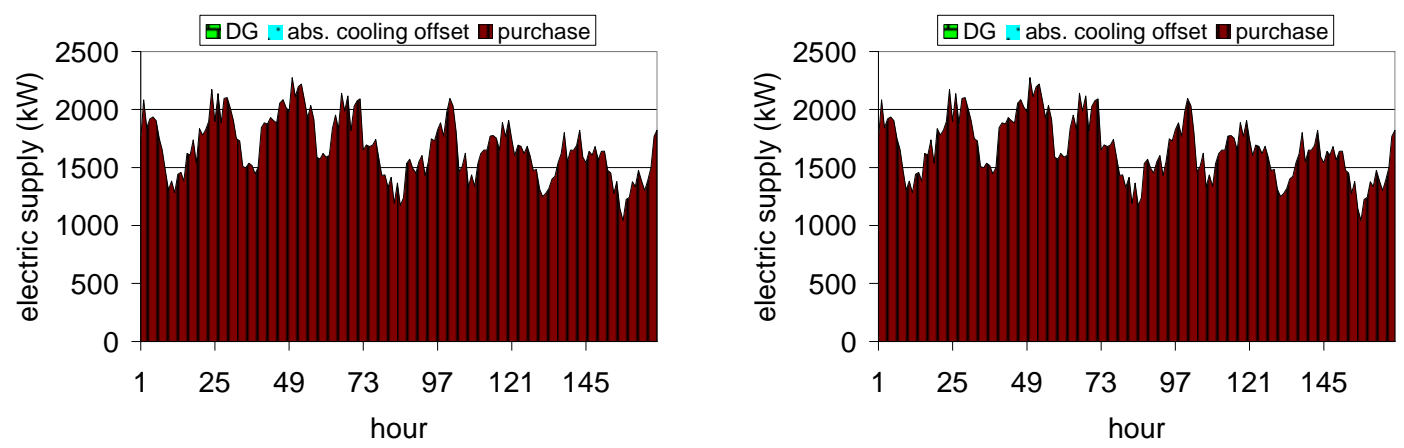

Figure 52. Houston - TOU - January 2004 - electricity supply for the first week of the month

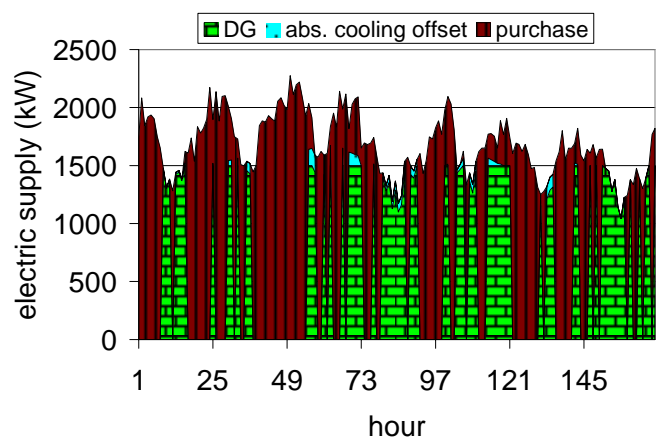

Figure 54. Houston - RTP - January 2004 - electricity supply for the first week of the month

Figure 53. Houston - CPP - January 2004 - electricity supply for the first week of the month

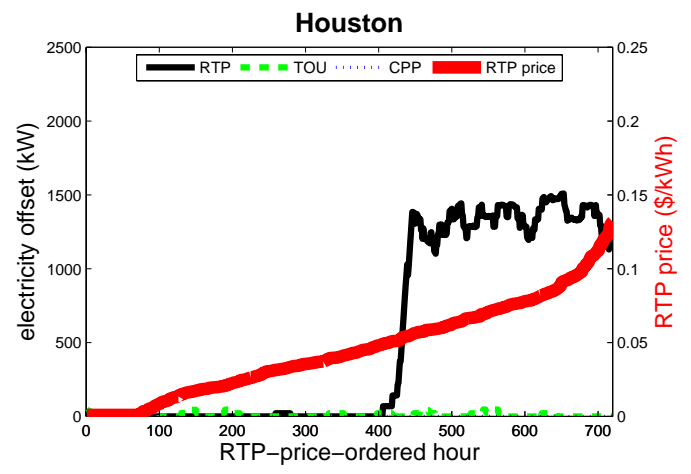

Figure 55. Houston - January $2004-$ electricity purchase by hour, ordered from least to highest RTP

In January 2004 in Houston, TOU and CPP electricity prices were low enough to make most DG dispatch uneconomic. However, the actual clearing prices were high enough in almost half of the hours (see Figure 55) to incent DG operation under RTP. 


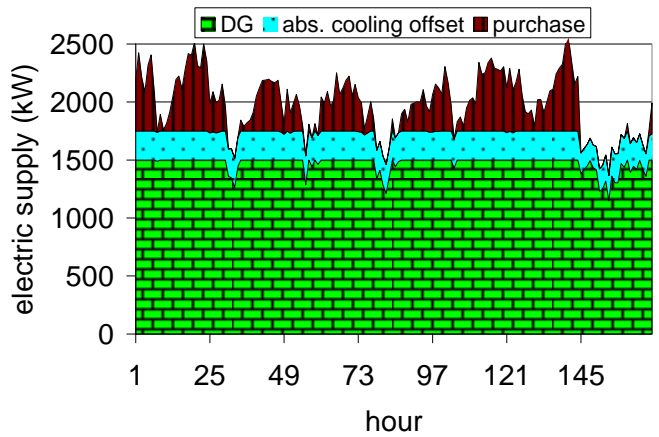

Figure 56. Houston - TOU - July 2004 electricity supply for the first week of the month

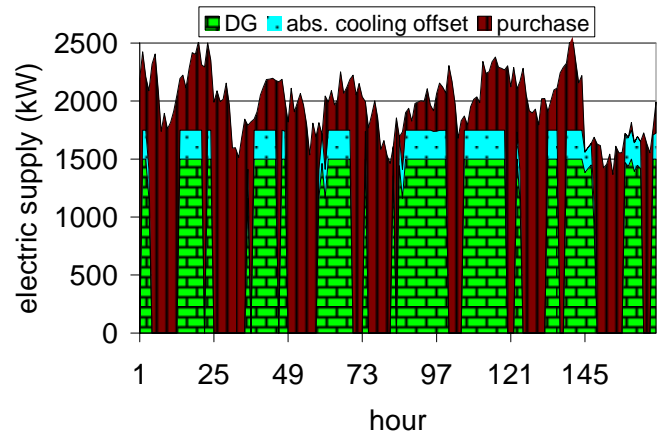

Figure 58. Houston - RTP - July 2004 electricity supply for the first week of the month

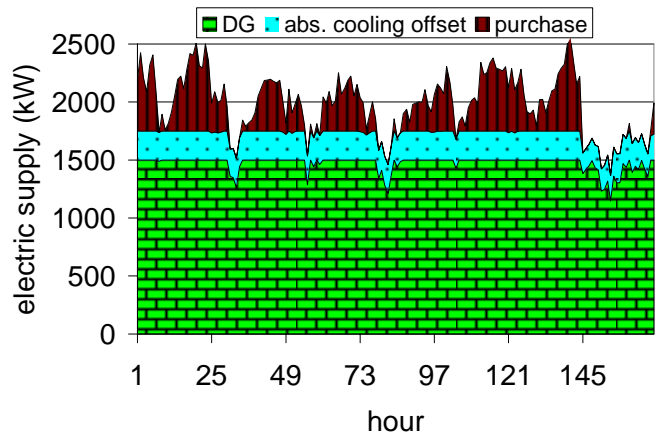

Figure 57. Houston - CPP - July 2004 electricity supply for the first week of the month

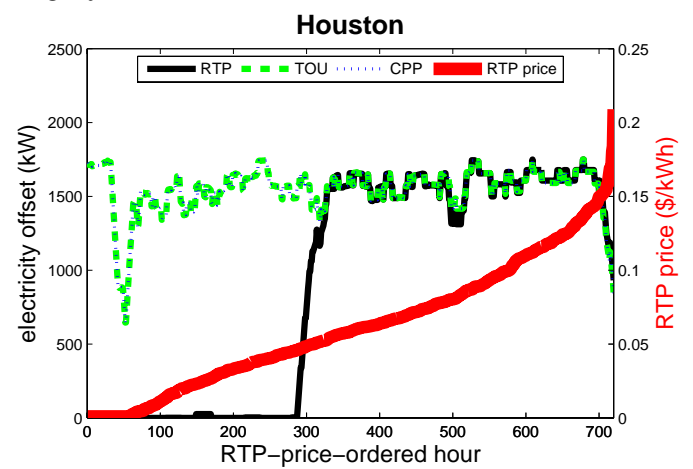

Figure 59. Houston - July 2004 electricity purchase by hour, ordered from least to highest RTP

In July 2004 in Houston, TOU and CPP electricity prices were high enough to make DG dispatch economic at all hours (Figure 56 and Figure 57), aided by the absorption chilling benefit of the waste heat. Under the RTP tariff, the generator was either run at rated capacity $(1500 \mathrm{~kW})$ or not at all (Figure 58$)$. This illustrates the bang-bang nature of optimal dispatch when all waste heat is useful and generation is most efficient at full load. 


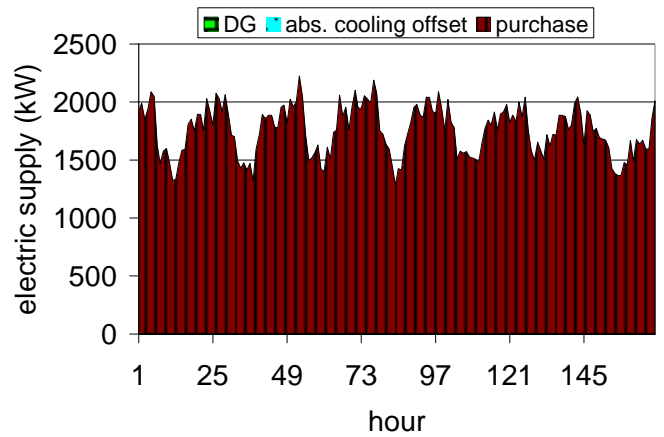

Figure 60. Houston - TOU - November 2005 - electricity supply for the first week of the month

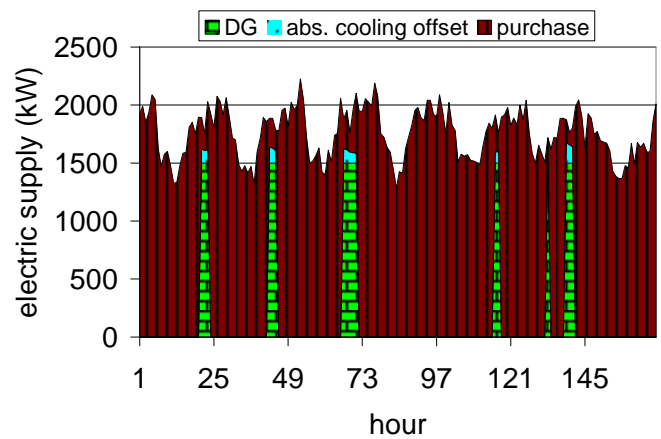

Figure 62. Houston - RTP - November 2005 - electricity supply for the first week of the month

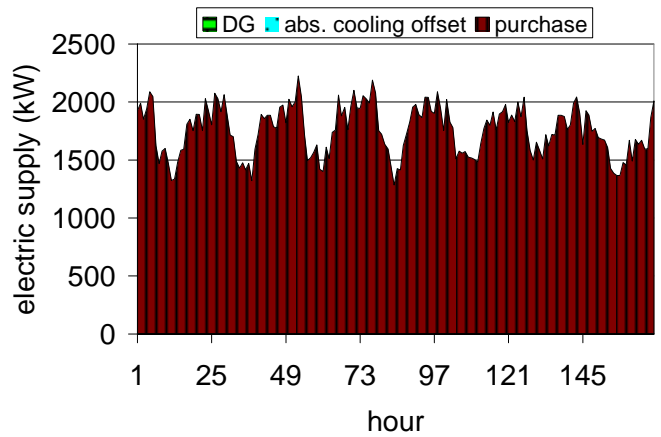

Figure 61. Houston - CPP - November 2005- electricity supply for the first week of the month

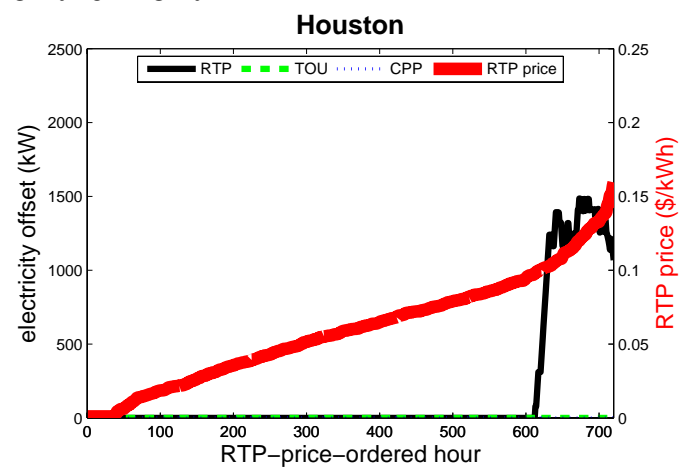

Figure 63. Houston - November 2005 electricity purchase by hour, ordered from least to highest RTP

In November 2005 in Houston, as in Baltimore and Boston, high natural gas prices made DG dispatch uneconomic under all tariffs, except for a small number of high RTP hours under RTP (Figure 63). 


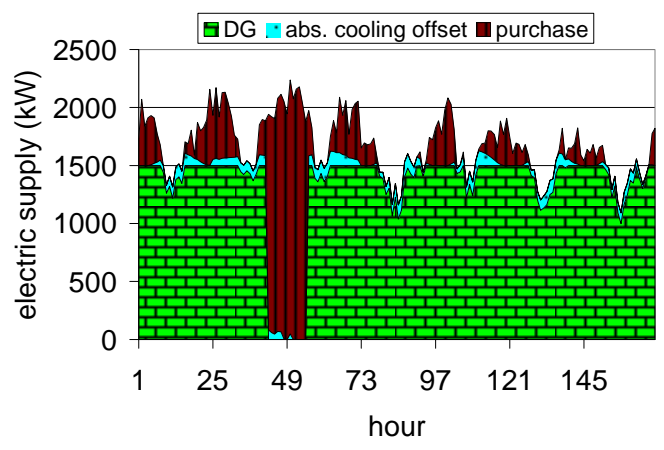

Figure 64. San Diego - TOU - January 2004 - electricity supply for the first week of the month

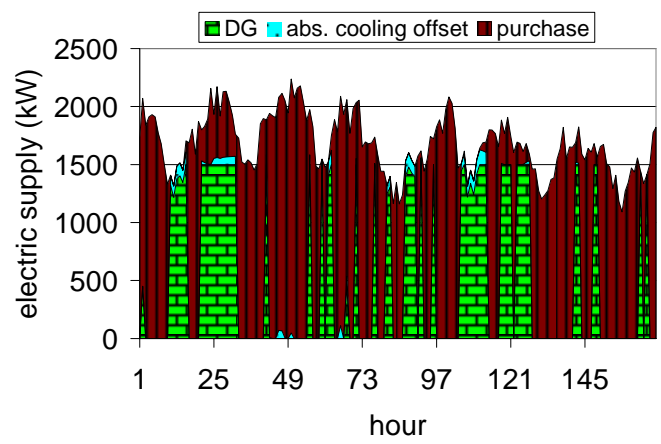

Figure 66. San Diego - RTP - January 2004 - electricity supply for the first week of the month

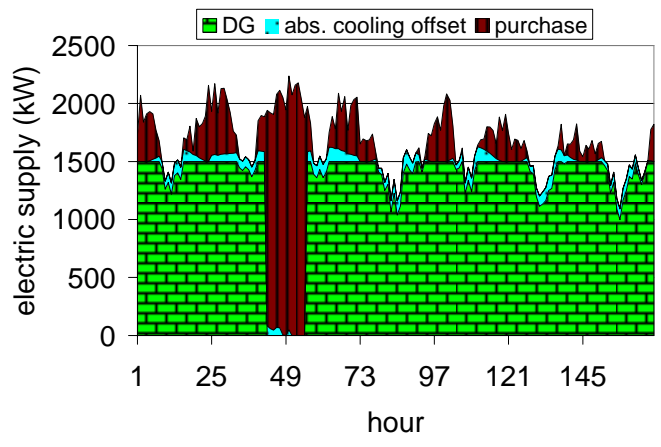

Figure 65. San Diego - CPP - January 2004 - electricity supply for the first week of the month

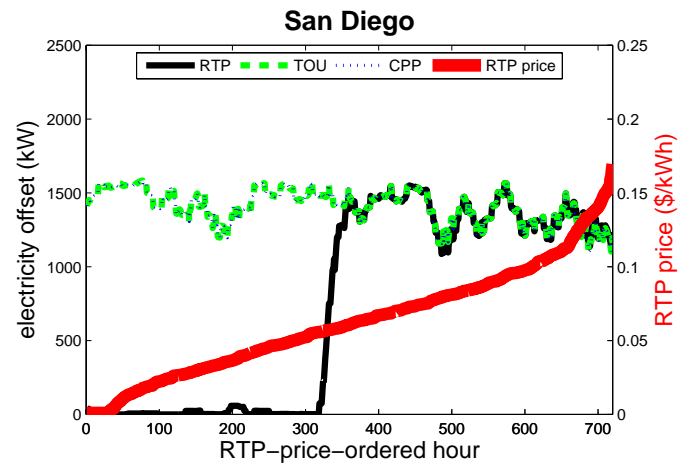

Figure 67. San Diego - January 2004 electricity purchase by hour, ordered from least to highest RTP

In January 2004 in San Diego, TOU and CPP electricity prices were high enough to make DG dispatch economic at all hours (Figure 64 and Figure 65), aided by the absorption chilling benefit of the waste heat. The absence of generation starting near hour 40 in these figures is because of a stochastic generator outage. Under the RTP tariff, the generator was typically either run at rated capacity $(1500 \mathrm{~kW})$ or not at all 
(Figure 66). When real-time prices were moderate, making generation and utility purchase comparable in cost, the generator was run in a heat-following pattern.

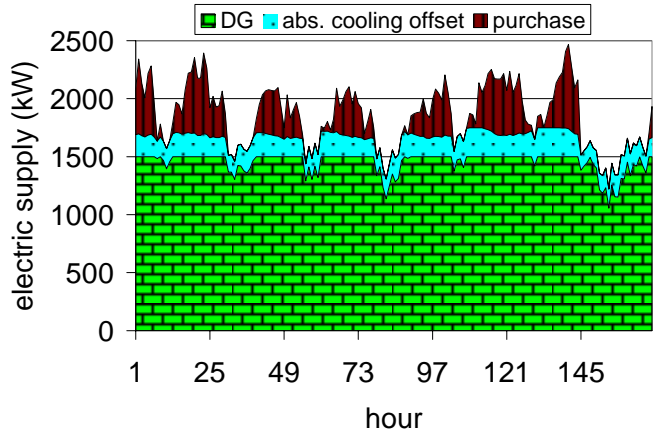

Figure 68. San Diego - TOU - July 2004 - electricity supply for the first week of the month

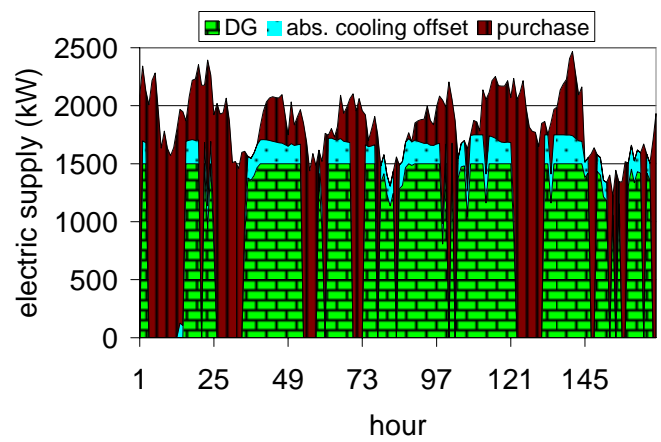

Figure 70. San Diego - RTP - July 2004 - electricity supply for the first week of the month

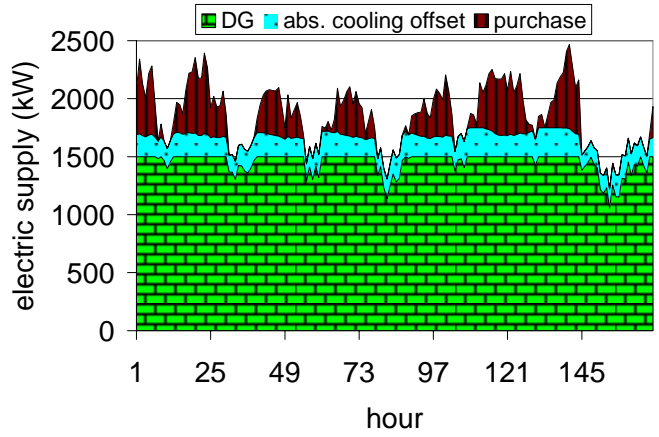

Figure 69. San Diego - CPP - July 2004 - electricity supply for the first week of the month

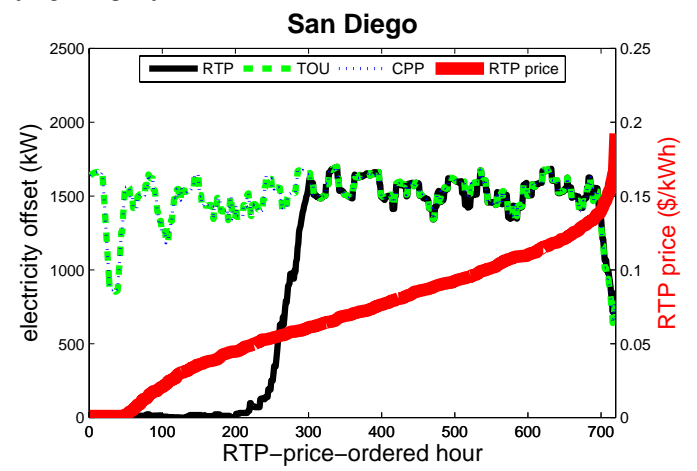

Figure 71. San Diego - July 2004 electricity purchase by hour, ordered from least to highest RTP

In July 2004 in San Diego, TOU and CPP electricity prices were high enough to make DG dispatch economic at all hours (Figure 64 and Figure 65), aided by significant absorption chilling benefit of the waste heat. Under the RTP tariff, the generator was typically either run at rated capacity $(1500 \mathrm{~kW})$ or not at all (Figure 66). Under RTP, the generator was dispatched more in July 2004 (Figure 70) than in January 2004 (Figure 66) because of the larger use for waste heat for absorption chilling. The San 
Diego P\&DC has no significant heat load, even during the winter, because of the mild climate.

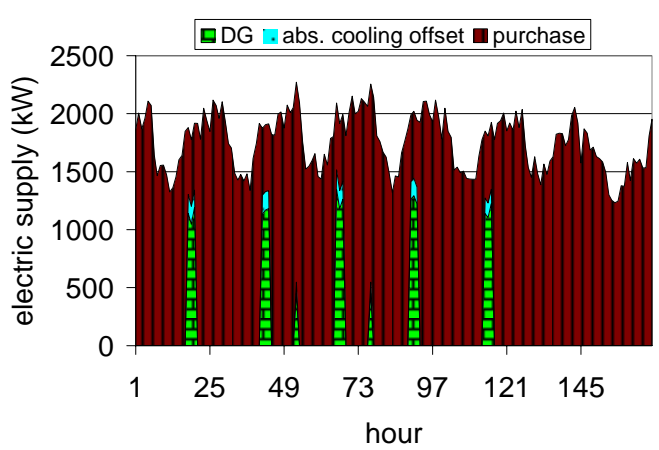

Figure 72. San Diego - TOU - November 2005 - electricity supply for the first week of the month

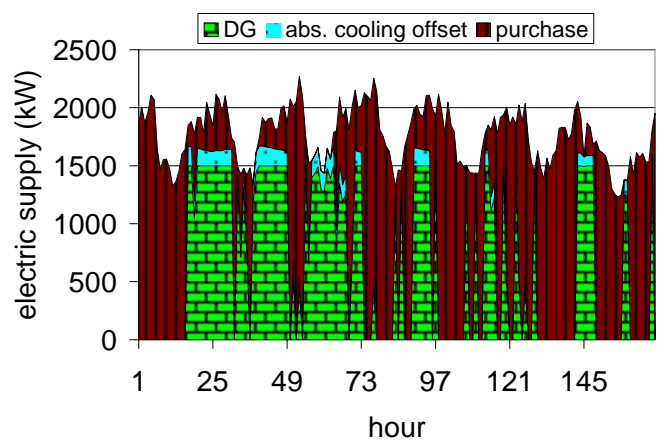

Figure 74. San Diego - RTP - November 2005 - electricity supply for the first week of the month

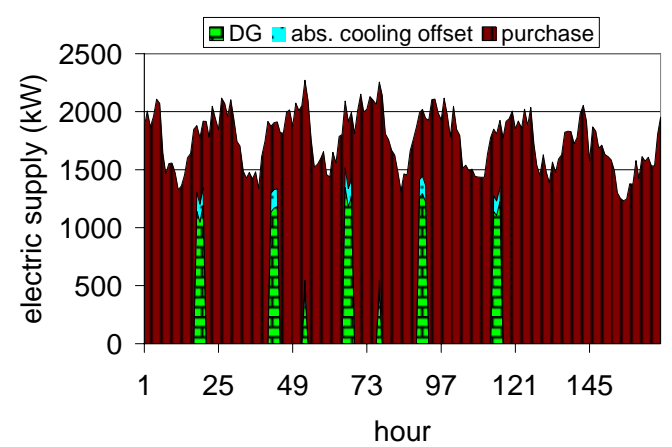

Figure 73. San Diego - CPP - November 2005- electricity supply for the first week of the month

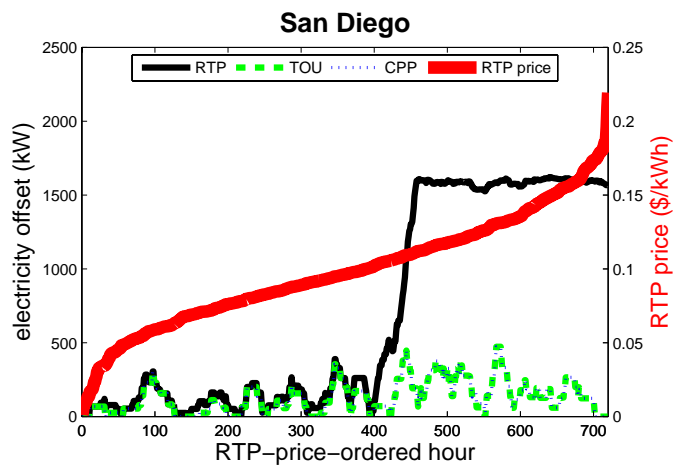

Figure 75. San Diego - November 2005 electricity purchase by hour, ordered from least to highest RTP

In November 2005 in San Diego high natural gas prices made DG dispatch economic under TOU and CPP tariffs. However, DG dispatch was economic under RTP tariff in almost half of the hours of the month. 


\subsubsection{Optimal Control Valuation - Observations}

It becomes clear by inspection of Figure 28 through Figure 75 that optimal dispatch under TOU tariffs is nearly identical to optimal dispatch under CPP tariffs for all four cities. This is because DG tends to be running during critical episodes, regardless of a price signal, because episodes occur during times (summer, on-peak) in which electricity is already relatively highly priced. This suggests that, from a regulator or utility's perspective, CPP tariffs would incent no different behavior from DG customers than non-DG customers, i.e. DG customers would have no additional surge in curtailment.

Furthermore, dispatch patterns under TOU and CPP tariffs are fairly simple and approximate the heuristic control strategies examined here: no-DG, load-follow (in this case running all of the time) and heat-following. An additional pattern not examined in this research is load- (or heat-) following during on-peak hours only. Developing an algorithm to determine which heuristic control strategy would be most effective at each month might be a cost-effective alternative to full optimal control for TOU or CPP customers.

RTP tariffs lead to more demanding near-optimal control - namely control that continuously responds to prices. Control would be more complicated, and involve significant hedging strategies, if limits on the number of generator starts and stops (or minimum run time constraints) were imposed. 


\subsection{Demand Side Management Valuation}

The second experiment conducted was a valuation of demand side management (DSM) programs. Unplanned DG outages often cause DG site utility consumption to be much peakier than that of their non-DG counterparts. It was hypothesized by the author that DSM programs could be more valuable to DG sites than non-DG sites because this peakiness, and thus demand charges, could be mitigated. This synergy between DG and DSM was demonstrated by Firestone, Stadler, and Marnay (2006b).

Figure 76 illustrates this phenomenon. The graph on the left is a load duration curve of on-peak hours for a site with no-DG. The red dashed line indicates $80 \%$ of peak demand; the intersection of the $80 \%$ line with the duration curve is used to identify the number of hours of DSM required to successfully reduce monthly demand by 20\%. Approximately 90 hours of curtailment would be required for this demand reduction. The middle graph plots utility electricity consumption for the same site, this time with DG and subject to random DG outages. Hours are ordered the same as in the left graph. Peaks in the middle graph indicate hours of DG outage. The graph on the right shows the load duration curve for the site with DG. In this example, DG successfully mitigates almost the full $20 \%$ of demand cost. Nearly $25 \%$ more demand could be mitigated if DSM could be used for the few hours of the month when the DG is unavailable. This figure shows how many fewer hours of DSM may 
be required to achieve equivalent (or greater) demand charge mitigation if DG is present.

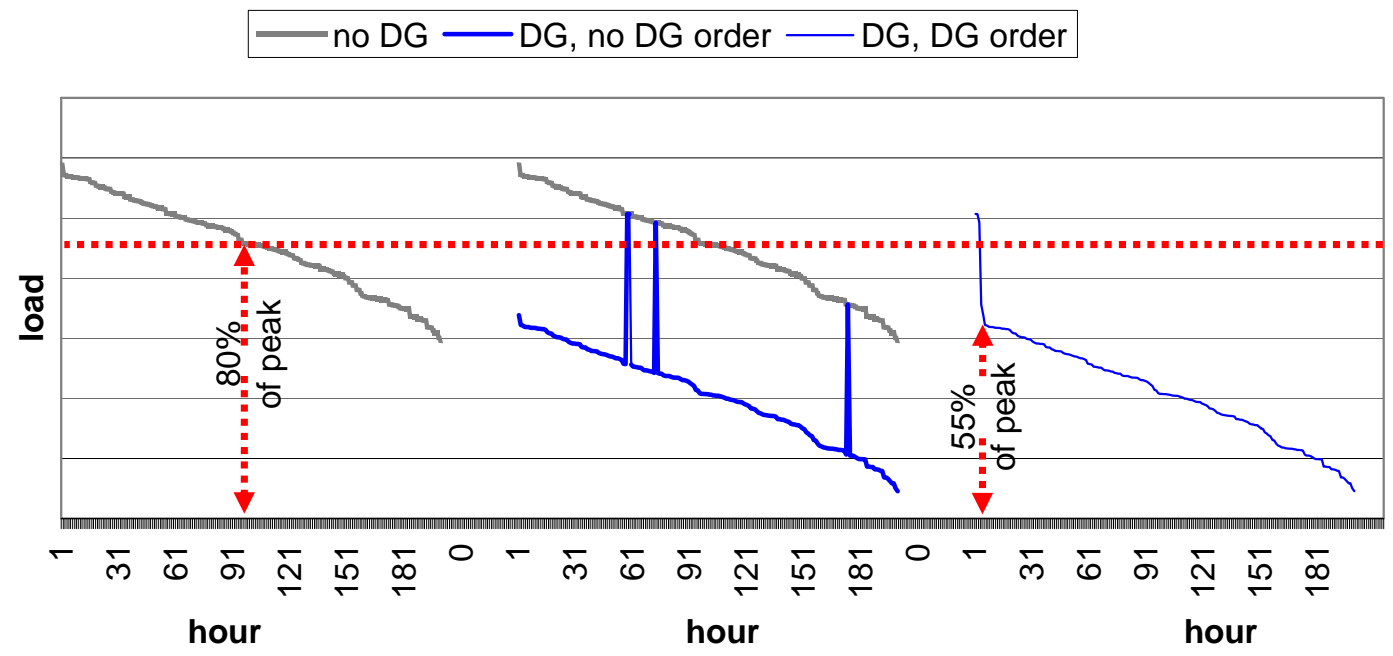

Figure 76. duration curves that demonstrate the peakier nature of DG customers' utility purchase

For this experiment, a DSM program of 1-hour curtailments was considered, with two program parameters: 1) number of allowable curtailments per month, and 2) the magnitude of curtailment. For each of the four sites, under each of the three tariff structures, for the 2006 data, site simulation using RT-OPTICOM for dispatch optimization was conducted for the following cases:

- no-DG or DSM dispatch

- DG dispatch only

- DSM dispatch only

- DG and DSM dispatch

For all cases with DSM dispatch, RT-OPTICOM runs with all combinations of curtailable hours $\{5,10,15,20,25\}$ and curtailable magnitude $(\mathrm{kW})\{50,100,150$, 
$200,250\}$ were considered. The results from these cases were then used to determine the value of DSM programs with and without DG systems. Figure 77 through Figure 88 show contour plots of both 1) the annual site energy costs under varying DSM programs and 2) the annual value of the DSM program, i.e. the difference between the annual energy cost without DSM and with DSM, ceteris paribus. 
Figure 77 and Figure 78 show the annual energy costs and DSM values for the four cities under TOU tariff and no-DG dispatch.
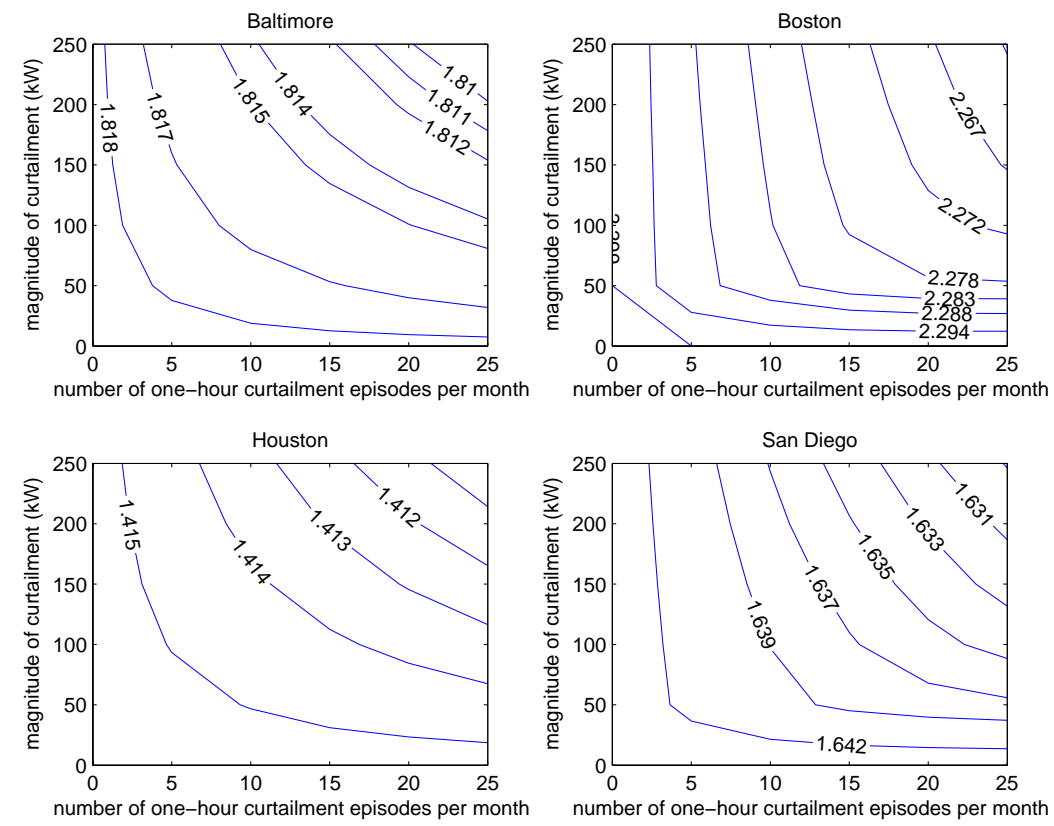

Figure 77. TOU - no-DG - annual energy cost (M\$) under varying DSM programs in 2006
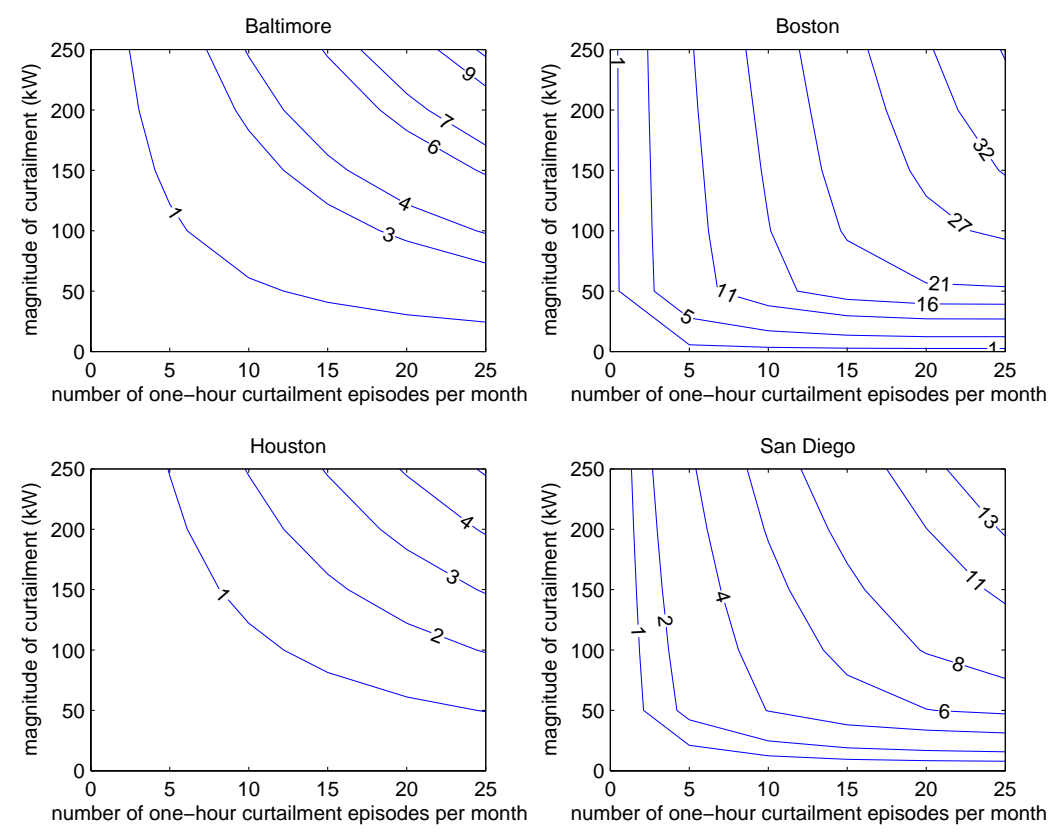

Figure 78. TOU - no-DG - annual value (k\$) of varying DSM programs in 2006 
Figure 79 and Figure 80 show the annual energy costs and DSM values for the four cities under TOU tariff and DG dispatch.
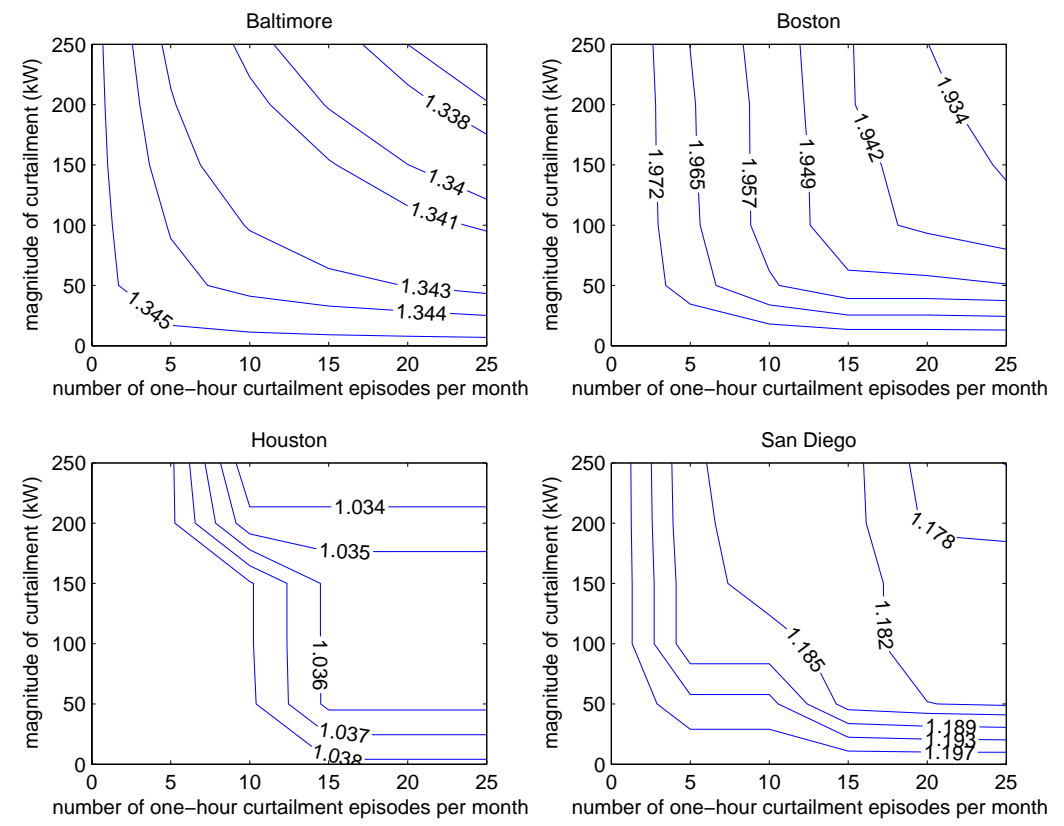

Figure 79. TOU - with-DG - annual energy cost (M\$) under varying DSM programs in 2006
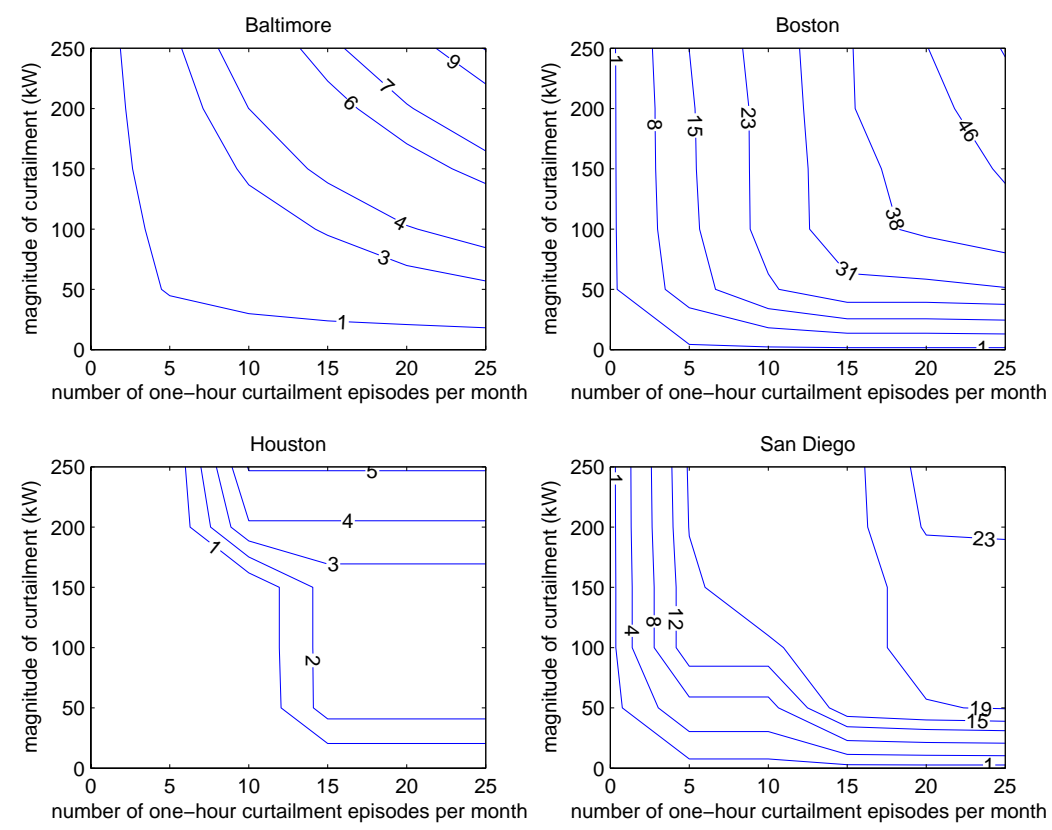

Figure 80. TOU - with-DG - annual value (k\$) of varying DSM programs in 2006 
Figure 81 and Figure 82 show the annual energy costs and DSM values for the four cities under CPP tariff and without DG dispatch.
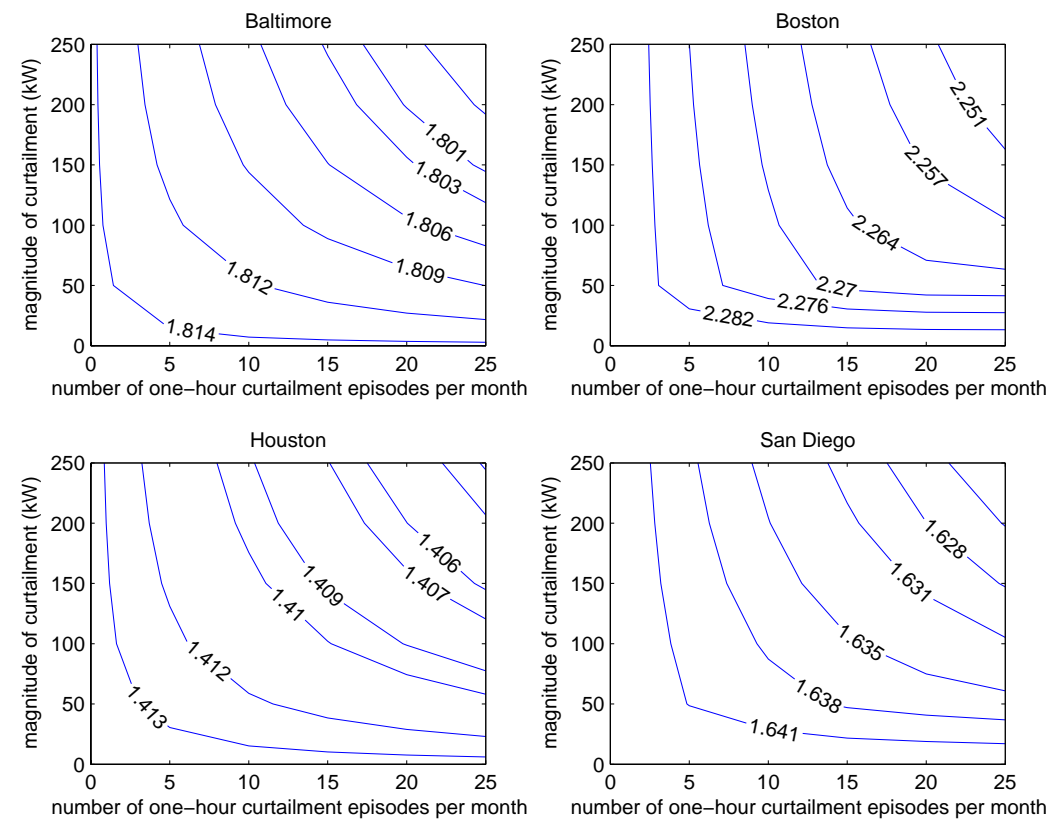

Figure 81. CPP - no-DG - annual energy cost $(\mathrm{M} \$)$ under varying DSM programs in 2006
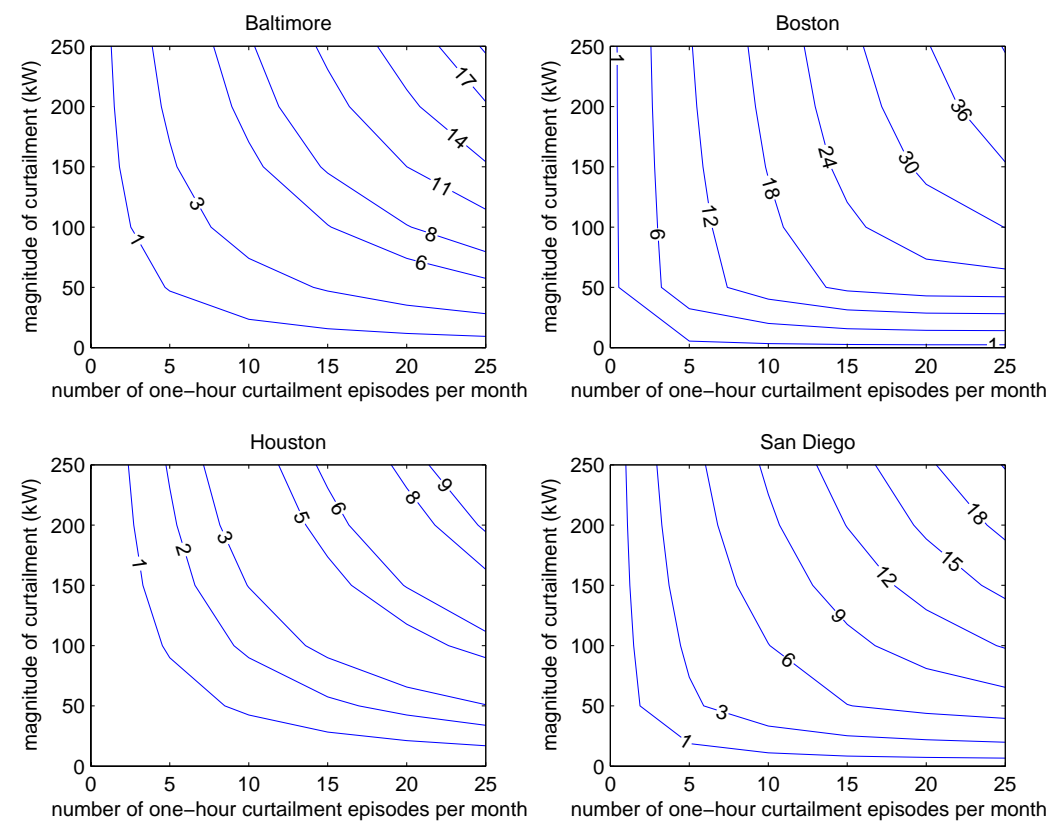

Figure 82. CPP - no-DG - annual value $(\mathrm{k} \$$ ) of varying DSM programs in 2006 
Figure 83 and Figure 84 show the annual energy costs and DSM values for the four cities under CPP tariff and with DG dispatch.
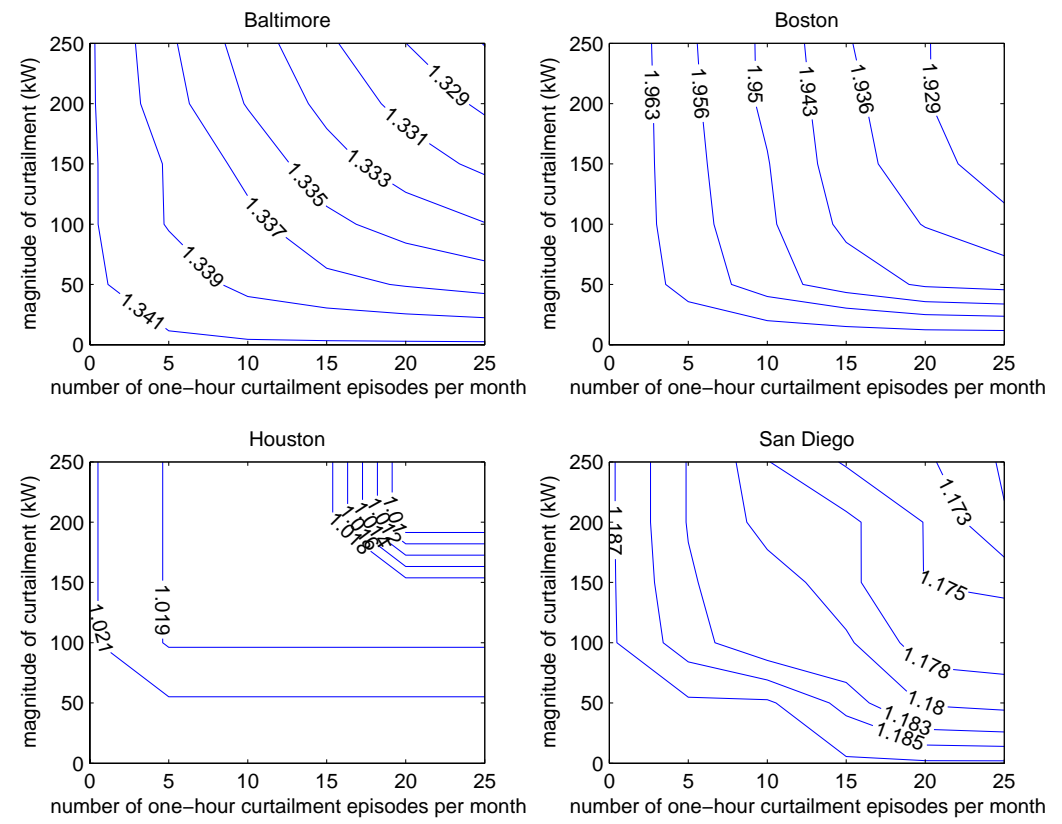

Figure 83. CPP - with-DG - annual energy cost (M\$) under varying DSM programs in 2006
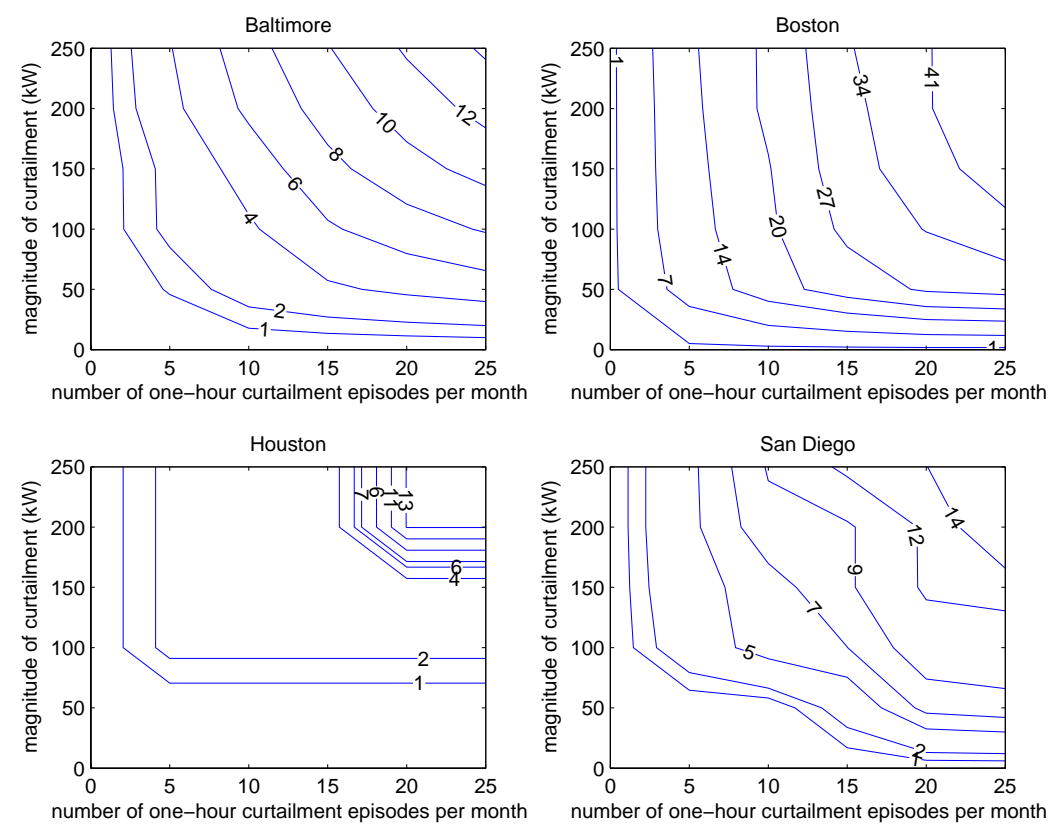

Figure 84. CPP - with-DG - annual value ( $\mathrm{k} \$$ ) of varying DSM programs in 2006 
Figure 85 and Figure 86 show the annual energy costs and DSM values for the four cities under RTP tariff and without DG dispatch.
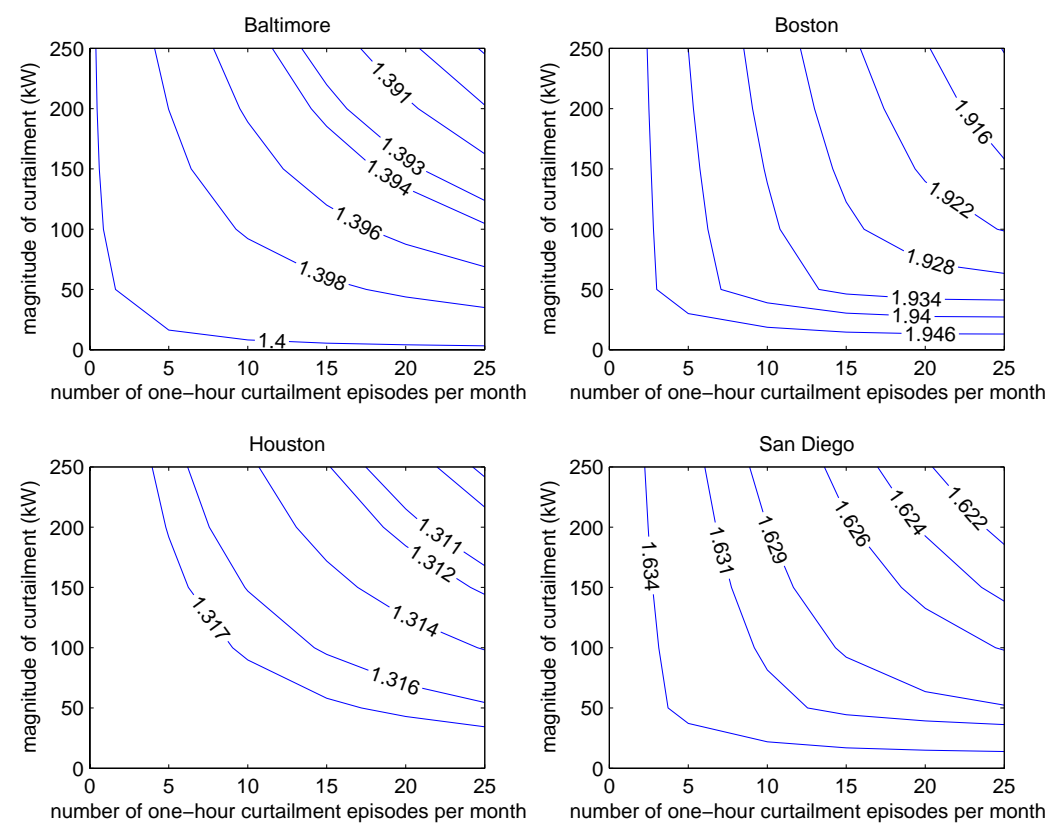

Figure 85 . RTP - no-DG - annual energy cost (M\$) under varying DSM programs in 2006
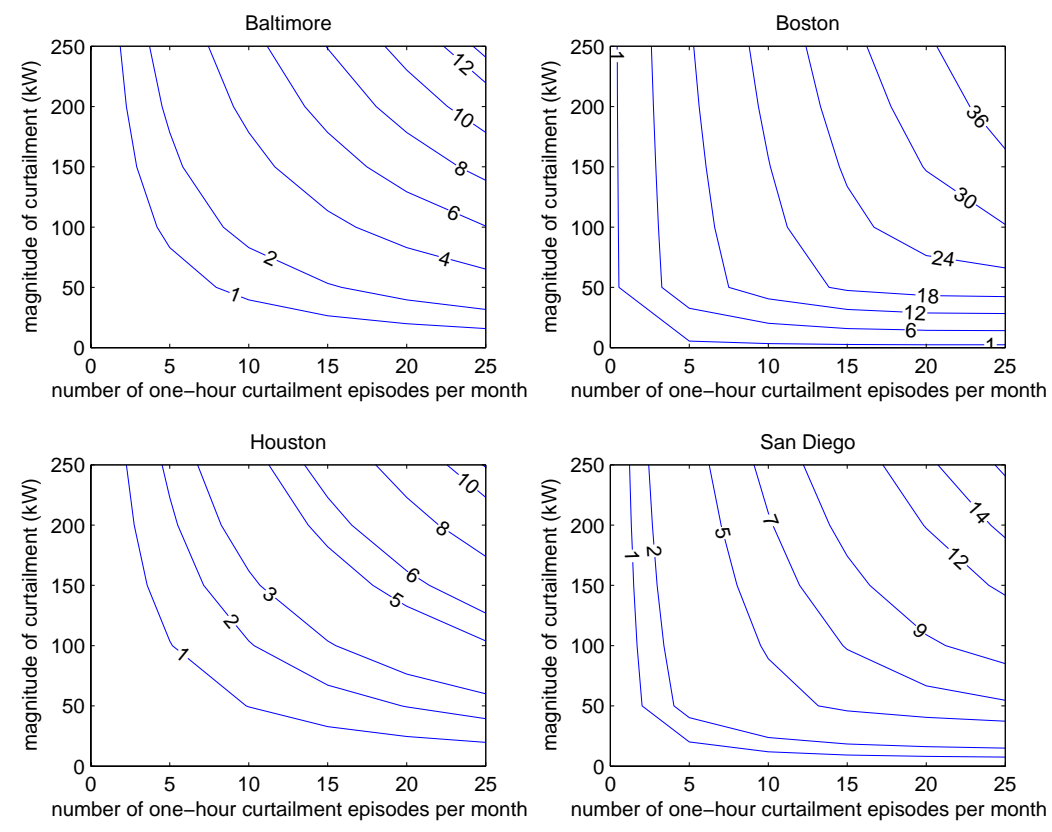

Figure 86. RTP - no-DG - annual value (k\$) of varying DSM programs in 2006 
Figure 87 and Figure 88 show the annual energy costs and DSM values for the four cities under RTP tariff and with DG dispatch
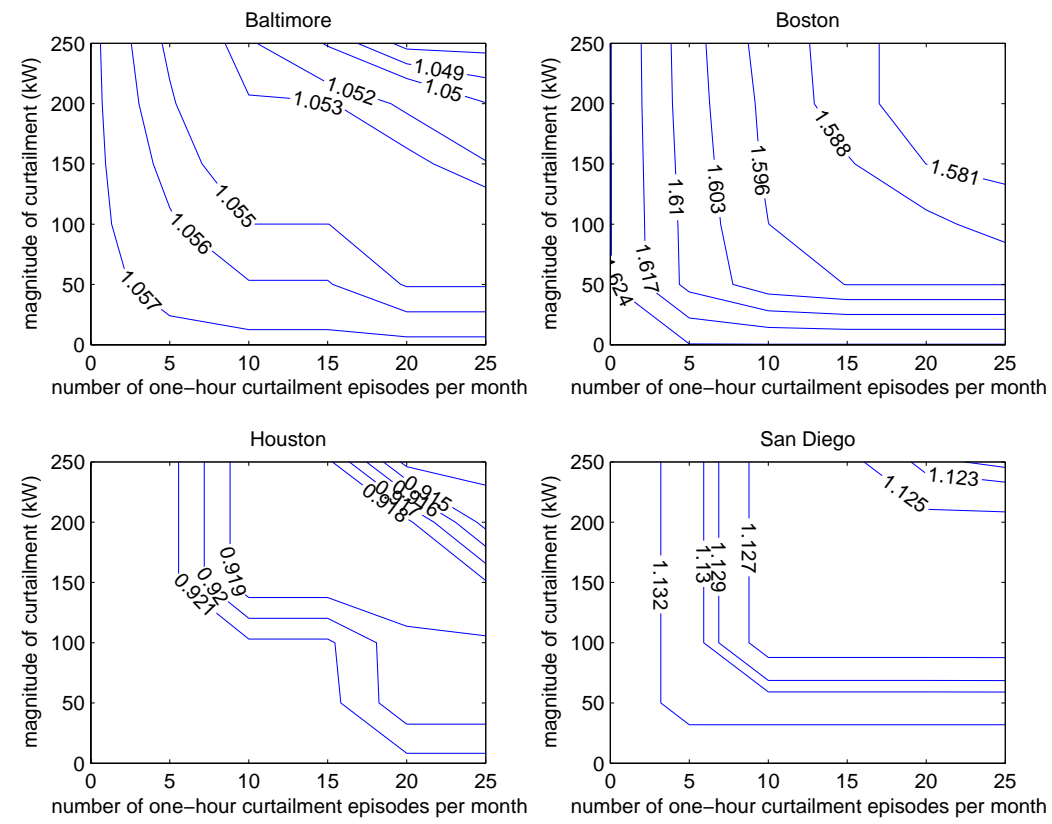

Figure 87. RTP - with-DG - annual energy cost (M\$) under varying DSM programs in 2006
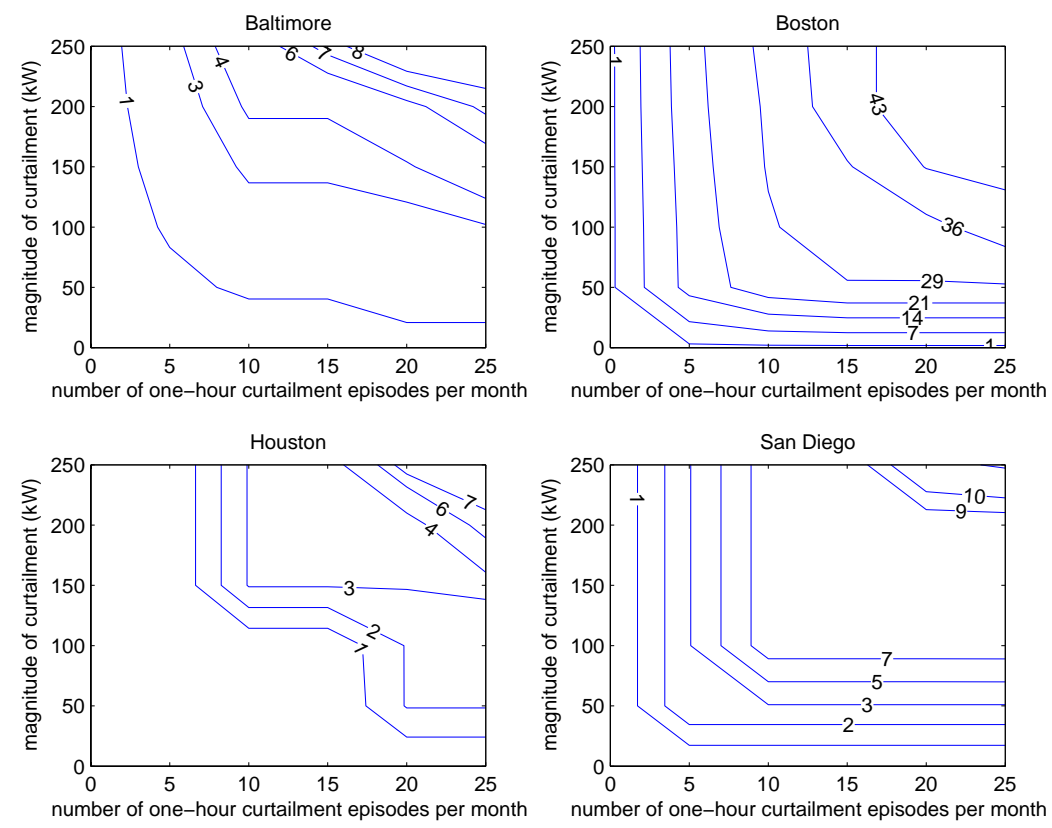

Figure 88. RTP - with-DG - annual value (k\$) of varying DSM programs in 2006 
Table 20 summarizes the DSM value for each combination of tariff, city, and presence/absence of DG dispatch at two levels: 1) 10 hours/month of $100 \mathrm{~kW}$ curtailment and 2) 25 hours/month of $250 \mathrm{~kW}$ curtailment. Peak loads at the sites are approximately $2 \mathrm{MW}$. Without DG, DSM is most valuable under CPP tariffs, where curtailment episodes coincide with critical episodes. When DG is included in the dispatch, DSM generally becomes more valuable for a small curtailment program (10 hours per month at $100 \mathrm{~kW})$. However, the results are not conclusive for a larger curtailment program (25 hours per month at $250 \mathrm{~kW}$ ); DSM becomes less valuable in two of the four cities (Baltimore and San Diego), more valuable in the other two (Boston and Houston). This result illustrates the complexity of determining DSM value, which is dependent on the particular DSM program, the size and structure of demand charges and the energy purchase duration curve. The duration curve is in turn dependent on generator availability and climate-driven thermal loads. The results of this experiment show the hypothesized synergy between DG and DSM for small DSM programs, but are inconclusive for larger programs. 
Table 20. DSM program value ( $\mathrm{k} \$ /$ year) for a $10 \mathrm{hour} /$ month, $100 \mathrm{~kW} /$ episode program and a 25 hour/month, $250 \mathrm{~kW} /$ episode program in 2006

\begin{tabular}{|c|c|c|c|c|c|}
\hline & \multicolumn{2}{|c|}{$\begin{array}{l}10 \text { one-hour curtailments per } \\
\text { month }\end{array}$} & \multicolumn{2}{|c|}{$\begin{array}{l}25 \text { one-hour curtailments per } \\
\text { month }\end{array}$} \\
\hline & & \multicolumn{2}{|c|}{$100 \mathrm{~kW}$ maximum curtailment } & \multicolumn{2}{|c|}{$250 \mathrm{~kW}$ maximum curtailment } \\
\hline & & without DG & with DG & without DG & with DG \\
\hline \multirow[t]{3}{*}{ Baltimore } & TOU & 2 & 2 & 10 & 10 \\
\hline & CPP & 3 & 4 & 18 & 14 \\
\hline & RTP & 2 & 2 & 14 & 8 \\
\hline \multirow[t]{3}{*}{ Boston } & TOU & 13 & 23 & 37 & 53 \\
\hline & CPP & 15 & 18 & 42 & 48 \\
\hline & RTP & 16 & 28 & 40 & 50 \\
\hline \multirow[t]{3}{*}{ Houston } & TOU & 1 & 1 & 5 & 5 \\
\hline & CPP & 2 & 2 & 10 & 13 \\
\hline & RTP & 2 & 1 & 10 & 7 \\
\hline \multirow[t]{3}{*}{ San Diego } & TOU & 4 & 14 & 14 & 25 \\
\hline & CPP & 5 & 5 & 21 & 15 \\
\hline & RTP & 5 & 7 & 16 & 11 \\
\hline
\end{tabular}

\subsection{Cost-Carbon Co-optimization}

The final experiment was to examine the trade-off between site-attributable carbon emissions and energy costs under optimal control and the three different tariffs. Siteattributable carbon emissions are the sum of emission from grid electricity and on-site natural gas consumption. One constraint in RT-OPTICOM is a ceiling on the amount of site-attributable carbon emissions in each month. For this experiment, for the months of January 2004 to December 2006, the simulation under optimal control and each of the three tariffs was rerun for a series of carbon constraint levels. For utility electricity, regional average marginal emissions factors from The Climate Trust (2005) were used (see Section 7.2.6). 
The set of costs and carbon emissions levels from these runs were then analyzed to obtain an estimate of the cost/carbon trade-off under each tariff structure. The results are plotted in Figure 89 through Figure 96, with carbon emissions on the horizontal axis and the corresponding minimum possible annual energy cost on the vertical axis. For each city, these values are plotted in average annual dollars and tons of carbon (graphs on the left) and as percentages of the lowest possible level of cost and carbon (graphs on the right). All points on these figures are determined by running the RTOPTICOM model for each city/month/tariff combination at many different levels of carbon constraint and then solving a separate optimization problem which finds the least-cost combination of monthly results for a given total level of carbon emissions. These least cost values could not be obtained in practice because they assume perfect foresight in natural gas prices for the three years and general trends in electricity prices; however they do provide an estimate of the cost/carbon trade-off.

Figure 89 and Figure 90 plot the results for Baltimore. The approximately right angles in Figure 89 under all tariffs illustrate that there is very little room in dispatch decision-making for trade-off between cost and carbon. Figure 90 shows these fronts in more detail, and in terms of percentage of best-cost and best-carbon values. For TOU and CPP tariffs, least-cost solutions result in about $10 \%$ more carbon than leastcarbon dispatch (bottom right corner of the graph), whereas least-carbon dispatch costs the site about $10 \%$ more than least cost dispatch. Under RTP tariffs, this angle is more rounded, showing more room for trade-off. 


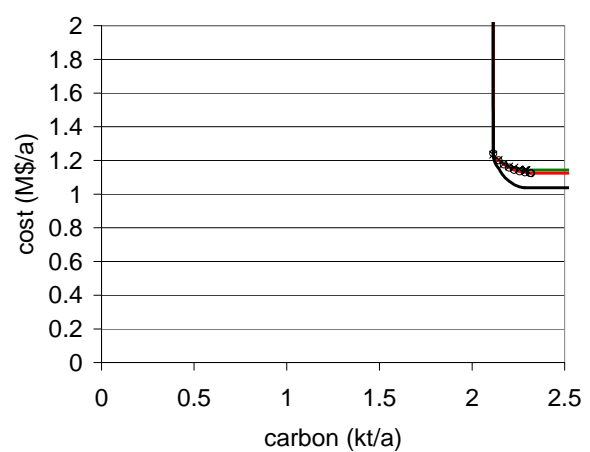

Figure 89. Baltimore - cost-carbon Pareto front

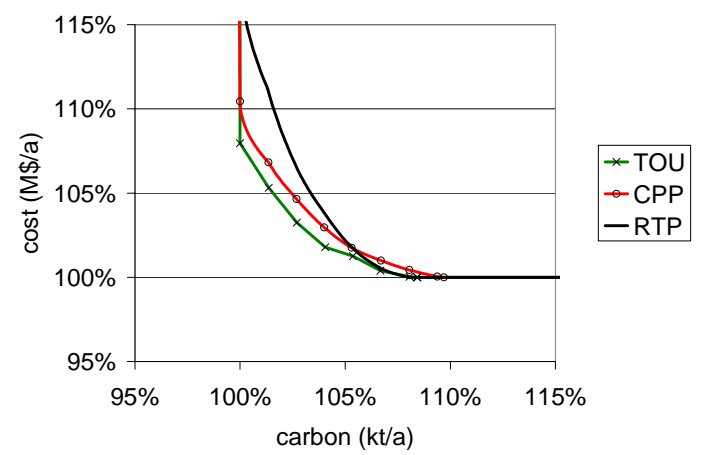

Figure 90. Baltimore - cost-carbon Pareto front, as percentage of best cost and best carbon solutions

Figure 91 and Figure 92 show these results for Boston. The angles are even sharper than in the Baltimore case, implying even less room for trade-off between cost and carbon.

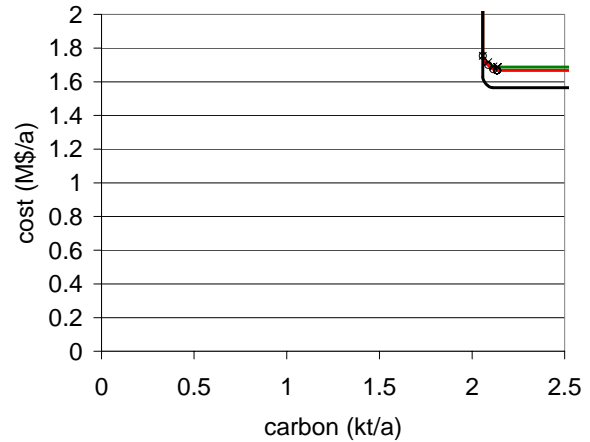

Figure 91. Boston - cost-carbon Pareto front

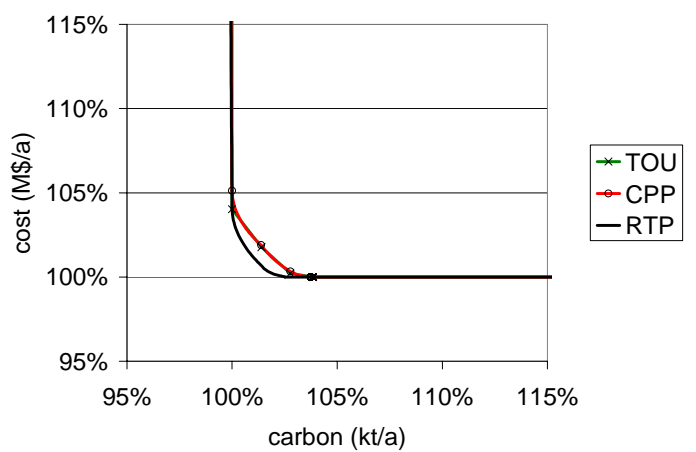

Figure 92. Boston - cost-carbon Pareto front, as percentage of best cost and best carbon solutions

Figure 93 and Figure 94 show these results for Houston. They are qualitatively very similar to those from Boston. 


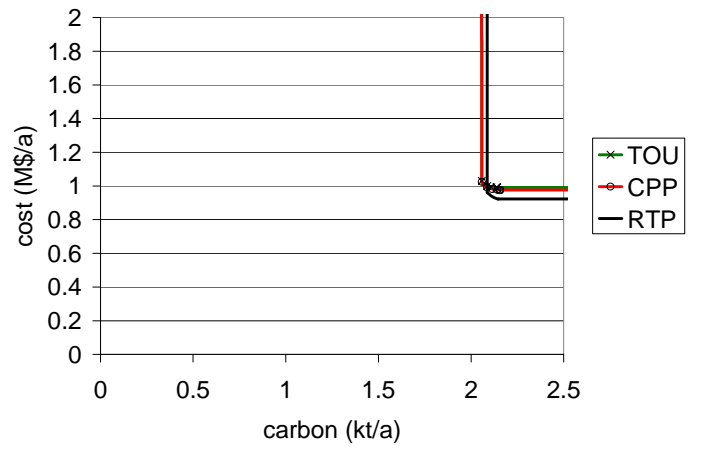

Figure 93. Houston - cost-carbon Pareto front

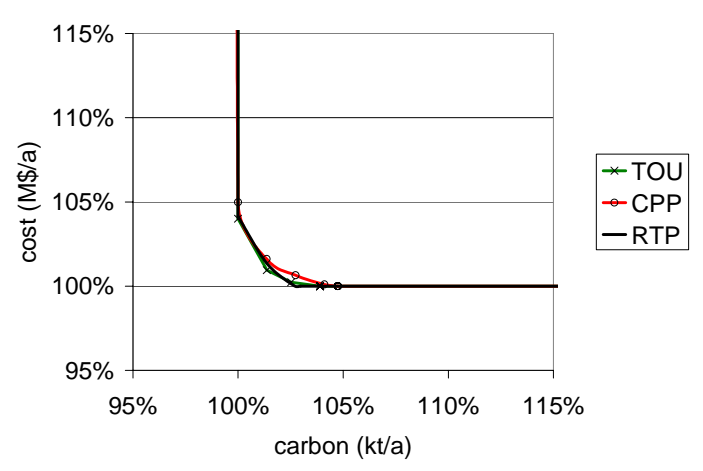

Figure 94. Houston - cost-carbon Pareto front, as percentage of best cost and best carbon solutions

Figure 95 and Figure 96 show these results for San Diego. Here, the Pareto fronts are right angles: least-cost dispatch is least-carbon dispatch.

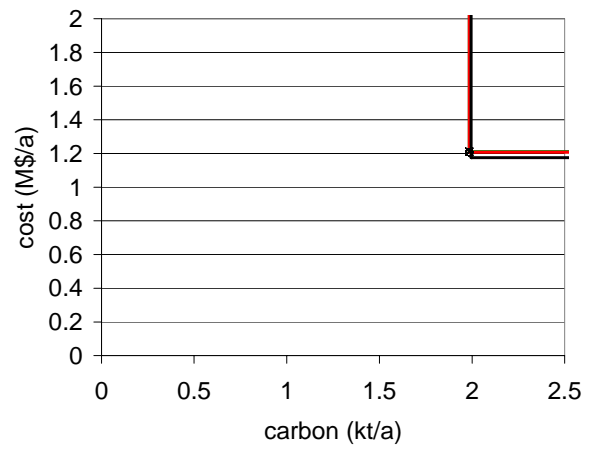

Figure 95. San Diego - cost-carbon Pareto front

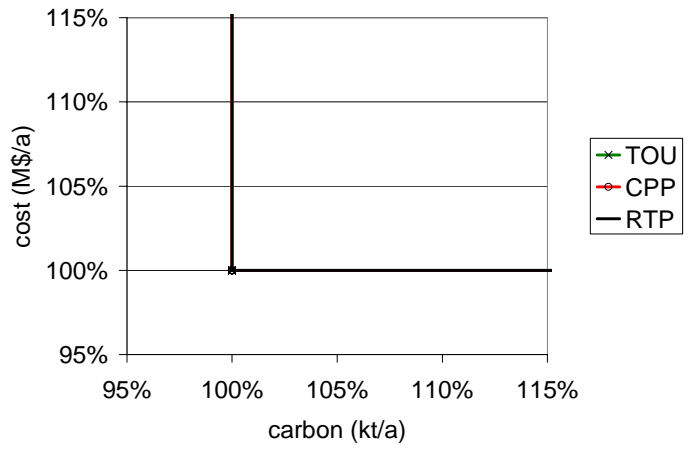

Figure 96. San Diego - cost-carbon Pareto front, as percentage of best cost and best carbon solutions

The results of this experiment show that, for the P\&DC sites considered, there is little or no difference between least-cost and least-carbon dispatch of the installed system. If greenhouse gas reductions are of interest to these sites, the crucial stage of the decision making is the design of the IES. 


\section{EXPERIMENT CONCLUSIONS}

The case study and experiments described in Chapters 7 and 8 demonstrate the usefulness of RT-OPTICOM in answering questions about dispatch optimization and resulting site energy cost and emissions implications. This chapter discusses these results. Note that these results are specific to sites with energy consumption patterns similar to those of the P\&DCs.

\subsection{Optimal Control Valuation}

This experiment compared energy costs that resulted from several control strategies: three heuristic control strategies (no-DG, load-following, heat-following), and optimal control. The results demonstrate that, quite often, optimal control can be reasonably approximated by a monthly selection between one of the three heuristic control strategies. This is particularly noticeable in the results under TOU and CPP tariffs. Under RTP tariffs, optimal control becomes more valuable, as scheduling alone is an inadequate approach to stochastic, volatile energy prices.

Table 21 summarizes these cost results. The maximum value of $D G$ is defined as the difference between average annual energy costs under no-DG and under optimal control strategies. The optimal control value is defined as the difference between average annual energy costs under heat-following (consistently the most valuable heuristic control strategy) and under optimal control. This value as a percentage of the maximum value is also reported. Figure 97 shows this information graphically, 
where it becomes clear that optimal control 1) has the most value in the two cities where DG has the least value (Baltimore and Boston), 2) has marginal value in the city where DG has intermediate value (Houston), and 3) has almost no value in the city where DG is most valuable (San Diego). In other words, the value of optimal control is generally inversely proportional to the overall value (with or without optimal control) of DG. The reason for this is that, in areas like San Diego or Houston, where dispatching DG is economic in most months, there is little need for a sophisticated controller. However, in areas like Baltimore or Boston, where dispatching DG is only economic in certain months, an intelligent controller provides value by identifying uneconomic DG dispatch.

Table 21. summary of average annual optimal control valuation

\begin{tabular}{|c|c|c|c|c|c|}
\hline & & \begin{tabular}{|l|} 
Baltimore \\
\end{tabular} & Boston & Houston & \begin{tabular}{|l|} 
San Diego \\
\end{tabular} \\
\hline \multirow[t]{3}{*}{ TOU } & $\begin{array}{r}\text { maximum value of DG } \\
\text { ( } \$ \$ \text { /year) }\end{array}$ & 200 & 184 & 265 & 415 \\
\hline & $\begin{array}{r}\text { optimal control value } \\
(\mathrm{k} \$ / \text { year })\end{array}$ & 77 & 71 & 19 & 3 \\
\hline & $\begin{array}{r}\text { optimal control value } \\
\text { (\% of maximum value) }\end{array}$ & $38 \%$ & $38 \%$ & $7 \%$ & $1 \%$ \\
\hline \multirow[t]{3}{*}{ CPP } & $\begin{array}{r}\text { maximum value of DG } \\
(\mathrm{k} \$ / \text { year) }\end{array}$ & 217 & 194 & 281 & 419 \\
\hline & $\begin{array}{r}\begin{array}{r}\text { optimal control value } \\
(\mathrm{k} \$ \text { /year) }\end{array} \\
\end{array}$ & 87 & 75 & 28 & 6 \\
\hline & $\begin{array}{r}\text { optimal control value } \\
\text { (\% of maximum value) }\end{array}$ & $40 \%$ & $39 \%$ & $10 \%$ & $1 \%$ \\
\hline \multirow[t]{3}{*}{ RTP } & $\begin{array}{r}\begin{array}{r}\text { maximum value of DG } \\
(\mathrm{k} \$ / \text { year) }\end{array} \\
\end{array}$ & 335 & 317 & 358 & 453 \\
\hline & $\begin{array}{r}\text { optimal control value } \\
\text { (k\$/year) }\end{array}$ & 134 & 118 & 57 & 9 \\
\hline & $\begin{array}{r}\text { optimal control value } \\
\text { (\% of maximum value) }\end{array}$ & $40 \%$ & $37 \%$ & $16 \%$ & $2 \%$ \\
\hline
\end{tabular}

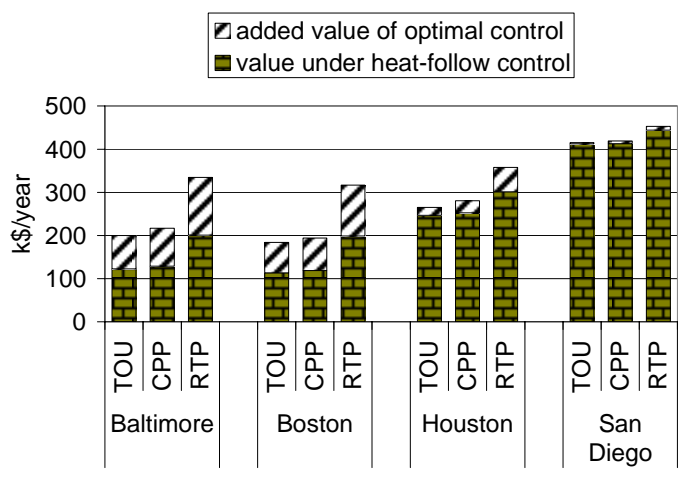

Figure 97. average annual value of DG

Given the conventional wisdom that two of the most attractive U.S. markets for DG are California and the Northeast, it is surprising that Houston proves to be a more economic location for DG at P\&DCs than Boston. The conventional wisdom is based on the relatively high electricity prices in the Northeast. While Houston electricity 
prices are lower than those in Boston, Houston natural gas prices are also lower. Furthermore, the Houston-site, like the San Diego site, has a larger, more consistent cooling load than the Boston-site. P\&DCs in general do not have large heating loads because of the significant heat put off by the mail sorting machinery. Often, it is heating loads that make DG in the Northeast attractive. The sub-par heating loads in Boston and the added value of absorption cooling in Houston tip the scales in favor of the Houston-site.

Figure 98 and Figure 99 show an a valuation of DG output based on the average industrial prices of electricity and natural gas in 2004 (Figure 98) and 2005 (Figure 99), reported by the EIA (2007a and 2007b). The value of generating one $\mathrm{kWh}$ of electricity is plotted if 1) only the electricity is used, 2) the waste heat is also used for heating, and 3) the waste heat is also used for cooling. Also plotted is the cost to produce this one $\mathrm{kWh}$ of electricity, assuming $35 \%$ electrical efficiency and a $\$ 0.01 / \mathrm{kWh}$ maintenance costs. Bars that are below the "cost to produce" line indicate situations where DG dispatch is uneconomic. Note that in both of these years Baltimore and Boston prices predict DG dispatch to be uneconomic, Houston prices predict DG dispatch to be economic when waste heat is useful, and San Diego prices predict DG dispatch to be highly economic, even when waste heat is not useful. Of course these graphs do not tell the full story; these are average annual energy prices the results of this research project demonstrate that there are many times when DG dispatch is economic in Baltimore and Boston. Also, these graphs do not reflect tariff structure - Boston, for example, has high demand charges, which can increase the 
value of distributed generation. Regardless, these graphs are an accurate predictor of the relative worth of DG in different locations.

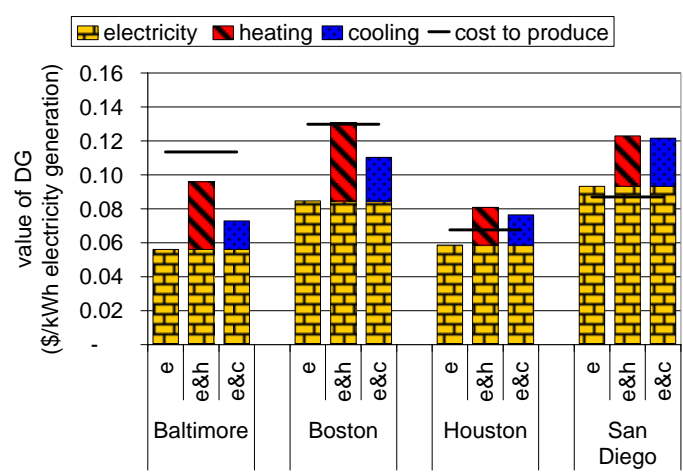

Figure 98. value of DG energy offsets in 2004

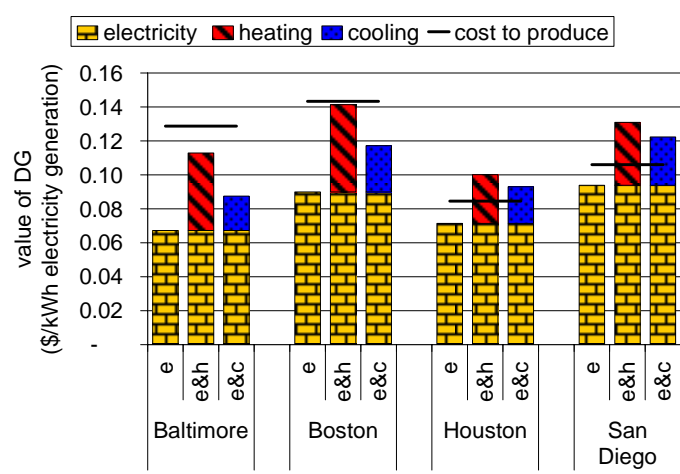

Figure 99. value of DG energy offsets in 2005

The results of this experiment demonstrate the potential price-responsiveness of DG under RTP tariffs. This behavior can improve price stability and grid stability to the extent that prices reflect supply security.

\subsection{DSM Valuation}

This experiment determined the value of a range of DSM programs 1) with DG as part of an integrated system and 2) without DG. Earlier work has supported the hypothesis that DSM and DG formed a synergistic relationship when their dispatch was integrated. The results of this research confirm this hypothesis for smaller curtailment programs but were inconclusive for larger curtailment programs. These results are particularly sensitive to the availability model that is used for DG, and the reliability of the particular DG units. Table 22 restates 
Table 20 in summarizing the value of DSM programs of 1) 10 hours per month, 100 $\mathrm{kW}$ per episode and 2) 25 hours per month, $250 \mathrm{~kW}$ per episode.

Table 22. DSM program value ( $\mathrm{k} \$ /$ year) for a 10 hour/month, $100 \mathrm{~kW} /$ episode program and a 25 hour/month, $250 \mathrm{~kW} /$ episode program in 2006

\begin{tabular}{|c|c|c|c|c|c|}
\hline & \multicolumn{2}{|c|}{$\begin{array}{l}10 \text { one-hour curtailments per } \\
\text { month }\end{array}$} & \multicolumn{2}{|c|}{$\begin{array}{c}25 \text { one-hour curtailments per } \\
\text { month }\end{array}$} \\
\hline & & \multicolumn{2}{|c|}{$100 \mathrm{~kW}$ maximum curtailment } & \multicolumn{2}{|c|}{$250 \mathrm{~kW}$ maximum curtailment } \\
\hline & & without DG & with DG & without DG & with DG \\
\hline \multirow[t]{3}{*}{ Baltimore } & TOU & 2 & 2 & 10 & 10 \\
\hline & CPP & 3 & 4 & 18 & 14 \\
\hline & RTP & 2 & 2 & 14 & 8 \\
\hline \multirow[t]{3}{*}{ Boston } & TOU & 13 & 23 & 37 & 53 \\
\hline & CPP & 15 & 18 & 42 & 48 \\
\hline & RTP & 16 & 28 & 40 & 50 \\
\hline \multirow[t]{3}{*}{ Houston } & TOU & 1 & 1 & 5 & 5 \\
\hline & CPP & 2 & 2 & 10 & 13 \\
\hline & RTP & 2 & 1 & 10 & 7 \\
\hline \multirow[t]{3}{*}{ San Diego } & TOU & 4 & 14 & 14 & 25 \\
\hline & CPP & 5 & 5 & 21 & 15 \\
\hline & RTP & 5 & 7 & 16 & 11 \\
\hline
\end{tabular}

\subsection{Cost-Carbon Co-optimization}

This experiment examined the trade-off between cost-minimization and carbonminimization. For all of the sites considered, under all tariffs, the largest room for trade-off was roughly an $8 \%$ increase in cost for an $8 \%$ decrease in carbon-emissions; in most cases the room for trade-off was less than 5\%. This suggests that carbonemissions implications are almost entirely decided at the design stage of a project, not in the dispatch. 
For fossil-baed CHP, carbon-savings are typically aligned with cost-savings. Figure 100 follows the style of Figure 98 and Figure 99 in comparing implications from conventional utility purchase to implications from on-site generation, this time comparing carbon emissions rather than cost. The horizontal black lines show how much carbon is emitted from one $\mathrm{kWh}$ of on-site electricity production. The yellow bars show how much carbon is attributed to the one kWh of grid-provided electricity that is offset. The red and blue bars show the additional carbon offset from utilized waste-heat, which offsets natural gas for heating or electricity for cooling. By comparing Figure 100 to Figure 98 and Figure 99, Baltimore is seen to have the least compelling economic case for DG, yet the most compelling carbon case for DG. This explains why the largest room for cost/carbon trade-off is seen in Baltimore. In cases where the disparity between economic case and carbon case are greater, real-time intelligence could be beneficial in balancing cost and carbon objectives.

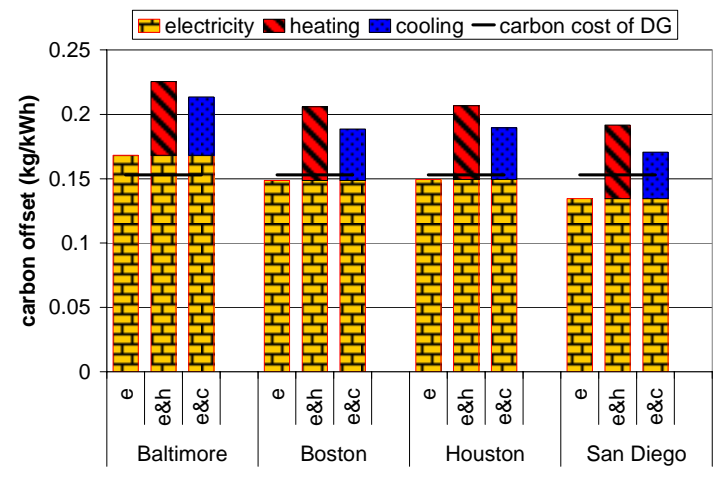

Figure 100. carbon value of energy offsets 


\section{PART 4: CONCLUSIONS AND FUTURE WORK}

Part 1 of this report described the IES dispatch optimization problem. Part 2 posed an algorithm for approximately solving it. Part 3 described several experiments conducted on a case-study building type to demonstrate the capabilities of the algorithm and the nature of optimal dispatch solutions.

Part 4, the final part of this dissertation, briefy summarizes the project and provides some concluding remarks. Chapter 10 summarizes the project. Chapter 11 discusses practical implementations of the RT-OPTICOM IES program, and Chapter 12 describes future work of immediate interest. 


\section{SUMMARY OF PROJECT AND CONCLUSIONS}

This project sought to quantify the economic savings possible from improved controls of integrated energy systems (IES). To accomplish this, a technique for obtaining near-optimal solutions to stochastic problems that are too complicated to solve analytically or using conventional operations research methods was required. This technique was developed, and applied to the specific IES problem. Finally, case studies using the resulting program were conducted to answer several pertinent questions about distributed generation (DG) dispatch and the integrated combination of DG and demand side management (DSM).

\subsection{The Real-time Optimal Control Model and Integrated Energy System Application}

The IES dispatch optimization problem is a multi-stage problem (hundreds of stages) with several stochastic parameters. Vertically-integrated utilities have tackled similar (and much more complicated) problems by developing heuristic approaches (often tailored to specific systems), thus making a tractable problem. This research takes a different approach, developing a general method for solving the multi-stage problems with multiple stochastic parameters. The Real-time Optimal Control Model (RTOPTICOM) accomplishes this.

RT-OPTICOM is then applied to the building IES problem by describing the details of the system: energy costs, energy balances, engineering constraints, regulatory 
constraints, and curtailment opportunities. This IES application was written as a mixed integer linear program for which commercial programming platforms and robust solvers are readily available.

\subsection{Case Study Experiments}

The United States Postal Services regional Processing and Distribution Centers (P\&DCs) were used as case study sites. The San Diego, California P\&DC recently installed a CHP system to provide electricity and thermally-activated cooling for their mail-handling and administrative activities. Data on the site's energy consumption and operational practices were collected through conversation with key players and a site visit. This information was used to develop a building energy simulation model of the P\&DC, which was used to tease out weather-related loads. Finally, this model was then applied to hypothetical P\&DCs in Baltimore, Maryland, Boston, Massachusetts, and Houston, Texas. Weather and energy price data were collected for the four cities considered.

At this point, an algorithm for solving real-time IES dispatch optimization problems and input data necessary for case studies were at hand. Three experiments were then conducted to begin to answer some of the motivating questions for this research. Experiments covered the four cities, three years of varying energy prices, and three tariff structures. 


\subsubsection{Optimal Control Valuation}

In this experiment, the site energy cost - the sum of electricity purchase, natural gas purchase, and CHP maintenance costs - were evaluated under several control strategies: no-DG, load-following, heat-following, and optimal control. The first three control strategies are heuristic, or "rule-of-thumb" strategies and do not require optimization. The fourth control strategy uses RT-OPTICOM for solutions. The optimal control strategy succeeds in being the lowest cost strategy in all 36 months, for all cities and all under all tariffs, validating (to some extent) the algorithm. Under time-of-use (TOU) and critical peak pricing (CPP) tariffs, the optimal control for a given month typically resembles one of the three heuristic control strategies. Optimal control under real-time pricing (RTP) is more complicated.

That optimal solutions resemble heuristic solutions for TOU and CPP tariffs suggests that heuristic control strategies can effectively capture most of the benefit of CHP. However, what many strategies lack is the automated intelligence to switch between heuristic strategies, i.e. to account for changes in load forecasts, energy prices, equipment availability in determining the best heuristic strategy for a given time. Assuming that optimal control provides the full economic benefit of CHP, the best heuristic control strategy (heat-following) provides only about $60 \%$ of the economic benefit in the marginally profitable cases of Baltimore and Boston P\&DCs. Much of the additional $40 \%$ of economic benefit would be achieved by a heuristic control strategy that switches between no-DG, load-following, and heat-following as 
conditions changed. In situations where the CHP system is not owned by the site, the control strategy may be contractually constrained - this experiment demonstrates the economic inefficiency of such contracts.

Optimal control under real-time pricing is more complicated, involving hedging behavior that accounts for forecasted energy prices and loads and the use for wasteheat. The results show a complicated pattern of switching the generator on and off. More realistic solutions that limit the number of on/off switching (to keep reliability and maintenance costs acceptable) would be even more complicated, although would require only slight modification to the RT-OPTICOM program. In some years, heuristic controls under RTP tariffs showed no economic benefit over not running DG at all. RTP is a reality in some locales and becoming a reality in more - developing the business case for CHP under these conditions will require more intelligent controls than those common today. The promise of RTP and intelligently controlled DG is a price elasticity much greater than that of typical (demand-only) customers; this contributes to improved price and grid stability.

\subsubsection{Demand Side Management Valuation}

In this experiment, the value of being able to curtail loads in limited quantities and frequencies is explored. For small curtailment programs ( $\sim 5 \%$ of load 10 hours per month), there is a synergy between DG and demand side management (DSM). For larger programs ( $\sim 15 \%$ of load 25 hours per month), this synergy is not statistically 
significant. The demand charges in current tariffs incent strategic curtailment, even in the absence of demand response programs ${ }^{19}$ and intelligent controls are capable of optimizing curtailments. However, the value of small curtailment programs in most cases does not exceed $1 \%$ of annual energy costs, suggesting limited potential for this capability. Most significant savings ( $2 \%$ of total costs in some cases) were seen in Boston, where demand charges were highest. Large curtailment programs were more valuable, but still not compelling. What typical tariffs do not reflect is the benefit to the whole customer base that curtailment during high-priced times provides: everyone benefits from lower clearing prices. These small values of DSM suggest that demand response programs, which provide additional incentives for curtailment, are necessary to make curtailment financially compelling and at the same time make decision making about curtailment more straightforward.

\subsubsection{Cost-Carbon Co-optimization}

This experiment illustrated that the energy-situations in three of the four cities did not create a compelling trade-off between cost-minimization and carbon-minimization. The energy-situation in Baltimore, however, which has the largest disparity between economic case and carbon case for CHP, did create a moderately compelling tradeoff: approximately $8 \%$ increase in cost would be incurred in going from a least-cost dispatch to a least-carbon dispatch, in which case carbon emissions would be reduced

${ }^{19}$ Demand response programs provide incentives in excess of cost savings under typical tariffs to customers who manually or automatically curtail loads at the request of the utility or independent system operator. 
by about $8 \%$. While greenhouse gas emissions from energy consumption remains an externality (i.e. not explicitly priced) of site value, intelligence could be useful in achieving co-optimization of cost and carbon in situations where there is a large disparity between least-cost and least-carbon dispatch. 


\section{PRACTICAL IMPLEMENTATION}

This work presents a tractable approach to the IES dispatch optimization problem and demonstrates its usefulness through simulation. RT-OPTICOM could be useful in simulation for many other purposes. This algorithm could also be used to control an actual IES. This chapter briefly describes some of these uses.

\subsection{RT-OPTICOM in Simulation}

As demonstrated in this work, RT-OPTICOM can be used to determine the value of a specified IES with and without optimal control. These valuations can help designers determine 1) optimal sizing of IES equipment, 2) near-optimal heuristic dispatch strategies, and 3) the worth of implementing optimal control. If optimal control is not implemented, RT-OPTICOM simulations could be done periodically by an analyst in order to update and fine-tune the heuristic strategies based on changes in energy prices, site loads, equipment performance, regulatory constraints and incentives, and changing site objectives.

Using RT-OPTICOM to develop near-optimal heuristic control strategies for simple IES would be particularly useful. As demonstrated in the optimal control valuation experiment (Section 8.1), for sites with only DG, much of the benefit of optimal control could be achieved simply by identifying which heuristic control strategy is best for the current month. A set of heuristic control strategies that included no-DG, load-following, heat-following, and time-of-use variants of these strategies would be 
ample for many situations. From the author's experience speaking with building managers, simply demonstrating the impact of strategy switching in response to changes in energy prices would be quite useful. Additional research is required to ensure that improved heuristics are robust to the myriad energy consumption patterns, tariff structures, and energy price regimes that DG is in or might be in.

RT-OPTICOM can be used as a screening tool to identify building types and locations that are best suited to IES. For simple systems such as CHP, renewables, and/or energy storage, extent software tools such as those described in Section 3.3 might be better suited, because they consider both the dispatch and investment optimization simultaneously. However, these programs might not capture the detail necessary for more complicated situations such as complex tariff structures, curtailment and/or rescheduling opportunities, significant uncertainty in price, load, or equipment availability, real-time pricing, or combined cost and environmental objectives. For these situations, RT-OPTICOM provides new potential for problem solving.

\subsection{RT-OPTICOM in the Field}

For more complicated IES, RT-OPTICOM could be used to directly control system equipment. Building managers typically do not have the resources required to continuously monitor energy conditions and adjust dispatch accordingly. However, more complicated IES tend to already be connected to an energy management system 
- typically software, housed on a personal computer - that monitors energy consumption and HVAC operations. A real-time optimization program such as RTOPTICOM could be tied into the energy management software or run in parallel on a neighboring personal computer, regularly providing suggestions or commands.

For smaller sites, the added cost of implementing an automated, real-time controller might not outweigh the benefits provided by optimal control. However, these implementations costs would not increase significantly with building (or load) size, and might be cost-effective for larger sites. 


\section{FUTURE WORK}

This section briefly discusses RT-OPTICOM IES algorithm improvements and research applications of immediate interest.

\subsection{Algorithm Improvement}

\subsubsection{On/off Constraints}

Looking at the results in Section 8.1.3, one obvious improvement to the algorithm is a constraint on the number of starts and stops dispatched to a generator. The results here show that there are often many starts and stops per day when exposed to realtime prices. This behavior would most likely cause increased maintenance costs, lower generator availability, and a shorter generator lifetime than anticipated. An additional constraint, posed as a minimum allowable run time once a generator is turned on, could address this issue.

Typically, frequent on/off switching suggests that there is not much difference in the objective function between the two solutions - it is anticipated that constraints on on/off switching would improve the practicality of dispatch solutions more than it would effect the objective function. This additional constraint would, however, increase computation time because the decisions made in one time-step would be more closely coupled to those in adjacent time-steps. 


\subsubsection{Storage and Intermittent Resources}

An interesting application for RT-OPTICOM would be to examine IES comprised of wind or solar power and electrical storage. Rising fossil fuel prices, public incentives, and improvements in storage technologies are renewable sources more economic. The intermittency and non-coincidence of renewable power with site loads can justify the use of electrical storage. The significantly stochastic nature of the renewable power would require significant hedging behavior on the part of the storage device, something that a spreadsheet analysis of the IES would not be able to capture. RT-OPTICOM could be used to assess the value of storage for renewable systems, and thus to optimally size the storage. In order to facilitate this, electrical storage would need to be added to the RT-OPTICOM IES model and a stochastic wind model would need to be obtained or developed.

\subsection{Research Applications}

\subsubsection{Near-optimal Heuristic Control}

As discussed earlier, for simple IES situations, near-optimal heuristics could provide much of the benefit of optimal control, at less cost and complication. An automated approach to analyzing RT-OPTICOM IES results and identifying heuristic control regimes could be developed, along with a method for assessing energy-situation inputs to determine which heuristic regime to dispatch the system in. 


\subsubsection{Scoping Studies of Building Types, Locations, and IES Designs}

The implications of the results of this research are quite limited because they only consider one building type and one (simple) IES design. The RT-OPTICOM IES model could be used for more scoping studies of any of the parameters in the problem, especially building type, regional location, IES design, but also energy prices, tariff structure, DSM opportunities. From the private perspective, these studies could be used to identify potential opportunities; for the public perspective, these studies could be used to inform policy where IES was of public interest. 


\section{REFERENCES}

Bailey, Owen, Charles Creighton, Ryan Firestone, Chris Marnay, Michael Stadler. 2003. "Distributed energy resources in practice: A case study analysis and validation of LBNL's customer adoption model" Lawrence Berkeley National Laboratory, Berkeley, CA. LBNL-52753

BGE [Baltimore Gas and Electric Company], 2007a. "Electric Service Rates and Tariffs - Schedule P"

http://www.bge.com/portal/site/bge/menuitem.ce4160ba3b66a30159c031e0da6176a0 I

BGE [Baltimore Gas and Electric]. 2007b. "Gas Service Rates \& Tariffs - General Service - Schedule C" http://www.bge.com/portal/site/bge/menuitem.6b0b25553d65180159c031e0da6176a $\underline{0 /}$

Borenstein, Severin and James B. Bushnell. 2000. "Electricity Restructuring: Deregulation or Reregulation?" Regulation, Vol. 23, No. 2, Summer 2000.

Borgonovo, E., M. Marseguerra, and E. Zio. 2000. "A Monte Carlo methodological approach to plant availability modeling with maintenance, aging, and obsolescence" Reliability Engineering and System Safety 2000; 67: 61-73

CAISO [California Independent System Operator] 2007. "Open Access Same-Time Information System (OASIS)" http://www.oasis.caiso.com.

CARB [California Air Resources Board] 2006. "Distributed Generation Program" website. http://www.arb.ca.gov/energy/dg/dg.htm

Caterpillar 2006. Product specification sheet for the $1600 \mathrm{ekW}$ continuous power gas generator set. Available online at

http://www.cat.com/cda/components/fullArticle/?m=39280\&x=7\&id=215797\&langu ageId $=7$

Chalermkraivuth, K.C. and M.D. Ilic, 2001. "Decision Criteria for the Deployment of Distributed Generation Technologies", Massachusetts Institute of Technology Energy Laboratory, Cambridge, MA MIT EL 01-006 WP

The Climate Trust, 2005. "U.S. Electricity Grid Intensity Factors" The Climate Trust, Portland, OR. http://www.climatetrust.org/solicitations_2005_Electricity.php

Coffey, Brian 2006 “A Model-Based Control Strategy for Responsive Building Systems" Concordia University, Montreal, Canada (report not yet published) 
Coffey, Brian, and Ed Kutrowski. 2006. "Demand charge considerations in the optimization of cogeneration dispatch in a deregulated energy market" International Journal of Energy Research, v 30, n 7, Jun 10, 2006, p 535-551

Curtis, Peter, and Jan Kreider. 2003. "Recent Developments in the Control of Distributed Electrical Generation Systems" Transactions of the ASME, volume 125, August 2003

Deng, Shijie. 2000. "Stochastic Models of Energy Commodity Prices and Their Applications: Mean-Reversion with Jumps and Spikes" University of California Energy Institute, Berkeley, CA PWP-073

Dhamdhere, Kedar, R. Ravi, and Mohit Singh. 2005. "On two-stage stochastic minimum spanning trees." In Proceedings of the 11th Integer Programming and Combinatorial Optimization Conference, pages 321-334, 2005.

EIA [Energy Information Administration], 2007a. "Average Retail Price of Electricity to Ultimate Customers by End-Use Sector", http://www.eia.doe.gov/cneaf/electricity/epa/epat7p4.html

EIA [Energy Information Administration], 2007b. "Natural Gas Navigator", http://tonto.eia.doe.gov/dnav/ng/ng pri top.asp

ERCOT [Electric Reliability Council of Texas]. 2007. "Balancing Energy Services Daily Reports” http://www.ercot.com/mktinfo/services/bal/index.html

Energy Nexus Group, 2002, “Technology Characterization: Microturbines” prepared for the Environmental Protection Agency. Arlington, VA.

Ferris, Michael C. 2005. "MATLAB and GAMS: Interfacing Optimization and Visualization Software" University of Wisconsin, Madison. http://www.cs.wisc.edu/math-prog/matlab.html

Firestone, Ryan. 2004. "Distributed Energy Resources Customer Adoption Model Technology Data”. Lawrence Berkeley National Laboratory, Berkeley, CA. Available online at http://der.lbl.gov/data/DERCAMTechDataOnline.pdf

Firestone, Ryan, Charles Creighton, Owen Bailey, Chris Marnay, and Michael Stadler, 2003. "A business case for on-site generation: The BD biosciences pharmingen project.” Lawrence Berkeley National Laboratory, Berkeley, CA. LBNL52759

Firestone, Ryan and Chris Marnay, 2005a. "Energy manager design for microgrids" Lawrence Berkeley National Laboratory, Berkeley, CA. LBNL-54447 
Firestone, Ryan, Chris Marnay, and Juan Wang, 2005 "Integrated Modeling of Building Energy Requirements Incorporating Solar Assisted Cooling” Proceedings of the 2005 International Conference on Solar Air Conditioning, Kloster Banz, Germany, 6th/7th October 2005. Published by Ostbayerisches Technologie-TransferInstitut e.V. (OTTI), Regensburg, Germany

Firestone, Ryan and Chris Marnay, 2005b. "The Effects of Electricity Tariff Structure on Distributed Generation Adoption in New York State" Lawrence Berkeley National Laboratory, Berkeley, CA. LBNL-57942

Firestone, Ryan, Chris Marnay, and Karl Magnus Maribu, 2006. "The Value of Distributed Generation under Different Tariff Structures", Proceedings of the ACEEE 2006 Summer Study on Energy Efficiency in Buildings, August 13 - 18, 2006,Pacific Grove, California

Firestone, Ryan, Michael Stadler and Chris Marnay, 2006. "Integrated Energy System Dispatch Optimization" Proceedings of the $4^{\text {th }}$ Annual IEEE Conference on Industrial Informatics, Aug. 2006 pp. 357-362.

Goldman, Charles A., Michael Kintner-Meyer, and Grayson Heffner, 2002. "Do 'Enabling Technologies' Affect Customer Performance in Price-Responsive Load Programs?". Proceedings of the 2002 ACEEE Summer Study on Energy Efficiency in Buildings.

Goldman, Charles, Nicole Hopper, Ozman Sezgen, Mithra Moezzi, and Ranjit Bharvirkar, 2004. "Customer Response to Day-ahead Wholesale Market Electricity Prices: Case Study of RTP Program Experience in New York.” Lawrence Berkeley National Laboratory, Berkeley, CA. LBNL-54761

Goldstein, L, B. Headman, D. Knowles, S.I. Freedman, R. Woods, T. Schweizer. 2003. "Gas-Fired Distributed Energy Resource Technology Characterizations" Golden, CO: National Renewable Energy Laboratory Report NREL/TP-620-34783.

Gupta, Anupam, Martin Pal, Ramamoorthi Ravi, Amitabh Sinha, 2005 "What about wednesday? Approximation algorithms for multistage stochastic optimization" Lecture Notes in Computer Science, v 3624, Approximation, Randomization and Combinatotial Optimization - Algorithms and Techniques: 8th Int. Workshop on APPROX 2005 and 9th Int. Workshop on RANDOM 2005, Proceedings, 2005, p 8698

Hillier, Frederick S., and Gerald Lieberman, 1995. Introduction to operations research, $6^{\text {th }}$ ed. New York, McGraw-Hill. 
InterEnergy Software 2002. "User Manual - d-gen PRO Version 3.5"

http://www.interenergysoftware.com/PDF/DGPManual.pdf

ISO-NE [Independent System Operator of New England]. 2007 “Hourly Zonal Information" http://www.iso-ne.com/markets/hstdata/znl info/hourly/index.html

James J. Hirsch \& Associates, 2007. “eQUEST: the Quick Energy Simulation Tool”, http://doe2.com/equest/

Keyspan Energy. 2007 "Gas Rates - Boston"

http://gasrates.keyspanenergy.com/ne/NEGasrates/NEGasratesController

Kintner-Meyer, M. C. Goldman, O. Sezgen, and D. Pratt. 2003. "Dividends with Demand Response" ASHRAE Journal, v. 45 i. 10

LaCommare, Kristina Hamachi, Ryan Firestone, Nan Zhou, Karl Maribu, and Chris Marnay, 2006. "A Model of U.S. Commercial Distributed Generation Adoption" Lawrence Berkeley National Laboratory, Berkeley, CA. LBNL-57962

Lilienthal, P., L. Flowers, and C. Rossmann, 1995. "The Hybrid Optimization Model for Electric Renewables". Windpower '95: Proceedings of the Annual Conference and Exhibition of the American Wind Energy Association, 26-30 March 1995, Washington, DC. pp. 475-480

Motegi, Naoya, Mary Ann Piette, Satkartar Kinney, and Jim Dewy, 2003. "Case Studies of Energy Information Systems and Related Technology: Operational Practices, Costs, and Benefits" Proceedings of the International Conference for Enhanced Building Operations, October 13-15, 2003, Berkeley, CA.

Motegi, N., M. A. Piette, and S. Kinney. 2003. "Web-based Energy Information Systems for Demand Response and Energy Management in Commercial Buildings" Lawrence Berkeley National Laboratory, Berkeley, CA. LBNL-52510.

Momoh, James A. 2001. Electric Power System Applications of Optimization Marcel Dekker, New York, NY.

National Grid, 2007. Electric Service - Large General, TOU (SC-3A) http://www.nationalgridus.com/niagaramohawk/business/rates/5 elec sc3a.asp

NRC [Natural Resources Canada] 2007. "RETScreen - Online Software \& Data" http://www.retscreen.net/ang/d_o_view.php

NRC [Natural Resources Canada] 2006. "Technologies and Applications: Solar Collectors" website.

http://www.canren.gc.ca/tech appl/index.asp?CaID=5\&PgID=282 
NSTAR, 2007. "Schedule of Rates - Boston, G-3"

http://www.nstar.com/ss3/business/rates tariffs/rates/schedule.asp

Piette, Mary Ann, Osman Sezgen, David Watson, Naoya Motegi,Christine Shockman, and Laurie ten Hope. 2004. "Development and evaluation of fully automated demand response in large facilities" Lawrence Berkeley National Laboratory, Berkeley, CA. LBNL-55085.

PUCT [Public Utilities Commission of Texas], 2007 "Expired Expired Price to Beat Tariffs for Affiliated Retail Electric Providers", http://www.puc.state.tx.us/electric/rates/PTB.cfm

Ravi, R, and Amitabh Sinha, 2004. "Hedging uncertainty: Approximation algorithms for stochastic optimization problems." In Proceedings of the 10th Integer Programming and Combinatorial Optimization Conference, pages 101-115.

Regan, T.; Sinnock, H.; Davis, A. 2003. Distributed Energy Neural Network Integration System: Year One Final Report. 120 pp.; NREL Report No. SR-56034216.

RReDC [Renewable Resource Data Center], 2007. "Solar Radiation Resource Information”, National Renewable Energy Laboratory, http://rredc.nrel.gov/solar/

SCE [Southern California Edison], 2007. " Schedule TOU-GS2-CPPV-1: Time-ofUse, General Service, Statewide Pricing Pilot Critical Peak Pricing, Variable Period" http://www.sce.com/AboutSCE/Regulatory/tariffbooks/ratespricing/businessrates.htm

SDG\&E [San Diego Gas and Electric], 2007b. "Electric Tariff Book Commercial/Industrial Rates - Rate AL-TOU-DER and" http://www.sdge.com/regulatory/tariff/elec_commercial.shtml

SDG\&E. 2007b. "Gas Tariff Book - Core Services - Schedule GN-3" http://www.sdge.com/regulatory/tariff/gas_core.shtml

Stadler, Michael, Ryan Firestone, Chris Marnay, and Dimitri Curtil, 2006. "On-Site Generation Simulation with EnergyPlus for Commercial Buildings" Proceedings of the ACEEE 2006 Summer Study on Energy Efficiency in Buildings, August 13 - 18 2006, Pacific Grove, California.

Suez Energy Resources, NA. 2007. "Market Fundamentals - PJM - Historical RT hourly pricing." http://www.suezenergyresources.com/Marketfund/PJM.aspx

The Climate Trust, 2005. "U.S. Electricity Grid Intensity Factors" http://www.climatetrust.org/solicitations_2005_Electricity.php\#US 
US-EPA [United States Environmental Protection Agency], 2007. "Catalogue of CHP Technologies". US-EPA Combined Heat and Power Partnership.

Valenzuela, Jorge and Alice E. Smith, 2002. "A Seeded Memetic Algorithm for Large Unit Commitment Problems" Journal of Heuristics, Springer Netherlands v $8 \mathrm{n}$ 2 Pages: 173 - 195

WADE [World Alliance for Decentralized Energy] 2003, “Guide to Decentralized Energy Technologies", Edinburgh, Scotland.

Watson, David S., Mary Ann Piette, Osman Sezgen, Naoya Motegi, 2004.

"Automated demand response" HPAC Heating, Piping, Air Conditioning Engineering, v 76, n SUPPL., October, 2004, p 20-28

Weather Underground 2007, online weather data, http:/www.wunderground.com/

Willis, H. Lee and Walter G. Scott, 2000. Distributed Power Generation: Planning and Evaluation Marcel Dekker, New York. 


\section{Appendix A. UTILITY ELECTRICITY SYSTEM DISPATCH OPTIMIZATION AND COMPARISON TO INTEGRATED ENERGY SYSTEMS}

Vertically integrated electric utilities face a very similar optimization problem as integrated systems (IES) for buildings. Utilities have many power plants and individual generators that they can dispatch at a given time to meet the immediate power demands of their customers. Similarly, a site with IES has several energy resources (i.e. generators, storage, demand side management (DSM) opportunities) that must be dispatched to meet the power demand of the site. Often, there is the opportunity to buy balancing energy from the utility and, in some cases, to sell excess energy as well. Although of much different magnitudes, electricity production equipment for both electric utilities and IES are subject to ramping rates, minimum down-time constraints, variable maintenance costs, fixed-batch energy supplies (e.g. hydropower or limited supplies of NG or other fuel), and emissions restrictions. Both problems must deal with uncertainty in load and in equipment availability, and realtime dispatch optimization for both problems requires future planning.

The utility dispatch problem, in its entirety, is enormous. Optimal or near-optimal control of the system requires decision making on the order of minutes, over a timespan of a year or more (to include maintenance scheduling and the rationing of scarce resources), with uncertainty in demand and in 
generator/transmission/distribution availability at every time-step. To make the problem manageable, it is typically divided into three separate problems:

- a planning problem for the day-to-day problem (over the course of months);

- a unit commitment problem for the hour-to-hour problem (over the course of several days); and

- a power flow problem for the minute-to-minute decisions (over the course of tens of minutes), to ensure that transmission lines are not overloaded, and to account for both real and reactive power demand.

Using this multi-tiered dispatch strategy, the availability of units is determined through planning; the prioritization of dispatch of available units is determined through unit commitment; and fine-tuning of the system is done through power flow optimization.

IES systems typically do not have much of a power flow problem to solve or monitor: Utility systems have a networked grid of generation and transmission equipment, leading to many control variables and safety checks (such as over-current on transmission lines) to apply, even after a particular set of generators is selected to operate. IES systems, however, are typically fixed, configured radially rather than in a network, and sized for the maximum possible power-flow.

IES systems do have problems similar to the unit commitment and planning problems of utility electricity systems. IES systems may need to plan over an annual timescale 
to meet minimum system efficiency requirements (an annual average) or maximum emissions caps and/or to best utilize scarce resources (such as a fixed volume fuel contract). Planning for the IES problem is less complicated than for the utility scale problem, though, because fewer dispatchable units are involved.

The unit commitment problem, however, is the stage of the utility electricity system dispatch optimization that is most similar to the IES dispatch optimization problem. Both require decisions on the order of an hour, and planning over many days. Both are made difficult by their combinatorial enormity because of the integer nature of dispatch decisions to individual units, the varying cost and performance characteristics of various units, operational constraints on various units, and planning required over many time-steps.

\section{Differences Between Unit Commitment And IES Dispatch Optimization}

While unit commitment research and practice is helpful in developing the IES dispatch optimization problem, there are significant differences between the two which necessitate a different approach to a solution for each.

The presence of demand charges for IES is one such difference from the unit commitment problem. Electric utilities are subject primarily to the fixed and volumetric costs of production. Planning is mostly required because of the ramping rates and minimum down-time constraints, which can each be on the order of hours to 
days. This explains the several-day timespan considered in unit commitment problems. While IES equipment may be more rapidly dispatchable (the smaller size of generators necessitates start-up times of only a few minutes or less), demand charges, when significant, require planning over the entire month in order to determine optimal dispatch at the beginning of the month ${ }^{20,21}$. Thus, while the IES problem has an order of magnitude fewer plants/equipment to dispatch (typically only a few), the combinatorial problem is similar to that of the unit commitment problem because planning is required over an order of magnitude more time-steps.

The energy balance constraint for the two classes of problems is another significant difference: while the unit commitment problem only requires that electric power provided equals electric power supplied, the IES problem requires that several types of energy be balanced and over different timescales; electric end-use loads must be met instantaneously while heating and cooling loads must be met on the order of minutes (or more if significant thermal storage is present). Furthermore, the supplies for these end-uses are not independent: electricity production may include recoverable thermal power as a byproduct, and cooling loads might be met by electric-driven compression chillers, natural-gas fired compression or absorption chillers, and/or thermally activated absorption chillers or desiccant dehumidifiers.

\footnotetext{
${ }^{20}$ Note that the necessary timespan decreases as the end of the month approaches. ${ }^{21}$ As mentioned earlier, IES annual constraints, such as minimum system efficiency, or emissions caps, require planning over an entire year. This long-range, low-detail planning is similar, although less complex, to the planning stage of utility electricity dispatch optimization.
} 
A further complication for the IES problem is uncertainty in electric loads and generator availability. Uncertainty in load of an aggregation of customers (i.e. the utility territory) is relatively small (on the order of a few percent) and fairly predictable by weather and time of day/year for a given region. However, the load uncertainty of a single customer is much larger, where seemingly randomly occurring demand spikes or heavy consumption days may be $150 \%$ or more of the predicted load. Unplanned outages are much more common in IES generators than in utility scale power plants because there is typically not a maintenance staff to nurse the IES generator; routine maintenance happens on the order of months to annually.

For utility scale unit commitment, uncertainty in the size of electric demand and generator availability is handled by including reserves: generation units that can be dispatched on short notice in the event of either demand in excess of forecast or generator outage. By selecting an appropriately large reserve margin, solutions to the unit commitment problem based on the assumption of deterministic loads and 100\% generator/transmission reliability are adequate. Because demand charges can be significant and yet minimum possible monthly utility demand is unknown ${ }^{22}$, hedging behavior is necessary for the IES system, whereas the utility electricity system can afford to view their problem deterministically.

${ }^{22}$ The minimum possible monthly demand at a site is MinimumDemand $($ month $)=\max _{t \in \text { month }}(\operatorname{SiteLoad}(t)-\operatorname{SiteSupply}(t))$ yet neither the load nor supply are deterministically know. 
Another difference between the two problems is how the energy balance between source and load are balanced: for the utility scale problem, load, for the most part, is not controlled: reserves are dispatched if power is needed in excess of planned resource. The IES system energy balance consists of both source and more significant load control. Dispatchable sources include on-site generation, utility purchase, and storage. Dispatchable loads are those that are curtailable or reschedulable.

A simplification of the IES problem over the unit commitment problem is that IES need not consider the line-overload checks, reliability and security checks, real/reactive power, and line loss details that necessitate the first tier of the utility problem (power flow modeling to optimize decisions for timespans on the order of minutes). Also, the unit-commitment problem must consider units with very constrained and very different operational characteristics, e.g. nuclear, coal, gas turbine, and wind turbine. Often, regulatory constraints restrict DG equipment from providing reactive power, sites with significant reactive power requirements typically have dynamic capacitor banks on-site to reduce the reactive power demand, and IES do not have multiple path opportunities, so that line losses are a fixed energy cost.

While combinatorially similar in magnitude, the presence of demand charges, relevant uncertainty, a complicated set of energy balance constraints, and heterogeneous dispatch options to meet energy demand all make the IES dispatch problem different than the utility dispatch problem. However, the identification and 173 
mathematical description of generator operation and constraints in the unit commitment problem is useful in developing the IES dispatch optimization problem. 


\section{Appendix B. QUANTIFICATION OF DISCRETE FEASIBLE SOLUTIONS TO THE IES DISPATCH PROBLEM}

This appendix describes a counting exercise to illustrate the combinatorial enormity of integrated energy system dispatch problems.

\section{Generator Dispatch}

Because of the minimum load constraints on generators, a binary decision is necessary for dispatch (generator on or off). Over the course of $N$ time-steps in the timespan of consideration (e.g. for the IES dispatch optimization problem, typically one month timespan in one hour time-steps $=720$ time-steps in a 30 day month), a dispatch decision is made at each time-step. If there are no constraints on minimum run time, then there are $N$ independent binary decisions for each of $G$ generators. There are then $2^{G N}$ feasible generator solutions.

\section{Curtailment Dispatch}

To approximate the number of feasible curtailment schedules, consider a timespan (e.g. one month for our dispatch optimization problem), broken into $N$ time-steps. Consider a site that will tolerate $C$ curtailment episodes, each of duration, $D$ (expressed in number of time-steps). Assume that the site incurs no cost for curtailing, so that in each month the optimal solution will be to use all $C$ curtailment 
episodes. How many feasible curtailment schedules are there? A straightforward way to approach this counting exercise is to consider the gaps in between each episode, plus those prior to the first curtailment and subsequent to the last episode. There are $C+1$ gaps, and their total value must add up to the time no curtailment is going on, i.e. $N-C D$. If we call this $\operatorname{sum} A$, then the following expression is the feasible number of curtailment schedules:

$$
\text { FeasibleCurtSolns }=\sum_{\mathrm{i}_{\mathrm{C}+1}=1}^{\mathrm{A}} \sum_{\mathrm{i}_{\mathrm{C}}=1}^{\mathrm{i}_{\mathrm{C}+1}} \cdots \sum_{\mathrm{i}_{1}=1}^{\mathrm{i}_{2}} \mathrm{i}_{1}
$$

A second order approximation of this expression is:

$$
\text { FeasibleCurtSolns }=\frac{\mathrm{A}^{\mathrm{C}+1}}{(\mathrm{C}+1) !}+\frac{1}{2} \frac{\mathrm{A}^{\mathrm{C}}}{(\mathrm{C}-1) !}+\mathrm{O}\left(\mathrm{A}^{\mathrm{C}-1}\right)
$$

Note that if a site is not constrained to use all of its curtailment episodes, even more solutions are possible.

\section{Total Feasible Discrete Solution Sets}

The total number of discrete feasible solution sets is then the product of feasible solution sets for generator dispatch and for curtailment dispatch. 


$$
\text { FeasibleSolns } \approx\left(2^{G N}\right)\left(\frac{\mathrm{A}^{\mathrm{C}+1}}{(\mathrm{C}+1) !}+\frac{1}{2} \frac{\mathrm{A}^{\mathrm{C}}}{(\mathrm{C}-1) !}\right)
$$

Table 23 shows the approximate number of feasible solution sets for several basic scenarios, assuming one-hour time-steps over the course of a 30 day month. Clearly, the number of feasible solution sets for even the smallest IES problem is too large for enumerative searches.

Table 23. approximate number of feasible solution sets for month long optimization with hourly time-steps

\begin{tabular}{|c|c|c|c|c|}
\hline Number of Generators & 1 & 3 & 0 & 1 \\
\hline $\begin{array}{l}\text { Number of Allowable } \\
\text { Curtailment Episodes } \\
\text { (episodes/month) }\end{array}$ & 0 & 0 & 5 & 5 \\
\hline $\begin{array}{l}\text { Duration of Curtailment } \\
\text { Episodes (time- } \\
\text { steps/episode) }\end{array}$ & $\mathrm{N} / \mathrm{A}$ & N/A & 1 & 1 \\
\hline $\begin{array}{l}\text { Number of Feasible } \\
\text { Solution Sets }\end{array}$ & $2^{720}=6 \times 10^{216}$ & $2^{2160}=2 \times 10^{650}$ & $2^{47}=2 \times 10^{14}$ & $2^{767}=1 \times 10^{231}$ \\
\hline
\end{tabular}




\section{Appendix C. STOCHASTIC MODEL OF REAL-TIME ELECTRICITY PRICES}

For this research, a stochastic model of electricity spot market clearing prices that could be calibrated to historic clearing prices was required. A standard model for stochastic commodity prices (especially extremely perishable commodities, such as electricity) is mean-reverting Brownian motion. In other words, prices are subject to random volatility over time which can be approximated as Brownian motion (i.e. a Wiener process) with a tendency for prices to return to their long term expected level. Equation (53) describes this model.

$$
d \operatorname{Price}(t)=(\kappa(\theta-\operatorname{Price}(t))) d t+\sigma d W
$$

where

- Price is the current electricity clearing price

- $\boldsymbol{\kappa}$ is the mean reversion coefficient

- $\quad \boldsymbol{\theta}$ is the long term mean electricity clearing price

- $\sigma$ is the volatility rate

- $\quad \mathbf{t}$ is the current time

- $\mathbf{W}$ is a Wiener process, i.e. $\mathrm{W}_{\mathrm{t} 2}-\mathrm{W}_{\mathrm{t} 1} \sim \mathcal{N}(0, \mathrm{t} 2-\mathrm{t} 1)$

This is a simplified version of the model described in Deng (2000): a mean reversion model that includes a term for influencing factor (such as natural gas price in the case of electricity price modeling), random jumps (to mimic price spikes), and time- 
varying volatility. The more complete Deng model was beyond the scope of this first cut at the research topic. However, the inclusion of price-spikes in future work would be useful, especially for larger sites where the ratio of cost-savings-potential to controls/intelligence costs is greater.

As a substitute for including an influencing factor, $\theta$ was a temperature-adjusted historic average clearing price for the particular time of day, day-type (weekday or weekend) and month, using the model described in Equation (54). This modification accounts for daily, seasonal, and climactic trends in prices that are not stochastic.

$$
\theta_{m, d t, h}=\beta_{m, d t, h, 0}+\beta_{m, d t, h, 1} H D+\beta_{m, d t, h, 2} C D+\mu
$$

where

- $\quad \mathbf{m}$ is the month $\{1,2, \ldots, 12\}$

- dt is the day-type \{weekday,weekend\}

- $\mathbf{h}$ is the hour $\{1,2, \ldots, 24\}$

- $\boldsymbol{\theta}$ is the temperature-adjusted historic average clearning price

- HD are the heating degrees (maximum(0,65 - temperature)) at the current hour

- CD are the cooling degrees (maximum(0, temperature - 65)) at the current hour

- $\quad \boldsymbol{\beta}$ are the linear coefficients of the variables 
For this research, a discrete mean reversion model was derived from Equation (53).

$$
\operatorname{Price}(t+1)-\operatorname{Price}(t)=(\kappa(\theta(t+1)-\operatorname{Price}(t))) \Delta t+\sigma \Delta W
$$

Where $\Delta t$ is a one hour time-step, and thus $\Delta W \sim \mathcal{N}(0,1)$.

This model assumes that real-time clearing prices are independent of the site's purchase behavior. This assumption is valid because the site's demand ( $2 \mathrm{MW})$ is miniscule relative to the system (10's of GW). However, if a significant portion of loads on the system contained price responsive DG, a more sophisticated model of clearing prices dependent on demand would be necessary.

For each of the four cities, the following procedure was used to determine the $\theta, \kappa$, and $\sigma$ :

1. Historic clearing price data from 2004 to 2006 were collected from the following sources:

a. Baltimore - PJM Baltimore Gas and Electric zone, Suez Energy Resources NA (2007)

b. Boston - ISO-NE Northeast Massachusetts and Boston zone, ISO-NE (2007)

c. Houston - ERCOT Houston zone, ERCOT (2007)

d. San Diego - CAISO zone SP-15, CAISO (2007)

2. Historic temperature data from 1961 to 1970 and from 2004 to 2006 were collected from Weather Underground (2007). 
3. An ordinary least squares (OLS) regression on Equation (54) was performed for each hour of each day-type (weekday, weekend) of each month, using the 2004 - 2006 clearing price and temperature data.

4. An ordinary least squares regression of the historic data on Equation (55) was performed to obtain $\kappa$ and $\sigma ; \kappa$ being the beta coefficient of $\theta(t+1)-\operatorname{Price}(t)$, and $\sigma$ being the standard deviation of the error term. The minimum and maximum values of the error term were also noted.

In order to develop the stochastic scenarios, temperature data from the years 19611970 were used. Successive hourly clearing prices were stochastically generated using Equation (55). Values of $\Delta W$ were drawn randomly from a normal distribution with mean of zero and variance of one. Values of $\sigma \Delta W$ were truncated at the maximum and minimum values of the error term from the results of the regression on Equation (55). Negative clearing prices were adjusted to zero. 


\section{Appendix D. ANNUAL ENERGY COSTS AND SAVINGS OVER NO-DG}

\section{CASE}

Figure 101 - Figure 124 are more detailed results from Section 8.1.2. They show the annual energy costs and savings over no-DG case for all cities (Baltimore, Boston, Houston, and San Diego) in all years (2004 - 2006) under all tariffs (TOU, CPP, and RTP) and all control strategies (no-DG, load-follow, heat-follow, and optimal).

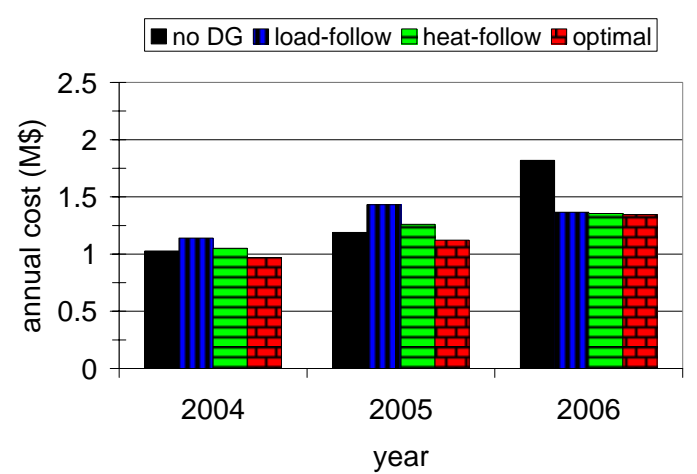

Figure 101. Baltimore - TOU - annual energy costs under all control strategies

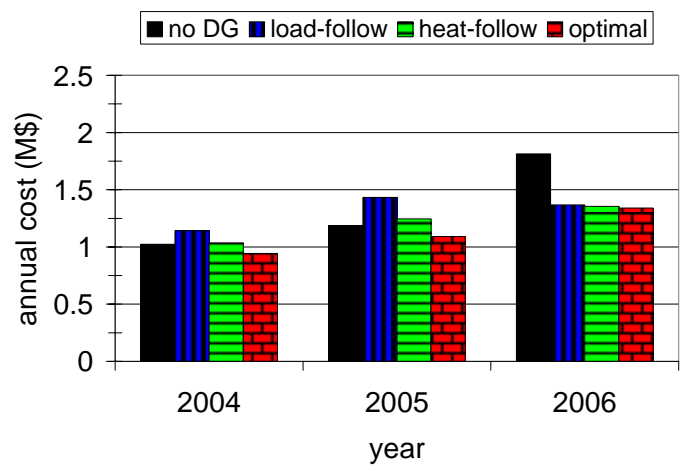

Figure 103. Baltimore - $\mathrm{CPP}$ - annual energy costs under all control strategies

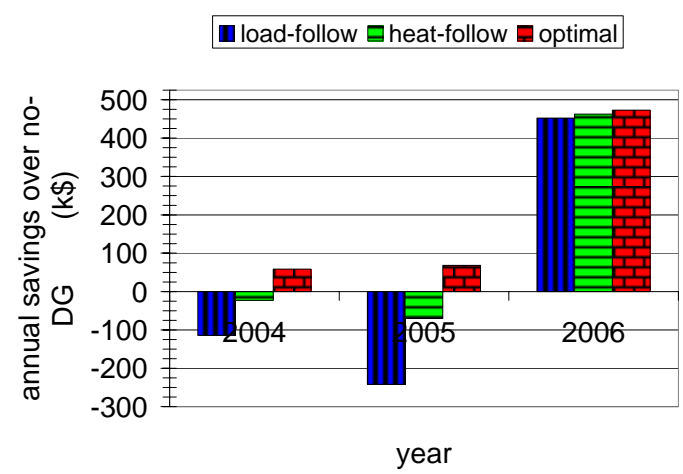

Figure 102. Baltimore - TOU - annual savings over no-DG case under all other control strategies

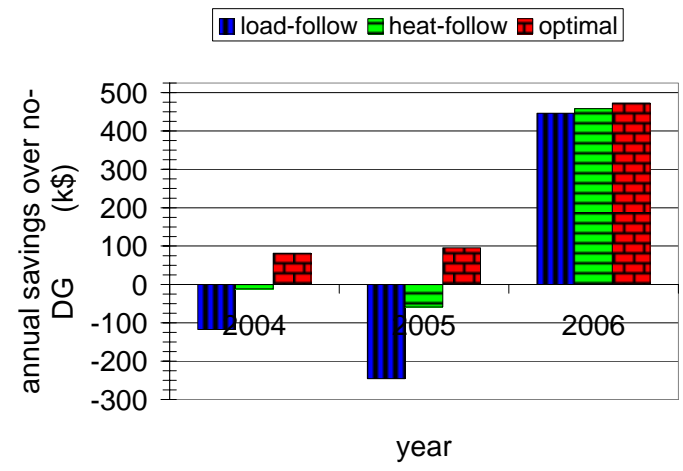

Figure 104. Baltimore - CPP - annual savings over no-DG case under all other control strategies 


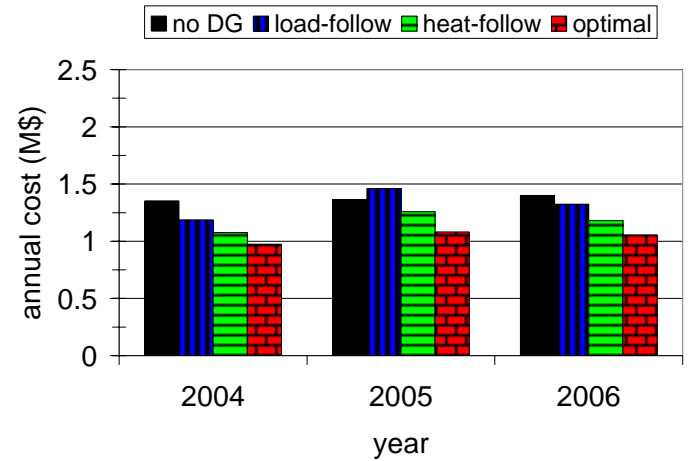

Figure 105. Baltimore - RTP - annual energy costs under all control strategies

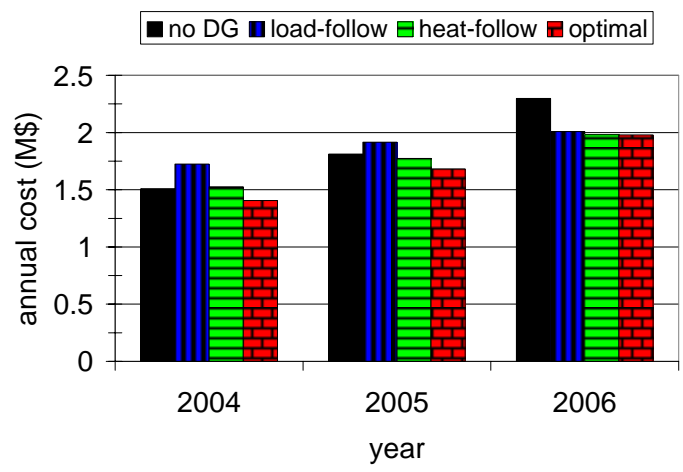

Figure 107. Boston - TOU - annual energy costs under all control strategies

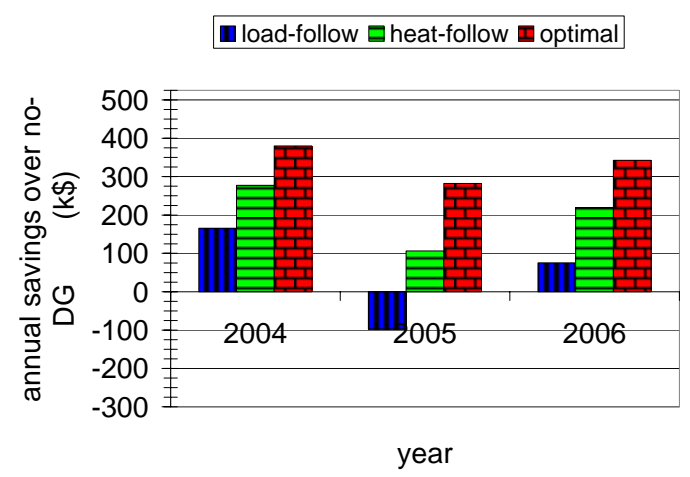

Figure 106. Baltimore - RTP - annual savings over no-DG case under all other control strategies

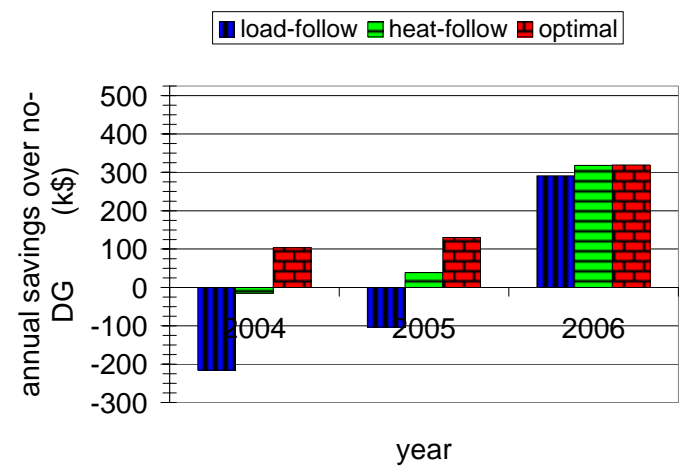

Figure 108. Boston - TOU - annual savings over no-DG case under all other control strategies 


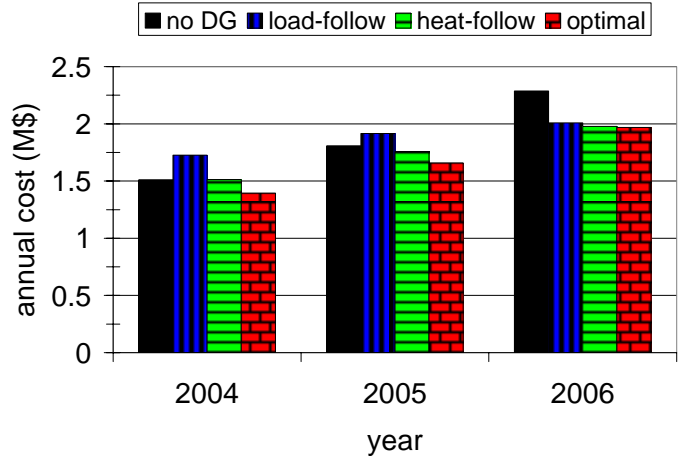

Figure 109. Boston - CPP - annual energy costs under all control strategies

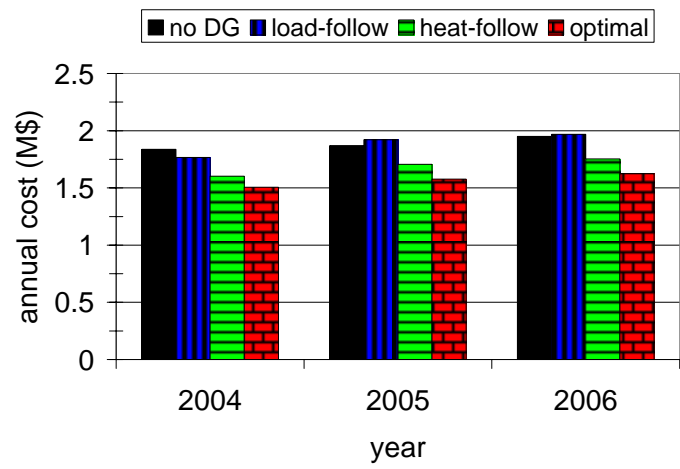

Figure 111. Boston - RTP - annual energy costs under all control strategies

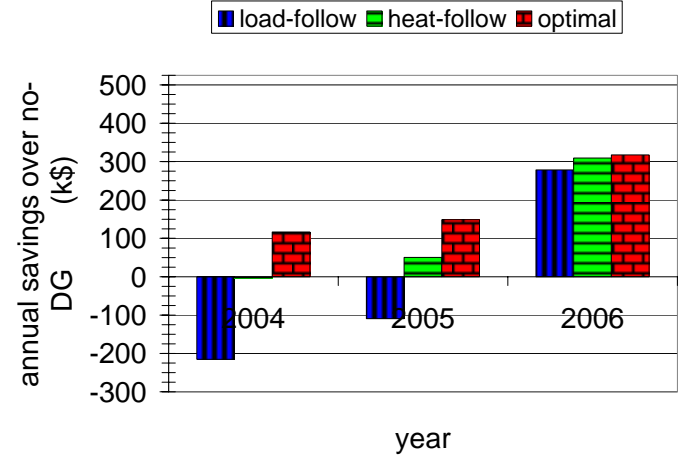

Figure 110. Boston - CPP - annual savings over no-DG case under all other control strategies

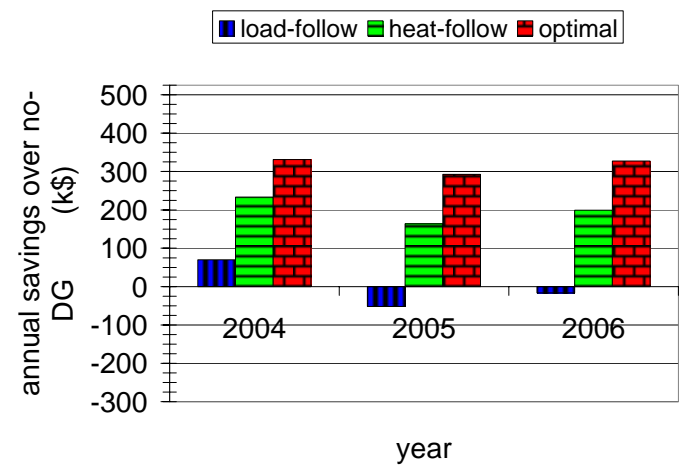

Figure 112. Boston - RTP - annual savings over no-DG case under all other control strategies 


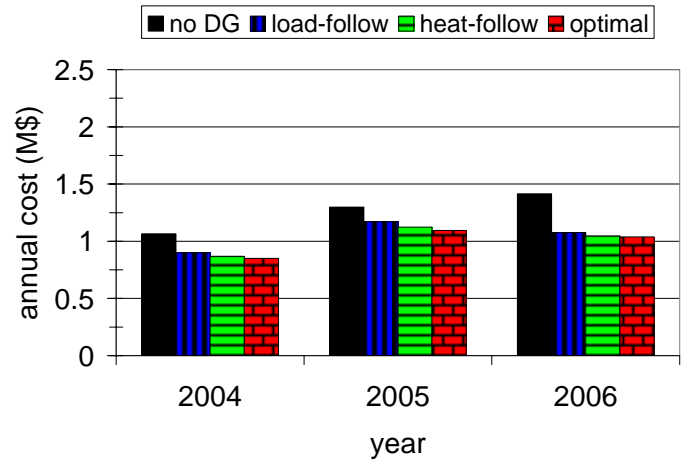

Figure 113. Houston - TOU - annual energy costs under all control strategies

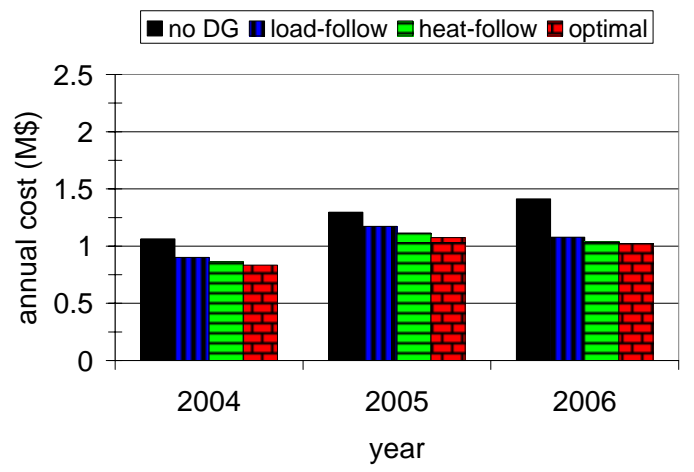

Figure 115. Houston - CPP - annual energy costs under all control strategies

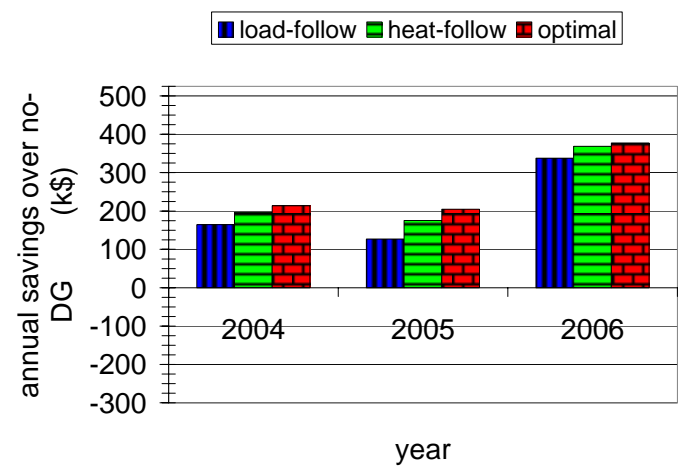

Figure 114. Houston - TOU - annual savings over no-DG case under all other control strategies

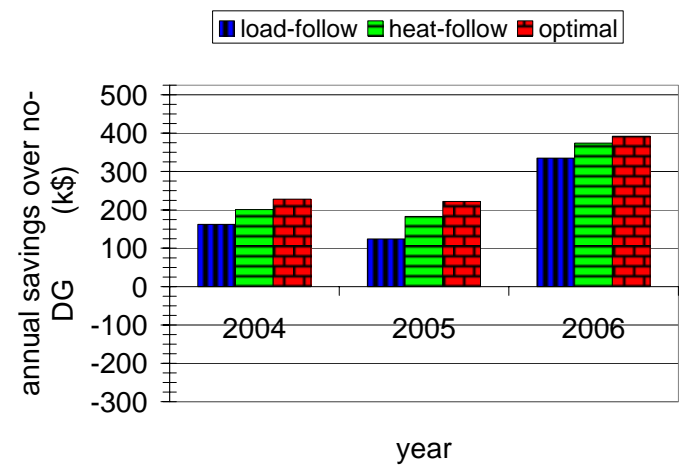

Figure 116. Houston - CPP - annual savings over no-DG case under all other control strategies 


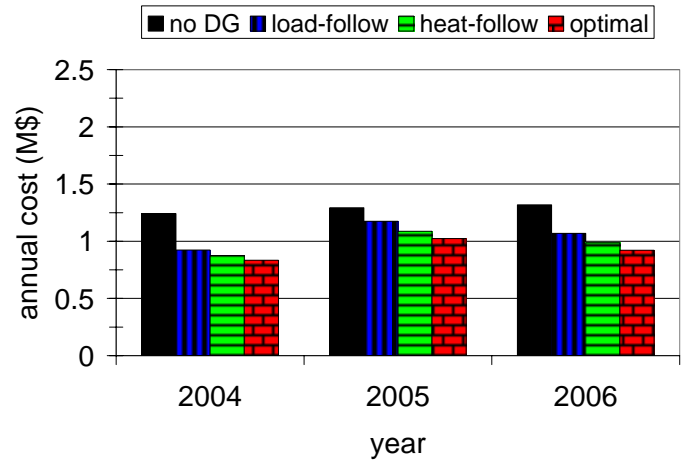

Figure 117. Houston - RTP - annual energy costs under all control strategies

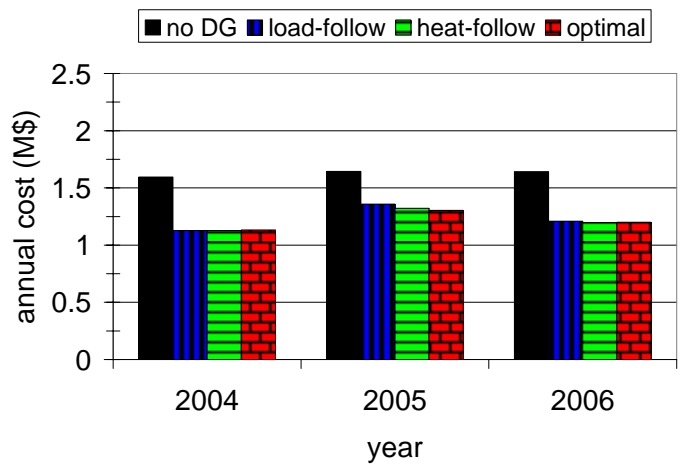

Figure 119. San Diego - TOU - annual energy costs under all control strategies

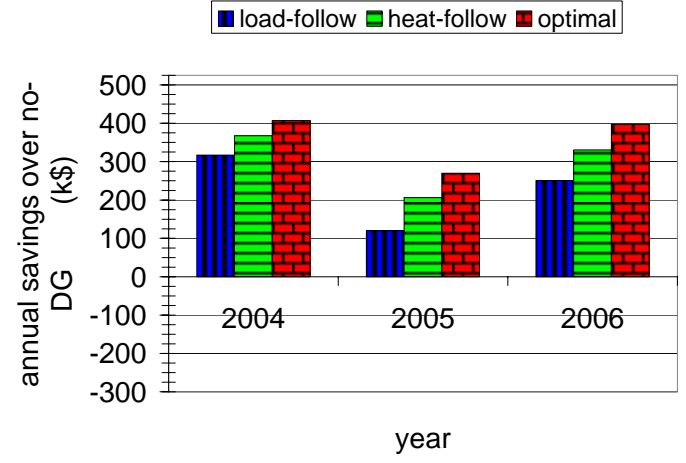

Figure 118. Houston - RTP - annual savings over no-DG case under all other control strategies

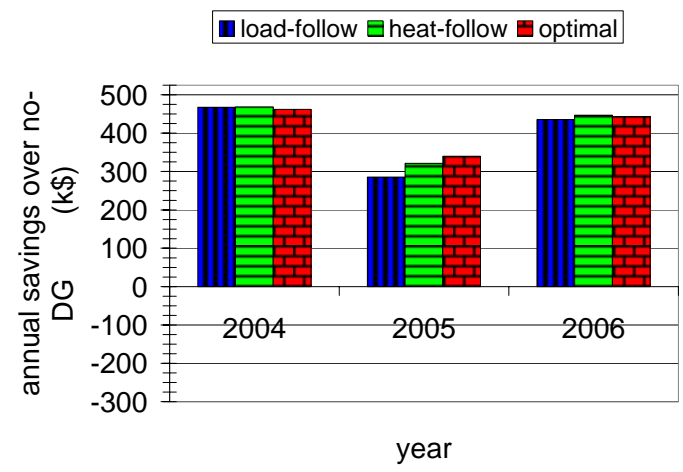

Figure 120. San Diego - TOU - annual savings over no-DG case under all other control strategies 


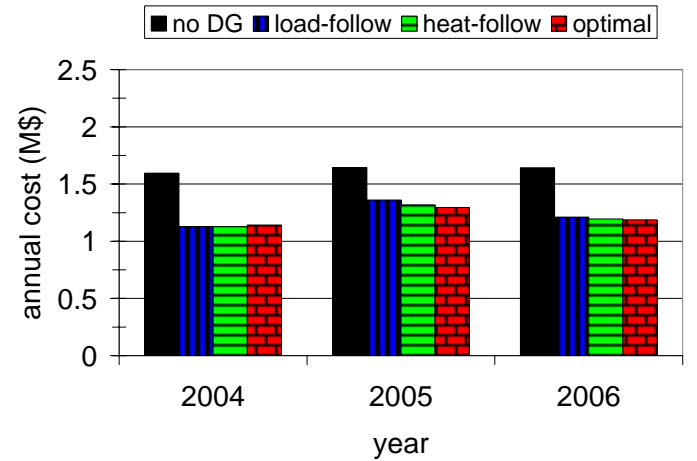

Figure 121. San Diego - CPP - annual energy costs under all control strategies

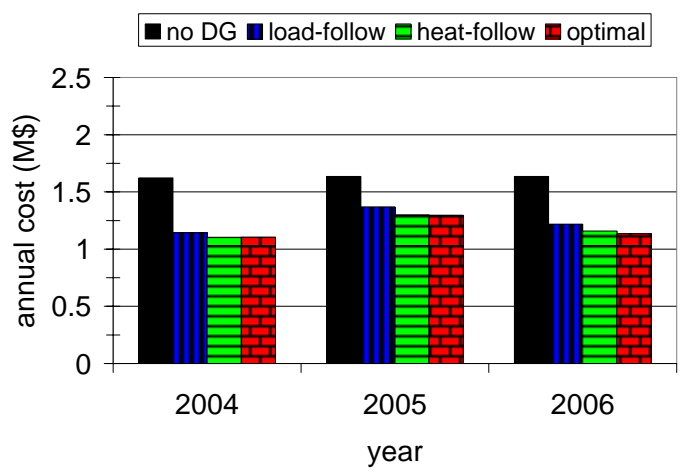

Figure 123. San Diego - RTP - annual energy costs under all control strategies

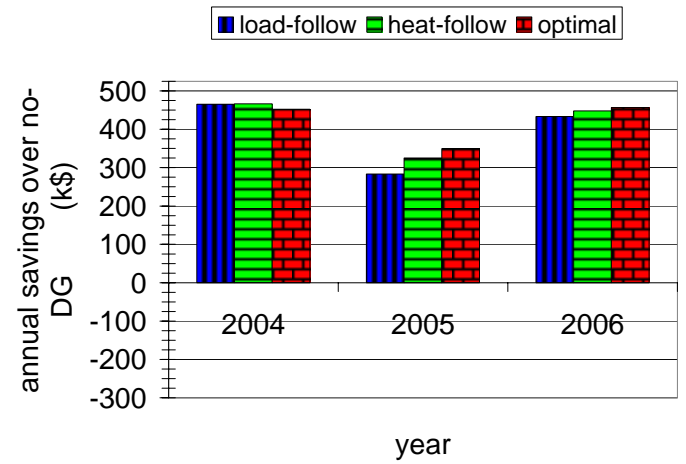

Figure 122. San Diego - CPP - annual savings over no-DG case under all other control strategies

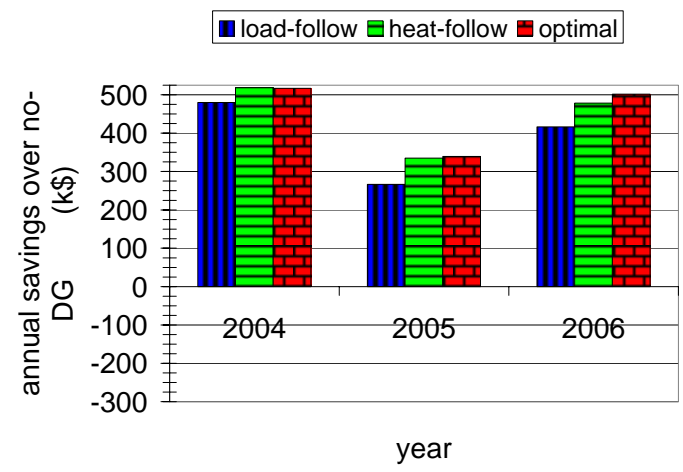

Figure 124. San Diego - RTP - annual savings over no-DG case under all other control strategies 


\section{Appendix E. PROGRAMMING PLATFORM}

The RT-OPTICOM program was written as a mixed integer linear program (MILP) in the General Algebraic Modeling System (GAMS). GAMS is a commercial programming platform for optimization problems. The CPLEX solver is used to solve the program. CPLEX is widely regarded as a particularly fast, robust MILP solver.

Matlab was used to automate the process of writing the data sections of GAMS code for the various RT-OPTICOM runs, and to collect and process the results after GAMS execution. The results in this paper represent more than 15,000 individual executions of the RT-OPTICOM program. Matlab was also used to process much of the data that were eventually turned into input for RT-OPTICOM. The Matlab and GAMS code developed by Ferris (2005) enabled Matlab to be used as the interface to GAMS - initiating the execution of individual RT-OPTICOM runs and storing results.

Microsoft Excel was used for the remainder of data processing.

The majority of RT-OPTICOM runs were done on two desktop computers, each containing an Intel Pentium 4 $3.39 \mathrm{GHz} \mathrm{CPU}$ and $1.98 \mathrm{~GB}$ of RAM. Estimation runs typically took from 15 seconds to 5 minutes. Estimation runs only run for the first two hours of the month being simulated, and then use the average values from the 188 
scenarios to predict cost, consumption, and emissions data. Full runs, which include successive optimizations at each of the 720 hours of the month, took several minutes to several hours to run. Full runs would be adequate for RT-OPTICOM if it were being used as a real-time controller, in which case a decision would only be required hourly. However, for this research, requiring so many thousands of program runs, only the estimation runs could be used. 